\title{
Engajamento por meio de elementos de jogos em comunidades online de colaboração aberta
}

\author{
Ana Paula Oliveira Bertholdo \\ TESE APRESENTADA \\ $\mathrm{AO}$ \\ Instituto De Matemática e Estatística \\ DA \\ Universidade DE SÃo PAUlo \\ PARA \\ OBTENÇÃO DO TÍTULO \\ $\mathrm{DE}$ \\ DOUTOR EM CIÊNCIAS
}

\author{
Programa: Doutorado em Ciência da Computação \\ Orientador: Prof. Dr. Marco Aurélio Gerosa \\ Coorientadora: Prof. Dra. Claudia de Oliveira Melo
}

Durante o desenvolvimento deste trabalho a autora recebeu auxílio financeiro da CAPES e da FAPESP

São Paulo, dezembro de 2018 


\section{Engajamento por meio de elementos de jogos em comunidades online de colaboração aberta}

Esta versão da tese contém as correções e alterações sugeridas pela Comissão Julgadora durante a defesa da versão original do trabalho, realizada em 06/12/2018. Uma cópia da versão original está disponível no

Instituto de Matemática e Estatística da Universidade de São Paulo.

Comissão Julgadora:

- Prof. Dr. Marco Aurélio Gerosa (orientador) - IME-USP/NAU

- Dra. Claudia de Oliveira Melo (coorientadora) - IAEA-ONU

- Prof. Dr. Artur Simões Rozestraten - FAU-USP

- Dra. Denise Del Re Filippo - ESDI-UERJ

- Profa. Dra. Lucia Vilela Leite Filgueiras - EP-USP

- Profa. Dra. Vania Mara Alves Lima - ECA-USP 


\section{Agradecimentos}

Agradeço a Deus por ter conseguido superar os desafios para concluir esta pesquisa. Agradeço a minha amada família por todo apoio, amor e reconforto espiritual em todos os momentos dessa caminhada. Em especial, agradeço profundamente à minha mãe Célia e ao meu marido Leonardo. Agradeço também aos meus irmãos Marcos e César, e a Humberto, Cícero e Thais que me ajudaram a passar com mais leveza por cada obstáculo.

Sou imensamente grata ao meu orientador Prof. Dr. Marco Aurélio Gerosa e à minha coorientadora Dra. Claudia de Oliveira Melo. Não tenho palavras para expressar a profunda gratidão por terem me orientado nessa jornada, ajudando-me a dar enfoque ao que realmente é importante. Imensa gratidão também à professora Dra. Heather O'Brien pela orientação durante o período de pesquisa na UBC, em Vancouver.

Agradeço a todos os membros do projeto Arquigrafia, especialmente, às equipes de desenvolvimento, design, catalogação/digitalização e comunicação do período entre 2015 e 2018. Agradeço ao Straus Michalsky e ao Aurélio A. M. Matsui pelo suporte no início do projeto com a configuração e migração de ambiente. Agradeço ao Nelson Lago por todo apoio e paciência ao me ensinar a configuração do ambiente de produção no servidor Linux, bem como, na migração do projeto para a nuvem USP. Em particular, agradeço imensamente ao professor Dr. Artur Simões Rozestraten por toda orientação e apoio na execução da pesquisa-ação no projeto Arquigrafia.

Gratidão por todo apoio e companheirismo de Yorah Bosse, Erika G. Suca, Jefferson Silva, Larissa Moraes, Suelen G. Carvalho e Rafael B. Oliveira. Agradeço também às contribuições valiosas a partir dos comentários na banca da Dra. Denise Del Re Filippo e das professoras Dra. Lucia Vilela Leite Filgueiras e Dra. Vânia Mara Alves Lima. Agradeço também à professora Dra. Cibele Araujo C. M. dos Santos pelas contribuições em workshops e experimentos. Agradeço ao professor Dr. Fabio Kon pelo apoio à pesquisa e ao desenvolvimento do projeto Open Air Museum e por me incentivar durante o mestrado a prosseguir na área de pesquisa de meu interesse. Agradeço também a Gustavo A. Oliva, Igor Steinmacher, Igor Wiese, Virgínia Carrara e Carlos Denner pelas dúvidas sanadas que contribuíram para a aplicação de métodos ou funções mais adequados em cada caso. Gratidão à Fapesp, à Capes e ao Programa de Mobilidade Internacional USP/Santander cujos suportes financeiros tornaram este trabalho possível. Por fim, agradeço a todos que direta ou indiretamente me ajudaram nesse processo. 


\section{Resumo}

BERTHOLDO, A. P. O. Engajamento por meio de elementos de jogos em comunidades online de colaboração aberta. 2018. 200 f. Tese (Doutorado) - Instituto de Matemática e Estatística, Universidade de São Paulo, São Paulo, 2018.

Galerias, Bibliotecas, Arquivos e Museus (GLAMs) têm enfrentado o desafio de envolver os usuários na seleção, catalogação, contextualização e curadoria de coleções por meio de crowdsourcing. Esse novo modo de interação se estende além do acesso passivo e pode levar a um nível mais profundo de engajamento com coleções. Como a participação do usuário é a chave para o sucesso nesse contexto, GLAMs precisam criar e manter sistemas de colaboração aberta. Contudo, tais sistemas precisam fomentar um senso de comunidade em torno dos artefatos e as comunidades dependem, dentre outros fatores, do engajamento de colaboradores. $\mathrm{O}$ termo engajamento indica a profundidade de investimento de um ator quando interagindo com um sistema digital. Para promover o engajamento dos usuários com comunidades online, tem-se discutido o uso da gamificação. Gamificação é o uso de elementos de projeto de jogos em contextos que não são jogos e tem como meta estimular a participação e engajar pessoas. Nos estudos teóricos sobre gamificação, a motivação intrínseca e a autodeterminação do usuário são as principais bases para a construção de aplicações. No entanto, a maior parte da literatura que descreve a implementação de gamificação utiliza elementos de recompensa, como pontos, distintivos e quadros de liderança, associados à pontificação, um subconjunto da gamificação; e não apresenta o monitoramento e a análise de cada elemento de jogo inserido durante o desenvolvimento, de modo a avaliar o impacto no comportamento dos usuários. Há também a necessidade de explorar como a gamificação pode ser implementada em domínios específicos. Esta pesquisa propõe uma abordagem para integrar gamificação e avaliação de engajamento durante o desenvolvimento de comunidades online de colaboração aberta. Nesse contexto, uma pesquisa-ação foi realizada no domínio de uma GLAM sobre arquitetura e urbanismo, chamada Arquigrafia, para investigar as práticas atuais de gamificação e uma proposta de abordagem. As métricas de engajamento foram analisadas estatisticamente por meio de pesquisas quantitativas experimentais e não-experimentais sobre dados coletados em três anos de monitoramento (2015-2018). Os resultados indicam que o uso de elementos de jogos em uma comunidade online de colaboração aberta, no domínio de GLAMs, tem um efeito positivo sobre o engajamento de usuários sob certas condições, as quais são consideradas na proposta de abordagem desta tese.

Palavras-chave: engajamento, motivação, comunidades de colaboração aberta, gamificação, GLAMs, DCU, IHC, CSCW, UX. 


\section{Abstract}

BERTHOLDO, A. P. O. Engagement through Game Elements in Open Collaboration

Online Communities. 2018. 200 f. Tese (Doutorado) - Instituto de Matemática e Estatística, Universidade de São Paulo, São Paulo, 2018.

Galleries, Libraries, Archives and Museums (GLAMs) have faced challenges for involving users in the selection, cataloging, contextualization and curation of collections through crowdsourcing. This new mode of interaction extends beyond passive access and can lead to a deeper level of engagement with collections. Because user engagement is the key to success in this context, GLAMs need to create and maintain open collaboration systems. However, such systems need to foster a sense of community around artifacts, and communities depend, among other factors, on colaborators engagement. The term engagement indicates the depth of an actor's investment when interacting with a digital system. To promote the engagement of users with online communities, the use of gamification has been discussed. Gamification is the use of game design elements in contexts that are not games and aims to stimulate participation and engage people. In the theoretical studies on gamification, intrinsic motivation and self-determination of the user are the main bases for the construction of applications. However, most of the literature describing the implementation of gamification uses reward elements, such as points, badges, and leaderboards, associated with pontification, a subset of gamification; and does not present the monitoring and analysis of each game element inserted during the development, in order to evaluate the impact on the behavior of the users. There is also a need to explore how gamification can be implemented in specific domains. This research proposes an approach to integrate gamification and evaluation of engagement during the development of open collaboration online communities. In this context, an action research was carried out in the domain of a GLAM on architecture and urbanism, the Arquigrafia project, to investigate current practices of gamification and an approach proposal. Engagement metrics were statistically analyzed using experimental and non-experimental quantitative research of data collected over three years of monitoring (2015-2018). The results indicate that the use of game elements in an open collaboration online community in the GLAM domain has a positive effect on user engagement under certain conditions, which are considered in the approach proposal of this thesis.

Keywords: engagement, motivation, open collaboration communities, gamification, GLAMs, UCD, HCI, CSCW, UX. 


\section{Sumário}

Lista de Figuras $\quad$ xi

Lista de Tabelas $\quad$ xiii

1 Introdução $\quad \mathbf{1}$

1.1 Problema de pesquisa $\ldots \ldots \ldots \ldots \ldots \ldots \ldots \ldots$

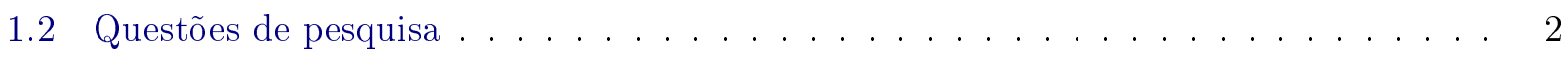

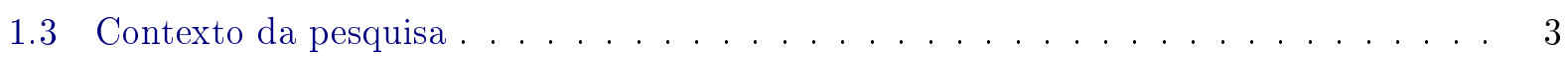

1.3.1 Relevância do contexto . . . . . . . . . . . . . . . . . 3

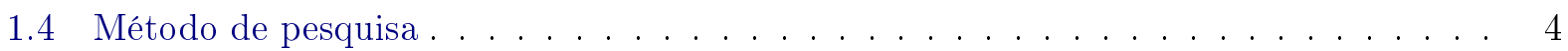

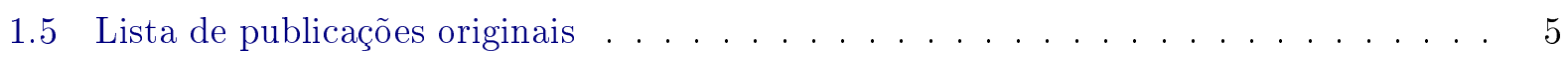

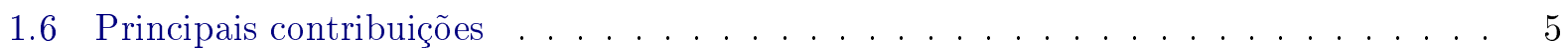

1.7 Organização do Trabalho . . . . . . . . . . . . . . . . . . 6

$\begin{array}{lll}2 & \text { Conceitos fundamentais } & 7\end{array}$

2.1 Colaboração . . . . . . . . . . . . . . . . . . . . . . . . 7

2.1 .1 Colaboração aberta . . . . . . . . . . . . . . . . 8

2.2 Comunidades online de colaboração aberta . . . . . . . . . . . . . . 9

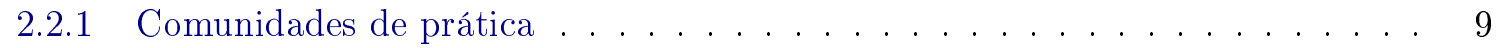

2.2 .2 Comunidades online de prática . . . . . . . . . . . . . . 10

2.2.3 Comunidades online de GLAMs ou crowdsourcing do patrimônio cultural . . 11

2.3 Motivação . . . . . . . . . . . . . . . . . . . . . . . 11

2.3 .1 Teorias sobre motivação . . . . . . . . . . . . . . . . 12

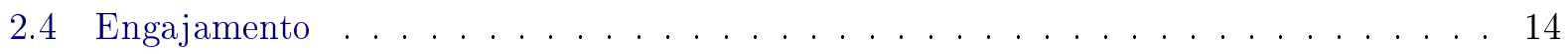

2.4 Modelo de engajamento . . . . . . . . . . . . . . 15

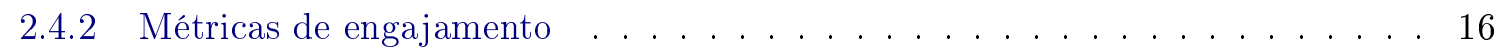

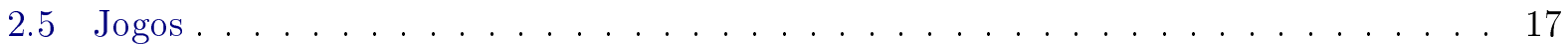

2.5 .1 Teoria do Fluxo . . . . . . . . . . . . . . . . . . . . 18

2.5.2 Tétrade elementar dos jogos . . . . . . . . . . . . . . 18

2.5 .3 Perfis de jogadores . . . . . . . . . . . . . . . . . . . . . 19

2.6 Gamificação . . . . . . . . . . . . . . . . . . . . . . . . 20

2.6.1 Passos para implantar gamificação . . . . . . . . . . . . . . . . . . 21

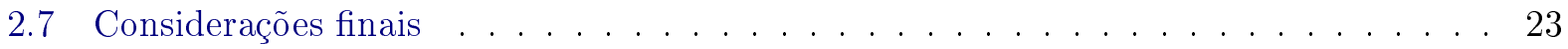


3 Estado da arte sobre gamificação e impacto no engajamento de usuários

3.1 Visão geral e classificação de arcabouços . . . . . . . . . . . . . . . . . . 25

3.2 Gamificação na prática . . . . . . . . . . . . . . . . . . 26

3.3 Trabalhos relacionados . . . . . . . . . . . . . . . . . . . 29

3.3.1 Definição de diretrizes, métodos e arcabouços teóricos ou conceituais . . . . . 29

3.3.2 Aplicações de gamificação com medição de engajamento de usuários . . . . . 31

4 Design da pesquisa $\quad 33$

4.1 Pesquisa-ação . . . . . . . . . . . . . . . . . . . . . . . . 33

4.1 .1 Fases da pesquisa-ação . . . . . . . . . . . . . . . . . . . . 34

4.1.2 Pesquisa-ação como método de pesquisa adequado a esta tese . . . . . . . . . 34

4.1 .3 Validade da pesquisa-ação no Arquigrafia . . . . . . . . . . . . . . . . 35

4.2 Pesquisa quantitativa experimental . . . . . . . . . . . . . . . . 38

4.2.1 Experimentos controlados online no Arquigrafia . . . . . . . . . . . . . 38

4.2 .2 Validade da pesquisa experimental no Arquigrafia . . . . . . . . . . . . . . . . 39

4.3 Pesquisa quantitativa não-experimental . . . . . . . . . . . . . . . . . . . 43

4.3.1 Validade da pesquisa correlacional no Arquigrafia . . . . . . . . . . . . . . . 43

4.3.2 Validade da pesquisa causal-comparativa no Arquigrafia . . . . . . . . . . . . 44

5 Pesquisa-ação: Monitoramento e pontificação com colaboração 47

5.1 Pesquisa-ação no projeto Arquigrafia . . . . . . . . . . . . . . . . 47

5.2 Monitoramento e exploração de pontificação com colaboração . . . . . . . . . . . . 50

5.2 .1 Ciclo 0: Registro de ações de usuários . . . . . . . . . . . . . . . . . 50

5.2.2 Ciclo 1: Implementação de awareness e prototipação de pontificação . . . . . 54

5.2.3 Ciclo 2: Implementação de elementos de colaboração e de pontificação . . . . 58

5.2.4 Ciclo 3: Implementação de scripts para análise de métricas objetivas . . . . . 63

5.2.5 Ciclo 4: Geração automática de métricas objetivas e definição da $1^{\mathrm{a}}$ versão de

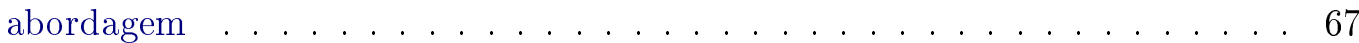

5.3 Primeira versão da abordagem . . . . . . . . . . . . . . . . . 72

6 Pesquisa-ação: Refinamento da abordagem proposta $\quad 79$

6.1 Refinamento da abordagem proposta no Arquigrafia . . . . . . . . . . . . . . . . 79

6.1.1 Ciclo 5: Workshops para instanciação da abordagem . . . . . . . . . . . . . 79

6.1.2 Ciclo 6: Experimento com gamificação e Refinamento da abordagem . . . . . 87

6.2 Reflexão sobre os 7 ciclos de pesquisa-ação no Arquigrafia . . . . . . . . . . . . . . 93

7 Pesquisa correlacional e causal-comparativa sobre dados de 2015 a $2018 \quad 97$

7.1 Evolução do engajamento de usuários de 2015 a 2018 . . . . . . . . . . . . . . . . . . 98

7.2 Pesquisa correlacional . . . . . . . . . . . . . . . . . . . . . 101

7.2.1 22 Ações independentes X métricas objetivas . . . . . . . . . . . . . . . 103

7.2.2 Tipos de elementos de interação X métricas objetivas . . . . . . . . . . . . . 106

7.2.3 Conjuntos de elementos de interação X métricas objetivas . . . . . . . . . . . 108

7.3 Pesquisa causal-comparativa . . . . . . . . . . . . . . . . . . . . 110

7.3.1 Pesquisa causal-comparativa entre conjuntos de elementos . . . . . . . . . . 110

7.3.2 Pesquisa causal-comparativa entre conjuntos por métrica . . . . . . . . . . . 121 
7.3.3 Pesquisa causal-comparativa entre ações mais acessadas . . . . . . . . . . . 125

7.4 Resposta da QPI . . . . . . . . . . . . . . . . . . . . . . 129

8 Proposta de integração da gamificação com o monitoramento e avaliação de engajamento 133

8.1 Construção de comunidades de prática . . . . . . . . . . . . . . . . . 133

8.2 Resposta da QPII: Proposta de abordagem . . . . . . . . . . . . . . . . . 137

8.2 .1 DCU ágil . . . . . . . . . . . . . . . . . . . . . . . . . . . . 142

8.2 .2 Enfoque sobre o domínio de GLAMs . . . . . . . . . . . . . . . . . . 143

9 Avaliação da pesquisa $\quad 147$

9.1 Validade dos resultados . . . . . . . . . . . . . . . . . . 147

9.2 Avaliação dos Resultados . . . . . . . . . . . . . . . . . . . . . . . . 149

9.2.1 Implicações para a teoria . . . . . . . . . . . . . . . . . . . . . . . 149

9.2 .2 Implicações para a prática . . . . . . . . . . . . . . . . . . . . . . 157

10 Síntese e Conclusões $\quad 165$

10.1 Síntese de resultados . . . . . . . . . . . . . . . . . . 165

10.2 Limitações do estudo . . . . . . . . . . . . . . . . . . . . 167

10.3 Implicações para estudos futuros . . . . . . . . . . . . . . . . . . . 168

$\begin{array}{ll}\text { Referências Bibliográficas } & 169\end{array}$

$\begin{array}{ll}\text { Índice Remissivo } & 182\end{array}$ 


\section{Lista de Figuras}

1.1 Relação entre os métodos e as questões de pesquisa desta tese. . . . . . . . . . . . . 4

2.1 Modelo 3C para trabalho em grupo a partir de Fuks et al. [FRGL05] . . . . . . . . 8

2.2 Taxonomia da teoria da integração orgânica para os tipos de motivação humana. Tradução a partir da figura original de Ryan e Deci [RD00a]. . . . . . . . . . . . . . 13

2.3 Modelo de engajamento de usuários. Tradução a partir da figura original de O’Brien e Toms [OT08]. . . . . . . . . . . . . . . . . . . . . . . . 15

2.4 Perfis de jogadores e suas fontes de interesse. Tradução a partir da figura original de Bartle [Bar96] . . . . . . . . . . . . . . . . . . . . . . . . . . . 19

2.5 Dimensões do jogo e da brincadeira e do jogo completo e partes do jogo. Tradução a partir da figura original de Deterding et al. [DDKN11] . . . . . . . . . . . . . . . 21

2.6 Passo 4 - Ciclo de atividade. Tradução a partir da figura original de Werbach e Hunter

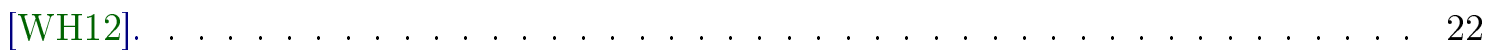

2.7 Passo 4 - Ciclo de escadas de progressão. Tradução a partir da figura original de Werbach e Hunter [WH12] . . . . . . . . . . . . . . . . . . . . . . . . 22

4.1 Espiral evolutiva de ciclos de pesquisa-ação contínuos a partir de [VZ03] . . . . . . . 34

5.1 Métodos e ferramentas utilizadas em cada fase de um ciclo de pesquisa-ação. . . . . . 48

5.2 Comparação entre os 60 dias anteriores ao início do Ciclo 0 (06/11/2014 - 04/01/2015) e os 60 dias finais do Ciclo $0(16 / 04 / 2015$ - 14/06/2015) para a métrica visão geral do Google Analytics. . . . . . . . . . . . . . . . . . . . . . 53

5.3 Comparação entre os 60 dias finais do ciclo 0 (16/04/2015 - 14/06/2015) e do Ciclo 1 (22/06/2015 - 20/08/2015) para a métrica visão geral do Google Analytics. . . . . 57

5.4 Comparação entre os 60 dias finais do ciclo $1(22 / 06 / 2015-20 / 08 / 2015)$ e do ciclo $2(25 / 10 / 2015$ - 23/12/2015) para a visão geral do Google Analytics. . . . . . . . . . 61

5.5 Comparação entre os 60 dias finais do ciclo $2(25 / 10 / 2015-23 / 12 / 2015)$ e do ciclo 3 (03/07/2016 - 31/08/2016) para a métrica visão geral do Google Analytics. . . . 66

5.6 Comparação entre os 60 dias finais do ciclo $3(03 / 07 / 2016$ - 31/08/2016) e do ciclo 4 (01/01/2017 - 01/03/2017) para a visão geral do Google Analytics. . . . . . . . . . 70

5.7 Ciclo de vida do DCU $[$ UEPA14] . . . . . . . . . . . . . . . . . . . . . . . 72

6.1 Comparação entre os 60 dias finais do ciclo $4(01 / 01 / 2017$ - 01/03/2017) e do ciclo 5 (02/06/2017 - 31/07/2017) para a visão geral do Google Analytics. . . . . . . . . . 84

6.2 Arcabouço teórico: Motivação e colaboração em práticas compartilhadas. . . . . . . . 85 
6.3 Comparação entre os 60 dias finais do ciclo $5(02 / 06 / 2017$ - 31/07/2017) e do ciclo $6(02 / 05 / 2018$ - 30/06/2018) para a visão geral do Google Analytics. . . . . . . . . . 91

6.4 Comparação entre os 60 dias finais do Pré-Ciclo 0 (06/11/2014 - 04/01/2015) e do ciclo 6 (02/05/2018 - 30/06/2018) para a visão geral do Google Analytics. . . . . . . 95

6.5 Comparação de 2014 a 2017 para a visão geral do Google Analytics. . . . . . . . . . 95

7.1 Monitoramento de métricas objetivas de engajamento do Arquigrafia ano a ano entre $14 / 06 / 2015$ e $30 / 06 / 2018 \ldots \ldots \ldots \ldots$. . . . . . . . . . . . . 99

7.2 Monitoramento de cada ação ao longo do período entre 14/06/2015 e 30/06/2018 . . 101

7.3 Comparação dos conjuntos a partir dos níveis Alto, Médio e Baixo alcançados para a métrica Frequência. . . . . . . . . . . . . . . . . . . . . . 111

7.4 Comparação dos conjuntos a partir dos níveis Alto, Médio e Baixo alcançados para a métrica Recenticidade. . . . . . . . . . . . . . . . . . . . . . . . . . . . . . . . 112

7.5 Comparação dos conjuntos a partir dos níveis Alto, Médio e Baixo alcançados para a métrica Duração. . . . . . . . . . . . . . . . . . . . . . . . . . 113

7.6 Comparação dos conjuntos a partir dos níveis Alto, Médio e Baixo alcançados para a métrica Viralidade. . . . . . . . . . . . . . . . . . . . . . . . . . . . . . . 114

7.7 Comparação dos conjuntos a partir dos níveis Alto, Médio e Baixo alcançados para a métrica Ações. . . . . . . . . . . . . . . . . . . . . . 116

7.8 Comparação dos conjuntos a partir dos níveis Alto, Médio e Baixo alcançados para a métrica NDias. . . . . . . . . . . . . . . . . . . . . . . 117

7.9 Comparação dos conjuntos a partir dos níveis Alto, Médio e Baixo alcançados para a métrica Classificação. . . . . . . . . . . . . . . . . . . . . . 118

7.10 Comparação dos conjuntos a partir dos níveis Alto, Médio e Baixo alcançados para a métrica Tempo de reação. . . . . . . . . . . . . . . . . . . . . . . . . . . . 119

7.11 Comparação das métricas objetivas entre conjuntos a partir do Teste de Kruskal-Wallis.122

7.12 Comparação das principais ações acessadas a partir do Teste de Kruskal-Wallis para cada métrica objetiva de engajamento. . . . . . . . . . . . . . . 126

8.1 Ciclo do DCU ágil [Sy07]. . . . . . . . . . . . . . . . . . . . . 143

8.2 Ciclo de vida de conteúdo digital e crowdsourcing a partir de Oomen e Aroyo [OA11].145

10.1 Resumo gráfico da proposta de abordagem. . . . . . . . . . . . . . . 167 


\section{Lista de Tabelas}

2.1 Elementos de projeto de jogo. Traduzido a partir da pesquisa de Deterding et al. [DDKN11]. ............................... 20

3.1 Resumo dos trabalhos relacionados. . . . . . . . . . . . . . . . . . . . . . . . 32

5.1 Métodos e ferramentas de coleta de dados usados nos ciclos de pesquisa-ação . . . . . 49

5.2 Métricas apresentadas pelo Google Analytics para visualização da visão geral do projeto monitorado. . . . . . . . . . . . . . . . . . . . . . . . . . 49

5.3 Dados do sistema em produção para o período entre 01 de Janeiro de 2011 a 31 de Dez de 2014 (4 anos) . . . . . . . . . . . . . . . . . . . . . . . . 50

5.4 Diagnóstico e Planejamento do Ciclo 0 . . . . . . . . . . . . . . . . . . . . . 51

5.5 Diagnóstico e Planejamento do Ciclo 1 . . . . . . . . . . . . . . . . . . . . . . 55

5.6 Respostas de 20 participantes à questão: Do que se trata este sistema? . . . . . . . . 56

5.7 Diagnóstico e Planejamento do Ciclo 2 . . . . . . . . . . . . . . . . . . . . . . . . . 59

5.8 Diagnóstico e Planejamento do Ciclo 3 . . . . . . . . . . . . . . . . . . . . . 63

5.9 Diagnóstico e Planejamento do Ciclo 4 . . . . . . . . . . . . . . . . . . . . . . 68

5.10 Primeira proposta de abordagem estruturada sobre as atividades de Design Centrado em Usuário. . . . . . . . . . . . . . . . . . . . . . . . . . . . . . 74

5.11 Detalhamento da diretriz Delinear comportamentos-alvo para comunidades de colaboração aberta . . . . . . . . . . . . . . . . . . . 76

6.1 Estratégia colaborativa para a funcionalidade de completude de dados . . . . . . . 80

6.2 Diagnóstico e Planejamento do Ciclo 5 . . . . . . . . . . . . . . . . . . . . . . . 81

6.3 Proposta de abordagem: Delinear comportamentos-alvo para comunidades de colaboração aberta . . . . . . . . . . . . . . . . . . . . . . 86

6.4 Estratégia colaborativa para a funcionalidade de completude de dados . . . . . . . 86

6.5 Diagnóstico e Planejamento do Ciclo 6 . . . . . . . . . . . . . . . . . . . . . . 87

6.6 Definição de cada tipo de elemento de interação de usuário abordado nesta pesquisa. 90

6.7 Dados do sistema em produção para o ciclo 6 . . . . . . . . . . . . . . . . . 96

7.1 Métricas de engajamento objetivas do tipo comportamental utilizadas para monitoramento e análise do engajamento do Arquigrafia ao longo de três anos (2015-2018).

7.2 Diretrizes para interpretação do rho ou coeficiente de correlação de classificação de Spearman a partir de $[$ Muk12] . . . . . . . . . . . . . . . . . . . . 102 
7.3 Correlações com Spearman's rank correlation rho entre ações independentes acessadas pelos usuários e cada métrica objetiva (2015 a 2018) - Recorte com as métricas Frequência, Recenticidade, Duração e Viralidade. . . . . . . . . . . . . . . . . . . . 104

7.4 Correlações com Spearman's rank correlation rho entre ações independentes acessadas pelos usuários e cada métrica objetiva (2015 a 2018) - Recorte com as métricas Ações, Ndias, Tempo de reação e Classificação. . . . . . . . . . . . . . . . . . . 105

7.5 Correlações com Spearman's rank correlation rho entre tipos de elementos de interação de usuário acessados e cada métrica objetiva de engajamento monitorada ao longo de três anos $(2015$ a 2018) . . . . . . . . . . . . . . . . . 107

7.6 Correlações com Spearman's rank correlation rho entre acessos a conjuntos de elementos de interação de usuário e cada métrica objetiva de engajamento (de 14 de junho de 2015 a 30 de junho de 2018). . . . . . . . . . . . . . . . . . . . . . . 109

7.7 Níveis Alto, Médio e Baixo alcançados para cada métrica objetiva de engajamento. . 110

7.8 Descrição dos dados apresentados na Figura $7.3 \ldots$. . . . . . . . . . . . . 111

7.9 Descrição dos dados apresentados na Figura 7.4 ～. . . . . . . . . . . . . . 112

7.10 Descrição dos dados apresentados na Figura 7.5. . . . . . . . . . . . . . . . 113

7.11 Descrição dos dados apresentados na Figura 7.6 . . . . . . . . . . . . . . 115

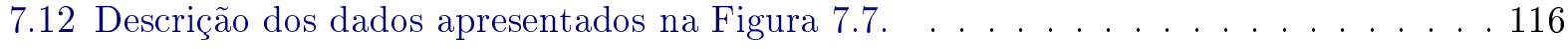

7.13 Descrição dos dados apresentados na Figura 7.8 . . . . . . . . . . . . . . 117

7.14 Descrição dos dados apresentados na Figura $7.9 . \quad$. . . . . . . . . . . . . . . . 118

7.15 Descrição dos dados apresentados na Figura 7.10 . . . . . . . . . . . . . . . 119

7.16 Resultados do Teste de Kruskal Wallis com tamanho de efeito Epsilon-squared $(\epsilon \hat{2})$ para a comparação entre a quantidade de elementos acessados por nível alcançado baixo, médio e alto (BMA) - de cada métrica para cada conjunto. . . . . . . . . . . . 121

7.17 Descrição dos dados apresentados na Figura 7.11 . . . . . . . . . . . . . . . 123

7.18 Resultados da comparação de métricas objetivas entre os cincos conjuntos a partir do Teste de Kruskal-Wallis. . . . . . . . . . . . . . . . . . . . . . . . . 125

7.19 Descrição dos dados apresentados na Figura 7.12 . . . . . . . . . . . . . . 127

7.20 Resultados da comparação das métricas objetivas entre as seis principais ações a partir do Teste de Kruskal-Wallis. . . . . . . . . . . . . . . . . . . . . . . 129

8.1 Resumo de cada estágio de desenvolvimento de uma comunidade de prática a partir de Wenger et al. [WMS02b] . . . . . . . . . . . . . . . . . . . . 135

8.2 Proposta de abordagem reformulada para considerar o enfoque de cada estágio da comunidade: recorte sobre atividades Especificar contexto de uso e Especificar requisitos. . . . . . . . . . . . . . . . . . . . . . 138

8.3 Pressupostos de cada ciclo a partir do estudo da literatura. . . . . . . . . . . . . 140

8.4 Resultados de pesquisa obtidos durante a pesquisa-ação. . . . . . . . . . . . . . . . 141

8.5 Proposta de abordagem: Delinear comportamentos-alvo para comunidades de colaboração aberta . . . . . . . . . . . . . . . . . . . . . 142

8.6 Classificação de iniciativas de crowdsourcing em GLAMs traduzida a partir da pesquisa de Oomen e Aroyo [OA11] . . . . . . . . . . . . . . . . . . . 144

9.1 Proposta de abordagem - Perspectiva da teoria. . . . . . . . . . . . . . . 151 
9.2 Avaliando resultados da pesquisa usando Fatores críticos de sucesso (FCS) para engajamento de comunidade $[$ Net18] . . . . . . . . . . . . . . . . . 154

9.3 Avaliando resultados da pesquisa usando conceitos para a prática da participação

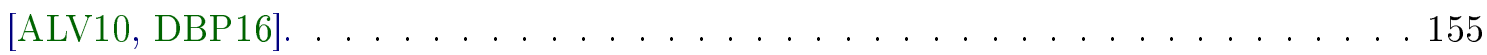

9.4 Proposta de abordagem - Perspectiva da prática. . . . . . . . . . . . 158

9.5 Proposta de abordagem - Detalhamento da diretriz Delinear comportamentos-alvo. . 160

9.6 Proposta de abordagem - Delinear comportamentos-alvo para GLAMs. . . . . . . . . 162 


\section{Capítulo 1}

\section{Introdução}

Galerias, Bibliotecas, Arquivos e Museus (do acrônimo em inglês GLAMs) e seus usuários habitam atualmente o mesmo espaço de informações compartilhadas. A abertura à participação nesse domínio pode gerar um impacto profundo nos fluxos de trabalho de instituições de patrimônio, por exemplo, convidando os usuários a auxiliar na seleção, catalogação, contextualização e curadoria de acervos [LSN07, OA11]. Essas atividades podem ser realizadas por usuários remotamente, o que reduz os custos operacionais. Esse novo modo de interação se estende além do acesso passivo e pode levar a um nível mais intenso de envolvimento com coleções [Huv08, OA11]. Como a participação do usuário é a chave para o sucesso nesse contexto [OA11], GLAMs precisam criar e manter sistemas de colaboração aberta [FL13].

Um sistema de software de colaboração aberta é um ambiente online que possibilita a produção coletiva de artefatos por meio de uma plataforma tecnologicamente mediada, com poucas barreiras para a entrada e saída de usuários e com suporte a estruturas sociais que oferecem oportunidades para pessoas realizarem atividades em conjunto [FL13]. Contudo, um sistema de colaboração aberta precisa fomentar um senso de comunidade [OT08] em torno dos artefatos.

Burke et al. [BML09] observam que o sucesso de comunidades depende, entre outros fatores, de motivar a participação de uma quantidade suficiente de pessoas, de modo que uma massa crítica de produção possa existir em volta de um conjunto de artefatos. Na criação de comunidades online, projetistas enfrentam o problema de massa crítica: o sistema ainda não possui conteúdo capaz de atrair novos membros e ao mesmo tempo há poucos participantes para criar conteúdo que possa atrair outros usuários [KR11].

No entanto, ao começar a participar, o indivíduo entra em um período de engajamento. Conforme O’Brien [O'B16], engajamento de usuário é "uma qualidade da experiência do usuário caracterizada pela profundidade de investimento de um ator quando interagindo com um sistema digital". De acordo com Zichermann [ZC11], usuários engajados estão afetivamente envolvidos e motivados. Como consequência, O'Brien e Toms [OT08] declaram que as "tecnologias de sucesso não são somente usáveis, elas engajam os usuários". Para promover o engajamento dos usuários com comunidades online [BNCP12], tem-se discutido o uso da "gamificação", que é o uso de elementos e técnicas de projeto de jogos em outros contextos com a meta de estimular a participação e engajar pessoas [DDKN11].

\subsection{Problema de pesquisa}

Teoria e prática não são correspondentes na área de gamificação [Bor17, SF15, Det14]. Nos estudos teóricos, a motivação intrínseca e a autodeterminação do usuário são as principais bases para a construção de aplicações com elementos de jogos. Entretanto, a maior parte dos estudos que relata a prática utiliza elementos de recompensa, como pontos, distintivos e quadros de liderança, que geralmente são associados a motivadores extrínsecos e pertencem a um subconjunto de gamificação ou pontificação (pointification) [BVD15, SF15, Bog11, Kap12, Rob10].

A maioria das abordagens para aplicar gamificação é muito genérica e não enfatiza os aspectos 
de colaboração [BVD15]. Um projeto baseado em recompensas pode ter o risco, especialmente em sistemas colaborativos, de mudar a proposta principal para a coleta de pontos, em vez de priorizar o objetivo de colaboração [BVD15].

Projetistas de jogos argumentam que o prazer do jogo não surge a partir de sistemas de recompensa, mas a partir de escolhas significativas na execução de "metas curiosamente difíceis" [Det12], em que se busca o equilíbrio entre o desafio e a habilidade do usuário [NC14]. Sendo assim, a maioria das implementações de gamificação tem apresentado o "menos essencial dos jogos" como "núcleo da experiência" [Det12].

Além disso, os estudos teóricos não apresentam aplicações na prática que possam demonstrar a teoria proposta em um contexto real [SF15], embora sejam baseados em teorias amplamente aceitas de motivação humana da área de Psicologia [DR12, DKR99, SDT16]. Existe também a necessidade de monitorar a inserção da gamificação durante o processo de desenvolvimento para analisar a evolução e o impacto no comportamento dos usuários, porém não por meio de estudos pontuais, que representam a maior parcela de pesquisas práticas publicadas na área [SF15]. A maioria dos estudos não apresenta análises estatísticas e não isola o efeito da gamificação, havendo a necessidade de explorar como a gamificação pode ser implementada em domínios específicos [SF15, Det14, LKB $\left.{ }^{+} 17\right]$.

Esses problemas possuem um mesmo ponto de convergência, os estudos que relatam a prática de gamificação não apresentam, de forma a ser replicada por outros pesquisadores, como os elementos de jogos foram inseridos para atender aos estudos teóricos sobre motivação humana, e como os elementos de jogos se relacionam com os aspectos de colaboração, fundamentais em comunidades de colaboração aberta. Além disso, não existem métricas amplamente aceitas para medir engajamento, então cada estudo relata engajamento a partir de seu conjunto de métricas, e alguns estudos limitamse a informar que o engajamento aumentou, sem informar como o engajamento foi monitorado e avaliado. Adicionalmente, a maioria dos estudos são pontuais, consequentemente, não respondem se o engajamento foi sustentável.

Portanto, ainda não há orientação suficiente nem evidências empíricas disponíveis sobre como aplicar a teoria de gamificação na prática durante o desenvolvimento de comunidades online de colaboração aberta, levando em consideração o monitoramento e avaliação do engajamento resultante como parte do processo, e de modo a isolar e avaliar os efeitos das mudanças. Este é o problema que esta tese busca investigar.

\subsection{Questões de pesquisa}

A partir da exploração da gamificação como possível solução para aumentar o engajamento, a tese investigada neste trabalho busca compreender como promover engajamento em comunidades online de colaboração aberta, no domínio de GLAMs, por meio de elementos de jogos. Duas questões de pesquisa foram definidas:

- (QPI) Qual o efeito do uso de elementos de jogos no engajamento de usuários em uma comunidade online de colaboração aberta no domínio de GLAMs?

- (QPII) Como integrar a gamificação com o monitoramento e a avaliação de engajamento de usuários durante o desenvolvimento de uma comunidade online de colaboração aberta?

A QPI aborda o problema de relatar o sucesso da gamificação sem o devido isolamento do efeito de cada elemento de jogo e de um conjunto de elementos de jogos, sem a apresentação de análises estatísticas longitudinais, e sem a descrição dos resultados em seu contexto específico de domínio de aplicação. A QPI ao mesmo tempo que torna possível a análise do efeito de cada elemento de jogo sobre o comportamento dos usuários, também possibilita analisar o efeito ao longo do tempo.

A QPII aborda o problema de insuficiência de evidências empíricas e de orientação de como aplicar e analisar a gamificação durante o desenvolvimento de comunidades online de colaboração aberta. Para esse fim, é descrita a aplicação na prática desde a pontificação [BVD15, SF15, Bog11, 
Kap12, Rob10] até o desenvolvimento de uma proposta de integração de gamificação em comunidades online de colaboração aberta, incluindo o monitoramento e a avaliação do engajamento resultante após cada intervenção.

O objetivo desta pesquisa é definir uma proposta de abordagem para integrar gamificação, baseada na teoria da área, e analisar os efeitos sobre o engajamento dos usuários durante o desenvolvimento de uma comunidade online de colaboração aberta no domínio de GLAMs.

\subsection{Contexto da pesquisa}

Arquigrafia (www.arquigrafia.org.br) é o projeto no qual a pesquisa-ação vem sendo realizada desde janeiro de 2015. Trata-se de um ambiente colaborativo digital público, sem fins lucrativos, dedicado à difusão de imagens de arquitetura, com especial atenção à arquitetura brasileira. O objetivo principal é contribuir para o estudo, a docência, a pesquisa e a difusão da cultura arquitetônica e urbanística, ao promover interações colaborativas entre pessoas e instituições na Internet.

O projeto é desenvolvido na Faculdade de Arquitetura e Urbanismo da Universidade de São Paulo (FAU-USP), em parceria com o Instituto de Matemática e Estatística (IME-USP) e a Escola de Comunicação e Artes (ECA-USP). O Arquigrafia recebeu o primeiro prêmio da Agência de Inovação USP na categoria de Tecnologias Sociais Aplicadas e Humanas na Olimpíada USP de Inovação de 2011. Em 2012 o projeto recebeu chancela do Ministério da Cultura por sua relevante contribuição à cultura brasileira. Em 2014 o Arquigrafia foi o projeto selecionado pelo Ministério da Cultura para representar o país na área de Arquitetura no Edital Cultura na Copa.

Desde 2011, a equipe do projeto Arquigrafia realiza um trabalho de conservação e digitalização do acervo original de imagens fotográficas do Setor Audiovisual da Biblioteca da FAU, e solicita aos autores de imagens autorização específica para a difusão de tais fotografias na Internet para fins acadêmicos, voltados ao ensino e à pesquisa. Nesse contexto, o Arquigrafia necessita fomentar uma comunidade em torno das imagens e informações de arquitetura e urbanismo de modo que o conhecimento coletivo favoreça o desenvolvimento de novas reflexões nesse domínio.

No entanto, embora o Arquigrafia tenha sido avaliado em diversos testes de usabilidade como um sistema útil, com boa usabilidade e com estética agradável, ainda não existia engajamento dos usuários com o sistema no início de 2015. Esse problema conduziu à realização da pesquisa-ação no Arquigrafia. O papel da pesquisadora no desenvolvimento da pesquisa-ação foi o de analista de requisitos, desenvolvedora, testadora e coordenadora da equipe de desenvolvimento, que esteve em constante mudança de acordo com os períodos de estágio de graduação dos alunos. Portanto, teve um papel de insider, participando ativamente das atividades como membro da equipe durante o decorrer da pesquisa. Mais detalhes são descritos no Capítulo 5.

\subsubsection{Relevância do contexto}

GLAMs vêm enfrentando o grande desafio de adaptação ao novo status quo da preservação e compartilhamento de conhecimento de acervos públicos e privados. Antes, como detentoras de um conhecimento acessível a poucos e apenas in loco. Hoje, como meios seguros de acesso a objetos e informações em um mundo de fake news e fatos alternativos. Contudo, seu valor cultural e econômico não costuma ser mensurado por políticas públicas e pela sociedade em geral.

A relação de GLAMs com o desenvolvimento econômico decorre da razão de que ao preservar a memória, e compartilhar conhecimento sobre objetos e fatos associados a ela, GLAMs abrem espaço para a liberdade de pensar, questionar, criar e discordar, e esta liberdade está no coração de uma sociedade democrática. Portanto, o trabalho associado a GLAMs não é apenas o de coletar e preservar memórias, mas sim, o de iniciar a cadeia criativa, fornecendo inspiração e material para artistas de todas as áreas, como autores, poetas, artistas digitais, músicos, pintores e diretores de filmes. Estes, por sua vez, influenciam cientistas e os mais diversos profissionais, o que faz o ciclo de desenvolvimento econômico, intelectual e cultural de uma sociedade acontecer [Ber17]. 
De acordo com Hedstrom e King [HK04], uma função chave na economia orientada pelo conhecimento é a integração de objetos e coleções amplamente distribuídos. Isso requer um rico conjunto de conhecimentos e habilidades em organização e classificação, bem como um olhar crítico em relação à maneira de descrever o mundo, da qual sistemas de organização do conhecimento se utilizam. Ainda conforme Hedstrom e King, essa habilidade foi construída ao longo de dois séculos e é uma parte fundamental do papel de GLAMs na infraestrutura de conhecimento global. Portanto, GLAMs têm fundamental importância para estruturação e compartilhamento de informação em múltiplas áreas de conhecimento.

\subsection{Método de pesquisa}

A QPI é respondida por meio de pesquisas quantitativas, experimentais (experimento controlado online) e não-experimentais (pesquisa causal-comparativa e pesquisa correlacional) [Cre02], ao longo de três anos (2015-2018) de monitoramento e avaliação de métricas de engajamento de usuários. A QPII é abordada por meio do método de pesquisa-ação [Dic93, KMS97, FIL08, VZ03, SE78], que responde "como integrar a gamificação baseada em sua teoria" e "como monitorar e avaliar o engajamento resultante". A pesquisa-ação é um dos métodos de pesquisa apropriados para responder questões de pesquisa do tipo "como" [Cre02, VZ03, SE78, Yin13]. Detalhes sobre cada um dos métodos são descritos no Capítulo 4.

A Figura 1.1 apresenta um resumo gráfico da pesquisa.

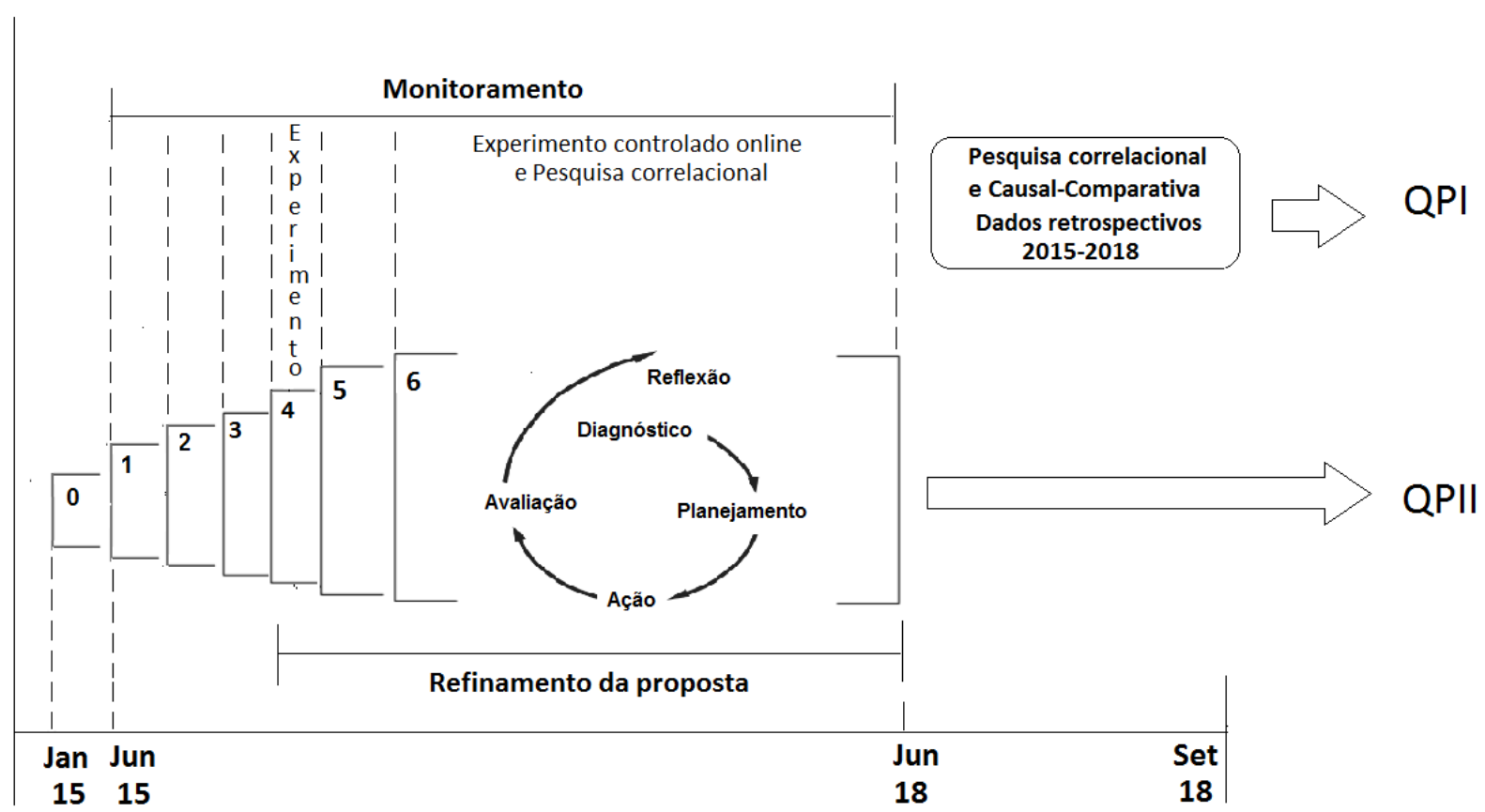

Figura 1.1: Relação entre os métodos e as questões de pesquisa desta tese.

Para o problema que esta pesquisa aborda, o método de pesquisa-ação possibilitou explorar a gamificação em um contexto real, no qual o problema da falta de engajamento existia, e analisar os resultados de forma iterativa. O método de pesquisa-ação vem sendo utilizado em pesquisas na área de Computação [FIL08, Mel13, Ens14] e se baseia no pressuposto de que teoria e prática podem ser estreitamente integradas a partir do aprendizado sobre os resultados de intervenções planejadas após um diagnóstico do contexto do problema [DMK04]. A pesquisa quantitativa possibilitou a avaliação das métricas de engajamento por meio de análises estatísticas descritivas e inferenciais após a inserção de elementos de jogo e de colaboração ao longo do desenvolvimento da comunidade. 


\subsection{Lista de publicações originais}

Esta pesquisa resultou até o momento nas seguintes publicações originais. As publicações são apresentadas, desde já, pois fazemos referências a elas nos próximos capítulos. O objetivo é abordar nesta tese os principais resultados, mantendo a descrição dos detalhes nos artigos.

1. Bertholdo, A.P.O., Gerosa, M.A. (2015) Engajamento de comunidades de colaboração aberta: Um modelo baseado em gamificação. VI Workshop de Teses e Dissertações em Sistemas Colaborativos. XII Simpósio Brasileiro de Sistemas Colaborativos.

2. Bertholdo A.P.O., Gerosa M.A. (2016) Promoting Engagement in Open Collaboration Communities by Means of Gamification. In: Stephanidis C. HCI International 2016 - Posters' Extended Abstracts. HCI 2016. Communications in Computer and Information Science, vol 618. Springer, Cham (https://doi.org/10.1007/978-3-319-40542-1_3).

3. Bertholdo A.P.O., Gerosa M.A., Rozestraten A.S. (2016) Promovendo engajamento por meio de gamificação. In: Caderno de resumos do II Seminário do Grupo de pesquisa CNPq Representações: Imaginário e Tecnologia- RITe - FAUUSP - São Paulo.

4. Bertholdo A.P.O., de O. Melo C., S. Rozestraten A. (2017) Improving Engagement Metrics in an Open Collaboration Community Through Notification: An Online Field Experiment. In: Meiselwitz G. Social Computing and Social Media. Human Behavior. SCSM 2017. Lecture Notes in Computer Science, vol 10282. Springer, Cham (https://doi.org/10.1007/ 978-3-319-58559-8_10).

5. Bertholdo, A.P.O., Rozestraten, A., Melo, C., Gerosa, M. (2017). Projeto Open Air Museum: Descrição de um piloto no Arquigrafia. In: Caderno de resumos do III Seminário do Grupo de pesquisa CNPq Representações: Imaginário e Tecnologia- RITe - FAUUSP - São Paulo

6. Rozestraten A.S., Bertholdo A.P.O., Faria J.H.K., da Silva F.S.C. (2017) Projeto Piloto Arquigrafia: Open-Air Museum. In:Revista Computação Brasil (SBC) vol 35 (http://www.sbc.org. br/images/flippingbook/computacaobrasil/computa_35/pdf/CompBrasil_35_out_180.pdf).

7. Bertholdo, A. P., Melo, C., Gerosa, M. (2018). Engajamento de usuários no Arquigrafia: Análises de experimentos de campo online. In: Caderno de resumos do IV Seminário do Grupo de pesquisa CNPq Representações: Imaginário e Tecnologia- RITe - FAUUSP - São Paulo.

8. Bertholdo, A. P., Melo, C., Rozestraten, A., Gerosa, M., \& O'Brien, H. (2018). User engagement in an open collaboration community after the insertion of a game design element: An online field experiment. AMCIS 2018 Proceedings - Virtual Communities and Collaborationm (http://aisel.aisnet.org/amcis2018/VirtualCC/Presentations/11/).

9. Bertholdo, A. P., Melo, C., Rozestraten, A., Gerosa, M. (2018). Relations between actions performed by users and their engagement. CRIWG 2018, Lecture Notes in Computer Science, vol 11001. Springer. (https://link.springer.com/chapter/10.1007/978-3-319-99504-5_17).

\subsection{Principais contribuições}

As contribuições desta pesquisa são:

- definição de um arcabouço teórico para integrar as teorias de motivação humana [DR12, DKR99, SDT16] que formam a principal base teórica da gamificação e se relacionam com o engajamento; a teoria para desenvolvimento de comunidades de prática [WMS02b, WTdL11], especialmente, as dimensões de uma prática compartilhada; e o Modelo 3C de colaboração [FRGL05]. A utilidade do arcabouço teórico é a de tornar clara a fundamentação teórica para a proposta de abordagem aos projetistas, convergindo a teoria de gamificação para o contexto desta pesquisa, desenvolvimento de comunidades online de colaboração aberta. 
- definição de uma abordagem baseada no arcabouço teórico para inserção de elementos de jogos durante o desenvolvimento de comunidades online de colaboração aberta e avaliação do engajamento resultante em cada intervenção. A proposta de abordagem é composta de três níveis: 1) localização da abordagem nas fases do Design Centrado em Usuário (DCU); 2) detalhamento de comportamentos-alvo de uma comunidade e avaliação do engajamento de usuário resultante da interação com eles; e 3) associação de comportamentos-alvo de comunidades às práticas do contexto de GLAMs;

- disponibilização dos componentes de software (software livre), relacionados à gamificação e colaboração, desenvolvidos durante a pesquisa-ação em uma GLAM sobre arquitetura e urbanismo;

- análise de um problema real no contexto do projeto Arquigrafia resultando em novas funcionalidades para o sistema e no aumento do engajamento de usuários ao longo dos ciclos de pesquisa-ação;

- lições aprendidas durante o desenvolvimento da pesquisa-ação, que por sua vez, fazem parte da proposta de abordagem;

- avaliação da efetividade da gamificação no contexto de uma GLAM sobre arquitetura e urbanismo;

- evidências encontradas nas pesquisas quantitativas:

- a análise do engajamento por meio do cruzamento entre as ações recorrentes dos usuários combinadas com o tempo médio de reação do usuário a cada ação pode informar melhor o engajamento do usuário do que apenas a frequência de ações sozinha;

- usuários engajados contribuem para a comunidade do sistema (acesso ativo) e/ou para a reunião de seus próprios objetivos (acesso passivo). Ambos são guiados por um objetivo específico que implica em uma motivação pré-existente, reforçando a ideia de que a motivação orientada por metas guia mais engajamento do que a exploração do sistema sem metas definidas.

- uma grande quantidade de ações repetidas não indica que os usuários estavam engajados quando as realizaram; é preciso considerar o conjunto de métricas.

- Existem diferenças nas táticas de uso e na distribuição de acesso a cada elemento de interação de usuário para usuários com níveis altos, médios ou baixos alcançados em cada métrica subjetiva de engajamento.

\subsection{Organização do Trabalho}

O Capítulo 2 aborda os principais conceitos envolvidos na realização desta pesquisa, respectivamente: colaboração aberta, comunidades online de colaboração aberta; engajamento de usuários; e gamificação. O Capítulo 3 apresenta o estado da arte sobre gamificação e o seu impacto no engajamento de usuários, bem como, os trabalhos relacionados a esta pesquisa. O capítulo 4 apresenta como os métodos de pesquisa relacionaram-se para responder as questões de pesquisa e a validação de procedimentos e construtos analisados em cada método. Os Capítulos 5 e 6 apresentam a descrição da pesquisa-ação dividida, respectivamente, em dois momentos: monitoramento e exploração de pontificação com colaboração até a definição de uma proposta de abordagem; e refinamento da proposta de abordagem no contexto do Arquigrafia. O Capítulo 7 responde a QPI por meio de um estudo longitudinal de métricas de engajamento de 2015 a 2018. O Capítulo 8 responde a QPII, destacando as reflexões dos ciclos de pesquisa-ação e a aplicação no contexto de GLAMs. O Capítulo 9 apresenta a avaliação da pesquisa de acordo com implicações para a teoria e a prática, como espera-se em uma pesquisa-ação [FIL08, Dic93, KMS97]. Por fim, o Capítulo 10 apresenta o resumo dos resultados, as limitações do estudo e pesquisas futuras. 


\section{Capítulo 2}

\section{Conceitos fundamentais}

Este capítulo relaciona os principais conceitos envolvidos nesta pesquisa. Apresenta-se a definição de colaboração, o que conduz para a apresentação de diretrizes para construção de comunidades de prática sustentáveis, e métricas para avaliar se as práticas estão gerando o engajamento de usuários desejado. Para esse fim, a relação entre a motivação humana e o engajamento é destacada, uma vez que ambos são construtos teóricos utilizados em gamificação, uma prática comumente descrita para melhoria do engajamento de usuários.

\subsection{Colaboração}

A colaboração envolve comunicação, coordenação e cooperação [FRGL05]. Comunicação é realizada com a troca de mensagens; coordenação é executada por meio do gerenciamento de pessoas, atividades e recursos; e cooperação ocorre por intermédio de operações num espaço compartilhado para a execução das tarefas. Aspectos de colaboração são definidos de acordo com o modelo 3C de colaboração [FRGL05] e fazem parte do desenvolvimento de sistemas colaborativos.

Conforme Gerosa et al. [GFL03], a colaboração em problemas complexos pode produzir melhores resultados do que o trabalho individual, uma vez que esforços, habilidades e conhecimentos individuais se complementam em um grupo. Ao colaborar, os membros do grupo recebem feedback, que lhes possibilita identificar inconsistências no processo de pensamento, de modo que possam, juntos, encontrar ideias, informação e referências para resolver os problemas. Um grupo tem maior capacidade de gerar alternativas de forma criativa. Trabalhar em grupo também motiva os membros, já que seu trabalho está sendo observado, comentado e avaliado por membros de uma comunidade. Além disso, ao debater suas ideias com os outros membros, os participantes ativamente desenvolvem conceitos e refinam ideias.

Contudo, trabalho colaborativo demanda esforço adicional para coordenar os membros do grupo. Caso não exista coordenação, grande parte do esforço de comunicação não será usada para cooperação. A coordenação também deve lidar com conflitos que prejudicam o grupo. Para tornar a coordenação possível, é necessário perceber a presença dos outros e saber o que está acontecendo, a fim de tomar as decisões adequadas sobre os procedimentos a serem adotados [GFL03]. Esse tipo de informação, conhecido como percepção de grupo, é usado pelos participantes para construir um entendimento sobre os objetos de cooperação e os objetivos das tarefas e do trabalho. A Figura 2.1 apresenta o modelo de colaboração de Fuks et al. [GFL03], que resume a natureza interativa da colaboração, na qual os participantes obtêm feedback a partir de suas ações e de seus companheiros, por meio da informação de percepção relacionada à interação entre os participantes $\left[\mathrm{FRG}^{+} 11\right.$, FRGL05, GFL03]. 


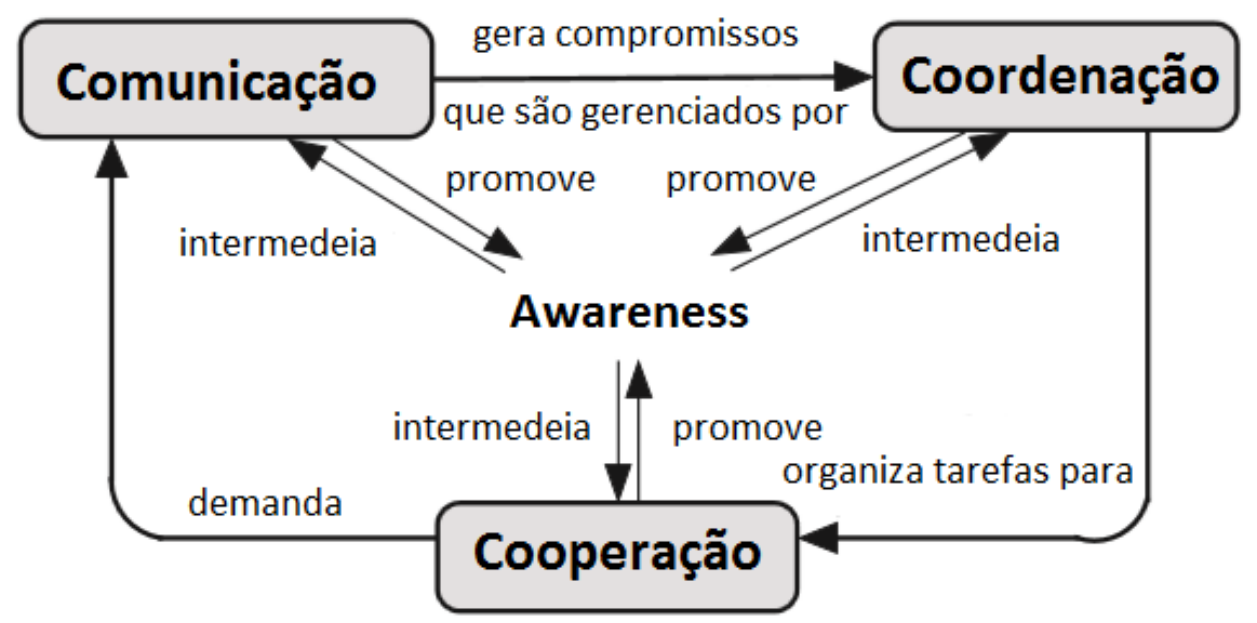

Figura 2.1: Modelo 3C para trabalho em grupo a partir de Fuks et al. [FRGL05].

\subsubsection{Colaboração aberta}

Projetos de colaboração aberta são esforços distribuídos e colaborativos que se tornaram possíveis por causa das mudanças nas tecnologias de informação e comunicação [FL13]. Colaboração aberta em grande escala geralmente acontece no contexto de uma meta de produção particular; sendo assim, diz respeito a pessoas trabalhando em algo juntas. O produto de colaboração aberta pode tomar muitas formas, desde trabalhos de referência, vídeos, software, novos recursos e mapas anotados. Conforme Forte e Cliff [FL13], um sistema de colaboração aberta é um ambiente online que:

1. dá suporte à produção coletiva de um artefato: participantes criam um ou mais artefatos compartilhados, geralmente com a ciência de que o produto será consumido por alguma plateia futura desconhecida. Criar o artefato compartilhado requer não só a colaboração em torno da criação do artefato, mas também em torno de sua administração e curadoria.

2. contém uma plataforma de colaboração tecnologicamente mediada: interações dentro dos sistemas de colaboração aberta ocorrem por meio de ferramentas de computação em rede, as quais têm interfaces que afetam os possíveis tipos de interações. Parte do que faz sistemas de colaboração aberta atraentes é possibilitar a participação em uma atividade compartilhada por um enorme número de usuários cujas interações são tecnologicamente mediadas.

3. apresenta baixa barreira para entrada e saída: pessoas devem possuir ou aprender as habilidades necessárias para participar de forma significativa e entender quais tipos de participação são valorizados. Sistemas de colaboração aberta apresentam poucas barreiras para novos participantes.

4. suporta a emergência de estruturas sociais persistentes, mas maleáveis: um aspecto importante da organização social em projetos de colaboração aberta é o papel dos líderes. Liderança tem sido identificada como fator crítico no sucesso de projetos de software livre e Wikipedia.

Ainda conforme Forte e Cliff [FL13], tais características combinadas produzem sistemas sociotécnicos complexos que oferecem novas oportunidades para as pessoas formarem laços e criarem juntas. Forte e Cliff descrevem os seguintes padrões presentes em sistemas de colaboração aberta:

- participação é desigual: frequentemente referida como a "lei do poder da participação", em todos os sistemas de colaboração aberta, pessoas que consomem informações fornecidas pelo site, isto é, aquelas que participam poucas vezes, e pessoas que fazem a maior parte do trabalho no site exibem comportamentos totalmente diferentes. Essa descoberta ressalta a necessidade de cultivar um forte núcleo de participantes "energizados" em colaborações abertas. 
- existem requisitos especiais para a socialização de novos usuários: em sistemas de colaboração aberta, baixas barreiras à entrada muitas vezes significam que os novos usuários podem entrar a qualquer momento. A maioria dos novos usuários não são membros fundadores; eles entram em um sistema sociotécnico em andamento no qual as estruturas sociais, práticas e normas já existem. Pode ser difícil para novos usuários discernir quais são as normas e estruturas sociais, o que precisa ser feito, e como suas contribuições podem ser valorizadas. Como os projetos podem experimentar desgaste ao longo do tempo, projetar para a socialização de novos usuários é importante para a sustentabilidade a longo prazo.

- usuários são muito heterogêneos tanto em como quanto em por quê participam: em colaborações em larga escala, usuários entram no sistema com ampla variedade de razões para participar e tipos de atividades em que se engajam. O tipo de trabalho que fazem, as funcionalidades do sistema que usam e as razões para manterem suas atividades são altamente dependentes das motivações. Para serem sustentáveis, sistemas de colaboração aberta não só precisam atrair e socializar número suficiente de participantes, como também precisam atrair e dar suporte a participantes que se especializam em tipos críticos de atividades.

\subsection{Comunidades online de colaboração aberta}

Comunidades podem ser formadas em diversos contextos, como, por exemplo, em ambientes fechados à participação de indivíduos específicos, caso de funcionários de empresas privadas. Em comunidades online privadas ou fechadas, os usuários apenas têm acesso à informação compartilhada se acessarem o sistema de autenticação, o qual depende de aprovação prévia para entrada na comunidade. Em comunidades online abertas, a autenticação não é necessária para acesso à informação compartilhada.

O contexto que interessa a esta pesquisa é a formação de comunidades em ambientes de colaboração aberta, como descrito na seção anterior. Uma comunidade é um grupo de várias pessoas, cujas identidades são definidas em grande parte pelos papéis que desempenham e relacionamentos que compartilham na atividade do grupo [RP04]. A coesão da comunidade deriva da construção conjunta de uma cultura da vida diária, definida sobre normas comportamentais, rotinas, regras e de um sentimento de finalidade compartilhada. A atividade da comunidade gera artefatos compartilhados e ideias que dão suporte à atividade do grupo [RP04]. As comunidades podem ser de várias gerações, ou seja, podem existir ao longo do tempo e resistir às idas e vindas de indivíduos. Uma comunidade difere de uma coleção de pessoas pela força e profundidade da cultura que é capaz de estabelecer e que, por sua vez, dá suporte a atividades de grupo e coesão [RP04].

\subsubsection{Comunidades de prática}

As comunidades existentes em uma área de domínio são definidas como comunidades de prática. O conceito foi inicialmente proposto pelo antropólogo cognitivo Jean Lave e pelo teórico educacional Etienne Wenger, em 1991, como sendo um grupo de pessoas que compartilham um ofício ou profissão [LW91]. Em 2002, Wenger et al. [WMS02b] expandiram o conceito para "grupos de pessoas que compartilham uma preocupação, um conjunto de problemas ou uma paixão sobre um tópico e que aprofundam seu conhecimento e experiência nesta área ao interagir em uma base contínua".

Conforme Wenger et al. [WTdL11, WMS02b], comunidades de prática referem-se ao "desenvolvimento de uma identidade compartilhada em torno de um tópico ou conjunto de desafios e representam uma intenção coletiva - tácita e distribuída - para administrar um domínio de conhecimento e sustentar aprendizado sobre ele". As comunidades de prática podem existir tanto em um ambiente real quanto online e podem ser definidas por meio de um modelo estrutural que corresponde a uma combinação única de três elementos fundamentais:

1. um domínio de conhecimento, que denota o tópico de enfoque da comunidade; 
2. uma comunidade de pessoas, que se preocupam com esse domínio; e

3. a prática compartilhada, que se refere ao conhecimento específico que a comunidade gera para ser eficaz dentro do domínio.

Os três elementos representam diferentes aspectos da participação que motivam as pessoas a se unirem a uma comunidade e fornecem um modelo prático para guiar o desenvolvimento de comunidades. Além desses três elementos, Wenger define três dimensões relacionadas à prática em si [WTdL11, WMS02b].

1. engajamento mútuo: a prática não existe no abstrato, então comunidades de prática residem em torno de pessoas engajadas em certas ações ou ideias comuns. Esse é um fator importante, pois significa que comunidades de prática podem ser formadas a partir de membros de diferentes categorias sociais ou a partir de diferentes regiões geográficas.

2. empreendimento conjunto: Wenger declara a importância do empreendimento conjunto ser constantemente renegociado pelos membros individuais. O empreendimento conjunto vai além das metas estabelecidas, como declaração da missão ou objetivos, e cria responsabilidade mútua entre os participantes.

3. repertório compartilhado: o repertório de uma comunidade de prática inclui rotinas, palavras, ferramentas, maneiras de fazer as atividades, histórias, gestos, símbolos, gêneros, ações ou conceitos que a comunidade tem produzido ou adotado no curso de sua existência.

\subsubsection{Comunidades online de prática}

Comunidade online é um termo usado para se referir a uma comunidade existente em um sistema de colaboração aberta [KR11, BNCP12, Pre00, AH00]. Nesse contexto, comunidades online relacionam-se com a definição de comunidades de inovação. Hippel [Hip05] define comunidades de inovação como nós (nodes) compostos de indivíduos ou empresas interconectados por linhas de transferência de informações que podem comunicar-se face a face, eletronicamente ou por meio de outra forma de comunicação. Embora não necessariamente, tais comunidades frequentemente incorporam qualidades das comunidades aos participantes. Além disso, podem desenvolver-se quando ao menos um indivíduo voluntariamente revela suas inovações e, por sua vez, outros membros da comunidade julgam a informação revelada como de seu interesse. Comunidades de inovação são frequentemente especializadas, servindo como pontos de coleta e repositórios para informações relacionadas a categorias específicas de inovação. Também podem fornecer funções adicionais para participantes, como salas de bate-papo e listas de e-mail com postagem pública, para que contribuidores possam trocar ideias e fornecer assistência mútua. Ferramentas para ajudar os participantes a desenvolver, avaliar e integrar seu trabalho podem ser fornecidas para membros da comunidade e são frequentemente desenvolvidas pelos próprios membros da comunidade.

De acordo com Kraut e Resnick [KR11], comunidades precisam alcançar as seguintes metas: iniciar uma nova comunidade, atrair e socializar novos membros, encorajar compromisso, encorajar contribuição e regular o comportamento. Comunidades online podem ter maior dificuldade em alcançar tais metas por causa de três características que são incomuns em grupos e organizações convencionais. A primeira é o anonimato: veteranos podem ser menos aptos a analisar recémchegados anônimos e recém-chegados podem ser menos inibidos por responsabilidade social. A segunda é a facilidade de entrada e saída, que conduz à alta rotatividade e prejudica a construção de laços pessoais ou o compromisso com o grupo. A terceira é a comunicação textual, que é propensa a erros de interpretação, porque falta fluidez e sinais não verbais da interação face a face.

Bista et al. [BNCP12] também reforçam que para a sustentabilidade de uma comunidade online é essencial que ela tenha contribuidores ativos e que fortalecer o engajamento é uma das formas de motivar os membros a contribuir. Os pesquisadores apresentam três desafios principais: (a) bootstrapping - como trazer membros para a comunidade e mantê-los engajados durante a fase inicial da 
comunidade; (b) monitoramento - como monitorar atividades da comunidade sob diferentes categorias, como leitura, classificação, comentários, seguir pessoas, entre outros; e (c) sustentabilidade como sustentar o engajamento da comunidade não somente durante o estágio inicial, mas ao longo da vida da comunidade.

Couros [Cou03] argumenta que seria interessante estudar comunidades de prática específicas, de modo a melhor compreender os processos e ferramentas utilizadas para trazer a realidade do que Wenger [Wen98] chama de vivacidade (do inglês aliveness), característica que torna as comunidades reais para seus membros.

\subsubsection{Comunidades online de GLAMs ou crowdsourcing do patrimônio cultural}

No contexto de GLAMs, as comunidades de prática convidam o público a colaborar com temas pertinentes de um determinado acervo digital. Os projetos de crowdsourcing oferecem oportunidades para o público se engajar ativamente com os materiais e práticas de pesquisa de disciplinas relacionadas a esses materiais, o que gera um impacto positivo sobre o conhecimento dos participantes que vai além da contribuição para o processamento de coleções da instituição.

Daren C. Brabham definiu o termo crowdsourcing como: "um modelo online distribuído de produção e resolução de problemas" [Bra08]. No contexto de GLAMs, crowdsourcing é realizado sobre o patrimônio cultural. Patrimônio cultural é definido como o conjunto de todos os bens tanto materiais quanto imateriais (intangíveis), que reconhecidos de acordo com sua importância histórica e cultural de uma região (país, localidade ou comunidade) adquirem um valor único e de durabilidade representativa simbólica ou material. São assim considerados como de interesse relevante para a permanência e identidade de uma cultura através do tempo, sendo portanto necessária a sua proteção para garantir continuidade e preservação [Wik18, dRSndjd85, dPHeANI14]. O Arquigrafia, sendo uma GLAM, mantém a memória iconográfica de arquitetura e urbanismo, especialmente brasileira.

\subsection{Motivação}

Segundo Ryan e Deci [RD00a], "a motivação intrínseca refere-se a fazer alguma coisa porque é inerentemente interessante ou agradável. A motivação extrínseca, por outro lado, refere-se a fazer alguma coisa porque ela conduz a um resultado separado". Décadas de pesquisa na área têm demonstrado que a qualidade da experiência e o desempenho podem ser muito diferentes quando alguém está se comportando por razões intrínsecas quando comparado com razões extrínsecas. Ryan e Deci [RD00a] destacam que, embora a motivação intrínseca seja uma razão interna do indivíduo, ela depende da atividade em questão, ou seja, do interesse que o indivíduo possui sobre uma atividade. Estudos como o de Covington e Müeller [CM01] indicam que a motivação extrínseca não é necessariamente incompatível com a intrínseca. É necessário considerar o contexto em que a motivação extrínseca pode prejudicar a motivação intrínseca [LMK01].

A motivação intrínseca, segundo a abordagem de Ryan e Deci [RD00a], enfoca as necessidades psicológicas ou as necessidades inatas para a competência, autonomia e relacionamento, que se referem à satisfação de uma pessoa ao realizar uma tarefa. Para Deci e Ryan [DR12, RD00a], a autonomia - ou o senso de agir de acordo com a vontade e em congruência com seus próprios objetivos, valores e identidade - é a necessidade psicológica básica e parte nuclear da motivação intrínseca. O que faz as atividades agradáveis ou valorosas para os indivíduos é a satisfação de necessidades psicológicas, como a autonomia ou a associação com valores ou competências que se desejam alcançar.

A motivação extrínseca é um construto que diz respeito a uma atividade feita para alcançar algum resultado distinto da atividade em si. A motivação extrínseca contrasta, assim, com a motivação intrínseca, que diz respeito a fazer uma atividade simplesmente pelo prazer da atividade em si, em vez de por seu valor instrumental [RD00a]. No entanto, ao contrário de algumas perspectivas que veem o comportamento extrinsecamente motivado como invariavelmente não autônomo, a teoria da autodeterminação propõe que a motivação extrínseca pode variar muito no grau em que 
ela é autônoma.

\subsubsection{Teorias sobre motivação}

Existem diferentes formas de classificação da motivação. Quanto ao tipo de teoria: natural ou racional; de conteúdo ou de processo. As teorias naturais assumem que as pessoas têm necessidades de ordem superior, o que contrasta com as teorias racionais, que sugerem que as pessoas não gostam de executar tarefas ou responsabilidades e só respondem a recompensas e punições. As teorias de conteúdo, por sua vez, abordam o que motiva as pessoas e se preocupam com as necessidades e objetivos individuais [Zan16]. A teoria de Maslow é um exemplo de teoria de conteúdo [Mas43, $\mathrm{MFF}^{+}$70]. As teorias de processo lidam com o processo da motivação e se preocupam com a maneira como ela ocorre. A teoria da meta, de Edwin Locke, é um exemplo de teoria de processo [LL90, LL02]. As teorias de motivação intrínseca e extrínseca e da autodeterminação, ambas de Ryan e Deci [DR12, RD00b, DR85, SDT16], são referenciadas em estudos teóricos da área de gamificação.

\section{Teoria da autodeterminação}

A teoria da autodeterminação, ou Self-Determination Theory (SDT) [DR12, RD00b, DR85, SDT16], é formulada em termos de fatores sociais e ambientais que facilitam a motivação intrínseca contra os que a diminuem. A teoria reflete a suposição de que a motivação intrínseca é catalisada ou estimulada (em vez de causada) quando os indivíduos estão em condições que conduzem à sua expressão [RD00a].

A teoria da autodeterminação representa um arcabouço para o estudo da motivação e personalidade humana, articulando uma metateoria para formular estudos motivacionais [RD00a]. A teoria também define fontes de motivação intrínseca e extrínseca variadas e descreve os respectivos papéis desses dois tipos de motivação no desenvolvimento cognitivo e social, incluindo diferenças individuais. O enfoque é compreender como fatores sociais e culturais facilitam ou enfraquecem o senso de vontade e iniciativa, em adição ao bem-estar e à qualidade do desempenho. A teoria baseia-se na experiência individual de autonomia, competência e relacionamento, descritos como elementos que promovem as formas de motivação de maior qualidade e engajamento para as atividades, incluindo desempenho melhorado, persistência e criatividade [RD00a].

A teoria da autodeterminação propõe que, se um dos três elementos - autonomia, competência e relacionamento - não é suportado dentro de um contexto social, isso terá impacto negativo no bem-estar dos envolvidos [DKR99, DR12, SDT16].

A teoria da integração orgânica, que faz parte da teoria da autodeterminação, foi introduzida para detalhar as diferentes formas de motivação extrínseca e os fatores contextuais que promovem ou dificultam a interiorização e a integração da regulação dos comportamentos [DR85].

A Figura 2.2 [RD00a] ilustra a taxonomia da teoria da integração orgânica para os tipos de motivação, dispostos da esquerda para a direita em termos do grau em que a motivação para o comportamento de alguém emana de si mesmo. 


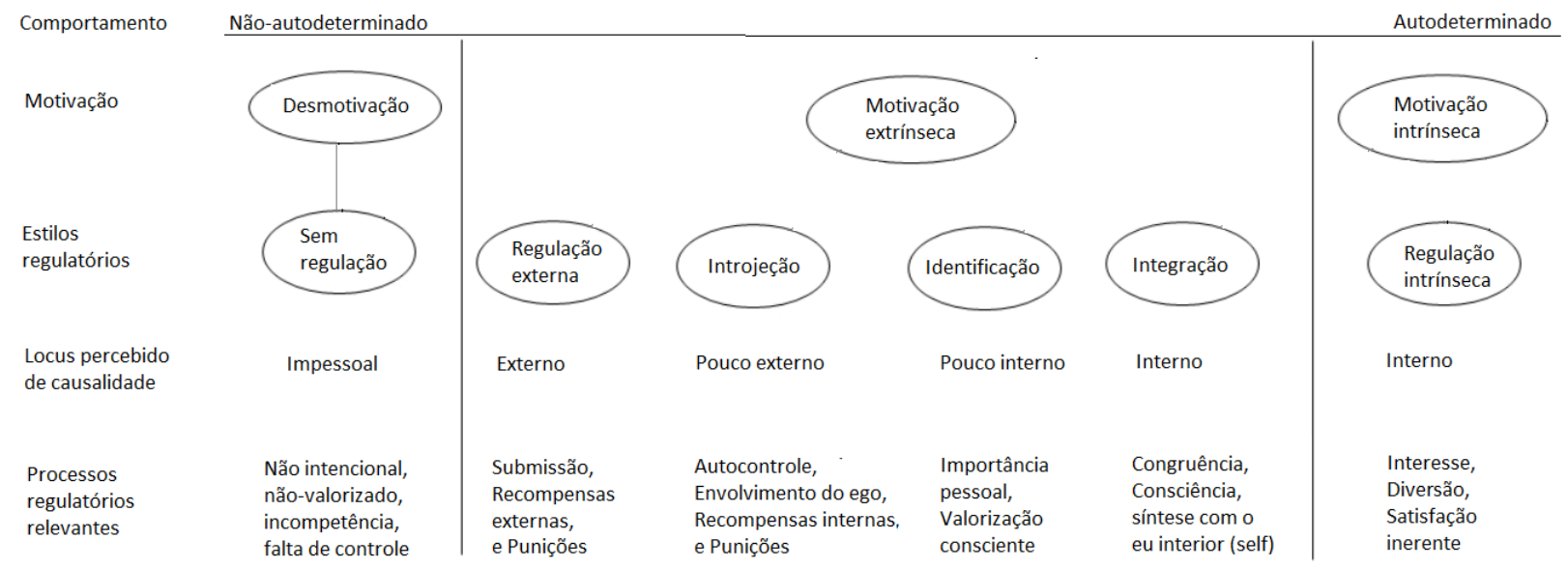

Figura 2.2: Taxonomia da teoria da integração orgânica para os tipos de motivação humana. Tradução a partir da figura original de Ryan e Deci [RD00a].

À esquerda está a desmotivação, que é o estado de falta de uma intenção para agir. Quando um indivíduo está desmotivado, seu comportamento não tem uma intenção e um sentido de causalidade pessoal. A desmotivação resulta em não valorizar uma atividade [Rya95, RD00a], não se sentir competente para realizá-la [DR75, RD00a], ou não acreditar que irá produzir o resultado desejado [RD00a].

Os pesquisadores que trataram a motivação como um conceito unitário preocuparam-se com a distinção entre a desmotivação e a motivação. No entanto, a partir da Figura 2.2 de Ryan e Deci [RD00a], é possível visualizar que à direita da desmotivação existem vários tipos de motivação que refletem diferentes graus de autonomia ou autodeterminação. Logo à direita da desmotivação está uma categoria que representa a forma menos autônoma de motivação extrínseca, chamada de regulação externa. Tais comportamentos são realizados para satisfazer uma demanda externa ou obter uma recompensa externa [RD00a].

Um segundo tipo de motivação extrínseca é a regulação introjetada. A forma clássica de introjeção é o envolvimento do ego [Nic84, RD00a], em que uma pessoa realiza um ato a fim de melhorar ou manter a autoestima e o sentimento de valor. Embora a regulação seja interna para a pessoa, comportamentos introjetados não são experimentados como parte integrante do ego.

Uma forma de motivação extrínseca mais autônoma, ou autodeterminada, é a regulação por meio da identificação. A pessoa identifica-se com a importância pessoal de um comportamento e aceita sua regulação como sendo sua [RD00a]. Por fim, a forma mais autônoma de motivação extrínseca é a regulação integrada. Integração ocorre quando as regulações identificadas foram totalmente assimiladas ao ego. Quanto mais interioriza as razões para uma ação e as assimila para si mesmo, mais as ações extrinsecamente motivadas tornam-se autodeterminadas. Formas integradas de motivação compartilham qualidades com a motivação intrínseca, sendo ambas autônomas e não conflituosas. No entanto, elas ainda são extrínsecas, porque o comportamento motivado pela regulação integrada é feito pelo seu resultado, que é separado do comportamento, embora seja voluntário e valorizado pelo indivíduo [RD00a].

No final, mais à direita da figura, está a motivação intrínseca. Esse posicionamento enfatiza que a motivação intrínseca é um protótipo de atividade autodeterminada. No entanto, isto não significa que à medida que as regulações extrínsecas tornam-se mais internalizadas, elas são transformadas em motivação intrínseca [RD00a]. Um indivíduo não tem de progredir por meio de cada estágio de internalização; de fato, pode-se, inicialmente, adotar uma nova regulação comportamental em qualquer ponto ao longo deste meio contínuo, dependendo de experiências anteriores e fatores situacionais [Rya95, RD00a].

Dada a significância da internalização tanto para a experiência pessoal quanto para os resultados comportamentais e de desempenho, há a questão de como promover a regulação autônoma 
de comportamentos extrinsecamente motivados, pois esses não são inerentemente interessantes e, portanto, precisam ser solicitados, em um primeiro momento, por um meio externo. A principal razão porque as pessoas tendem a estar dispostas a realizar tais comportamentos é o fato de serem valorizados por outros indivíduos com quem elas se sentem (ou gostariam de se sentir) conectadas, seja a família, um grupo de pares ou uma sociedade. Isto sugere que a base para facilitar a internalização está em proporcionar uma sensação de pertencimento e conexão entre pessoas, grupos ou culturas, disseminando um objetivo, ou o que na teoria da autodeterminação (SDT) chama-se um senso de relacionamento [RD00a].

Uma segunda questão diz respeito à percepção de competência. Adotar como própria uma meta extrínseca requer que a pessoa sinta-se eficaz com respeito a ela. Assim, Deci e Ryan teorizam que o suporte para a competência (por exemplo, oferecendo desafios ideais e feedback relevante) facilita a internalização. De acordo com a abordagem SDT, uma regulação que foi internalizada pode ser somente introjetada, e esse tipo de regulação poderia deixar as pessoas sentirem-se satisfeitas em suas necessidades por competência e relacionamento [RD00a].

Contudo, apenas contextos que dão suporte à autonomia irão produzir a autorregulação integrada. Para internalizar uma regulação e, assim, tornar-se autônomo em relação a ela, as pessoas devem interiormente compreender seu significado e valor [RD00a]. Estas são algumas das descobertas nesta área que sugerem como o suporte ao relacionamento e à competência facilita a internalização e como o suporte à autonomia, adicionalmente, facilita a integração de regulações comportamentais. Quando isso ocorre, as pessoas não apenas se sentem competentes e bem relacionadas, mas também autodeterminadas [RD00a].

\subsection{Engajamento}

A motivação para agir pode ser facilitada por meio da integração de regulações comportamentais e de acordo com o contexto, conforme as seis teorias que compõem a teoria da autodeterminação, descritas na seção anterior. Nesse sentido, uma motivação extrínseca ou intrínseca conduz o indivíduo a acessar determinado meio interativo computacional. Ao começar a interagir com esse meio, a experiência do usuário pode aumentar ou reduzir a sua motivação prévia, por exemplo, curiosidade. Isso é especialmente importante quando se trata de comunidades de colaboração aberta, porque existe um caráter voluntário; o indivíduo não está sendo pago ou pressionado a participar e a busca por uma das três ou as três necessidades psicológicas - autonomia, competência e relacionamento - está envolvida. Portanto, existe o desafio de design de manter o indivíduo motivado a utilizar um sistema e essa motivação pode ser estimulada por meio do engajamento, que, nesse sentido, funciona como um facilitador.

Segundo O'Brien e Toms [OT08], engajamento é uma categoria de experiência do usuário caracterizada por atributos de desafio, afeto positivo, apelo estético e sensorial, atenção, feedback, variedade/novidade, interatividade e controle percebido pelo usuário. Para Lehmann et al. [LLYTD12], engajamento de usuário é a qualidade da experiência do usuário que enfatiza aspectos positivos da interação e, em particular, o fenômeno associado com ser cativado por um sistema e, consequentemente, tornar-se motivado a usá-lo. Aplicações bem-sucedidas não possuem somente usabilidade: elas engajam os usuários e, por isso, estes investem tempo, atenção e emoção nelas. Com tantas opções possíveis, capturar a atenção do usuário é um recurso nobre, portanto é essencial projetar experiências engajadoras.

Para Attfield et al. [AKLP11], engajamento de usuário pode ser descrito por meio de três dimensões: emocional, cognitiva e comportamental, e apresenta as seguintes características: atenção focada; afeto positivo; estética; suportabilidade (endurability); novidade; riqueza e controle; reputação, confiança e expectativa; e contexto do usuário. Os pesquisadores também examinam o engajamento sob a noção de imersão como é usada na área de jogos. Em particular, existe a pesquisa de Brown et al. [BC04] sobre imersão em jogos, na qual os autores relatam três níveis progressivamente profundos de imersão, denominados engajamento, absorção e imersão total.

Chapman [Cha97] relatou engajamento a partir da teoria do fluxo [CC92], que será descrita na 
Seção 2.5.1, por estar relacionada com o design de jogos. Em adição à teoria do fluxo, outras teorias foram relatadas na literatura: teoria da estética [Bea70], teoria do jogo [Ste64] e interação da informação [Tom02b]. O'Brien e Toms [OT08] examinaram tais teorias para delinear um entendimento de experiências do usuário, que foi expresso por meio da definição de um modelo de engajamento, descrito na próxima seção.

\subsubsection{Modelo de engajamento}

A Figura 2.3 exibe o modelo de engajamento de usuários definido por O’Brien e Toms [OT08], apresentando quatro fases distintas para o engajamento. São apresentados os atributos pertencentes a cada fase. Nesse caso, existe uma relação entre o processo descrito na teoria de integração orgânica, conforme a Figura 2.2, e o modelo de engajamento de O'Brien e Toms.

Conforme o modelo, o problema de manter um usuário engajado com novas funcionalidades diz respeito a fases distintas de interação do usuário, a saber, o primeiro contato com o sistema e o período de uso a partir da segunda utilização. A primeira utilização é importante porque primeiras impressões podem ser as únicas impressões, caso a impressão seja negativa. No entanto, é preciso manter o usuário engajado também a partir do segundo uso.
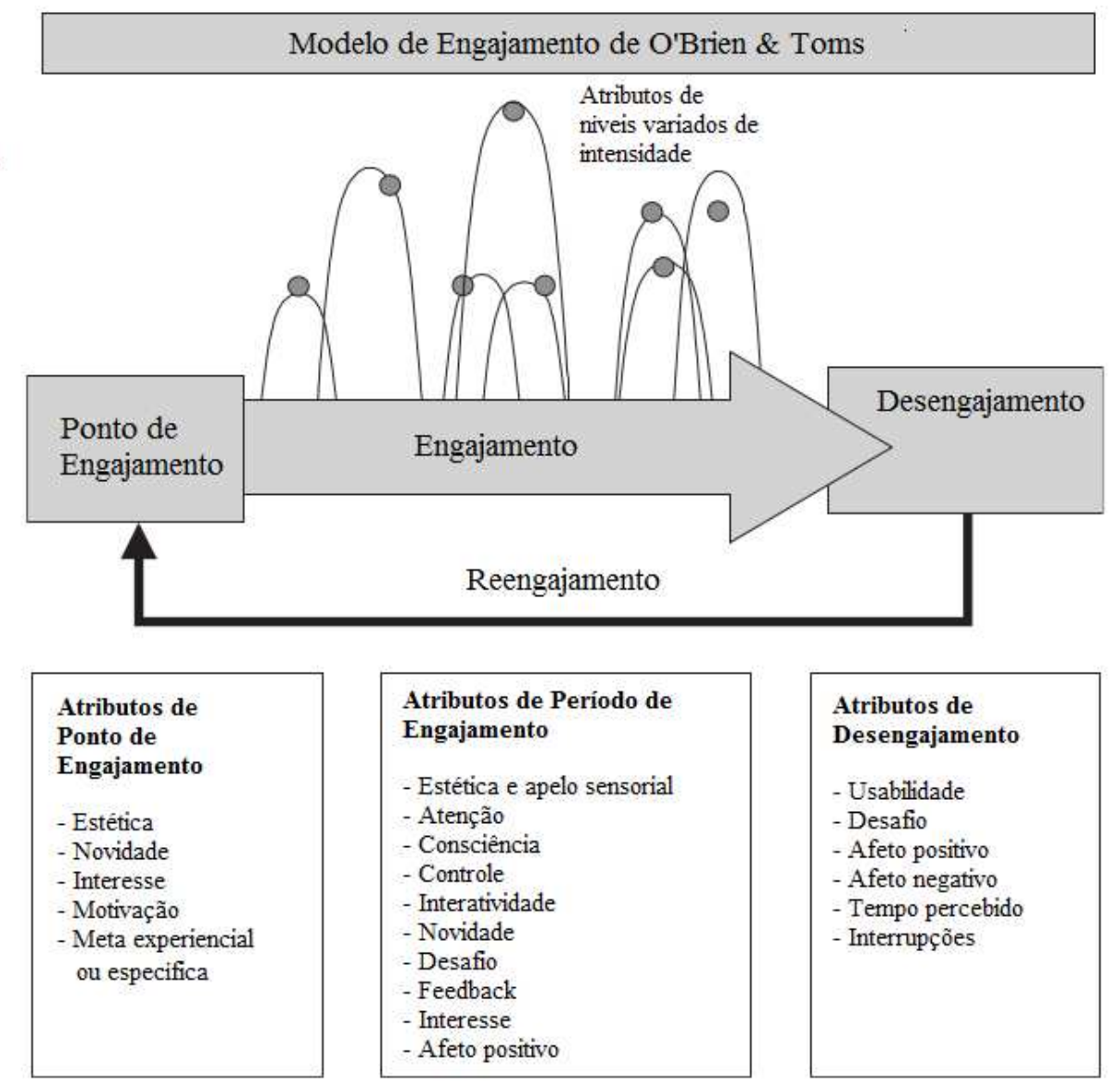

\begin{tabular}{|l|}
\hline Atributos de Período de \\
Engajamento \\
- Estética e apelo sensorial \\
- Atenção \\
- Consciência \\
- Controle \\
- Interatividade \\
- Novidade \\
- Desafio \\
- Feedback \\
- Interesse \\
- Afeto positivo \\
\hline
\end{tabular}

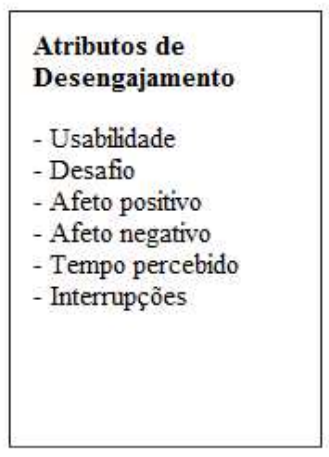

Figura 2.3: Modelo de engajamento de usuários. Tradução a partir da figura original de O’Brien e Toms [OT08].

Engajamento emerge como um processo com atributos distinguíveis inerentes a cada estágio. Os passos desse processo são: (1) ponto de engajamento, quando o engajamento é iniciado; (2) período de engajamento sustentado; (3) desengajamento; e (4) reengajamento. O ponto de engajamento é iniciado pela composição estética ou informacional da interface com os usuários. Esses elementos capturam a atenção e o interesse dos participantes, direcionando-os para o engajamento.

O período de engajamento sustentado é marcado pela atenção e interesse dos participantes sendo mantidos na interação. Para O'Brien e Toms [OT08], esse objetivo pode ser alcançado pela apresen- 
tação de feedback, novas informações e funcionalidades da interface. Usuários conseguem manter-se motivados quando percebem que estão no controle da interação e são apropriadamente desafiados. Em contrapartida, o desengajamento acontece por meio de fatores internos e externos. Usuários podem ter decisões conscientes de parar suas atividades por causa da perda de interesse ou quando se sentem pressionados com a opinião de outros, ou pelo tempo, ou ainda porque precisam realizar outras tarefas. Questões externas podem ser distrações ou interrupções, ausência de novidade na aplicação e problemas de usabilidade, os quais fazem os usuários perderem o engajamento.

O reengajamento pode ocorrer tanto em curto quanto em longo prazo. Usuários se reengajam quando abandonam suas tarefas para cuidar de necessidades pessoais ou quando usam tempo para comparar informações ou trocar de tarefas. As motivações para retornar a uma aplicação no futuro são relacionadas à diversão, ser recompensado com conveniências ou incentivos e aprender ou descobrir algo novo.

Comparando com a teoria da integração orgânica de Ryan e Deci [RD00a], quando o usuário acessa o sistema por meio de uma motivação (extrínseca ou intrínseca), ele entra em um ponto de engajamento, em que atributos específicos devem ser projetados para essa primeira interação, de modo a manter a motivação. Ao entrar no período de engajamento, atributos de engajamento deste período devem ser priorizados para facilitar ou possibilitar a internalização e a integração de comportamentos. Nesse ponto, elementos de interface podem ser utilizados para compor a ponte entre a motivação e o atributo de engajamento facilitador, por exemplo, novidade. Quando isso não ocorre, o usuário entra em um ponto de desengajamento que é o estado não motivado. Durante o período de engajamento, existe a relação da internalização do comportamento com o quão engajado o usuário está. Nesse sentido, quanto mais o indivíduo internaliza o comportamento, mais caminha do engajamento, passando para a absorção e indo para a imersão total, conforme Brown et al. [BC04].

\subsubsection{Métricas de engajamento}

Métricas de avaliação da experiência do usuário podem ser divididas em dois tipos: subjetivas e objetivas. Métricas subjetivas registram a percepção do usuário, geralmente autorrelatada. As experiências subjetivas do usuário são centrais para o engajamento e podem ter consequências objetivamente observáveis [AKLP11], que incluem medidas independentes como o tempo de interação do usuário com um sistema. Métricas objetivas podem ser comportamentais ou fisiológicas.

As métricas comportamentais incluem o número de usuários distintos e recorrentes, o número de visitas e visualizações de páginas e o tempo gasto interagindo com um sistema por sessão ou por vários dias. Essas métricas são usadas como indicadores de engajamento do usuário, atividade, fidelidade e popularidade dos sistemas. Métricas fisiológicas podem ajudar a entender a experiência de um indivíduo porque fornecem "representação contínua, em alta resolução, dos sujeitos ao longo do tempo" [LGE08]. As métricas fisiológicas incluem freqüência cardíaca, eletromiografia, atividade eletrodérmica e respiração [OL13].

Métricas comportamentais e fisiológicas explicam "quais são" os comportamentos do usuário, mas não o "porquê" de usuários se comportarem de determinadas maneiras. Métricas subjetivas, que geralmente são coletadas com questionários de autorrelato, abordam o "porquê" enquanto exploram as motivações, preferências e atitudes dos usuários. Em contraponto, usuários podem ampliar ou reduzir o relato de suas experiências [OL13].

O'Brien e Toms [OT10] desenvolveram um instrumento padronizado para avaliar o engajamento subjetivo de usuários. Contudo, os autores relatam que, devido à aplicação em domínios e contextos diferentes, é necessário descobrir características de engajamento para tipos específicos de interação por meio de estudos qualitativos e exploratórios. Uma questão que surge com questionários ou testes após a experiência do usuário com o sistema é que eles não são sensíveis a maneiras como a interação muda ao longo do tempo. Para medir mudanças temporais, métricas objetivas podem ser mais adequadas [AKLP11].

Uma estratégia para medições objetivas é desenvolver métricas que podem indicar de forma confiável estados subjetivos. Attfield et al. [AKLP11] consideram as seguintes métricas objetivas: 
percepção de tempo subjetiva, desempenho na tarefa seguinte, sensores fisiológicos, comportamento online e métricas de recuperação de informação. Por exemplo, a métrica de recuperação de informação pode utilizar a ideia de cenários de busca simulados, em que o usuário é convidado a seguir um cenário de busca que especifica o quê, por que e em que contexto o usuário está buscando.

As métricas são compreendidas como representantes do engajamento de usuários; por exemplo, quanto maior e mais frequente o uso, mais engajado o usuário supostamente está. Contudo, o engajamento de usuário possui diferentes características; dependendo da aplicação, por exemplo, o engajamento com uma ferramenta de e-mails ou com um portal de notícias é muito diferente [LLYTD12]. Por esse motivo, conforme Zichermann et al. [ZC11], não existe uma única métrica na Web ou em uma tecnologia móvel que possa medir engajamento suficientemente. Assim, o engajamento pode ser melhor analisado por meio de um conjunto de métricas inter-relacionadas que se combinam para formar um todo. Para Zichermann et al., essas métricas são: recenticidade, frequência, duração, viralidade e classificação.

A métrica recenticidade indica quão recente foi o último acesso do usuário ao sistema quando comparado ao penúltimo acesso. A métrica frequência representa a quantidade de acessos ao sistema. Duração refere-se a quanto tempo o usuário permanece no sistema. Viralidade define o grau de compartilhamento real de uma parte do conteúdo em um curto espaço de tempo. A classificação apresenta uma avaliação em termos de qualidade, quantidade ou alguma combinação de ambas. Essas métricas podem ser reunidas como uma pontuação de engajamento. A proporção relativa, ou importância, de cada uma dessas métricas varia dependendo do tipo de negócio que se está considerando.

No contexto de jogos, existem dois níveis de engajamento: envolvimento em nível micro e envolvimento em nível macro [Cal11]. Para Calleja, [Cal11], 2011, p. 40, envolvimento de nível micro refere-se ao "envolvimento momento-a-momento do jogo", enquanto o envolvimento no nível macro refere-se a "motivações de longo prazo, bem como pensamento offline e atividades que mantêm os jogadores retornando ao jogo", cobrindo tanto "experiências pós-jogo quanto pré-jogo". Iacovides et al. $\left[\mathrm{ICM}^{+} 15\right]$ apresentam que as expectativas de nível macro são informadas pela experiência anterior, outros atores e a comunidade em geral; o micro envolvimento repetido depende das expectativas serem reúnidas, de fatores dentro do jogo, como recompensas, e fatores externos. Portanto, nível macro pode ser relacionado a métricas subjetivas de engajamento, ou autorrelatadas; e nível micro pode ser relacionado a métricas objetivas de engajamento [BMR $\left.{ }^{+} 18\right]$.

\subsection{Jogos}

Antes de entrar no conceito de gamificação, faz-se necessário uma breve visão geral do conceito de jogos. Jogar é uma atividade intrinsecamente motivadora que não depende de recompensas externas visíveis, como dinheiro ou comida [Mal80]. Isso significa que as pessoas jogam somente porque querem jogar [VdS14, SW05, Bro10].

Seaborn e Fels [SF15] destacam que a noção de jogador do sexo masculino, adolescente e solitário não é mais relevante: o jogador médio tem 30 anos, $45 \%$ de probabilidade de ser do sexo feminino, tende a jogar quebra-cabeça, jogos casuais ou de tabuleiro e provavelmente pertence a uma parte dos $62 \%$ que jogam socialmente. Ainda conforme as pesquisadoras, os ganhos obtidos por meio de jogos digitais têm motivado sua adoção além do entretenimento.

A vontade de jogar é dirigida por características da relação que emerge a partir da interação do usuário com um jogo, como curiosidade, fantasia e desafio [VdS14, Mal80], bem como concentração, autoconsciência, senso de controle, distorção da experiência temporal e recompensas intrínsecas [CC92], que são atributos associados à motivação e ao engajamento.

Isto acontece em qualquer atividade agradável, pois a satisfação obtida em realizar tais tarefas está relacionada ao desejo natural humano de entender o mundo por interagir com ele [VdS14, Lit05]. O prazer, o entusiasmo e a alegria experimentados durante um jogo são geralmente conhecidos como diversão. Diversão é um requisito essencial para jogos: se não existir, as pessoas não vão querer jogálos [VdS14, SW05]. 
Porém, projetar diversão não é uma tarefa trivial. Projetistas de jogos usam padrões ou heurísticas para preencher necessidades situacionais como desafios, interação social e preferências estéticas, com o objetivo de aumentar as chances de obtenção de experiências agradáveis pelo usuário [Has03]. Heurísticas são um conjunto de regras que definem aspectos-chave do design, conforme Sharp et $a l$. [SRP07], e são tradicionalmente usadas para verificar princípios de usabilidade em interfaces de software.

Os projetistas precisam continuamente aprender o que seus usuários querem [Che07], o que envolve testar o jogo com eles, que é um dos processos de projeto de jogos mais importantes [VdS14]. Questionários sobre a experiência do jogo (do inglês game experience questionnaire - GEQ) [IPdK08] são usados para coletar as pontuações subjetivas de diversão em termos de imersão, fluxo, desafio e efeitos positivos e negativos para análise qualitativa.

\subsubsection{Teoria do Fluxo}

A teoria do fluxo [CC92, NC01] explica a satisfação (enjoyment) como sendo a consequência do equilíbrio apropriado entre desafios e habilidades, o que é alcançado pelos indivíduos quando são capazes de concentrar sua atenção completa em dada tarefa. Em essência, experiências agradáveis geralmente têm desafios que não excedem nem subutilizam as habilidades dos indivíduos, o que significa que as pessoas em fluxo estão constantemente em um estado em que as capacidades de ação percebidas coincidem com as oportunidades de ação percebidas [NC01].

Grandes desafios com habilidades menores transformam-se em preocupação e ansiedade, e pequenos desafios com habilidades maiores transformam-se em relaxamento e tédio [NC01]. Boas experiências mantêm os níveis de desafio e habilidade constantemente acima da média do indivíduo, enquanto uma pessoa melhora a si mesma na atividade desempenhada e procura por metas mais desafiadoras [CC92]. O estado desafio-habilidade muda constantemente entre os estados de controle e de estimulação.

\subsubsection{Tétrade elementar dos jogos}

No domínio de design de jogos, a experiência do usuário depende de regras do jogo (mecânica), técnicas narrativas (história), estética e tecnologia [SSZV09]. Esses quatro elementos, ou tétrade elementar, são comumente descritos como elementos básicos de um jogo e estão diretamente relacionados [Sch14]:

1. mecânica refere-se ao conjunto de procedimentos e regras de um jogo que descreve seu objetivo e como os jogadores podem ou não tentar alcançá-lo. A mecânica fortalece a história e faz com que os jogadores fiquem imersos no "mundo" definido pela estética, o que requer que a tecnologia seja construída.

2. história é a sequência de eventos que ocorrem em um jogo. A história torna a mecânica significativa para os jogadores, faz a estética emergir no momento certo, o que causa um impacto maior na experiência, que é conduzida pela tecnologia.

3. estética é a forma como o jogo afeta os sentidos. A estética enfatiza a mecânica, reforça ideias da história e explora as capacidades da tecnologia para deslumbrar os sentidos.

4. tecnologia é o meio no qual ocorrem as interações. A tecnologia possibilita que a estética e a mecânica aconteçam e a história se desenrole.

Conforme Shell [Sch14], nenhum elemento é mais importante do que o outro, pois todos são essenciais e cada um influencia o outro. O autor informa, ainda, que para todo design de jogo será necessário tomar decisões sobre os quatro elementos. 


\subsubsection{Perfis de jogadores}

A Figura 2.4 apresenta os quatro perfis de jogadores e suas fontes de interesse [Bar96]. O eixo $\mathrm{x}$ do gráfico compreende desde a ênfase nos jogadores, à esquerda, até a ênfase no ambiente, à direita. O eixo y compreende desde interagir com (parte inferior) até atuar em (parte superior). Os quatro cantos extremos do gráfico mostram as quatro preferências de jogo típicas associadas a cada quadrante.

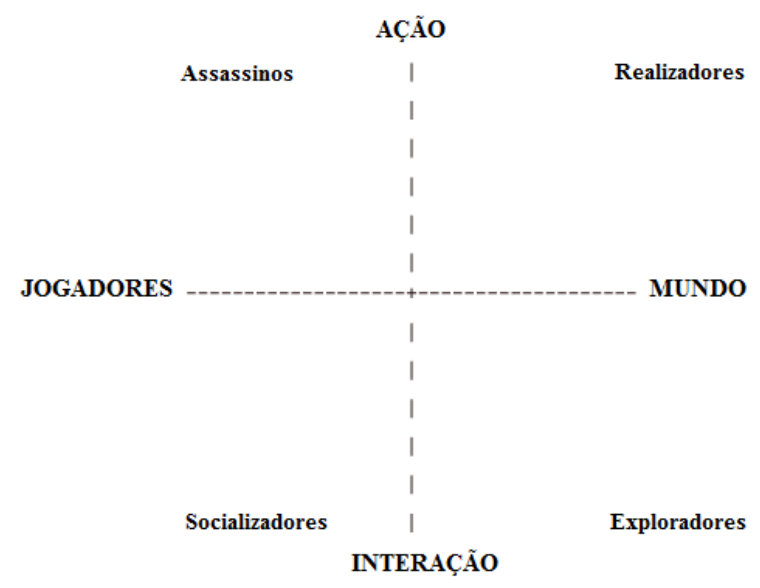

Figura 2.4: Perfis de jogadores e suas fontes de interesse. Tradução a partir da figura original de Bartle [Bar96].

De acordo com Bartle [Bar96, Bar04], os quatro perfis de jogadores são:

1. Realizadores (Achievers): estão interessados em fazer ações no jogo, ou seja, em agir no mundo. $\mathrm{O}$ ambiente do jogo é um mundo pleno em que eles podem mergulhar onde acharem mais atraente. O ponto do jogo é dominar o jogo, e fazê-lo fazer o que querem que ele faça. Os realizadores são orgulhosos de seu status formal na hierarquia de nível interna do jogo e do tempo que eles levaram para alcançá-lo.

2. Exploradores (Explorers): estão interessados em serem surpreendidos com o jogo, ou seja, em interação com o mundo. É a sensação de maravilha que o mundo virtual impregna que eles anseiam. Os exploradores são orgulhosos do seu conhecimento dos pontos mais finos do jogo, especialmente se os novos jogadores tratá-los como fontes de todo o conhecimento.

3. Socializadores (Socialisers): estão interessados em interação com outros jogadores. O mundo do jogo é apenas um cenário, são os personagens que tornam o jogo atraente. Socializadores são orgulhosos de suas amizades, seus contatos e sua influência.

4. Assassinos (Killers): estão interessados em agir sobre os outros jogadores. Normalmente, isso não é com o consentimento desses outros jogadores.Não há diversão para um assassino, a menos que possa afetar uma pessoa real em vez de uma entidade sem emoção computadorizada. Os assassinos são orgulhosos de sua reputação e de suas habilidades de combate frequentemente praticadas.

Yee [Yee06] desenvolveu uma teoria de características motivacionais, no contexto, de Massive Multiplayer Online Role Playing Games (MMORPG), tendo como base a taxonomia proposta por Bartle [Bar96, Bar04]. Yee identificou dez fatores motivacionais (ou subcomponentes) agrupados em três grandes fatores (ou componentes principais). Os componentes principais são: realização, social e imersão.

Os subcomponentes de realização são: avanço (ou progresso rápido, acumulação, status e poder), mecânica (ou análises, cálculos, otimização e padronização) e competição (desafio, provocação 
e dominação). Os subcomponentes de social são: socialização (ou conhecer, encontrar, conversar e ajudar pessoas), relacionanento (intimidade com seus pares, buscam relacões significativas a amigos íntimos) e trabalho em grupo (trabalho e colaboração com outros, realizações do grupo mais do que individuais). Os subcomponentes de imersão são: descoberta (explorar, coletar informações, artefatos ou itens raros), encenação (Imersão em uma história por meio de um personagem que projetaram, buscam a integração do personagem à história), customização (personalização da aparência de seus personagens, buscam estilo único ou diferenciado) e escapismo (evitam problemas da realidade, ou buscam aliviar o stress).

\subsection{Gamificação}

A gamificação (do inglês gamification) tem sido em grande parte referida como a incorporação seletiva de elementos de jogos em um sistema interativo sem que um jogo completo seja o produto final [SF15].

A gamificação tem como objetivo estimular a participação e engajar pessoas e é derivada a partir de princípios como design thinking para jogos e design centrado em usuário (DCU) [ZC11, DDKN11]. Deterding et al. [DDKN11] destacam que elementos de projeto de jogo foram identificados em vários níveis de abstração e que todos os níveis devem ser incluídos na definição de gamificação. A Tabela 2.1 apresenta os cinco níveis distinguidos por Deterding et al. que foram ordenados a partir de elementos concretos a abstratos [DDKN11].

Tabela 2.1: Elementos de projeto de jogo. Traduzido a partir da pesquisa de Deterding et al. [DDKN11].

\begin{tabular}{lll}
\hline Nível & Descrição & Exemplo \\
\hline $\begin{array}{l}\text { Padrões de design } \\
\text { de interface de jogo }\end{array}$ & $\begin{array}{l}\text { Componentes de design de interação } \\
\text { de sucesso, comuns, e soluções de } \\
\text { design para um problema conhecido } \\
\text { em um contexto, incluindo } \\
\text { implementações prototípicas }\end{array}$ & $\begin{array}{l}\text { Distintivo, quadro de liderança, } \\
\text { níveis }\end{array}$ \\
\hline $\begin{array}{l}\text { Mecânicas e padrões } \\
\text { de design de jogo }\end{array}$ & $\begin{array}{l}\text { Partes comumente recorrentes } \\
\text { do design de um jogo que dizem } \\
\text { respeito ao jogar (gameplay) }\end{array}$ & $\begin{array}{l}\text { Limitação de tempo, } \\
\text { recursos limitados, } \\
\text { loops }\end{array}$ \\
\hline $\begin{array}{l}\text { Heurísticas e } \\
\text { princípios de } \\
\text { design de jogo }\end{array}$ & $\begin{array}{l}\text { Diretrizes avaliativas } \\
\text { para abordar um problema } \\
\text { de design ou analisar } \\
\text { uma determinada solução } \\
\text { de design }\end{array}$ & $\begin{array}{l}\text { Jogo duradouro (enduring play), } \\
\text { metas claras, variedade de } \\
\text { estilos de jogos }\end{array}$ \\
\hline Modelos de jogos & $\begin{array}{l}\text { Modelos conceituais dos componentes } \\
\text { de jogos ou da experiência de jogo }\end{array}$ & $\begin{array}{l}\text { Mechanics-Dynamics-Aesthetics } \\
\text { (MDA) [HLZ04], } \\
\text { desafio, fantasia, curiosidade, } \\
\text { átomos de design de jogo, } \\
\text { Core Elements of Game Experience } \\
\text { (CEGE) [CGCC15] }\end{array}$ \\
\hline $\begin{array}{l}\text { Métodos de design } \\
\text { de jogo }\end{array}$ & $\begin{array}{l}\text { Práticas e processos específicos } \\
\text { de design de jogo }\end{array}$ & $\begin{array}{l}\text { Teste de jogo, } \\
\text { design centrado em } \\
\text { jogo, design de jogo } \\
\text { consciente de valor }\end{array}$ \\
& &
\end{tabular}

É importante não confundir gamificação com jogos sérios. O segundo diz respeito à construção de um jogo completo para engajar os usuários em tarefas que poderiam ser cansativas ou entediantes e o primeiro diz respeito ao uso de alguns elementos de projeto de jogos para incentivar ou melhorar o engajamento de usuários em determinados cenários de uso de um sistema ou produto, sem que um jogo completo seja desenvolvido [DDKN11]. É importante também diferenciar o jogo da brincadeira. O jogo possui regras para alcançar um objetivo, envolve sucesso ou não no cumprimento desse 
objetivo, como por exemplo, passar ou não para uma fase mais avançada, o que pode estimular a competição. A brincadeira é livremente estruturada, não envolvendo regras bem delimitadas, sendo mais voltada à criação de um ambiente lúdico. A Figura 2.5 torna mais clara essa diferença, apresentando a dimensão do jogo e da brincadeira e do jogo completo e partes do jogo, conforme Deterding et al. [DDKN11].

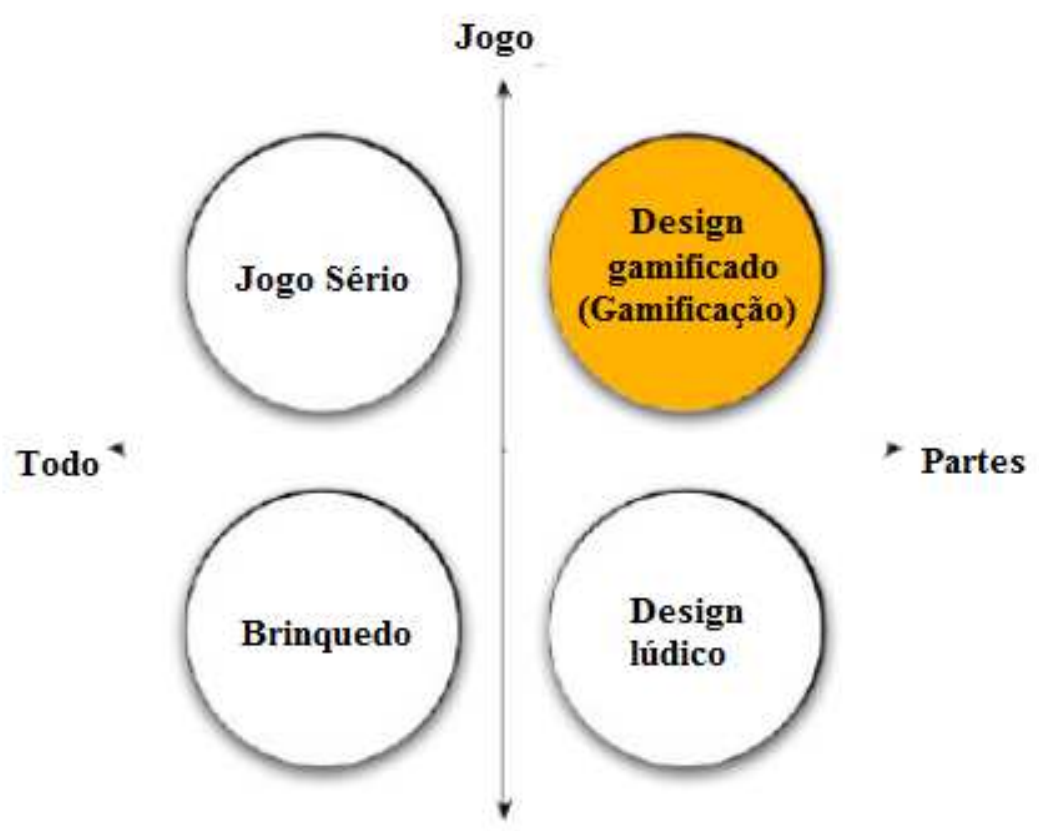

Brincadeira

Figura 2.5: Dimensões do jogo e da brincadeira e do jogo completo e partes do jogo. Tradução a partir da figura original de Deterding et al. [DDKN11].

\subsubsection{Passos para implantar gamificação}

Diversos arcabouços foram propostos para implantar gamificação [SF15, MRGAM15] de forma genérica. O arcabouço mais referenciado por autores [MRGAM15] é o proposto por Werbach e Hunter [WH12].

Werbach e Hunter [WH12] definiram um conjunto de seis passos para implantar gamificação: (1) definir objetivos de negócios; (2) delinear comportamentos-alvo; (3) descrever seus jogadores; (4) conceber ciclos de atividade; (5) não esquecer da diversão; e (6) implantar as ferramentas apropriadas. Conforme Werbach e Hunter, o passo 1 - definir objetivos de negócio -, é uma atividade crítica para realizar uma gamificação eficaz. Nesse passo é preciso definir metas de desempenho específicas para o sistema gamificado, como aumentar a retenção de clientes, construir a fidelidade à marca ou melhorar a produtividade dos funcionários.

Para o passo 2, comportamentos-alvo devem ser concretos e específicos, por exemplo: "publique um comentário em um fórum de discussão". Para o passo 3, é preciso entender o perfil de usuários do sistema e o que pode motivá-los e desmotivá-los. Em outras palavras: o que torna os usuários menos propensos a completar uma tarefa relevante: falta de vontade ou a percepção da falta de capacidade? A primeira direciona a uma abordagem orientada ao engajamento, enquanto a última conduz a sistemas de progressão que podem levar o jogador até a curva de dificuldade. Neste passo, é preciso considerar também o ciclo de vida de um jogador: novato, regular ou especialista.

O novato precisa de alguém que segure em suas mãos para que possa aprender por meio do reforço. Para ter sucesso em uma tarefa, precisa de ajuda ou do envolvimento de seus amigos. A fim de continuar a realizar a atividade, uma vez que o novato se torna um jogador regular ele precisa 
de novidade, pois as atividades tornaram-se fáceis. Quando se torna um jogador especialista, o usuário precisa de desafios difíceis o suficiente para mantê-lo engajado. Ele também tende a querer reforço explícito de seu status. Os jogadores não estão no mesmo estágio, embora o sistema tenha mais jogadores experientes quanto mais tempo esteja funcionando. As oportunidades devem ser oferecidas para todos os jogadores em todas as fases.

O passo 4 apresenta dois tipos de ciclos de desenvolvimento: ciclos de engajamento e escadas de progressão. Ciclos de engajamento descrevem, em um micronível, o que os jogadores fazem, por que fazem e o que o sistema faz em resposta; escadas de progressão fornecem uma macroperspectiva da jornada do jogador. A Figura 2.6 apresenta o ciclo de atividade que faz parte dos ciclos de engajamento. A Figura 2.7 apresenta as escadas de progressão que refletem o fato de que a experiência do jogo muda conforme os jogadores se movem nele, o que significa um nível crescente de desafios.

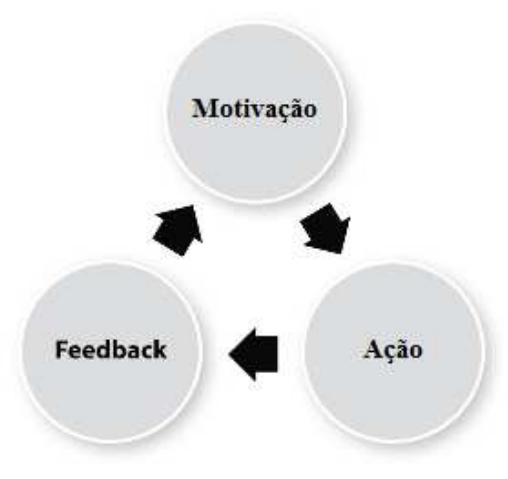

Figura 2.6: Passo 4 - Ciclo de atividade. Tradução a partir da figura original de Werbach e Hunter [WH12].

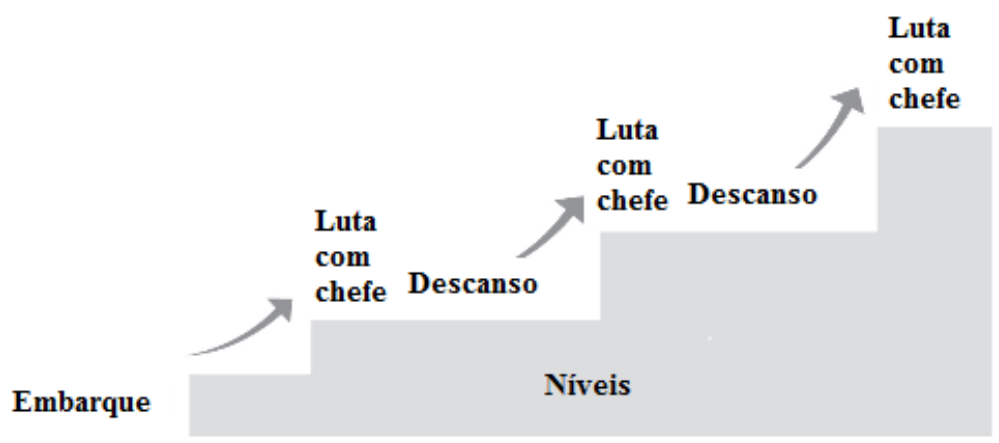

Figura 2.7: Passo 4-Ciclo de escadas de progressão. Tradução a partir da figura original de Werbach e Hunter [WH12].

O passo 5 refere-se à importância da diversão em sistemas gamificados. Werbach e Hunter afirmam ser necessário fazer questões como: se recompensas extrínsecas não forem oferecidas, os usuários continuarão a utilizar o sistema? Os tipos de diversão que o sistema gamificado deve fornecer depende do contexto. Tal como acontece com tipos de jogador, Werbach recomenda não assumir que todos os jogadores vão querer o mesmo tipo de diversão ou que os participantes não vão mudar. Os melhores jogos oferecem um amplo espectro de diversão. Um usuário pode ser normalmente atraído por desafios, mas hoje ele pode querer apenas desabafar com os amigos, por isso um sistema gamificado deve ser flexível.

O passo 6 diz respeito à implantação de sistemas gamificados, em que é preciso escolher as mecânicas e componentes adequados e codificá-los no sistema. Na fase de implantação, integram-se todas as demais para apresentar a experiência ao jogador. Será preciso testar e iterar, enquanto se aprende como seguir para refinar o sistema. Os autores apontam para a necessidade de uma equipe 
com múltiplas habilidades, reforçando que uma pessoa pode implementar um sistema eficaz, por exemplo em startup, mas ela necessitará de experiência em mais de uma área.

As habilidades necessárias são: pessoas que entendam das metas de negócio do projeto; entendimento do grupo-alvo de jogadores e da psicologia básica (teorias da motivação); projetistas de jogo ou pessoas que assumam esse papel; especialistas analíticos para fornecer sentido aos dados gerados pelo sistema; e tecnólogos capazes de implementar a visão gerada pelos passos anteriores. Os detalhes de como implementar e monitorar o engajamento não são fornecidos, pois, de acordo com os autores, isso vai além do escopo que pretendiam descrever.

\subsection{Considerações finais}

Esta pesquisa trata do engajamento de usuários por meio de elementos de jogos (gamificação) em comunidades online de colaboração aberta. Os conceitos apresentados neste capítulo buscam mostrar a relação entre o objetivo esperado (engajamento de usuários), o meio pelo qual espera-se alcançá-lo (gamificação sustentada por teorias motivacionais, em particular SDT) e em um contexto específico (comunidades online de colaboração aberta). Entende-se que para avaliar se a gamificação suportada pela teoria de motivação resulta em efeitos positivos sobre o engajamento de usuários, é necessário explicar como a teoria foi colocada em prática, em um determinado ambiente e medir o que ocorre no comportamento de usuários após a intervenção. O próximo capítulo apresenta o estado da arte sobre essas questões. 


\section{Capítulo 3}

\section{Estado da arte sobre gamificação e impacto no engajamento de usuários}

Este capítulo apresenta uma visão geral do estado da arte sobre o impacto da gamificação no engajamento de usuários. Inicialmente, apresentamos as principais categorias em que os arcabouços podem ser classificados. Na sequência, uma seleção de experimentos controlados evidencia os principais elementos de jogos utilizados e como engajamento é medido de diversas formas distintas. Em particular, na análise de engajamento, ainda existem poucos estudos longitudinais e com a apresentação de tamanhos de efeito a partir das análises estatísticas.

\subsection{Visão geral e classificação de arcabouços}

Os resultados do survey realizado por Seaborn e Fels [SF15] apresentam um consenso em três áreas dentre as pesquisas analisadas: teoria de design; construtos teóricos; e arcabouço teórico. Design centrado em usuário (DCU) é a escolha consistente para teoria do design. Os construtos teóricos de motivação intrínseca e extrínseca são baseados na Teoria da autodeterminação (SDT) [SDT16], de Ryan e Deci. Em particular, Deterding [DDKN11] propõe que um dado elemento de jogo pode ser tanto intrinsecamente, quanto extrinsecamente motivador para certas pessoas em certas situações em certo tempo, embora outras pesquisas argumentam que motivadores extrínsecos precisam ser projetados com o objetivo de abordar fatores intrínsecos. Arcabouços específicos de gamificação foram desenvolvidos em isolamento, sem evidência de completude, revelando a necessidade de serem aplicados para avaliar aplicabilidade e convergência.

Mora et al. [MRGAM15] realizaram uma revisão da literatura, a partir de arcabouços de projeto de gamificação e forneceram uma avaliação de suas principais características, em diferentes níveis e escopos. Dezenove itens relacionados foram identificados, embora alguns não sejam comuns em contexto de jogo. No entanto, os autores relatam que tais itens são de especial interesse para o processo de gamificação e podem ser agrupados nas cinco categorias abaixo, nas quais os itens são apresentados entre parênteses:

1. Econômica: definem metas de desempenho específicas (objetivos), incluem estudos de viabilidade (viabilidade), análise de risco (risco) e de retorno sobre o investimento (ROI), tendo a participação das partes interessadas (stakeholders) no processo de design como uma necessidade.

2. Lógica: mecânicas de jogos combinadas com reforço e feedback (loop) para manter o jogador nas ações-chave para o sistema. Definição de um fim de jogo pré-estabelecido ou vitória épica (end game /epic win) para levar os jogadores aos limites de suas habilidades para alcançar um fim. Apresentam uma maneira de iniciar os participantes (on-boarding) e um corpo de regulamentos prescritos pelo projetista (regras). 
3. Medição: medição de eficiência, desempenho, progresso, processo ou qualidade (métricas) e algoritmos e dados usados para medir indicadores de desempenho-chave (analytics).

4. Psicologia: baseiam-se em prazer ou brincadeiras (diversão), no comportamento que conduz uma pessoa a querer repetir uma ação e vice-versa (motivação), na interação entre os jogadores (social), na resposta esperada dos jogadores após a interação (comportamentos desejados) e na filosofia que envolve sistematizar, defender e recomendar conceitos de condutas corretas e erradas (ética).

5. Interação: descreve uma história e o contexto criado pelos projetistas (narrativas); projeta dentro do sistema gamificado onde o jogador pode interagir, bem como, seus comportamentos, atitudes, e emoções (UI/UX); e o uso ou necessidade de um componente de software para desenvolvimento (tecnologia).

Os pesquisadores analisaram os itens e concluíram que princípios e componentes de projeto de jogo estão sendo herdados para a descrição dos arcabouços de gamificação. A maioria deles está presente na lente de projeto de jogo proposta por Schell [Sch14]. Contudo, a maneira que princípios e componentes são aplicados não é a mesma que ocorre em um ambiente de projeto de jogo. Além disso, os autores relatam que alguns arcabouços são baseados em outros, como explicitamente declarado em suas definições ou identificável por leitura. A definição de Werbach e Hunter [WH12] é a mais referenciada por autores. SDT é uma abordagem predominante para necessidades de motivação intrínseca, o que está de acordo com Zichermann [ZC11], que informa que gamificação é composta de $75 \%$ de psicologia e $25 \%$ de tecnologia.

Para a categoria econômica, a maioria dos arcabouços considerou a participação de partes interessadas no processo de design. No entanto, a definição de objetivos de negócios foi generalizada. A partir da categoria lógica, loop foi considerado pela maioria dos arcabouços, enquanto poucos consideraram on-boarding e end game /epic win, ou meios de entrada e saída. Para a categoria medição, a maioria dos arcabouços refere-se explicitamente aos dados do usuário e a importância de coletá-los. Entretanto, o uso de métricas não é difundido em todas as abordagens como uma ferramenta para quantificar dados. Para a categoria psicologia, os arcabouços apresentam-na como chave no processo de design, tendo como consequência natural processos centrados em humanos para o projeto. A categoria interação é referida na maioria dos arcabouços, enfatizando a importância da interface, da experiência do usuário e do desenvolvimento de software.

\subsection{Gamificação na prática}

Em 2014, a revisão sistemática de Hamari et al. [HKS14] sobre estudos empíricos com gamificação buscou responder se a gamificação funciona. Os resultados indicam que a gamificação fornece efeitos positivos, contudo, os efeitos são dependentes do contexto em que a gamificação está sendo implementada, bem como, dos usuários do sistema. Assim como Seaborn e Fels [SF15], Hamari et al. também relatam que as publicações sobre a prática de gamificação descrevem os resultados para um conjunto de elementos de jogos implementados, e não para cada elemento de jogo em isolamento.

Um esforço multidisciplinar para pesquisar os efeitos da gamificação vem crescendo, mas ainda há a necessidade de exploração de uma ampla variedade de elementos de jogos por meio de contextos diferentes, com projetos de experimentos mais fortes e investigações de várias trajetórias [HKS14]. Ainda conforme os autores, pesquisas empíricas com métodos mistos, que empregam análises estatísticas e relatam o efeito da inserção de elementos, dinâmicas e experiências de projeto de jogos são necessárias para fundamentar os efeitos positivos relatados nos estudos.

De acordo com o survey de Seaborn e Fels [SF15] de 2015, existem as seguintes áreas de domínio nas quais a gamificação vem sendo aplicada: educação; comunidades online e redes sociais; saúde e bem-estar; crowdsourcing; sustentabilidade; orientação; ciência e engenharia da computação; pesquisa; marketing; e trabalho cooperativo suportado por computador (do inglês computer-supported cooperative work - CSCW). Contudo, a lista limitada de elementos de jogos explorados nos estudos 
sugerem que pontificação - pontos, distintivos e quadros de lideranças (do inglês points, badges, leaderboards - PBL) - é uma estratégia generalizada de aplicação de gamificação. Convenções das disciplinas, ausência de consolidação entre os campos e o estado inicial da pesquisa de gamificação levam a replicação e criatividade limitada na aplicação [SF15]. A maioria dos estudos, no entanto, não menciona ou aborda suas fundações teóricas. Os principais objetivos notados para o uso da gamificação é encorajar a participação e comportamentos de usuários; ou uma combinação de ambos.

Em 2016, a revisão sistemática de Darejeh and Salim [DS16] apresentou a estrutura de soluções de gamificação. Eles descobriram dois tipos de gamificação: gamificação estrutural e gamificação de contéudo. Gamificação estrutural é para motivar e engajar usuários por meio de recompensas tais como pontos, distintivos ou conquistas. Gamificação de conteúdo refere-se a aplicar gamificação sobre o conteúdo de software. Por exemplo, na gamificação estrututal, o conteúdo é típico da área de domínio e usuários são recompensados por realizar alguma atividade no sistema. Na gamificação de conteúdo, o conteúdo do sistema é apresentado com algum nível de diversão, como a de um jogo, em adição a apresentar recompensa por alguma atividade.

Os principais problemas de engajamento de usuários foram agrupados em seis categorias: necessidade de gerar conteúdo dentro do software (como participar de fóruns e blogs); interesse em mudar comportamento de usuários (como praticar esporte, ou parar de fumar); trabalhar com prática do software (ou prática da comunidade) por meio do uso do sistema; usar conteúdo de software; dificuldade em aprender a usar um novo software; e necessidade de uso da identidade real como em ambientes de aprendizagem, nos quais pessoas tímidas não querem se expor.

Para uso da identidade real, a solução mais aplicada é não usar qualquer mecânica de jogo e aplicar apenas avatares como elementos de interface. Para gerar contéudo em software, os elementos mais utilizados são pontos, desafios e quadros de liderança. Para trabalhar com práticas do software, os elementos mais utilizados são pontos, distintivos, desafios, e quadros de liderança. Para dificuldade em aprender, usam-se os elementos pontos, níveis, metas claras, feedback imediato, progressão e fantasia. Para usar conteúdo de sofware, os elementos são pontos, metas claras, distintivos e mapa. Para mudança de comportamento, os elementos mais utilizados são pontos, desafios, metas claras e quadro de liderança. Os resultados reforçam as conclusões da pesquisa de Seaborn e Fels [SF15], que indicam que um mesmo conjunto de elementos é usado na maioria dos casos.

Conforme Darejeh and Salim [DS16], as análises dos efeitos da gamificação são realizadas por meio de coletas de percepções de usuários quanto à sua interação com o sistema; avaliações de engajamento comportamental (por exemplo, frequência de uso do software); avaliações de desempenho do usuário; e avaliações de usabilidade do software. Os instrumentos de coleta que foram descritos são: questionários, entrevistas e registros de ações de usuários. Os resultados mostraram efeitos positivos.

Em 2017, Looyestyn et al. $\left[\mathrm{LKB}^{+} 17\right]$ apresentaram os resultados de uma revisão sistemática sobre estudos experimentais com versão de controle e versão gamificada, sendo esta última contendo pelo menos um elemento de jogo e no contexto de população adulta. Os autores informaram que tamanhos de efeito não foram fornecidos e por isso usaram os dados fornecidos nos artigos para conseguirem calcular tamanhos de efeito e intervalos de confiança de 95\%. Para alguns artigos, Looyestyn et al. precisaram contactar os autores para solicitar informações adicionais e conseguirem calcular os tamanhos de efeito e intervalos de confiança.

As seguintes métricas de engajamento foram incluídas nos estudos: tempo gasto (ou duração); volume de contribuições; e número de ocasiões de visita ao sistema (ou frequência). Além dessas métricas, alguns comportamentos subjacentes tais como desempenho do usuário e comportamentos saudáveis também foram relatados nos estudos de acordo com o contexto em que se inseriam.

Dos cinco estudos que investigaram o tempo gasto no sistema, dois encontraram que a gamificação foi associada a efeitos positivos de médios a grandes, enquanto três estudos não encontraram efeitos significativos. Dos quatro estudos que investigaram o número de ocasiões de visita ao sistema, três relataram efeitos positivos significativos de pequenos a médios em magnitude, enquanto um estudo não apresentou diferença significativa. Dos onze estudos que examinaram o volume de contribuições, por exemplo, número de comentários postados ou número de quizzes completados, 
oito estudos apresentaram efeitos positivos significativos, tipicamente de médios a grandes em magnitude, enquanto três estudos não apresentaram efeitos significativos.

Para comportamentos subjacentes, gamificação foi associada com melhoria de utilização de cuidados de saúde, mas não apresentou diferença para atividades físicas ou uso de medicação correta. Para os quatro estudos que investigaram o desempenho dos usuários, três mediram desempenho por meio de um teste de conhecimento, e todos relataram efeito positivo significativo associado à gamificação e apenas um estudo não encontrou efeito significativo. Somente um estudo comparou a eficácia de diferentes tipos de gamificação, nele o elemento quadro de liderança foi mais eficaz em aumentar contribuições quando comparado com níveis e pontos.

Dentre os oito estudos que relataram tamanhos de efeito de médio a grande em magnitude, seis utilizaram uma combinação de técnicas da gamificação, enquanto dois utilizaram apenas um elemento de jogo: quadro de liderança e pontos. Dentre os seis estudos que não relataram efeitos significativos para gamificação, ou relataram efeitos significativos pequenos, três utilizaram uma combinação de técnicas de gamificação e três utilizaram apenas um elemento de jogo (distintivos, em todos os casos).

Dentre os nove estudos que relataram tamanhos de efeito de médio a grande em magnitude, cinco estudos examinaram engajamento medindo-o em uma sessão única, enquanto quatro estudos mediram engajamento por um período de tempo extendido (sendo que dois estudos não relataram a duração, um teve a duração de 10 semanas e outro de 4 meses). Para os seis estudos que não apresentaram efeitos significantes, ou efeitos significantes pequenos, apenas um mediu engajamento em uma única sessão, enquanto cinco estudos mediram em um período de tempo estendido (três semanas, 26 dias, um mês, 1.5 anos e dois anos). Dos 15 artigos considerados, 5 avaliaram apenas um elemento de jogo, enquanto a maioria dos estudos (10) avaliaram uma combinação de elementos.

Looyestyn et al. $\left[\mathrm{LKB}^{+} 17\right]$ concluem que gamificação pode aumentar engajamento em programas online e melhorar resultados relacionados, tais como aprendizado e comportamentos relacionados à saúde. Também apontam que evidências preliminares sugerem que quadros de liderança podem ser formas úteis para aumentar engajamento e que tal evidência está de acordo com estudos anteriores que relacionam o sucesso de quadros de liderança à promoção de comparação social, o que resulta em motivação por meio de competição entre pares [GTS13].

Contudo, destacam que a eficácia da gamificação para aumentar engajamento pode ter um período de tempo, com impactos positivos evidentes em estudos de uma única sessão, enquanto que resultados mistos foram apresentados para estudos que consideraram engajamento sustentado sobre um período de tempo. Os autores também destacam a falta de padronização para medição de engajamento e a diminuição do engajamento com o tempo, dado que a novidade dura por curto período de tempo, usando como exemplo a aplicação móvel Foursquare, que experimentou uma grande redução de engajamento de seis a doze meses após sua implementação original, ou seja, após a novidade passar.

Looyestyn et al. $\left[\mathrm{LKB}^{+} 17\right]$ evidenciam também que os estudos, em geral, apresentaram detalhes limitados de quais elementos de jogos foram usados e como eles foram incorporados no sistema online, o que tornou difícil a análise dos autores tanto para elegibilidade dos estudos quanto para os efeitos reais das intervenções. Além disso, as descrições limitadas sobre os elementos impactam diretamente na replicação dos estudos. Adicionalmente, não houve padronização na terminologia para elementos de jogos que foram apresentados de forma similar como distintivos e recompensas, ou desafios e missões (quests).

Como resultado da revisão sistemática, os autores elencaram 5 recomendações para pesquisas futuras: 1) mais pesquisas são necessárias para explorar a eficácia de gamificação sobre engajamento em uma ampla variedade de contextos; 2) diretrizes de relatório são necessárias nos estudos para especificar quais elementos de jogos estão sendo usados, como eles estão sendo implementados e para quais razões; 3) mais estudos são necessários para entender o impacto de tipos específicos de gamificação (ou elementos de jogos independentes); 4) mais estudos são necessários para entender como gamificação pode ser implementada com maior eficácia para suportar engajamento de longo prazo; e 5) mais estudos são necessários com design de pesquisa mais rigoroso e de maior qualidade 
no campo da gamificação. Experimentos controlados randomizados (Randomised controlled trials) para investigar engajamento com gamificação são recomendados.

Ainda em 2017, um estudo experimental de Sailer et al. [SHMM17] abordou o fato de que gamificação vem sendo tratada como um construto genérico, negligenciando o fato que existem muitos elementos de jogos distintos que podem resultar em diversas aplicações. Os pesquisadores usaram um ambiente de simulação online com diferentes configurações de elementos de jogos e os analisaram a respeito do efeito sobre as necessidades psicológicas básicas (ou motivação intrínseca). Os resultados mostraram que distintivos, quadros de liderança e grafos de desempenho afetam positivamente competência e o significado percebido da tarefa, enquanto avatares, histórias significativas e colegas de equipe afetam experiências de relacionamento social.

O estudo também reforçou a lacuna de pesquisa com designs experimentais sobre elementos de jogos únicos e a importância de manipular elementos isoladamente. Contudo, os pesquisadores reconhecem que a simulação não apresentou o retrato de um contexto real, e esse tipo de investigação é necessário. Os pesquisadores relatam também que os elementos de jogos parecem ser dependentes de estética e qualidade das implementações de design, portanto todo o processo tem um papel muito importante. Por esse motivo, podem ser soluções poderosas para abordar problemas motivacionais.

Em 2018, Kasurinen e Knutas [KK18] buscaram entender quais eram as maiores tendências atuais na área de gamificação e como estavam sendo estudadas. A maior parte dos trabalhos foram relacionados à educação. Os tipos comuns de pesquisa em gamificação são provas de conceito e os trabalhos teóricos são sobre os diferentes conceitos e elementos da gamificação. O estudo identificou 400 autores que publicaram dois ou mais estudos na área e acima de 500 publicações diferentes, sendo uma tendência crescente, com todas as publicações identificadas apresentando menos de dez anos. A questão de trabalho atual de gamificação é a coleta de evidências sobre suas aplicações práticas e seu impacto nos usuários. Os resultados coincidem com os resultados já apresentados pelas revisões sistemáticas desde 2015. Portanto, o problema de entender como projetar gamificação para melhorar engajamento de usuários em contextos específicos ainda existe e é uma tendência forte de estudo na área.

\subsection{Trabalhos relacionados}

Os trabalhos relacionados apresentados nesta seção referem-se à: 1) definição de métodos, diretrizes ou arcabouços; e 2) ao desenvolvimento na prática de propostas suportadas pela teoria de gamificação, com a análise de engajamento de usuários.

\subsubsection{Definição de diretrizes, métodos e arcabouços teóricos ou conceituais}

Nicholson [Nic12] apresentou em 2012 um arcabouço teórico centrado em usuário para gamificação significativa, o qual descreve como colocar as necessidades e metas dos usuários acima das necessidades da organização. Se os usuários têm uma experiência positiva e significativa baseada em jogo sem ser um jogo de fato, então em longo prazo a organização será beneficiada. O enfoque é sobre a inserção de elementos de jogos distintos em vez de apenas elementos associados à pontificação, reforçando que as mesmas atividades não são significativas para todos os usuários. Conforme Nicholson, a dependência de recompensas externas para a motivação deve ser substituída por conexões entre a atividade não jogo e necessidades ou objetivos na vida dos usuários, o que lhes possibilitaria ter uma experiência internalizada positiva. $\mathrm{O}$ arcabouço utilizou a teoria da integração orgânica associada ao DCU.

Em 2013, Nah et al. [NTRV13] propuseram um arcabouço conceitual de gamificação que sintetiza descobertas da literatura com princípios de gamificação, elementos de projeto de sistema para gamificação e dimensões do engajamento do usuário. O arcabouço baseou-se em um conjunto de elementos de jogos pré-definidos. Ainda em 2013, Marins [Mar13] apresentou como resultado um arcabouço conceitual e um processo baseados no estudo da literatura. $\mathrm{O}$ arcabouço envolveu os conceitos motivação, jogador, relações sociais, ação e progressão relacionando-os com o conceito central 
de gamificação. O processo contém quatro etapas gerais: análise de objetivos; ciclo de motivação; elementos de jogos; e análise de resultados. Um estudo de caso na produção de um livro interativo de teoria musical foi desenvolvido. Testes com usuários apresentaram que a progressão clara dos jogadores é um fator motivacional importante.

Em 2014, Wongso et al. [WRB14] apresentaram um arcabouço conceitual baseado em engajamento social e gamificação, usando o modelo de Design Science Research como metodologia. Os pesquisadores informaram que o arcabouço pode ser útil para implementar gamificação em sistemas de e-learning. Ainda em 2014, Clementi [Cle14] apresentou diretrizes motivacionais baseadas em gamificação para serem aplicadas por moderadores de comunidades de prática. As diretrizes propostas foram derivadas a partir das teorias de comunidades de prática de Wenger et al. [WMS02b], de motivação de Ryan e Deci [RD00a], de gamificação de Werbach e Hunter [WH12] e da teoria sobre perfis de jogadores de Bartle [Bar04] e foram classificadas de acordo com a fase da comunidade de prática, sendo validadas por meio do método Delphi [OP04].

Bista et al. [BNCP12, BNPC14] projetaram e desenvolveram gamificação em uma comunidade online, no contexto de entrega de serviços de governo. Foi definido um modelo formal de gamificação e um processo de projeto de gamificação.

O processo foi composto das seguintes fases: identificar contextos de gamificação; identificar ações de membros potenciais; identificar intervalos de pontos; alocar pontos a ações; identificar conjunto de distintivos; alocar distintivos a pontos. Os autores relatam que não puderam relatar os efeitos da implementação da gamificação baseada em distintivos sobre o engajamento dos usuários porque não realizaram um experimento controlado.

Em 2015, Mora et al. [MZGAM15] apresentaram uma abordagem de arcabouço conceitual para projetar a gamificação de experiências de aprendizado. O enfoque é sobre ensino superior e baseado em métodos ágeis com o objetivo de obter rapidamente o produto mínimo viável (Minimum Viable Product (MVP)) para testes. A estratégia contém quatro passos - declaração, criação, execução e aprendizado - e situa a definição do jogador e da mecânica de jogos dentro das iterações ágeis de Programação Extrema (XP). Engajamento é avaliado na abordagem por meio de testes de aceitação.

Em 2016, Poffo [Pof16] avaliou se a aplicação da gamificação em um ambiente de ensino de Engenharia de Software poderia transformar a motivação extrínseca em intrínseca nos alunos, e qual seria a percepção dos alunos referente a contribuição do ambiente com a aprendizagem. O autor relatou transformação da motivação extrínseca em intrínseca, em um ambiente de ensino gamificado, após avaliação com questionários aplicados aos alunos, baseados em instrumentos para avaliação dos construtos motivação, experiência do usuário e aprendizagem. Os resultados foram positivos para todos os construtos.

Morschheuser et al. [MWHA17], em 2017, apresentaram as melhores práticas relacionadas ao projeto de gamificação. Os pesquisadores sintetizaram o corpo de literatura atual sobre métodos de projeto de gamificação e entrevistaram 25 especialistas na área. Na sequência, desenvolveram um método para projeto de gamificação e avaliaram-no por meio de entrevistas com 10 especialistas. As atividades dos métodos considerados podem ser dividas em sete fases: (1) preparação do projeto: atividades que precisam ser realizadas antes do projeto iniciar; (2) análise: atividades para identificar o conhecimento necessário sobre usuários, processos e o projeto em si; (3) ideação: atividades para colocar ideias para projetos de gamificação; (4) projeto: projetar abordagens de gamificação e a criação de protótipos; (5) implementação: implementar uma abordagem de gamificação; (6) avaliação: avaliar e testar a abordagem de gamificação; e (7) monitoramento: monitorar a abordagem de gamificação após o lançamento.

As principais diferenças entre esta tese e as pesquisas apresentadas nesta subseção referem-se ao fato de que a maioria não foi implementada em um contexto real; e as pesquisas que foram aplicadas não apresentaram o monitoramento e a avaliação do construto engajamento, que é o enfoque desta tese. 


\subsubsection{Aplicações de gamificação com medição de engajamento de usuários}

Em 2012, Simões et al. [SARV12] buscavam compreender quais os elementos de jogos que faziam sentido aplicar em atividades pedagógicas e apresentaram suas linhas de orientação para aplicação do conceito numa plataforma de aprendizagem social. Os resultados foram a definição de um cenário de aplicação de gamificação no contexto da plataforma e a seleção da pesquisa-ação como meio para desenvolvimento de um modelo de referência e implementação de um conjunto de ferramentas que possibilitam a aplicação do conceito de gamificação em atividades pedagógicas [SARV12]. Um ano mais tarde, 2013, os pesquisadores [SRV13] apresentaram a definição de funcionalidades de gamificação social por perfil de usuário - estudantes, professores e pais -; e sete diretrizes para habilitar professores a organizar seus conteúdos em uma plataforma de aprendizado social.

Em 2014, Simões et al. [SRVA14] publicaram uma arquitetura composta de três camadas para desenvolvimento de sistemas gamificados - interface de usuário, lógica do sistema e interface de dados. Os elementos de jogos pontos, distintivos e barra de progresso foram desenvolvidos na plataforma de aprendizado social existente e dados foram monitorados, mas sem a apresentação de resultados para o engajamento resultante. Em 2015, a tese de doutorado de Simões [Sim15] apresentou além dos resultados já citados [SARV12, SRV13, SRVA14], a análise de engajamento por meio da verificação, com um instrumento de auto-relato [JE02] definido no contexto de atividade física, se houve aumento na tendência do estudante em experimentar o estado de fluxo. Os resultados mostraram um pequeno aumento na percepção de fluxo com um nível relativamente baixo de significância estatística.

Na tese de doutorado de Andrade [And18], em 2018, investigou-se a personalização com base na teoria de motivações para engajamento em jogos de Yee [Yee06], que trata o perfil do usuário como um conjunto de diferentes subcomponentes motivacionais correlacionados, que são agrupados em macro-componentes. Para isso, adaptou-se a teoria para o contexto da gamificação e elaborou-se dois modelos o de Macro-Gamificação, o qual relaciona-se com a teoria de Autodeterminação e às necessidades de Competência, Relacionamento e Autonomia do usuário, e o de Micro-Gamificação, que relaciona os elementos de jogos a um determinado subcomponente motivacional, disponibilizando-os mediante o interesse do usuário no subcomponente.

Para avaliar se a gamificação personalizada influenciou no engajamento dos usuários quando comparada a gamificação não personalizada, os modelos foram implementados em um ambiente virtual de aprendizagem, preparado para criar os perfis de gamificação dos usuários dinamicamente e adaptar interface em tempo real. O autor definiu um questionário para identificação de perfis de jogadores [AMBI16] a partir da adaptação do questionário de motivação para jogos online proposto por Yee [Yee06].

Engajamento foi avaliado por suas dimensões comportamentais, emocionais e cognitivas. Engajamento comportamental foi avaliado por meio da duração das sessões, número de questões respondidas em cada sessão, o número de acertos e erros, interações com elementos de jogos, e as navegações realizadas pelos usuários. Engajamento emocional foi avaliado por meio do método SelfAssesment Manekin, para que o usuário informasse seu humor de acordo com a expressão de um desenho de manequim. Esse dado foi coletado apenas quando o usuário se dispôs a fornecer seu feedback espontaneamente após o fim de uma sessão.

Engajamento cognitivo foi avaliado de acordo com o número de questões respondidas em cada sessão, quantidade de acertos, quantidade de ajudas solicitadas e quantidade de consultas aos materiais de referência. Os resultados indicaram que não foi possível afirmar que a gamificação personalizada proporciona um maior engajamento quando comparada com a gamificação sem personalização, embora os resultados sugiram que usuários que permanecem utilizando o sistema por mais tempo tem um maior engajamento no ambiente personalizado. A Tabela 3.1 apresenta um resumo dos trabalhos relacionados apresentados nesta seção. 
Tabela 3.1: Resumo dos trabalhos relacionados.

\begin{tabular}{|c|c|c|}
\hline Autores & Ano & Descrição \\
\hline Nicholson [Nic12] & 2012 & $\begin{array}{l}\text { Definição de um arcabouço teórico centrado em usuário para } \\
\text { gamificação significativa, colocando as necessidades e metas dos } \\
\text { usuários acima das necessidades da organização. }\end{array}$ \\
\hline $\begin{array}{l}\text { Simões et al. } \\
\text { [SARV12] }\end{array}$ & 2012 & $\begin{array}{l}\text { Definição de um cenário de aplicação de gamificação no contexto de } \\
\text { uma plataforma de aprendizagem social. }\end{array}$ \\
\hline $\begin{array}{l}\text { Simões et al. } \\
\text { [SRV13] }\end{array}$ & 2013 & $\begin{array}{l}\text { Definição de funcionalidades de gamificação social por perfil de } \\
\text { usuário; e sete diretrizes para organização de conteúdo em uma } \\
\text { plataforma de aprendizagem social. }\end{array}$ \\
\hline Nah et al. [NTRV13] & 2013 & $\begin{array}{l}\text { Definição de um arcabouço conceitual de gamificação com princípios } \\
\text { de gamificação, elementos de projeto de sistema para gamificação e } \\
\text { dimensões do engajamento de usuário. }\end{array}$ \\
\hline Marins [Mar13] & 2013 & $\begin{array}{l}\text { Definição de um arcabouço conceitual e um processo. O arcabouço } \\
\text { envolveu os conceitos motivação, jogador, relações sociais, ação e } \\
\text { progressão relacionando-os com o conceito central de gamificação. }\end{array}$ \\
\hline $\begin{array}{l}\text { Simões et al. } \\
\text { [SRVA14] }\end{array}$ & 2014 & $\begin{array}{l}\text { Definição de uma arquitetura composta de três camadas para sistemas } \\
\text { gamificados. }\end{array}$ \\
\hline $\begin{array}{l}\text { Wongso et al. } \\
\text { [WRB14] }\end{array}$ & 2014 & $\begin{array}{l}\text { Definição de um arcabouço conceitual baseado em engajamento social } \\
\text { e gamificação, usando Design Science Research como metodologia. }\end{array}$ \\
\hline Clementi [Cle14] & 2014 & $\begin{array}{l}\text { Definição de diretrizes motivacionais baseadas em gamificação para } \\
\text { serem aplicadas por moderadores de comunidades de prática. }\end{array}$ \\
\hline $\begin{array}{l}\text { Bista et al. } \\
\text { [BNCP12, BNPC14] }\end{array}$ & 2014 & $\begin{array}{l}\text { Gamificação baseada em distintivos com a definição de um modelo } \\
\text { formal e um processo de projeto de gamificação. }\end{array}$ \\
\hline $\begin{array}{l}\text { Mora et al. } \\
\text { [MZGAM15] }\end{array}$ & 2015 & $\begin{array}{l}\text { Definição de um arcabouço conceitual para projetar a gamificação de } \\
\text { experiências de aprendizado, com o objetivo de obter rapidamente o } \\
\text { produto mínimo viável para testes. }\end{array}$ \\
\hline Simões [Sim15] & 2015 & $\begin{array}{l}\text { Análise de engajamento por meio da verificação se houve aumento na } \\
\text { tendência do estudante em experimentar o estado de fluxo. Os } \\
\text { resultados mostraram um pequeno aumento na percepção de fluxo } \\
\text { com baixa significância estatística. }\end{array}$ \\
\hline Poffo [Pof16] & 2016 & $\begin{array}{l}\text { Avaliação de efetividade da gamificação para transformar a motivação } \\
\text { extrínseca em intrínseca nos alunos, e percepção de contribuição para } \\
\text { aprendizagem. Os resultados foram positivos. }\end{array}$ \\
\hline $\begin{array}{l}\text { Morschheuser et al. } \\
\text { [MWHA17] }\end{array}$ & 2017 & $\begin{array}{l}\text { Definição de um método para projeto de gamificação avaliado por } \\
\text { especialistas. }\end{array}$ \\
\hline Andrade [And18] & 2018 & $\begin{array}{l}\text { Definição de modelo de macro-gamificação e micro-gamificação. } \\
\text { Resultados indicaram não ser possível afirmar que a gamificação } \\
\text { personalizada proporciona um maior engajamento quando comparada } \\
\text { com a gamificação sem personalização. }\end{array}$ \\
\hline
\end{tabular}

Em comum, todas as pesquisas reforçam, em suas revisões da literatura, que os meios para a aplicação de gamificação ainda não foram bem definidos e os resultados obtidos atualmente mostram-se dependentes do contexto e da população-alvo. As principais diferenças entre esta tese e as pesquisas apresentadas nesta subseção referem-se ao contexto da pesquisa - comunidades de colaboração aberta no domínio de GLAMs, ao estudo longitudinal que esta tese apresenta, comparando efeitos produzidos por elementos de jogos e de colaboração, em particular no engajamento de usuários, e o desenvolvimento dos elementos ao longo de uma pesquisa-ação que informa o contexto e o processo em que foi produzida a proposta de abordagem, sendo portanto uma descrição sincrônica (ao mesmo tempo ou contexto) e diâcronica (através do tempo ou processo) da proposta. 


\section{Capítulo 4}

\section{Design da pesquisa}

Três tipos de pesquisa podem ser abordados em estudos empíricos: (1) pesquisa qualitativa, (2) pesquisa quantitativa e (3) abordagem de métodos mistos [Mel13, Cre13, Sea99]. A pesquisa qualitativa estuda os objetos em sua configuração natural e tem como objetivo interpretar um fenômeno com base nas explicações que as pessoas trazem deles. A pesquisa quantitativa preocupase com a descoberta de causas percebidas pelo sujeito no estudo e tem como meta quantificar uma relação ou comparar dois ou mais grupos. A abordagem de métodos mistos busca compensar as limitações e vieses das duas anteriores e objetiva alcançar a convergência no cruzamento dos métodos. De acordo com Neuman e Robson [NR07], existem três tipos de propostas para um estudo: (1) exploratória, (2) descritiva e (3) explanatória. Na pesquisa exploratória, o pesquisador busca examinar uma nova área de modo a formular questões para abordar em pesquisa futura, e o enfoque é sobre a questão "O que?". A pesquisa descritiva apresenta uma figura dos detalhes específicos de uma situação e o enfoque é sobre as questões "Como?" e "Quem?". A pesquisa explanatória documenta causas, testa teorias e fornece razões, baseia-se em pesquisas exploratórias e descritivas e tem como enfoque a questão "Por quê?". As pesquisas explanatórias suportam ou refutam explicações ou previsões [NR07].

Esta pesquisa utiliza a abordagem de métodos mistos, uma vez que a QPI, definida na Seção 1.2, está no contexto de pesquisa quantitativa, enquanto que a questão de pesquisa QPII está no contexto de pesquisa qualitativa. As questões de pesquisa QPI e QPII configuram-se em estudos descritivos e explanatórios.

\subsection{Pesquisa-ação}

Para responder às questões de pesquisa definidas na Seção 1.2, vem sendo realizada uma pesquisa-ação no projeto Arquigrafia.

Conforme Filippo [FIL08], "na pesquisa-ação busca-se avançar na teoria atuando na prática, o que é feito através de ações no contexto de uma organização específica. O foco do pesquisador é na compreensão do problema e das ações realizadas para solucioná-lo dentro de um ambiente real particular e não na verificação de uma hipótese de caráter geral num ambiente de laboratório". O pesquisador adota um posicionamento não neutro, ou seja, não é apenas um observador, mas sim interfere com ações e se integra aos membros da equipe ou organização onde a pesquisa é realizada [MM01]. Ainda conforme Filippo: "Pesquisadores e pesquisados colaboram visando compreender um problema, as ações propostas para solucioná-lo adequadamente e o efeito destas ações. A pesquisa é conduzida num processo cíclico de agir e refletir criticamente sobre as ações: o pesquisador, fazendo uso de seu arcabouço teórico; os membros do grupo, a partir do conhecimento prático do contexto em que trabalham".

Sendo assim, pesquisa-ação possui um duplo objetivo: fazer pesquisa para ampliar o conhecimento científico e realizar uma ação para promover uma melhoria na organização ou comunidade onde a pesquisa está sendo realizada, isto é, teoria e prática andam juntas por meio de pesquisa e ação. Por esse motivo, o pesquisador age e se envolve com a pesquisa [Dic93, KMS97]. 


\subsubsection{Fases da pesquisa-ação}

A Figura 4.1 ilustra a evolução espiral de ciclos de pesquisa-ação contínuos.

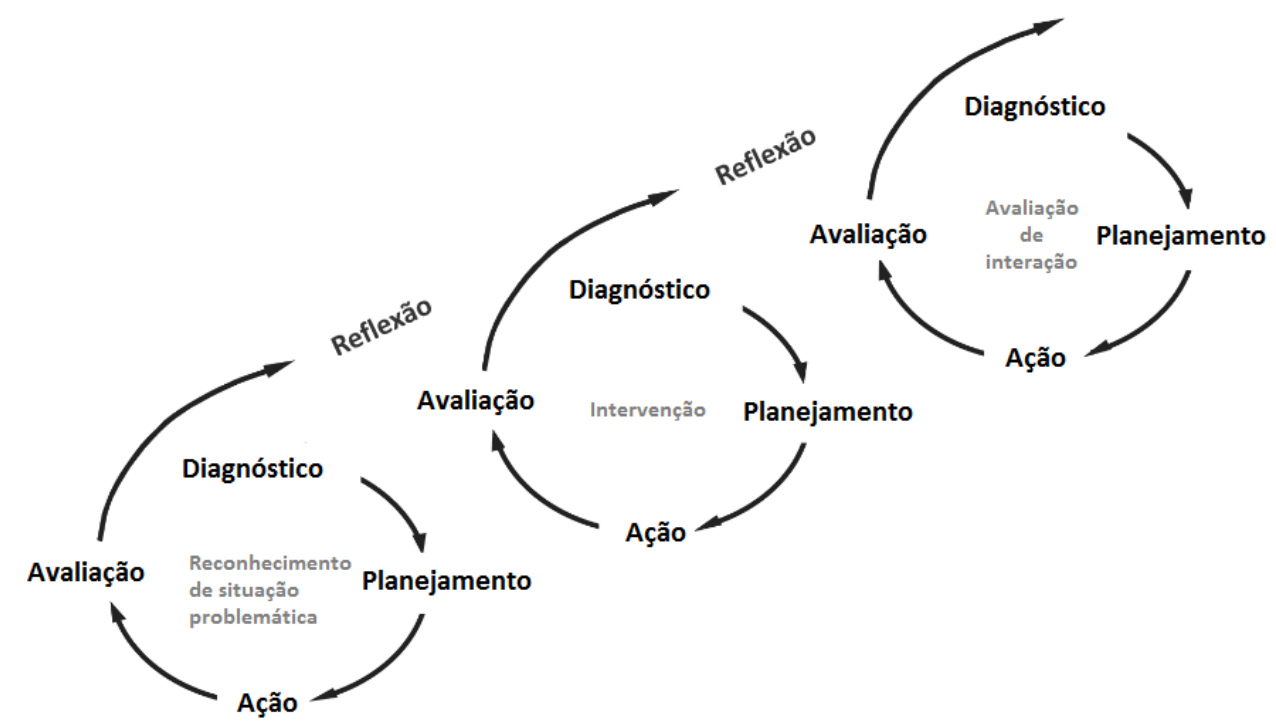

Figura 4.1: Espiral evolutiva de ciclos de pesquisa-ação contínuos a partir de [VZ03].

As cinco fases de cada ciclo da pesquisa-ação propostas por Susman e Evered [SE78] foram:

1. diagnóstico: refere-se à identificação conjunta entre pesquisador e praticantes de problemas reais e suas causas subjacentes.

2. planejamento: processo de especificação das ações para melhorar a situação do problema, considerando possibilidades alternativas.

3. ação: refere-se à seleção e implementação de uma intervenção especificada na fase de planejamento das ações.

4. avaliação: implica a análise conjunta da intervenção, por profissionais e pesquisadores, acerca das consequências de uma ação.

5. reflexão: designa o processo de documentar e resumir os resultados de aprendizagem do ciclo de pesquisa-ação, identificando descobertas gerais. Os resultados de aprendizagem devem contribuir com conhecimento tanto para a teoria quanto para a prática, mas também são reconhecidos como uma compreensão temporária, que serve como ponto de partida para um novo ciclo de pesquisa.

\subsubsection{Pesquisa-ação como método de pesquisa adequado a esta tese}

Para a escolha do método de pesquisa-ação desta tese considerou-se o objetivo da pesquisa, o envolvimento do pesquisador no contexto em que a pesquisa se realiza e a existência de um problema neste contexto específico. Esta pesquisa tem como objetivo compreender como colocar em prática a teoria da gamificação no projeto de comunidades online de colaboração aberta, no domínio de GLAMs, analisando os efeitos dessas intervenções sobre o engajamento dos usuários. Portanto, compreendendo como integrar gamificação e avaliação de engajamento resultante nesse contexto. Dessa forma, busca-se um entendimento aprofundado do processo de como integrar e dos seus efeitos sobre o engajamento de usuários. Conforme Yin [Yin09, FIL08], pesquisas qualitativas têm interesse em responder "Como" e "Por que" e demandam ambientes reais em que o problema ocorre. 
A pesquisa-ação é um método que envolve o pesquisador no ambiente de pesquisa, como ocorre nesta tese. Realizei uma pesquisa-ação no projeto durante o mestrado sobre práticas de usabilidade ágil entre 2010 e 2011. Para a pesquisa-ação que iniciou em janeiro de 2015, tive os papéis de pesquisadora, analista de requisitos, coordenadora de desenvolvimento, desenvolvedora e testadora. Portanto, um papel de insider na pesquisa-ação. Conforme Felippo [FIL08], uma visão de insider é "daquele que vivencia ou já vivenciou as situações que são investigadas".

A pesquisa-ação inicia-se a partir da identificação de um problema em um contexto particular, como ocorre nesta tese. No Arquigrafia, o problema identificado foi que embora o sistema tenha sido avaliado em diversos testes de usabilidade como um sistema útil, com boa usabilidade e com estética agradável, ainda não existia engajamento dos usuários com o sistema. Portanto, é um sistema adequado para investigar a falta de engajamento de usuários e avaliar teorias e práticas que visam aumentar o engajamento.

Por esses motivos, a pesquisa-ação foi considerada um método de pesquisa adequado para conduzir as investigações realizadas nesta tese. A próxima seção apresenta o tratamento adotado para validação da pesquisa-ação com o objetivo de assegurar o rigor do método aplicado.

\subsubsection{Validade da pesquisa-ação no Arquigrafia}

A pesquisa-ação no projeto Arquigrafia foi realizada de janeiro de 2015 a junho de 2018 com o objetivo de responder a QPII e pode ser dividida em dois momentos: 1) aplicação de práticas atuais de gamificação e construção de ambiente de monitoramento de métricas objetivas de engajamento, até a definição de uma primeira proposta de abordagem; e 2) aplicação da proposta de abordagem e refinamento da proposta. A proposta de abordagem foi baseada em um arcabouço teórico e nas lições aprendidas durante os ciclos.

Conforme Kock [Koc04], as principais ameaças à validade de uma pesquisa-ação são geralmente referidas como: incontrolabilidade (uncontrollability), contingência e subjetividade. A ameaça da incontrolabilidade, acontece porque embora frequentemente as mudanças no ambiente estudado ocorram de formas previstas pelo pesquisador, algumas vezes o ambiente muda de maneira completamente inesperada. A mudança pode, em alguns casos, forçar o pesquisador a rever seus métodos, pressupostos teóricos e até mesmo seu tema de pesquisa antes que uma única iteração do ciclo de pesquisa-ação seja concluída. Além disso, o pesquisador pode ser forçado a abandonar o local de pesquisa antes da conclusão do estudo, devido a eventos que estão fora de seu controle. A ameaça da contingência diz respeito à dificuldade para generalizar as descobertas científicas ou para aplicar as descobertas da pesquisa em contextos diferentes daquele em que foram geradas. Ou seja, descobertas altamente contingentes têm pouca validade externa. A ameaça da subjetividade depende do fato de que, na pesquisa-ação, o envolvimento pessoal do pesquisador pode conduzir a interpretações de dados da pesquisa de formas potencialmente subjetivas, o que pode resultar em interpretações erradas.

Para assegurar a validade do método de pesquisa-ação em sistemas de informação, Davison et al. [DMK04] propuseram princípios e critérios para apresentar com clareza os papéis envolvidos, a abordagem de coleta de dados e como o processo foi controlado, o que assegura rigor de pesquisa. Os resultados para essa validação são apresentados abaixo.

1. Papéis: Quais foram os papéis do pesquisador e do profissional e como eles se desenvolveram sobre o tempo? A pesquisa-ação no Arquigrafia foi desenvolvida com a parceria de clientes, estagiários de desenvolvimento e design e a pesquisadora. Os clientes são professores da FAU e da ECA, e seus estagiários, alunos de graduação e pós-graduação de arquitetura e urbanismo e de comunicação, respectivamente. Os estagiários de desenvolvimento e design são os membros da equipe de desenvolvimento e design do sistema de software.

A equipe de desenvolvimento foi composta de alunos de graduação e pós-graduação do IME, da Escola Politécnica e da Física da USP e um aluno de engenharia em redes de computadores e comunicação multimídia da Universidade Politécnica de Grenoble na França (Polytech Grenoble), que estava realizando intercâmbio no IME. A equipe de design foi composta por 
alunos de graduação da FAU. Todos os alunos participantes eram bolsistas com períodos de três meses a dois anos de duração da bolsa.

Contudo, a quantidade de membros da equipe de desenvolvimento e design variou ao longo do tempo, desde dois indivíduos no início de 2015, um aluno de graduação do IME e eu, até alcançar o máximo de sete pessoas, cinco de desenvolvimento e duas de design no segundo semestre de 2015. A partir de 2016, a equipe de desenvolvimento e design variou entre 3 e 5 membros, sendo pelo menos três de desenvolvimento até julho de 2017, quando os períodos de bolsa e estágio finalizaram. A partir de julho de 2017, a equipe de desenvolvimento contava com dois membros, sendo eu uma deles, enquanto três novos estagiários da FAU, passaram a constituir a equipe de design.

Minhas atividades na equipe foram de pesquisa, coordenação de desenvolvimento, análise de requisitos, desenvolvimento, testes (funcionais e de usabilidade) e configuração do ambiente de homologação e produção. Contudo, o enfoque das atividades mudou ao longo dos ciclos. Nos ciclos 0 a 2, meu papel foi de pesquisadora e líder de desenvolvimento, trabalhando presencialmente com a equipe diariamente em tarefas de seleção de requisitos, desenvolvimento de funcionalidades do Arquigrafia, testes e configuração dos ambientes de homologação e produção. A partir do ciclo 3, minhas atividades concentraram-se em pesquisa, coordenação dos requisitos a serem implementados em cada iteração, desenvolvimento da ferramenta de cálculo de métricas, testes e configuração dos ambientes de homologação e produção. O acompanhamento da equipe passou a ser semanal, e não mais diariamente como nos primeiros ciclos. De setembro a dezembro de 2017, passei a acompanhar remotamente o desenvolvimento com reuniões semanais via ferramentas de video-conferência (Skype), pois realizei um período de doutorado-sanduíche na University of British Columbia (UBC), com o objetivo de definir e executar um experimento de campo online no Arquigrafia (mais detalhes no ciclo 6).

Portanto, meu papel foi de pesquisadora insider no Arquigrafia, ou "daquele que vivencia ou já vivenciou as situações que são investigadas" [FIL08]. Isso ajudou-me a observar e entender o contexto real do projeto, mas ao mesmo tempo pode ter influenciado a interpretação dos dados. Nós buscamos superar essa limitação por triangular múltiplas fontes de dados, como descrito no próximo item. Conforme Denzin [Den17], a triangulação em pesquisa pode ser realizada com dados, pesquisadores, teorias e metodologias.

2. Documentação: Quais foram os dados coletados para dar suporte à resolução do problema e o objetivo de pesquisa? Como esses dados foram coletados? Como a qualidade dos dados foi garantida? Conforme Melo [Mel13], "credibilidade é estabelecida por meio de triangulação de informação" e "depende do rigor com o qual contexto e a natureza especial da cena da pesquisa é descrita e analisada". A coleta de dados desta pesquisa-ação envolveu 18 métodos e ferramentas, conforme Tabela 5.1. Adicionalmente, os dados foram coletados por meio de um estudo longitudinal. O rigor foi desenvolvido por meio do método sistemático de descrição dos ciclos seguindo a lista de verificação de Davison et al. [DMK04]: (1) princípio do acordo entre pesquisador e cliente; (2) princípio do modelo de processo cíclico; (3) princípio da teoria; (4) princípio da mudança por meio de ações; e (5) princípio da aprendizagem por meio da reflexão.

A credibilidade também envolve checar as interpretações, teorias e conclusões do pesquisador antes, durante e após o processo de pesquisa. As reuniões de desenvolvimento e as reuniões entre equipe, clientes e usuários possibilitaram compartilhar pensamentos e interpretações com a equipe. Os seminários RITe (Representações: Imaginário e Tecnologia) de 2016 a 2018 também foram um meio de discutir em mesas-redondas os resultados e interpretações de pesquisa com uma comunidade maior de membros do Arquigrafia que não participam das reuniões semanais. O processo de revisão de artigos enviados para publicação também foi um meio de checagem de resultados e interpretações por pesquisadores não envolvidos com a pesquisa. 
3. Controle: Como a relação cliente-pesquisador foi estabelecida? Quem exerceu autoridade sobre o processo? Até que ponto os mecanismos de controle formalizados foram adotados?

Conforme Avison [ABM07], estruturas de poder em pesquisa-ação podem ser classificadas como formal, informal e em evolução: "estruturas de poder formais são bem definidas em acordos escritos no início do projeto. Estruturas de poder informais serão iniciadas e completadas com, no máximo, a escrita de acordos amplos e gerais. Estruturas de poder em evolução requerem mudanças nas estruturas de poder à medida que o escopo da pesquisa se desenvolve progressivamente, mas não necessariamente das estruturas informais às formais". Nossa pesquisa foi formalmente controlada por meio de um projeto de pesquisa enviado à Fapesp, para uma bolsa de treinamento técnico nível $\mathrm{V}$, que envolvia pesquisa, gestão e desenvolvimento de software, com o envio de relatórios anuais dos objetivos cumpridos no período. O parecer final da Fapesp reporta a conclusão dos objetivos formalizados.

A partir do ponto de vista de autoridade, Avison descreve três tipos principais: dominação do cliente, a dominação encenada e a dominação de identidade. Conforme Avison, "em um projeto de pesquisa-ação dominado pelo cliente, a própria equipe de pesquisa não possui um mandado de ação. Em vez disso, a equipe recomenda e justifica a ação para gerentes organizacionais fora da equipe". "A dominação encenada envolve uma migração da dominação do poder entre os participantes da pesquisa-ação", por exemplo, a partir do pesquisador para a equipe. "A dominação de identidade significa que os pesquisadores e os praticantes profissionais da organização eram a mesma pessoa (ou pessoas). Em outras palavras, um ou mais dos pesquisadores eram membros internos da organização, e possuíam a garantia de autoridade de ação necessária para fazer as intervenções" [ABM07]. Esta pesquisa adequa-se dentro da dominação de identidade.

\section{Utilidade: Como a utilidade da solução foi estabelecida na situação do problema?}

Conforme Iversen [IMN04], "a validade de uma contribuição de pesquisa-ação depende intrinsecamente de se alguma mudança desejável foi criada". Baskerville e Wood-Harper declaram também que estabelecer a utilidade dos resultados na situação-problema sustenta a imparcialidade de pesquisa e cria uma linha de base sobre a qual os resultados podem ser transferidos [BWH96].

As ações e mudanças inseridas no projeto para avaliar seus efeitos, especialmente sobre o engajamento de usuários, foram monitoradas. A análise qualitativa com diários de campo, testes de usabilidade e reuniões com equipe/clientes e a análise quantitativa com a pesquisa correlacional e experimentos de campo online, indicaram que os efeitos desejados foram criados, conforme descrito nas Seções 6.2 e 7.4.

5. Teoria: Como os arcabouços são usados para suportar o estudo? Como os resultados foram subsequentemente relacionados a esses arcabouços?

É necessário deixar claro como as experiências e os resultados se baseiam e se relacionam com os corpos de conhecimento existentes [IMN04]. A proposta de abordagem desta pesquisa representa um avanço no estado da arte de aplicação da teoria de gamificação para construção de comunidades online de colaboração aberta. Adicionalmente, detalhamos a abordagem no contexto específico de GLAMs. Os ciclos iniciais da pesquisa-ação foram suportados pelo corpo de conhecimento existente sobre a prática de gamificação e avaliação de engajamento. Durante os ciclos, pesquisa e ação possibilitaram a construção de uma proposta de abordagem, baseada em um arcabouço teórico, que foi instanciada nos ciclos finais. Nós apresentamos as relações entre a teoria e os pressupostos de cada ciclo, bem como, as lições aprendidas.

6. Transferência: Sob quais condições os resultados podem ser transferidos ou adaptados em outros contextos? Quais são as habilidades e capacidades que facilitadores e outros atores devem possuir? 
A proposta de abordagem foi apresentada de forma genérica para aplicação no desenvolvimento de comunidades online de colaboração aberta de diversos domínios, podendo ser aplicada a partir de qualquer estágio de vida da comunidade. A instanciação no domínio de GLAMs possibilitou detalhar as práticas de comunidade comuns nesse domínio que podem ser associadas aos comportamentos-alvo a serem gamificados. Contudo, como a proposta foi construída por meio da abordagem plug-and-play [WT13], é possível remover ou incluir diretrizes para aplicação da proposta em contextos diferentes.

Quanto às habilidades e capacidades dos facilitadores, a proposta de abordagem requer uma competência geral em organizar workshops para reflexão colaborativa, testes de usabilidade e experimentos de campo online, bem como, conhecimentos em análise estatística descritiva e inferencial.

\subsection{Pesquisa quantitativa experimental}

Conforme Järvinen [Jär12], o conceito de experimento refere-se ao isolamento e à manipulação de uma única variável enquanto assegura-se que todas as outras variáveis sejam constantes. Dessa forma, o pesquisador é apto a medir o efeito que a variável manipulada (independente) tem sobre o comportamento das demais variáveis (dependentes) do objeto do experimento.

Em geral, se os objetos manipuláveis estão sob estudo [Jär12, Aul82], então: (1) repetição do estado inicial é possível, ou um objeto se repete automaticamente ou o objeto pode ser substituído por um objeto idêntico tendo o mesmo estado inicial; e (2) o estado final pode ser controlado, isto é, um pesquisador é capaz, por meio da variação do estado inicial, de controlar o estado final do objeto.

No experimento de campo, o fenômeno de interesse é estudado no ambiente onde ele ocorre naturalmente [Jär12, Ben84]. No experimento de campo, o pesquisador controla o tempo e a extensão da mudança na variável independente [Jär12, Sis77]. Além disso, os grupos de controle podem ser estabelecidos como uma garantia adicional de que qualquer mudança na variável dependente que ocorra após a variável independente ter sido manipulada é o resultado da mudança específica e não de fatores não controlados. A alteração provocada pelo experimento não se destina a ser permanente após o fim do experimento [Jär12].

Um experimento controlado online refere-se à realização de um experimento de campo em ambiente online, isto é, por meio de um sistema disponível para acesso pela Internet. Conforme Kohavi et al. $\left[\mathrm{KDF}^{+} 13, \mathrm{KDF}^{+} 12\right]$, em um experimento controlado online os usuários são divididos aleatoriamente entre as variantes, por exemplo, os dois diferentes layouts de um anúncio, de forma persistente, isto é, um usuário recebe a mesma experiência em várias visitas. Suas interações com o sistema são instrumentadas e métricas-chave são calculadas. No experimento controlado online chamado de Teste $\mathrm{A} / \mathrm{B}\left[\mathrm{KDF}^{+} 12\right]$, os usuários são aleatoriamente expostos a uma de duas variantes: Controle (A) ou Tratamento (B).

\subsubsection{Experimentos controlados online no Arquigrafia}

Nesta pesquisa, os experimentos controlados foram desenvolvidos como parte da proposta de abordagem para avaliar engajamento durante o desenvolvimento de uma comunidade online. Os experimentos foram aplicados durante os ciclos de pesquisa-ação e serviram a dois propósitos: 1) avaliar as métricas de engajamento a partir dos elementos inseridos durante o desenvolvimento (avaliação de engajamento resultante como parte da proposta de abordagem); e 2) explorar os métodos de monitoramento e avaliação do engajamento durante o ciclo de pesquisa-ação (aplicação e refinamento da proposta de abordagem).

Os experimentos controlados online respondem ao problema de avaliar o que ocorre com as métricas de engajamento após o acesso de duas versões distintas do sistema. O primeiro experimento foi executado sobre um elemento colaborativo - a notificação, de modo a analisar as métricas de 
engajamento do mesmo conjunto de usuários, antes e após acessar o elemento. O segundo experimento foi executado a partir da disponibilização de duas versões distintas de uma funcionalidade do sistema - com ou sem gamificação - para usuários que acessaram o sistema durante um período definido. As duas versões foram apresentadas de forma aleatória aos usuários, utilizando-se de uma ferramenta que garantisse o acesso a mesma versão visualizada no primeiro acesso da funcionalidade.

Dessa forma, a variável independente ou manipulada em cada experimento foi o conjunto de elementos de jogos ou de colaboração, sendo este conjunto o que caracteriza a versão de tratamento em contraste com a versão de controle, que tem como única diferença a remoção do conjunto de elementos de jogo ou de colaboração. O objetivo, portanto, foi medir o efeito que a variável independente (elemento de jogo ou de colaboração) teve sobre o comportamento das variáveis dependentes, ou as métricas de engajamento.

\subsubsection{Validade da pesquisa experimental no Arquigrafia}

Creswell [Cre02] apresenta critérios úteis para a validação de um estudo experimental. Utilizamos esses critérios para validar os experimentos realizados no Arquigrafia.

- O experimento tem uma intervenção poderosa.

Uma boa intervenção é uma que já tenha sido usada por outros pesquisadores e prevê uma mudança nos resultados. A revisão da literatura e uma avaliação de teorias para prever relações pode ajudar pesquisadores a localizar uma intervenção, prevendo mudanças. Isto ajuda a formular hipóteses para testar relações de causa e efeito.

Intervenções precisam ser projetadas para pouca intrusão na configuração e sobre os participantes. Isso significa que o pesquisador precisa respeitar o ambiente sendo estudado e ganhar a cooperação de patrocinadores e participantes do estudo. A intervenção deve ser baseada em um pequeno teste-piloto, por meio da seleção de um grupo de participantes na população e fornecimento da intervenção a eles. Essa abordagem pode envolver um design pré-experimental com um único grupo, para facilitar a implementação, ou uma intervenção de curta duração, com poucos indivíduos. A partir do piloto, é possível desenhar conclusões sobre o impacto potencial da intervenção para o experimento final.

Os dois experimentos executados no Arquigrafia foram construídos com base na literatura, tendo um teste-piloto executado antes da implementação do experimento real. O primeiro experimento foi executado sobre um elemento colaborativo - notificação - o qual a literatura apresenta como um meio eficaz de aumentar engajamento de usuários, uma vez que aumenta a consciência do ambiente [Bur05, $\mathrm{CNI}^{+}$03, MP02]. Por esse motivo, o primeiro experimento foi projetado para avaliar as métricas objetivas selecionadas para avaliação de engajamento. Esperava-se, portanto, que as métricas apresentassem aumento de engajamento para usuários que acessaram a notificação no período experimental. Este experimento foi construído com o design Within-Group, no qual o número de participantes pode ser limitado, e analisa-se um mesmo grupo em momentos distintos. Within-group pode ter um design de séries de tempo (time series), que consiste em estudar um grupo sobre o tempo com medidas ou observações pré-teste e pós-teste feitas pelo pesquisador. Este foi o design aplicado neste primeiro experimento.

O segundo experimento foi realizado sobre uma abordagem gamificada versus a não-gamificada de uma funcionalidade - Revisão de dados - e foi construído sobre a proposta de abordagem desta pesquisa, a partir de um arcabouço teórico. O objetivo foi comparar dois grupos distintos durante um mesmo período de tempo com respeito ao efeito da intervenção sobre o engajamento dos usuários. Portanto, utilizou-se um design Between-group, no qual a única diferença entre um grupo e outro foi a gamificação da funcionalidade apresentada em uma das versões.

- Os grupos de tratamento são poucos em número. 
Ter poucos grupos de tratamento significa maior controle dos efeitos por experimento. Além disso, se existirem muitos grupos aumenta-se a chance de um se comunicar com o outro e o grupo de controle aprender informações sobre os tratamentos (difusão de tratamentos), o que cria uma ameaça à validade interna. Os experimentos executados no Arquigrafia foram projetados para terem um grupo de controle e um grupo de tratamento.

- Os participantes ganharão com a intervenção.

Segundo o princípio de equalização compensatória, quando apenas o grupo experimental recebe um tratamento, existe uma desigualdade que pode ameaçar a validade do estudo. Os benefícios, ou seja, os bens ou serviços considerados desejáveis do tratamento experimental, precisam ser igualmente distribuídos entre os grupos de estudo. Para contrapor este problema, os pesquisadores usam grupos de comparação, como palestras distintas para grupos distintos, para que todos recebam algum benefício durante o experimento.

No Arquigrafia, o experimento Within-Group foi executado sobre o mesmo conjunto de indivíduos antes e após o período de experimentação com a funcionalidade de notificação. $O$ experimento Between-group foi executado com o lançamento de uma nova funcionalidade, nas versões com ou sem gamificação. Portanto, nos dois experimentos, todos os grupos receberam um benefício: uma nova funcionalidade em versões diferentes.

- O pesquisador deriva o número de participantes por grupo de uma maneira sistemática.

A abordagem mais rigorosa é atribuir aleatoriamente indivíduos aos tratamentos. Atribuição aleatória é o processo de atribuir indivíduos aleatoriamente a grupos ou a grupos diferentes em um experimento. A designação aleatória de indivíduos para grupos (ou condições dentro de um grupo) distingue um experimento rigoroso e verdadeiro de um quase-experimento adequado, mas pouco rigoroso. Usa-se uma atribuição aleatória para que qualquer tendência nas características pessoais dos indivíduos no experimento seja distribuída igualmente entre os grupos. Dessa forma, controla-se as variáveis externas que podem influenciar a relação entre o novo tratamento e o resultado.

No Arquigrafia, o experimento Within-Group foi feito sobre a análise do comportamento natural de acessos ao sistema durante o período de experimentação. Portanto, as métricas de engajamento foram analisadas em dois períodos antes e depois do acesso à funcionalidade de notificação. No experimento Between-group utilizamos a ferramenta Google Optimize para distribuir os usuários que acessaram o Arquigrafia durante o período do experimento para as versões com ou sem gamificação. Portanto, a atribuição foi aleatória, distribuindo variabilidades de indivíduos, como a motivação inicial para acessar o sistema, habilidades e atenção.

- Um número adequado de participantes foi usado no estudo.

Em muitos experimentos, o tamanho do número total de participantes (e participantes por grupo) é ditado por questões práticas do número de voluntários que se inscrevem para o estudo ou os indivíduos disponíveis para o pesquisador. O pesquisador também usa estatísticas para analisar os dados, e essas estatísticas exigem números mínimos de participantes.

Na revisão sistemática de Looyestyn et al. $\left[\mathrm{LKB}^{+} 17\right]$ identificou-se que um grande número de estudos com gamificação, e design Between-group, possuíam amostras muito pequenas. Os pesquisadores, então, utilizaram cálculos de poder estatísticos para selecionar estudos para a revisão. Os resultados indicaram que amostras com n menor que 54 tinham baixo poder para detectar até mesmo um grande tamanho de efeito.

No experimento Within-Group, analisou-se um conjunto de 31 usuários, portanto a força do experimento está em serem exatamente os mesmos indivíduos antes e após a intervenção em uma configuração natural de acesso, uma vez que nenhum dos dois momentos foram influenciados pela pesquisa. Para o experimento Between-group a distribuição aleatória de indivíduos aos dois grupos resultou em $\mathrm{n}=73$, o que adequa-se aos cálculos de poder estatístico indicados por Looyestyn et al. [LKB $\left.{ }^{+} 17\right]$. 
- O pesquisador usa medidas e observações válidas, confiáveis e sensíveis. Esse princípio refere-se a seleção de variáveis dependentes e independentes adequadas ao estudo. Variáveis independentes devem conter pelo menos uma variável com múltiplos níveis, e o pesquisador precisa manipular um dos níveis. Variáveis dependentes são resultados, e os pesquisadores frequentemente estudam vários resultados. As variáveis são medidas em um instrumento ou registradas como observações. Elas precisam produzir pontuações válidas e confiáveis.

No experimento Within-Group, a variável independente foi a funcionalidade de notificação em dois níveis - presente ou não em períodos distintos para o mesmo conjunto de usuários -, ou a intervenção para a qual desejava-se avaliar os efeitos, e as variáveis dependentes foram as métricas objetivas de engajamento, para as quais esperava-se um efeito positivo, de acordo com a literatura. No experimento Between-group, a variável independente foi a funcionalidade de revisão de dados em dois níveis - com ou sem gamificação no mesmo período para um conjunto distinto de usuários -, e as variáveis dependentes foram as métricas objetivas e subjetivas de engajamento com o objetivo de avaliar efetividade da gamificação sobre o engajamento de usuários.

- O pesquisador controla fatores externos que possam influenciar o resultado.

Fatores externos são quaisquer influências na seleção de participantes, nos procedimentos, nas estatísticas ou no design que possam afetar o resultado e fornecer uma explicação alternativa para ele.

Os itens anteriores refletem o controle sobre essas influências, indicando que a única diferença nos experimentos foi o nível da variável independente para cada período, no caso do experimento Within-Group, e para cada grupo, no caso do experimento Between-group. Questões específicas de personalidade ou comportamentais dos indivíduos estão presentes em qualquer estudo e não é possível controlar todas as variabilidades, especialmente em um estudo online, dependente do acesso natural do usuário ao sistema.

A análise estatística foi realizada de acordo com pré-requisitos específicos de cada função estatística, com respeito a dados paramétricos ou não-paramétricos, em busca de comparar dados pareados, ou mesmo conjunto em tempos distintos, ou dados não pareados, grupos distintos em um mesmo período. Intervalos de confiança e tamanhos de efeito foram apresentados.

- O pesquisador aborda ameaças à validade interna e externa.

Ameaças à validade externa são problemas que ameaçam nossa capacidade de extrair inferências corretas dos dados da amostra para outras pessoas, configurações, variáveis de tratamento e medidas. Conforme Creswell [Cre02], três ameaças podem afetar essa generalização: interação de seleção e tratamento; interação de configuração e tratamento e interação da história e tratamento.

Interação de seleção e tratamento refere-se à incapacidade de generalizar além dos grupos no experimento, como outros grupos sociais, geográficos, de idade, gênero ou personalidade. Uma estratégia é tornar a participação no experimento o mais conveniente possível para todos os indivíduos de uma população. No caso dos experimentos no Arquigrafia, o experimento foi executado sobre uma configuração natural de uso, portanto, o mais conveniente possível para a população de usuários do sistema.

Interação de configuração e tratamento refere-se à incapacidade de generalizar a partir do cenário em que o experimento ocorreu para outro cenário. A solução prática é analisar o efeito de um tratamento para cada tipo de configuração ou contexto. Nos experimentos realizados no Arquigrafia, analisamos os efeitos dos tratamentos no contexto de comunidades online de colaboração aberta no domínio de GLAMs.

Interação da história e tratamento refere-se a tentar generalizar as descobertas para situações passadas e futuras, sendo que os experimentos podem ocorrer em um período ou horário especial. Uma solução é replicar o estudo mais tarde, em vez de tentar generalizar os resultados 
para outros momentos. Nos experimentos realizados no Arquigrafia analisamos os resultados apenas sobre o período de experimentação, sem generalizar para outros períodos, uma vez que os experimentos ocorreram como parte dos ciclos de pesquisa-ação e tinham o objetivo de analisar os efeitos de intervenções do ciclo.

Ameaças à validade interna são problemas no desenho correto de inferências sobre se a covariação (ou seja, a variação em uma variável contribui para a variação de outra variável) entre a variável de tratamento presumida e o resultado refletem relação causal. Ameaças à validade interna podem ser classificadas em três categorias [Cre02].

A primeira categoria aborda as ameaças relacionadas aos participantes do estudo e suas experiências: história, maturação, regressão, seleção, mortalidade e interações com a seleção. Em linhas gerais, história refere-se ao passar do tempo entre o começo do experimento e o fim, portanto eventos podem ocorrer durante esse período. Maturação refere-se à mudança dos indivíduos durante o experimento (mais velhos, mais sábios, mais fortes, etc.), portanto essas mudanças podem afetar pontuações entre pré e pós-teste. Regressão refere-se a seleção de participantes de acordo com pontuações extremas (ou as melhores ou as piores pontuações), que resultam naturalmente em resultados melhores ou piores no pós-teste. Seleção refere-se a selecionar indivíduos de acordo com fatores pessoais, o que pode gerar a seleção de pessoas mais receptivas a um tratamento. Mortalidade refere-se à desistência de participantes por qualquer motivo ao longo de um experimento. Interações com a seleção referem-se à interação das ameaças já relatadas, o que pode adicionar ameaças adicionais.

Para os experimentos executados no Arquigrafia, nenhuma, dentre as ameaças da primeira categoria, se aplica pois tratam-se de experimentos realizados com atribuição aleatória, em configuração natural ou sem a seleção de usuários específicos e em períodos curtos de tempo. O experimento com design Within-Group avaliou dois períodos subsequentes cada um com 14 dias. O experimento Between-group avaliou os dois grupos de usuários em um mesmo período de 20 dias. Adicionalmente, cuidamos para que os experimentos fossem executados sem nenhum evento do projeto em paralelo.

A segunda categoria diz respeito às ameaças relacionadas aos tratamentos usados no estudo: difusão de tratamentos, equalização compensatória, rivalidade compensatória e desmoralização ressentida. Difusão de tratamentos e equalização compensatória já foram definidos acima. Concorrência compensatória refere-se a anunciar publicamente atribuições ao grupo de controle ou aos grupos de tratamento, gerando rivalidade entre grupos, porque o grupo de controle sente-se em desvantagem em relação ao grupo com tratamento. Desmoralização ressentida refere-se ao grupo de controle sentir-se ressentido ou desmoralizado porque entende que recebeu tratamento menos desejável do que outro grupo. Para os experimentos executados no Arquigrafia, nenhuma das ameaças de segunda categoria se aplica, uma vez que não foi divulgado publicamente aos usuários que um experimento estava sendo executado com duas versões distintas do sistema, seja em um mesmo período ou em períodos distintos.

A terceira categoria diz respeito aos procedimentos do estudo: teste e instrumentação. Teste refere-se à possibilidade dos participantes tornarem-se familiarizados com as medidas de resultados e lembrarem-se de respostas para testes posteriores. Instrumentação diz respeito à mudança do instrumento, por exemplo, mudança de procedimentos de pontuação ou em sua escala. No Arquigrafia, os resultados foram relatados para a comparação entre grupos para o período experimental. Portanto, mudanças em procedimento ocorreram entre um experimento e outro, uma vez que a pesquisa-ação buscava aprender como integrar monitoramento de engajamento ao longo do desenvolvimento de uma comunidade de colaboração aberta. Contudo, as mudanças entre procedimentos aplicados no primeiro experimento e no segundo não afetam os resultados de cada experimento, porque os participantes de cada um, foram avaliados sobre os mesmos parâmetros. 


\subsection{Pesquisa quantitativa não-experimental}

Estudiosos de metodologias de pesquisa, na área de educação, fazem uma distinção em seus textos entre dois métodos não experimentais chamados: pesquisa causal-comparativa e pesquisa correlacional [Cha98, GMA06, MNMM99]. De acordo com os autores, a pesquisa causal-comparativa inclui uma variável independente categórica e/ou uma variável dependente, desde que a palavra comparativa implica em uma comparação de grupos. A pesquisa correlacional inclui apenas variáveis quantitativas. Pesquisa causal-comparativa busca estabelecer relações de causa e efeito em um ambiente natural, enquanto pesquisa correlacional busca avaliar a relação entre variáveis [GMA06].

Uma pesquisa quantitativa não-experimental que é empregada para explorar relações de causa e efeito é chamada ex post facto ("a partir do fato passado") ou pesquisa causal-comparativa. O título de ex post facto é aplicada para estudos em que dados são coletados retrospectivamente, enquanto causal-comparativa é usado quando dados são coletados a partir de grupos e a variável independente não é manipulada como em um experimento [Bus14].

A pesquisa causal-comparativa envolve comparar grupos a fim de explicar diferenças existentes entre eles sobre algumas variáveis ou variáveis de interesse. A única diferença entre a pesquisa causal-comparativa e a pesquisa experimental é que os grupos sendo comparados na primeira já foram formados e qualquer tratamento (se existir um tratamento) já foi aplicado sem a interferência ou manipulação do pesquisador. O pesquisador precisa analisar os registros dos dois grupos para visualizar se eles oferecem uma explicação para a diferença existente entre os dois grupos, isto é, o que a causou. Pesquisa correlacional, por outro lado, não enfoca as diferenças entre grupos, em vez disso, procura por relações dentro de um grupo. Sendo assim, pode-se concluir que existe uma relação de alguma ordem, mas não que variável A causou alguma variação em B. Portanto, pesquisa-causal comparativa possibilita inferir sobre causas e pesquisa correlacional sobre relações [FWH11].

\subsubsection{Validade da pesquisa correlacional no Arquigrafia}

Nesta pesquisa realizamos dois tipos de correlações: correlação transversal (cross-sectional), que foi pontual ao ciclo de pesquisa-ação e parte da proposta de abordagem para avaliar engajamento a partir de intervenções em um ciclo; e correlação longitudinal com o objetivo de analisar os dados dos três anos de pesquisa-ação. A pesquisa correlacional visa responder a QPI.

A correlação transversal responde se as intervenções resultaram em engajamento aumentado em curto prazo, especialmente durante o período de um experimento de campo. A correlação longitudinal visa responder se as intervenções, de 2015 a 2018, resultaram em engajamento a longo prazo, ou não apenas concentrado no período de lançamento das intervenções ou experimentos; o que implica em um período de engajamento sustentado, conforme modelo de O’Brien e Toms [OT08].

A pesquisa correlacional também foi realizada de modo a integrar resultados entre métricas subjetivas e objetivas de engajamento e de modo a distinguir os resultados a partir da entrada de um único elemento de interação, em isolamento, e de um conjunto de elementos. O processo de reflexão sobre as intervenções, ajudou-nos a classificar os conjuntos de elementos a partir de níveis alcançados em cada métrica, tipos de elementos de interação acessados e ações realizadas, os quais foram definidos como parte do processo de abordagem de avaliação de engajamento.

Para avaliar a qualidade de um bom estudo correlacional, Creswell [Cre02] apresenta os seguintes critérios: tamanho de amostra adequado para o teste de hipóteses; exibição de resultados em uma matriz ou gráfico; interpretação sobre a direção e magnitude da associação entre duas (ou mais) variáveis; avaliação da magnitude da relação baseada no coeficiente de determinação, valores de p, tamanho do efeito ou o tamanho do coeficiente; escolha de uma estatística apropriada para análise; e clara identificação dos procedimentos estatísticos. Para design de predição, é necessária a identificação do preditor e das variáveis de critério, incluindo se existir um modelo visual avançado das relações, a direção esperada das relações entre as variáveis, ou a direção prevista com base em dados observados.

Com respeito ao tamanho da amostra, a pesquisa correlacional foi executada sobre dados de 
1591 usuários que acessaram o sistema entre 2015 e 2018, sendo adequado para o teste de hipóteses. Todos os dados são descritos e apresentados por meio de gráficos e tabelas. A direção (positiva ou negativa) e magnitude da associação ou força de associação (negligente, baixa, moderada, alta e muito alta) são apresentadas de acordo com o coeficiente de correlação de classificação de Spearman a partir de [Muk12]. A função de Spearman foi selecionada porque os dados não são paramétricos, conforme testes de normalidade de Shapiro-Wilk (Shapiro-Wilk normality test), portanto trata-se da estatística adequada para análise.

Para avaliação da magnitude da relação, consideramos o $p$-value $<0.05$ para definir os resultados como estatisticamente significativos. O intervalo de confiança de $95 \%$ para os coeficientes encontrados para cada correlação foi apresentado, e, para interpretar os resultados, consideramos o menor efeito apresentado para cada intervalo.

O propósito de um projeto de pesquisa de predição é identificar variáveis que prevêem um resultado ou critério. Nessa forma de pesquisa, o pesquisador identifica uma ou mais variáveis preditoras e uma variável de critério (ou desfecho). Uma variável preditora é uma variável usada para fazer uma previsão sobre um resultado em pesquisa correlacional. Em muitas pesquisas de previsão, os pesquisadores frequentemente usam mais de uma variável preditora. O resultado previsto na pesquisa correlacional, entretanto, é chamado de variável de critério.

Outro tipo de design correlacional é o design explanatório. Um projeto de pesquisa correlacional explanatório é um projeto correlacional no qual o pesquisador está interessado na medida em que duas variáveis (ou mais) co-variam, isto é, onde as mudanças em uma variável são refletidas nas mudanças na outra. Design explanatório consiste em uma associação simples entre duas variáveis (por exemplo, senso de humor e desempenho no drama) ou mais de dois (por exemplo, a pressão de amigos ou sentimentos de isolamento que contribuem para o consumo excessivo de álcool). No caso da pesquisa correlacional desta tese, aplicamos o design correlacional explanatório, sendo assim, temos interesse em saber como as ações, tipos de elementos de interação ou conjuntos de elementos de interação distintos acessados pelos usuários correlacionam-se com as métricas de engajamento resultantes.

\subsubsection{Validade da pesquisa causal-comparativa no Arquigrafia}

A pesquisa causal-comparativa é aplicada no Arquigrafia sobre os dados coletados entre 2015 e 2018. O objetivo é buscar relações de causa e efeito entre: conjuntos de elementos acessados pelos usuários e o nível alcançado em cada métrica (valor alto, médio ou baixo a partir de percentis); conjuntos de elementos acessados pelos usuários e o resultado para cada métrica objetiva; e ações mais acessadas e o resultado para cada métrica objetiva. A pesquisa causal-comparativa, assim como a pesquisa correlacional, visa responder a QPI. Os experimentos de campo online executados dentro do ciclo de pesquisa-ação são analisados juntamente com os resultados de dados coletados retrospectivamente para responder a QPI com um olhar de perspectivas de curto e longo prazo, de modo a entender se o engajamento foi sustentável ou apenas pontual ao período de lançamento da funcionalidade sob análise.

Pesquisa causal-comparativa não realiza atribuição aleatória a grupos, uma vez que utiliza dados a partir de fatos passados. Contudo, o design é muito próximo do aplicado em um experimento controlado. Portanto, removendo-se as questões relacionadas à atribuição de usuários, é necessário avaliar os mesmos itens aplicados a experimentos: pesquisador usa medidas e observações válidas, confiáveis e sensíveis; e pesquisador aborda ameaças à validade interna e externa, conforme definições apresentadas na validação do experimento, de acordo com Creswell [Cre02].

- O pesquisador usa medidas e observações válidas, confiáveis e sensíveis.

Esse princípio refere-se a seleção de variáveis dependentes e independentes adequadas ao estudo. No caso desta tese, foram executados três análises: 1) conjuntos de elementos acessados pelos usuários e o nível alcançado em cada métrica (valor alto, médio ou baixo a partir de percentis); 2) conjuntos de elementos acessados pelos usuários e o resultado para cada métrica objetiva; e 3) ações mais acessadas e o resultado para cada métrica objetiva. Para 
análise 1, variáveis independentes foram os conjuntos de elementos de interação acessados e variável dependente foi o nível alcançado por métrica de engajamento. Para análise 2, variáveis independentes foram os conjuntos de elementos de interação acessados e variáveis dependentes foram as métricas objetivas de engajamento. Para análises 1 e 2, os conjuntos foram definidos considerando apenas usuários que acessaram exclusivamente os elementos de interação do conjunto. Para análise 3, variáveis independentes foram as ações mais acessadas pelos usuários de cada tipo de elemento de interação - funcional, de jogo, colaborativo - e variáveis dependentes foram as métricas objetivas de engajamento. Analisou-se as métricas de engajamento de usuários que acessaram uma ação específica.

\section{- O pesquisador aborda ameaças à validade interna e externa.}

Assim como ocorre em experimentos controlados, três ameaças podem afetar a validade externa, ou a generalização: interação de seleção e tratamento; interação de configuração e tratamento e interação da história e tratamento. Os dados sob análise para a pesquisa causalcomparativa desta tese foram extraídos a partir da configuração natural de uso e os efeitos obtidos para cada conjunto foram descritos no contexto de comunidades online de colaboração aberta no domínio de GLAMs. Com respeito à interação de história e tratamento, as análises foram realizadas sobre médias e totais, de modo a não generalizar um resultado pontual no tempo para o período de três anos.

Quanto a ameaças à validade interna apenas a primeira categoria utilizada em experimentos controlados - ameaças relacionadas aos participantes do estudo e suas experiências (história, maturação, regressão, seleção, mortalidade e interações com a seleção) - aplica-se em pesquisa causal-comparativa.

Para história e maturação, eventos ocorreram durante o período de três anos do Arquigrafia, e houve a mudança do perfil de usuários que acessam desde 2015 de novatos a experientes. No entanto, não analisamos as variáveis dependentes entre antes e depois de uma intervenção ou a partir de intervenções distintas. A análise foi feita sobre a média obtida no período de três anos, portanto, todas as variações específicas de mudanças dos indivíduos, bem como de eventos realizados, que estão presentes em todos os conjuntos, foram diluídos na média de acessos para cada conjunto.

Para regressão, dentre as análises, a relacionada a ações específicas, dá enfoque sobre as mais acessadas. No entanto, as comparações são feitas entre as duas ações mais acessadas de cada tipo de elemento de interação. Portanto, as comparações estão equiparadas. Quanto à seleção, os grupos de indivíduos não foram definidos de acordo com fatores pessoais e sim pelas ações e conjunto de elementos acessados no sistema. Mortalidade e interações com a seleção não se aplicam porque avaliamos médias e não o mesmo conjunto de usuários em dois períodos. 


\section{Capítulo 5}

\section{Pesquisa-ação: Monitoramento e pontificação com colaboração}

Este capítulo apresenta os resultados obtidos por meio dos ciclos de pesquisa-ação realizados no Arquigrafia. Apresentamos para todos os ciclos um diagnóstico que direciona as ações realizadas no ciclo em questão dentre os sete ciclos realizados. Usamos esse mesmo formato para apresentar o problema que se busca resolver no Arquigrafia e o seu contexto, antes de iniciarmos as primeiras ações no projeto, no diagnóstico do Ciclo 0.

Os ciclos 0 a 4 marcam um período de aplicação de pontificação e de configuração de ambiente de software, que culminam em uma primeira proposta de abordagem para integrar a gamificação com o monitoramento e a avaliação de engajamento de usuários durante o desenvolvimento de uma comunidade online de colaboração aberta. Por esse motivo, denominamos os ciclos 0 a 4 como "Monitoramento e pontificação com colaboração". Os ciclo 5 e 6 representam um período de aplicação e avaliação da proposta e foi denominado como "Refinamento da proposta de abordagem no contexto do Arquigrafia".

Com o objetivo de organizar o contéudo da pesquisa-ação nesses dois momentos, este capítulo dá enfoque aos ciclos 0 a 4 e o próximo capítulo apresenta os ciclos 5 e 6 , que finaliza com uma nova proposta de abordagem refinada pelos resultados dos dois ciclos. A Seção 5.1 apresenta uma visão geral de todos os 7 ciclos de pesquisa-ação realizados com os métodos de coleta e análise que suportaram a reflexão sobre cada ciclo e as seções subsequentes descrevem os ciclos 0 a 4 de acordo com as fases da pesquisa-ação.

\subsection{Pesquisa-ação no projeto Arquigrafia}

A pesquisa-ação no projeto Arquigrafia referiu-se: à pontificação - comumente descrita na literatura sobre a prática de gamificação; à criação do ambiente para monitoramento de métricas objetivas de engajamento; à aplicação de experimentos entre versões com e sem gamificação; à avaliação de métricas objetivas e subjetivas de engajamento; e ao refinamento de uma proposta de abordagem no contexto do sistema. A Figura 5.1 apresenta os métodos e ferramentas utilizados para acompanhar e analisar cada fase de um ciclo de pesquisa-ação. 

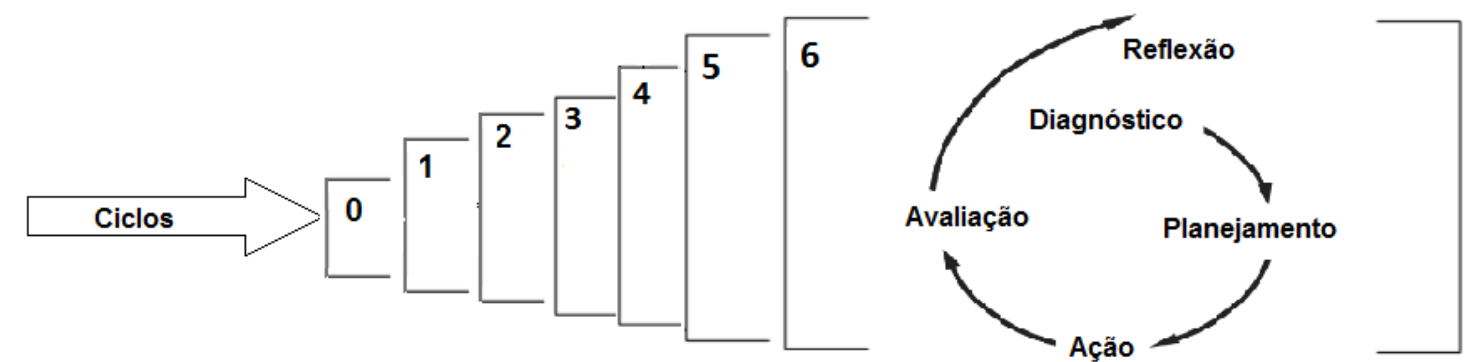

\section{Diagnóstico}

1. Compreender o problema:

- Relatórios do

Google Analytics

- Resultados de

Pesquisas (2010-

2013)

- Banco de dados

(produção)

- Reuniões semanais

(clientes, usuários,

equipe)

- Resultados de

Testes de

usabilidade

- Eventos do projeto

- Imersão da

pesquisadora e

experiência prévia

no projeto

\section{Estudo da \\ Literatura: \\ Métricas de \\ engajamento \\ - Criação e \\ sustentabilidade de \\ Comunidades de \\ prática \\ Práticas atuais de \\ gamificação \\ - Suporte teórico de \\ gamificação \\ (motivação)}

\section{Planejamento}

3. Seleção da
abordagem de
solução:
- Reuniões semanais
(clientes, usuários,
equipe)
- Resultados de
Testes de
usabilidade

4. Definir solução

- Descrição de como

implementar

- Métodos e

ferramentas para

coleta de dados

\section{Avaliação}

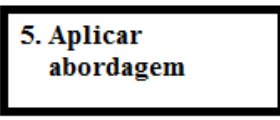

6. Monitoramento:

- Reuniões semanais

(clientes, usuários, equipe)

- Relatórios do

Google Analytics

- Banco de dados

(produção)

- Diários de campo

\section{Reflexão}

8. Analisar utilidade dos resultados

- Consolidação de resultados

- Reuniões semanais (clientes, usuários, equipe)

usabilidade

Google Analytics

- Banco de dados (produção)
9. Elicitar resultados de pesquisa

Figura 5.1: Métodos e ferramentas utilizadas em cada fase de um ciclo de pesquisa-ação.

Para monitorar os dados durante a pesquisa-ação, métodos e ferramentas de coleta de dados foram utilizados ao longo dos ciclos. A Tabela 5.1 resume os meios de coleta de dados usados nos ciclos de pesquisa-ação realizados. Os dados monitorados possibilitam comparar os resultados após as intervenções realizadas em cada ciclo. 
Tabela 5.1: Métodos e ferramentas de coleta de dados usados nos ciclos de pesquisa-ação

\begin{tabular}{|c|c|c|c|c|c|c|c|c|}
\hline $\mathbf{N}^{\circ}$ & Método de coleta de dados & $\begin{array}{l}\text { Ciclo } \\
0\end{array}$ & $\begin{array}{l}\text { Ciclo } \\
1\end{array}$ & $\begin{array}{l}\text { Ciclo } \\
2\end{array}$ & $\begin{array}{l}\text { Ciclo } \\
3\end{array}$ & $\begin{array}{l}\text { Ciclo } \\
4\end{array}$ & $\begin{array}{l}\text { Ciclo } \\
5\end{array}$ & $\begin{array}{l}\text { Ciclo } \\
6\end{array}$ \\
\hline 1 & Reuniões de desenvolvimento & $\mathrm{x}$ & $\mathrm{x}$ & $\mathrm{x}$ & $x$ & $\mathrm{x}$ & $\mathrm{x}$ & $\mathrm{x}$ \\
\hline 2 & $\begin{array}{l}\text { Reuniões entre equipe, clientes } \\
\text { e usuários }\end{array}$ & $\mathrm{x}$ & $\mathrm{x}$ & $\mathrm{x}$ & $\mathrm{x}$ & $\mathrm{x}$ & $\mathrm{x}$ & $\mathrm{x}$ \\
\hline 3 & E-mails & $\mathrm{x}$ & $\mathrm{x}$ & $\mathrm{x}$ & $\mathrm{x}$ & $\mathrm{x}$ & $\mathrm{x}$ & $\mathrm{x}$ \\
\hline 4 & Página de Facebook do projeto & $\mathrm{x}$ & $\mathrm{x}$ & $\mathrm{x}$ & $\mathrm{x}$ & $\mathrm{x}$ & $\mathrm{x}$ & $\mathrm{x}$ \\
\hline 5 & Métricas do Google Analytics & $\mathrm{x}$ & $\mathrm{x}$ & $\mathrm{x}$ & $\mathrm{x}$ & $\mathrm{x}$ & $\mathrm{x}$ & $\mathrm{x}$ \\
\hline 6 & $\begin{array}{l}\text { Resultados de pesquisas de } \\
\text { usabilidade (2010-2013) }\end{array}$ & $\mathrm{x}$ & & & & & & \\
\hline 7 & Teste de usabilidade remoto & & $\mathrm{x}$ & & & & & \\
\hline 8 & Teste de usabilidade presencial & & & & $\mathrm{x}$ & & $\mathrm{x}$ & \\
\hline 9 & $\begin{array}{l}\text { Teste-piloto (usabilidade e } \\
\text { experimento) }\end{array}$ & & & & & & & $\mathrm{x}$ \\
\hline 10 & Banco de dados de produção & $\mathrm{x}$ & $\mathrm{x}$ & $\mathrm{x}$ & $\mathrm{x}$ & $\mathrm{x}$ & $\mathrm{x}$ & $\mathrm{x}$ \\
\hline 11 & Diários de campo & & & $\mathrm{x}$ & $\mathrm{x}$ & & & \\
\hline 12 & Eventos do projeto & $\mathrm{x}$ & & $\mathrm{x}$ & $\mathrm{x}$ & $\mathrm{x}$ & $\mathrm{x}$ & $\mathrm{x}$ \\
\hline 13 & Estudo estatístico exploratório & & & & $\mathrm{x}$ & & & \\
\hline 14 & $\begin{array}{l}\text { Workshop para mecânica de } \\
\text { jogo }\end{array}$ & & & & & & $\mathrm{x}$ & \\
\hline 15 & $\begin{array}{l}\text { Reuniões no grupo de pesquisa } \\
\text { da UBC }\end{array}$ & & & & & & & $\mathrm{x}$ \\
\hline 16 & Experimentos de campo online & & & & & $\mathrm{x}$ & & $\mathrm{x}$ \\
\hline 17 & Questionário online & & & & & & & $\mathrm{x}$ \\
\hline 18 & Pesquisa correlacional pontual & & & & & & & $\mathrm{x}$ \\
\hline
\end{tabular}

A ferramenta GoogleAnalytics foi configurada para monitorar o sistema desde o seu lançamento, por esse motivo, foi utilizada para acompanhar a evolução do projeto em conjunto com as informações obtidas a partir do banco de dados do sistema em produção. Para dar suporte ao diagnóstico e monitorar métricas de engajamento ao longo de todos os ciclos da pesquisa-ação, as seguintes métricas do Google Analytics foram selecionadas: comercial, novos usuários, sessões, número de sessões por usuário, visualizações de página, páginas por sessão, média de duração da sessão e taxa de rejeição. As métricas são definidas na Tabela 5.2.

Tabela 5.2: Métricas apresentadas pelo Google Analytics para visualização da visão geral do projeto monitorado.

\begin{tabular}{|c|c|}
\hline Métrica & Definição \\
\hline Comercial & $\begin{array}{l}\text { Número de usuários que iniciaram pelo menos uma sessão durante o } \\
\text { período selecionado. }\end{array}$ \\
\hline Novos usuários & $\begin{array}{l}\text { Número de usuários que estão acessando pela primeira vez durante o } \\
\text { período selecionado. }\end{array}$ \\
\hline Sessões & $\begin{array}{l}\text { Número total de sessões dentro do intervalo de datas. Uma sessão é o } \\
\text { período em que um usuário está ativamente utilizando um website, } \\
\text { aplicativo, etc. Todos os dados de uso (exibições de tela, eventos, } \\
\text { entre outros) estão associados a uma sessão. }\end{array}$ \\
\hline Número de sessões por usuário & Número médio de sessões por usuário. \\
\hline Visualizações de página & $\begin{array}{l}\text { Número total de páginas visualizadas. Visualizações repetidas de uma } \\
\text { única página são contadas. }\end{array}$ \\
\hline Páginas/sessão & $\begin{array}{l}\text { Número médio de páginas visualizadas durante uma sessão. } \\
\text { Visualizações repetidas de uma única página são contadas. }\end{array}$ \\
\hline Média de Duração da sessão & Duração média de uma sessão. \\
\hline Taxa de rejeição & $\begin{array}{l}\text { A porcentagem de sessões de página única em que não houve interação } \\
\text { com a página. Uma sessão devolvida tem uma duração de } 0 \text { segundos. }\end{array}$ \\
\hline
\end{tabular}

As próximas seções apresentam os ciclos de pesquisa-ação realizados. Apenas as atividades 
diretamente relacionadas à pesquisa de engajamento e gamificação são descritas. Portanto, detalhes da implementação das funcionalidades foram removidos. O estudo da literatura foi descrito nos capítulos anteriores sobre comunidades de prática e colaboração aberta; motivação e engajamento; e gamificação. Em todos os ciclos, o diagnóstico e as avaliações foram realizados com base em reuniões com clientes, usuários e equipe e a análise dos relatórios do Google Analytics e do banco de dados de produção do ciclo anterior. A exceção é o ciclo 0 para o qual a análise dos relatórios e do banco de dados teve como base os anos anteriores ao início da pesquisa-ação.

\subsection{Monitoramento e exploração de pontificação com colaboração}

\subsubsection{Ciclo 0: Registro de ações de usuários}

O ciclo 0 foi realizado entre 05 de janeiro de 2015 e 14 de junho de 2015 e teve como objetivo a inserção de um registro de ações de usuários para monitoramento de métricas objetivas de engajamento. Seu principal resultado foi a compreensão de que inserções/alterações de funcionalidades, mesmo que não sejam relacionadas a elementos de colaboração ou de jogo, geram efeitos no engajamento de usuários.

\section{Diagnóstico}

De acordo com a métrica visão geral do Google Analytics, para o período entre 2011 e 2014 foram contabilizados 39.895 sessões, 29.576 usuários, 166.863 visualizações de página, com 4.18 páginas por sessão. As sessões apresentam duração média de $03 \mathrm{~m}: 16 \mathrm{~s}$, com uma taxa de rejeição de $56.79 \%$ e $74.07 \%$ de novas sessões ou novos visitantes para o período. Até a quinta página acessada pelo usuário no sistema não são observados acessos à página de login e cadastro no sistema, conforme dados da métrica fluxo de usuários.

Cruzamos esses resultados com os dados obtidos por meio do banco de dados de produção. Os dados possibilitaram visualizar a quantidade de cadastros no sistema para o período de 01 de Janeiro de 2011 a 31 de Dez de 2014 para: usuários, imagens, comentários, álbuns e interpretações de imagens. Os dados obtidos são sumarizados na Tabela 5.3.

Tabela 5.3: Dados do sistema em produção para o período entre 01 de Janeiro de 2011 a 31 de Dez de 2014 (4 anos)

\begin{tabular}{ll}
\hline Dados & Quantidade \\
\hline Usuários & 581 cadastrados \\
Imagens & 936 imagens a partir de 71 usuários \\
& 4518 imagens a partir de 2 acervos \\
Comentários & 75 comentários a partir de 25 usuários \\
Álbuns & 292 álbuns a partir de 228 usuários \\
Interpretações de imagens & 42 a partir de 20 usuários \\
\hline
\end{tabular}

Embora 29.576 usuários distintos tenham acessado o sistema, apenas 581 usuários realizaram o cadastro em um período de quatro anos. A atividade com a maior quantidade de usuários cadastrados que a utilizaram foi a criação de álbuns. A interpretação de imagens, funcionalidade-chave para os pesquisadores da área de arquitetura, apresenta apenas 42 imagens interpretadas a partir de 20 usuários.

Ao analisar as funcionalidades do sistema, foi possível notar a necessidade de incluir algumas funcionalidades básicas, ainda inexistentes no sistema. Definimos funcionalidades básicas como funcionalidades necessárias para acesso ao sistema, como o Login pelo Facebook, e para a realização das práticas em torno das quais espera-se fomentar uma comunidade de prática. Esse termo foi necessário para distinguir as funcionalidades básicas, de funcionalidades colaborativas e funcionalidades de gamificação. As funcionalidades colaborativas referem-se a funcionalidades relacionadas 
ao Modelo 3C e as funcionalidades de gamificação referem-se aos elementos de jogos. Finalmente, como parte do processo de diagnóstico, foi discutida, com os clientes e equipe, a necessidade de contratar novos membros para o desenvolvimento do sistema.

\section{Planejamento}

A Tabela 5.4 apresenta cada item do diagnóstico e a ação planejada para solucioná-lo.

Tabela 5.4: Diagnóstico e Planejamento do Ciclo 0

\begin{tabular}{ll}
\hline Item diagnosticado & Ação planejada \\
\hline Criar um ambiente para coleta e monitoramento & 1- Inserção de registro de ações de usuários para \\
de métricas de engajamento & monitorar métricas objetivas de engajamento \\
Análise dos elementos de jogo em isolamento & 2- Refatoração do código para inserção dos elementos de \\
& gamificação como componentes isolados das demais \\
& funcionalidades do sistema \\
Necessidade de incluir funcionalidades básicas & 3- Inclusão das funcionalidades básicas: acesso pelo \\
& Facebook, acesso pelo Stoa e representação em gráficos \\
& da média de interpretações das imagens \\
\hline
\end{tabular}

Além dos itens de diagnóstico, foi planejado pela equipe da FAU, um workshop para os alunos ingressantes para o dia 25 de fevereiro de 2015 e, para este fim, a funcionalidade para acesso pelo Facebook foi a atividade priorizada para ser a primeira a ser implementada.

A ação planejada "inserção de registro de ações de usuários para monitoramento de métricas objetivas de engajamento" utiliza as métricas definidas por Zichermann et al. [ZC11]. Os arquivos com o registro de ações de usuários foram planejados para serem armazenados com a extensão .log, dentro de pastas com a data do registro de ação, de modo que todos os registros de um dia a partir de usuários e visitantes ficassem reunidos na mesma pasta. Cada linha do arquivo representa um registro de ação que associa-se diretamente com uma ou mais métricas de engajamento a serem analisadas ou favorece a compreensão do fluxo de navegação do usuário com o sistema, por exemplo, acesso a quais fotos e busca realizada por meio de quais palavras. Além disso, pode-se analisar o que ocorre antes e após a inserção de uma única funcionalidade no sistema.

A ação "refatoração do código para inserção dos elementos de gamificação como componentes isolados das demais funcionalidades do sistema" foi planejada para definir uma nova estrutura de pastas para o projeto de software de modo que os elementos de gamificação, que serão implementados em ciclos futuros, ficassem separados em pastas específicas como componentes isolados, que pudessem ser inseridos ou removidos do sistema com a configuração de uma única linha de código. Dessa forma, torna-se possível a realização de experimentos para responder a QPI que podem ser configurados com ou sem a presença de um componente, mantendo o funcionamento normal das demais funcionalidades.

\section{Ação}

A nova estrutura de código do projeto a partir da ação "refatoração do código para inserção dos elementos de gamificação como componentes isolados das demais funcionalidades do sistema" apresenta uma pasta para inclusão dos componentes relacionados à gamificação, que serão implementados nos próximos ciclos. Cada diretório presente no diretório app/modules é um componente que pode ser incluído ou retirado do projeto por uma única chamada. Mais detalhes do código podem ser obtidos em:

https://github.com/NAWEB-USP/Arquigrafia-Laravel/tree/master/app/modules/gamification.

O monitoramento das ações realizadas durante o ciclo 0 foi feito por meio das métricas do Google Analytics e os dados atualizados no banco de dados de produção. As reuniões semanais com clientes, usuários e equipe, complementam o monitoramento, pois tornavam possível discutir as ações em andamento e realizar correções durante o ciclo. 


\section{Avaliação}

Para a avaliação da ação "inserção de registro de ações de usuários para monitoramento de métricas objetivas de engajamento" foi realizada a análise dos arquivos (.log) gerados. A avaliação dos arquivos foi realizada por meio da seleção de alguns arquivos e a verificação manual por meio da extração das métricas definidas por Zichermann et al. [ZC11].

A ação "refatoração do código para inserção dos elementos de gamificação como componentes isolados das demais funcionalidades do sistema" foi analisada por membros da equipe de desenvolvimento com a realização de testes. Todas as ações realizadas foram discutidas em reuniões semanais com clientes, usuários e equipe.

Os 60 dias anteriores ao início do ciclo 0 foram comparados com os 60 dias finais do ciclo 0. Este padrão será adotado em todos os ciclos, isto é, apenas os dois últimos meses de cada ciclo serão comparados com os dois últimos meses do ciclo anterior. Essa medida foi adotada porque os ciclos possuem tamanhos diferentes. Os eventos que são promovidos por membros da equipe são relevantes pois implicam em maior quantidade de usuários acessando o sistema em períodos específicos. Sendo assim, sempre que eventos ocorrerem ao longo dos ciclos, estes serão mencionados. Adicionalmente, considerando que boa parte dos usuários do Arquigrafia são estudantes de arquitetura, especialmente da FAUUSP, períodos de férias escolares e de provas também geram impactos nos acessos ao projeto.

A Figura 5.2 apresenta a comparação para a visão geral do projeto entre final do Pré-Ciclo 0 e do Ciclo 0. Embora as quantidades totais de usuários e de novos usuários tenham diminuído, todas as demais métricas tiveram resultados melhores para o final do ciclo 0. Contudo, esses efeitos não podem ser atribuídos apenas à inserção das novas funcionalidades, uma vez que é preciso considerar que os 60 dias considerados para o Pré-Ciclo 0 compreenderam 1 mês de provas finais (novembro) e um mês de férias (dezembro). No entanto, os usuários que acessaram o sistema permaneceram mais tempo, 1 min e $26 \mathrm{seg}$ a mais na sua interação, sendo esta mais profunda (3301 páginas a mais), mesmo o Ciclo 0 tendo 30 usuários a menos do que o Pré-ciclo 0. 

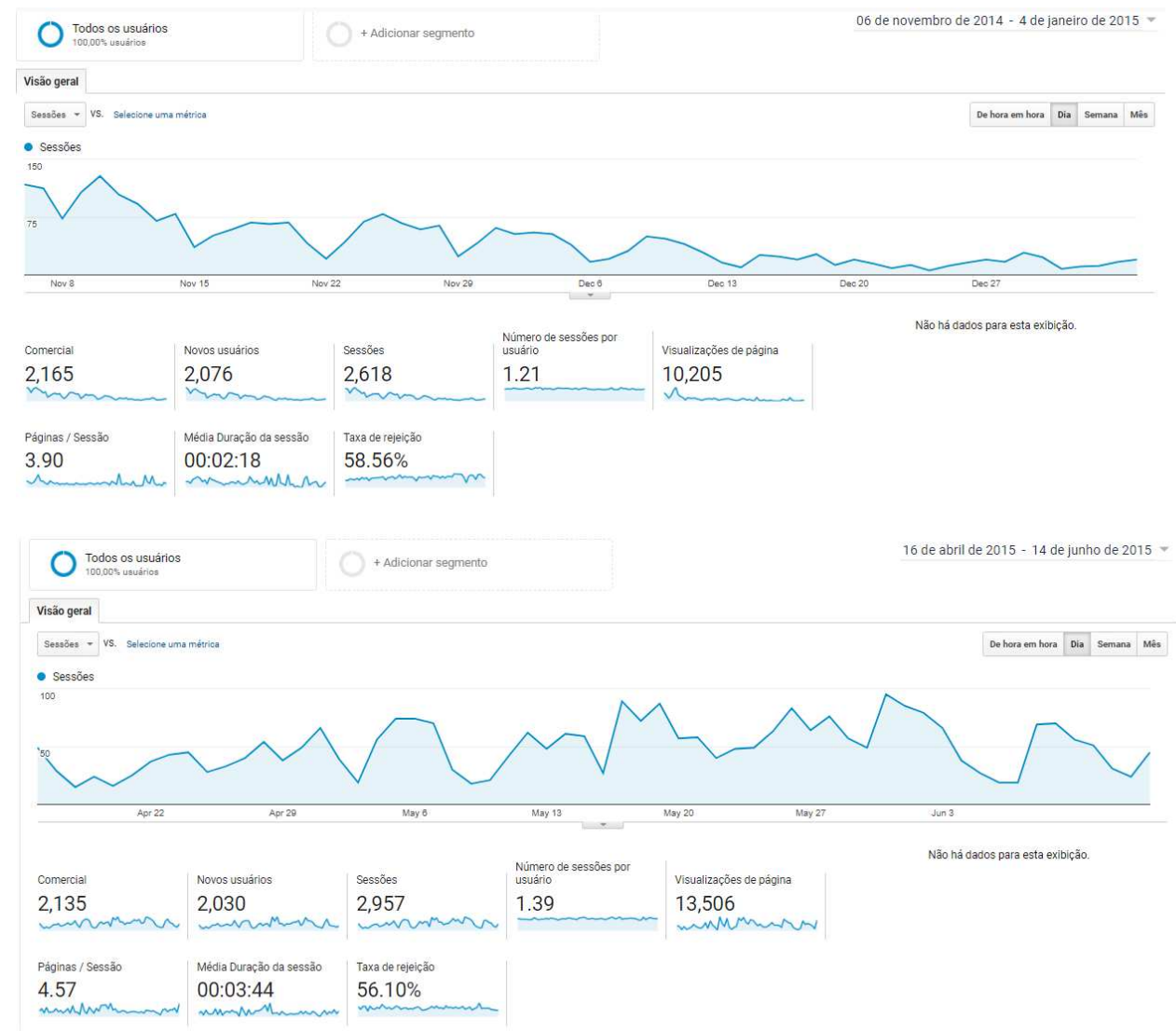

Figura 5.2: Comparação entre os 60 dias anteriores ao início do Ciclo $0(06 / 11 / 2014$ - 04/01/2015) e os 60 dias finais do Ciclo 0 (16/04/2015 - 14/06/2015) para a métrica visão geral do Google Analytics.

\section{Reflexão}

O ciclo 0 impactou especialmente na quantidade de novos usuários a se cadastrarem no sistema e na quantidade de novas interpretações de imagens. O aumento do número de novos usuários a se cadastrarem é confirmado tanto pela quantidade de novos usuários no banco de dados do sistema em produção, quanto pelo fluxo de usuários do ciclo 0, que apresenta a tela de login como umas das 5 primeiras interações do usuário com o sistema.

Para facilitar a reflexão, vamos dividi-la em pressupostos - que entendemos como importantes para iniciar uma pesquisa de monitoramento de engajamento - e aprendizados do ciclo. Para esse fim, apresentamos uma lista de pressupostos que guiaram o desenvolvimento de cada ciclo e uma lista de aprendizados do ciclo em questão. Os pressupostos foram baseados nos estudos da literatura, bem como, a partir do diagnóstico das necessidades do sistema.

Para o ciclo 0 três pressupostos guiaram a implementação: 1) Pré-requisito para avaliação de engajamento: inserção de registros de ações de usuários. Os registros de ações de usuários possibilitam o monitoramento do engajamento dos usuários, e consequentemente, a avaliação dos efeitos da gamificação sobre o engajamento para cada intervenção no sistema; 2) Priorização do desenvolvimento de funcionalidades relacionadas às práticas da comunidade antes de definir elementos de jogos. Há a necessidade de analisar as funcionalidades atuais já desenvolvidas no sistema para verificar se existem funcionalidades básicas que ainda não foram implementadas, elas devem ser priorizadas antes de definir elementos de jogos porque estão diretamente relacionadas com as práticas da comunidade ou com os meios de acesso a ela; e 3) Necessidade de melhorar a usabilidade para aumentar o engajamento dos usuários.

Os aprendizados deste ciclo foram dois: 1) necessidade de coletar/monitorar continuamente dados qualitativos da interação e não apenas dados quantitativos. $O$ objetivo é conseguir explicar melhor o que ocorre em cada momento de mudança das métricas quantitati- 
vas; e 2) entendimento de que inserções/alterações de funcionalidades geram efeitos no engajamento de usuários, mesmo que as funcionalidades não sejam diretamente relacionadas à colaboração ou ao jogo, e, inclusive, sem a divulgação das mudanças aos usuários. Esse comportamento pode ser explicado pela curiosidade dos antigos usuários em conhecer o que há de novo no sistema. No entanto, ainda não é possível saber se esse comportamento é sustentável e, se sim, por quanto tempo.

\subsubsection{Ciclo 1: Implementação de awareness e prototipação de pontificação}

O ciclo 1 foi realizado entre 15 de junho de 2015 e 20 de agosto de 2015 e teve como objetivo a inserção do elemento de colaboração Notificação e a definição do protótipo de elemento de jogo Quadro de liderança. Seu principal resultado foi a compreensão da necessidade de analisar as ações de usuários que acessaram a funcionalidade para a qual monitoram-se métricas de engajamento.

\section{Diagnóstico}

O registro de ações de usuários foi um primeiro passo para coletar as métricas de engajamento. Porém, não é possível analisar manualmente todos os registros de ações de cada usuário que acessa o sistema. Além disso, para realizar a análise estatística das métricas de engajamento seria necessário criar scripts para extração das métricas por funcionalidade e grupo de usuários que a acessaram. Como o enfoque da pesquisa é sobre os elementos de colaboração e de jogos, então dois caminhos eram possíveis nesse momento. Um caminho era primeiro criar o ambiente para extração das métricas a partir dos arquivos de log para análise estatística com a ferramenta R. O segundo caminho era o de priorizar o desenvolvimento dos elementos de colaboração e de jogos para ter mais tempo de monitoramento da interação dos usuários com eles. Além disso, ainda existiam funcionalidades básicas que não tinham sido implementadas e outras que foram levantadas a partir das reuniões entre equipe, usuários e clientes.

Os resultados obtidos com a funcionalidade de representação em gráficos da média de interpretações das imagens, no ciclo 0, indicam que houve uma mudança de comportamento dos usuários ao fornecermos o feedback sobre como sua interpretação relaciona-se com as demais. Por isso, para buscarmos o engajamento com as funcionalidades que não sofreram mudanças relevantes a partir do ciclo 0, o mesmo raciocínio pode ser aplicado. Isto é, fornecer feedback sobre como as ações de cada usuário, como realizar um comentário, afetam os outros usuários do sistema.

\section{Planejamento}

Dentre os dois caminhos possíveis definidos no diagnóstico, a opção escolhida para aplicação neste ciclo foi a segunda por meio de reuniões com a equipe. A criação dos scripts para extração automatizada das métricas, para posterior análise com a ferramenta $\mathrm{R}$, dependeria de um tempo de estudo de testes estatísticos, que poderia ocorrer enquanto os usuários já estivessem interagindo com os elementos de jogos, de modo a ter mais dados para análise. Um teste de usabilidade remoto foi programado para o fim do semestre e teve como objetivo avaliar uma primeira versão atualizada do projeto antes da inserção de elementos de jogos ou novos elementos de colaboração. Em todos os ciclos, foram realizados testes de funcionalidade, como testes unitários e testes de integração, como parte da tarefa de desenvolvimento e por esse motivo não são descritos como tarefas específicas do planejamento.

A Tabela 5.5 apresenta cada item do diagnóstico do ciclo 1 e a ação planejada para solucioná-lo. 
Tabela 5.5: Diagnóstico e Planejamento do Ciclo 1

\begin{tabular}{ll}
\hline Item diagnosticado & Ação planejada \\
\hline $\begin{array}{l}\text { Necessidade de incluir funcionalidades } \\
\text { colaborativas e fornecer feedback para ações dos }\end{array}$ & 1- Implementação da funcionalidade de notificação \\
usuários & $\begin{array}{l}\text { 2- Protótipo de alta fidelidade do elemento de jogo } \\
\text { Priorizar o desenvolvimento dos elementos de } \\
\text { colaboração e de jogos }\end{array}$ \\
$\begin{array}{ll}\text { Necessidade de incluir funcionalidades básicas } \\
\text { 3- Implementação das funcionalidades: cadastro de } \\
\text { usuário com envio de código por email e Área }\end{array}$ \\
$\begin{array}{ll}\text { Anstitucional } \\
\text { de elementos de jogo ou colaboração }\end{array}$ \\
\hline
\end{tabular}

As notificações foram planejadas para que: (1) No canto superior direito da Home, fosse inserido um ícone para visualizar todas as notificações/atualizações do usuário; (2) Ao passar o mouse sobre o ícone o usuário deveria visualizar o texto: "X notificações", onde X é a quantidade de notificações que o usuário ainda não teria verificado; (3) Ao clicar no ícone de Notificações, apresenta-se um popup no canto superior direito da Home, com as últimas atualizações. Neste pop-up ao fim das cinco primeiras atualizações existiria um link: "Ver todas"; (4) Ao clicar no link "Ver todas", o usuário pode ser encaminhado para a página de Notificações do seu perfil organizado por datas. As possíveis notificações podem ser relacionadas ao usuário logado para os seguintes eventos: comentários de outros usuários em fotos ou comentários inseridos pelo usuário logado e usuários que começaram a segui-lo.

O quadro de liderança foi planejado para retornar uma lista dos usuários com o maior número de imagens compartilhadas no sistema (upload de imagens) e o maior número de interpretações de imagens. A lista seria apresentada com a opção de filtrar resultados por uploads ou por interpretações de imagens. Em ambos os casos, a ordem seria do maior número para o menor. O usuário logado também poderia visualizar a sua posição na lista.

A área institucional foi definida para acessos de estagiários e funcionários de acervos institucionais como a Biblioteca da FAUUSP e o acervo Quapá; e o cadastro de usuário com envio de código por e-mail foi necessário pela imensa quantidade de contas criadas com endereços de e-mail inválidos.

\section{Ação}

Ao colocar uma primeira versão em produção da funcionalidade de notificação, foi possível perceber que muitas das notificações que estavam sendo exibidas poderiam ser agrupadas para não ter sobrecarga de informação. A identificação dessa melhoria foi rápida porque estava ocorrendo a catalogação de imagens de acervos por estagiários do projeto atuando nessa frente de trabalho. Dessa forma, dezenas de imagens eram catalogadas por dia e dezenas de notificações eram geradas. Esse comportamento, trouxe como consequência a atualização da funcionalidade de notificação ainda neste ciclo. A notificação passou a agrupar objetos compartilhados por usuário no sistema. Por exemplo, se dez usuários comentassem um único conteúdo compartilhado por um usuário A no sistema, na primeira versão da funcionalidade, o usuário A receberia dez notificações diferentes, e na segunda versão apenas uma notificação informando que dez usuários comentaram o conteúdo específico.

Em discussões com a equipe durante as reuniões semanais, foi decidido que o teste de usabilidade teria como enfoque apenas as funcionalidades básicas, sem os novos elementos de colaboração, que no momento, eram representados pela notificação. Sendo assim, removemos a funcionalidade de notificação para realizar o teste sem a entrada de nenhum elemento novo de colaboração ou de jogo. O período do teste de usabilidade remoto foi entre 29 de junho e 14 de julho. O teste consistiu em quatro tarefas relacionadas às funcionalidades recém atualizadas, Login e Avaliação de imagens, e às duas que em reunião decidiu-se que seriam importantes de serem atualizadas: Upload de imagem 
e Busca. O protótipo da funcionalidade de quadro de liderança foi implementado e disponibilizado para análise da equipe, mas não foi inserido no sistema em produção, para manter o isolamento do teste de usabilidade apenas para funcionalidades básicas. O monitoramento das ações realizadas durante o ciclo 1 foi realizado conforme o ciclo 0.

\section{Avaliação}

A aprovação da funcionalidade de notificação e do quadro de liderança foi realizada por meio de reuniões entre os membros da equipe de desenvolvimento, clientes e usuários do projeto, nas quais cada funcionalidade é discutida e avaliada pelos presentes.

Resumidamente, os testes de usabilidade resultaram na participação de 15 usuários novatos e 5 usuários antigos, totalizando 20 participantes do teste. 95\% dos usuários realizaram a tarefa de login com sucesso, sendo que os que não conseguiram realizá-la foi porque não lembravam a senha. Para a avaliação de imagens, 100\% dos usuários a realizaram com sucesso. 90\% dos usuários conseguiram realizar a busca corretamente; e apenas $80 \%$ dos usuários conseguiram realizar o upload pelo fluxo esperado. Priorizamos a correção da funcionalidade de login, uma vez que esta ainda não possuía a opção de "Esqueceu a senha", a qual foi implementada e disponibilizada em produção ainda neste ciclo.

Reuniões foram necessárias com todas as frentes de trabalho do Arquigrafia, especialmente da ECA-USP, para definirmos os campos necessários para catalogação de imagens de acordo com as necessidades de acervos institucionais, antes de alterarmos a funcionalidade de upload de imagem. As respostas dos participantes às questões abertas ajudaram-nos a filtrar melhor os campos para avaliação de imagens e entender futuras explorações com essa funcionalidade, bem como a entender a imagem que os participantes tinham do Arquigrafia. A Tabela 5.6 apresenta os resultados para a questão: Do que se trata este sistema?

Tabela 5.6: Respostas de 20 participantes à questão: Do que se trata este sistema?

\begin{tabular}{ll}
\hline Participante & Resposta \\
\hline 1 & Fotografias de arquiteturas históricas e contemporâneas passíveis de uso público. \\
2 & imagens de arquitetura \\
3 & de um banco de dados de fotos de arquitetura \\
4 & Sistema de partilha de imagens de arquitetura \\
5 & catálogo de imagens de arquitetura. \\
6 & Uma plataforma ou banco de dados contendo fotos de arquitetura. \\
7 & De arquivamento de imagens de arquitetura. \\
8 & Trata-se de um site de armazenamento de fotografias de projetos de arquitetura. \\
9 & ejemplos de architectura en general en brasil \\
10 & Na verdade eu já sabia, mas eu não lembrava e é sobre fotos de arquitetura, \\
11 & urbanismo e outros devidamente georeferenciadas. \\
12 & Imagens de arquitetura. \\
13 & Mostrar imagens arquitetônicas referenciais para que todos tenham acesso a tal \\
14 & De um banco de dados sobre arquitetura \\
15 & Fotos de edifícios \\
16 & De um acervo de fotos de obras arquitetônicas \\
17 & se trata de um sistema de armazenamento de imagens sobre arquitetura doados ao \\
18 & acervo arquigrafia. parte dessas imagens faz parte do acervo da fauusp. \\
19 & De um ambiente colaborativo de imagens de arquitetura \\
20 & propõe se explorar imagens de arquitetura \\
& Acervo de fotografia de arquitetura no qual é possível me cadastrar e contribuir com \\
& as minhas próprias fotos. \\
& De imagens relacionadas à arquitetura \\
\end{tabular}

De modo geral, o entendimento que os usuários tinham do Arquigrafia era o de que tratava-se de um banco de dados de imagens de arquitetura. Apenas três usuários definiram o sistema conforme clientes e equipe esperam que ele seja reconhecido (sistema de partilha de imagens de arquitetura, 
ambiente colaborativo de imagens de arquitetura e propõe-se explorar imagens de arquitetura). Esses resultados reforçam o porquê da colaboração, com reflexões e informações sobre arquitetura, ser tão difícil no Arquigrafia.

Os dois últimos meses do ciclo 1 foram comparados com os dois últimos meses do ciclo 0 . A Figura 5.3 apresenta esta comparação para a visão geral do Google Analytics. As métricas comercial, novos usuários, sessões e número de sessões por usuário reduziram do final do ciclo 0 para o final do ciclo 1 e as métricas visualizações de página, páginas/sessão, média de duração da sessão e taxa de rejeição melhoraram. As métricas que sofrem impacto direto a partir da quantidade de usuários - comercial, novos usuários e número de sessões - foram menores, enquanto que as demais métricas, relacionadas com a profundidade da interação, foram melhores, a exceção foi a métrica sessões. Embora esta tenha sido menor, ela foi acompanhada de um aumento de 1 min e 12 segundos de duração por sessão de usuário, indicando que os usuários passaram mais tempo em cada sessão em vez de realizar mais sessões por interação, o que resultou em uma queda na taxa de rejeição de aproximadamente $7 \%$ de um ciclo para o outro. Esta queda significa que embora o final do ciclo 1 tenha tido menos usuários, eles permaneceram mais tempo no sistema do que os usuários do ciclo 0 .

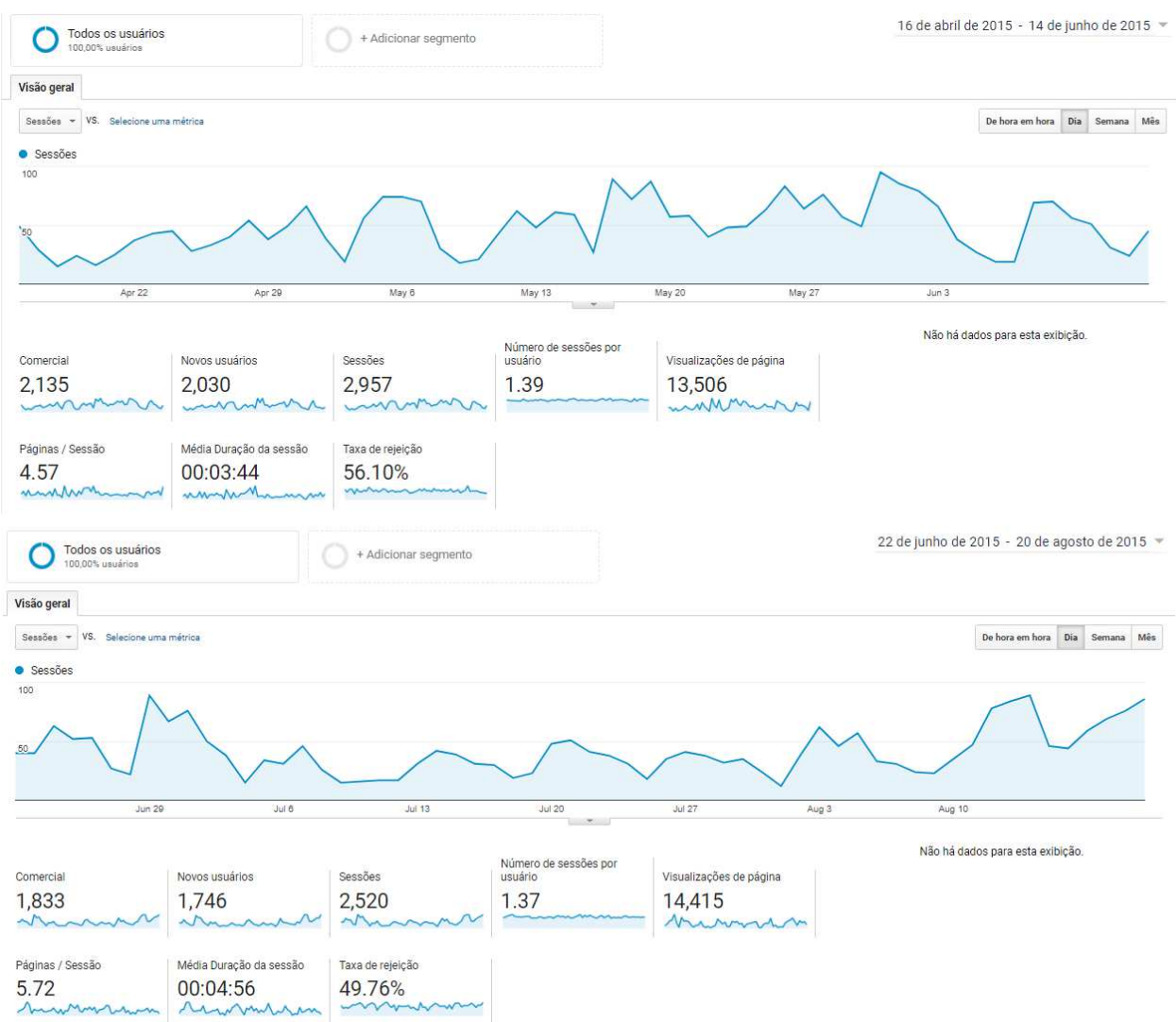

Figura 5.3: Comparação entre os 60 dias finais do ciclo 0 (16/04/2015 - 14/06/2015) e do Ciclo 1 (22/06/2015 - 20/08/2015) para a métrica visão geral do Google Analytics.

Em 20 de julho de 2015 ocorreu o lançamento de uma reportagem sobre o Arquigrafia na Revista de Fotografia do Instituto Moreira Salles ${ }^{1}$. Contudo, não visualizamos um aumento da quantidade de usuários neste ciclo. Os efeitos da publicação podem demorar a surgir, dado que trata-se de um mês de férias para uma parte significativa dos usuários do Arquigrafia: estudantes e professores de arquitetura. Este também pode ser o motivo para a menor quantidade de usuários no final do ciclo 1.

\footnotetext{
${ }^{1}$ A reportagem completa pode ser encontrada neste link: https://revistazum.com.br/radar/arquigrafia/
} 


\section{Reflexão}

A visão geral do Google Analytics para o período em que a notificação foi inserida no sistema até o fim do ciclo apresenta uma mudança positiva, porém discreta, no engajamento após a inserção da funcionalidade de notificação, especialmente no que diz respeito à duração das sessões e à taxa de rejeição. Contudo, uma análise específica sobre as ações dos usuários que acessaram a notificação poderia definir melhor a utilidade da funcionalidade no que diz respeito ao engajamento. A utilidade do elemento de jogo quadro de liderança só poderá ser analisada quando a funcionalidade for disponibilizada em produção. Nesse momento, a avaliação foi feita com clientes e usuários sobre o protótipo apresentado em reuniões semanais.

Dentre as maiores críticas à análise de engajamento a partir da inserção de gamificação, esteve o não-isolamento do efeito de cada elemento, segundo a revisão sistemática de Seaborn e Fels [SF15]. Portanto, o pressuposto deste ciclo foi baseado no entendimento de que para realizar análises dos efeitos de elementos de jogo ou de colaboração é necessário inseri-los isoladamente no sistema, de modo que a análise de métricas de engajamento possa ser realizada sobre apenas uma intervenção ou uma nova funcionalidade durante um período.

O aprendizado deste ciclo foi a necessidade de analisar o fluxo de ações de usuários que acessaram as funcionalidades cujas métricas de engajamento estão sob análise. Esta necessidade surgiu a partir da inserção da funcionalidade de notificação, que não diz respeito à execução de uma atividade específica de colaboração ou de consumo de dados de imagens de arquitetura. Entretanto, o acesso à notificação pode direcionar o usuário a essas atividades como consequência.

\subsubsection{Ciclo 2: Implementação de elementos de colaboração e de pontificação}

O ciclo 2 foi realizado entre 21 de agosto de 2015 e 23 de dezembro de 2015 e teve como objetivo a inserção de elementos de colaboração e de jogos, para os últimos especificamente pontificação. Seus principais resultados foram a verificação da importância do balanceamento adequado para a dificuldade de mecânica de jogo e a importância de apresentar as "regras do jogo" para informar ao usuário como alcançar objetivos específicos.

\section{Diagnóstico}

Seguindo o raciocínio aplicado ao ciclo 1, mantemos a priorização de implementar primeiro as funcionalidades para depois implementar os scripts para análise estatística das métricas objetivas de engajamento. O objetivo do ciclo 2 é avaliar a entrada de elementos de colaboração ainda ausentes no sistema e na sequência, os elementos de jogo mais descritos na prática de gamificação (PBLs), ou pontificação, serão disponibilizados. O problema ainda é o de aumentar o engajamento com funcionalidades diretamente associadas à colaboração com dados e informações sobre arquitetura e urbanismo, como upload de imagens e comentários. Portanto, os problemas de usabilidade levantados pelos usuários para essas funcionalidades foram priorizados neste ciclo. Elementos de colaboração e de jogos foram definidos para entrada em momentos distintos no sistema em produção para análise em isolamento de seus efeitos sobre as métricas de engajamento.

\section{Planejamento}

A Tabela 5.7 apresenta cada item do diagnóstico do ciclo 2 e a ação planejada para solucioná-lo. 
Tabela 5.7: Diagnóstico e Planejamento do Ciclo 2

\begin{tabular}{ll}
\hline Item diagnosticado & Ação planejada \\
\hline Entrada de elementos de colaboração & $\begin{array}{l}\text { 1- Implementação das funcionalidades Curtir e Notícias } \\
\text { Entrada de elementos de pontificação }\end{array}$ \\
$\begin{array}{l}\text { 2- Entrada do quadro de liderança e Implementação de pontos } \\
\text { Correção de problemas de usabilidade }\end{array}$ & $\begin{array}{l}\text { 3- Correção das funcionalidades busca e acesso ao upload de } \\
\text { imagens }\end{array}$ \\
\hline
\end{tabular}

A funcionalidade Curtir foi definida para relacionar-se com a funcionalidade de notícias e de distintivos. Pensamos em associar os distintivos à quantidade de likes que o usuário alcançar para uma imagem. Dessa forma, um usuário recebe um distintivo de acordo com a quantidade de curtidas que ele receber para uma imagem compartilhada. O valor inicial de 5 curtidas foi definido para receber um distintivo, reconhecendo que esse usuário teve uma imagem que foi bem avaliada por 5 outros usuários. Portanto, a quantidade de likes, representa os pontos obtidos para receber um distintivo.

Ao mesmo tempo, o usuário que compartilhou a imagem, receberia uma notificação, quando um usuário curtisse a sua imagem. Quando o número de cinco curtidas é alcançado, o usuário recebe uma notificação de que ganhou um distintivo que o leva para uma página descrevendo o porquê de receber essa recompensa. O distintivo é um "bem" que o usuário acumula, portanto em seu perfil a partir desse momento, sempre será exibido. Todos os usuários que seguem este usuário receberão como uma notícia, a informação de que ele recebeu um distintivo por cinco curtidas em uma imagem. Desse modo, estão diretamente relacionadas as funcionalidades curtir, notificações, notícias e distintivos. Adicionalmente, os usuários que tiverem o maior número de curtidas em uma imagem ou comentário em uma semana, ganham um distintivo especial de "Destaque da semana" que é apresentado a todos os membros do projeto.

A funcionalidade de notícias também será responsável por exibir todas as novas imagens de acervos para todos os usuários. A funcionalidade de colaboração, já existente no sistema, de seguir usuários, associa-se às notícias. Uma vez que para todos os usuários que o usuário logado segue, serão divulgadas as suas ações no sistema: comentários, novas imagens, novas interpretações de imagens, novos álbuns, curtidas, distintivos recebidos. Para o quadro de liderança, foi mantido o filtro por uploads de imagens e interpretações de imagens, com algumas correções de design.

\section{Ação}

Neste ciclo iniciou-se o estudo com diários de campo. O estudo foi realizado com quatro estagiárias do projeto na área de catalogação de imagens dos acervos da biblioteca da FAU-USP. As participantes pertencem ao perfil típico de usuário do Arquigrafia: estudantes de arquitetura e urbanismo. O objetivo com o estudo foi manter um monitoramento, ainda que em uma escala pequena, mas que tornasse possível a avaliação de dados qualitativos da experiência de interação com o sistema e de maneira contínua. O diários escritos para o ciclo 2 compreendem o período entre 27 de agosto e 18 de dezembro de 2015. Além dos diários, o monitoramento das ações realizadas durante o ciclo 2 também foi feito como nos ciclos anteriores. Adicionalmente, neste ciclo foram realizadas atualizações na apresentação do painel de imagens da Home, uma vez que a funcionalidade estava demorando para carregar as imagens, o que poderia gerar a desistência de continuar a utilizar o sistema por novos usuários.

\section{Avaliação}

O enfoque da descrição dos diários de campo neste ciclo foi sobre as funcionalidades colaborativas que foram inseridas e atualizadas enquanto os alunos participavam do estudo. O contato com os elementos de jogos não foram relatados nos diários. Para a funcionalidade de notificação foram identificados os seguintes diários: 
- Usuário1: "Acessei o Arquigrafia para navegação no site sem intenção específica e ao fazer login, na parte superior, havia uma notificação de novos seguidores. Fiquei feliz e achei uma boa maneira de reforçar o caráter de rede social do Arquigrafia. Isso também me incentivou a postar novas imagens no sistema".

- Usuário2: "Amei receber a notificação de que tinha um novo usuário me seguindo. Fiquei muito feliz de subir uma imagem e ver as novas mudanças no upload da imagem. A especificação da data ficou dinâmica e clara".

- Usuário3: "Sentimento durante o uso: Expectativa de ver como será a experiência. Motivo de entrar no sistema: Vontade de colocar mais fotos no Arquigrafia Resultado: ÍCONES Fiquei curiosa para ver o que os icones significavam. Vi que no icone do Mundo tinha uma mensagem (Novo seguidor). Pensei: O que será isso???? Segui mais pessoas, gostei de interagir neste aspecto".

Para a funcionalidade Curtir foram identificados os seguintes diários:

- Usuário1: "Entrei no sistema para navegar sem propósito específico e ao clicar em uma imagem fiquei surpresa de ver que agora existe o botão 'curtir'. Acho que este artifício irá melhorar a experiência do usuário no Arquigrafia".

- Usuário2: "Fiquei imensamente feliz de hoje subir minha primeira imagem através do Acervo da Biblioteca da FAUUSP, também fiquei em êxtase ao ver que já é possivel curtir uma imagem".

Para a funcionalidade Notícias foi identificado o seguinte diário:

- Usuário1: "Ao fazer login institucional no usuário Acervo da Biblioteca FAUUSP notei que havia mudanças na página, com a adição de notícias. Esta parte pareceu interessante porém meio confusa, talvez pelo fato das informaçôes escritas estarem sobre as imagens. Também dá a impressão de que houve um carregamento incompleto das notícias devido à falta de dois retângulos no canto inferior direito. Apesar disso, achei uma boa atualização, uma vez que ela reforça o sentido de rede social."

De modo geral, os diários relataram comentários positivos sobre as funcionalidades notificação, curtir e notícias. Sentimentos de curiosidade, surpresa e felicidade foram relatados pelos usuários ao visualizarem pela primeira vez as novas funcionalidades colaborativas. Um dos usuários relatou que a notificação de novos seguidores o incentivou a postar novas imagens. Contudo, alguns problemas foram relatados para a funcionalidade de notícias e durante a reunião semanal, correções foram propostas para resolvê-los.

Os sentimentos positivos descritos nos diários de campo, indicam o quanto as participantes estavam envolvidas previamente com o sistema. São, portanto, usuárias motivadas a utilizá-lo, seja por motivações intrínsecas - interesse sobre imagens de arquitetura e urbanismo para seus estudos, trabalhos e hobbies -, bem como, por motivações extrínsecas - todas recebiam bolsas de estudo para trabalhar no projeto Arquigrafia. Sendo assim, sabemos que parte desse entusiamo é proveniente de motivações anteriores ao acesso do sistema, mas de todo modo, indicam que as novas funcionalidades atenderam em parte suas expectativas, pois seus relatos não indicam frustração durante o uso.

A Figura 5.4 apresenta a comparação entre os 60 dias finais do ciclo 1 e do ciclo 2 para a visão geral do Google Analytics. Com exceção da métrica taxa de rejeição, que teve um aumento de aproximadamente $3 \%$, todas as demais melhoraram. Contudo, um evento externo foi realizado nesse período: o $3^{\circ}$ Seminário Internacional "Representar 2015". A atividade relacionada ao Arquigrafia foi executada entre 17 e 24 de novembro de $2015^{2}$.

\footnotetext{
${ }^{2}$ Mais informações sobre o evento podem ser encontradas em http://representar2015.blogspot.com/p/programa_ 16.html
} 
Entendemos que a divulgação do evento teve um papel importante no aumento de 322 usuários entre os dois ciclos (de 1833 para 2155), o que pode explicar também o aumento na taxa de rejeição: mais usuários acessando o sistema vindos a partir da chamada para o evento. O evento também foi divulgado na comunidade do Facebook do projeto e compartilhado com a rede de amigos dos seguidores, que podem não ser usuários típicos do sistema e sendo assim, não se interessaram pela exploração do sistema.

Contudo, para os usuários que interagiram com o Arquigrafia, a média de duração da sessão aumentou aproximadamente 1 min por usuário (de 04:56 para 06:00), e teve aproximadamente 1 página a mais visualizada/sessão de usuário (de 5.72 para 6.61 páginas/sessão), resultando em um aumento de 6154 páginas a mais visualizadas entre um ciclo e outro (de 14.415 para 20.569 páginas). Portanto, embora seja um movimento lento, os ciclos 0 a 2 apresentaram um crescimento do engajamento de usuários; o ciclo 0 em relação ao pré-ciclo 0 , o ciclo 1 em relação ao ciclo 0 ; e o ciclo 2 em relação ao ciclo 1 , o que configura um crescimento continuado desde que as mudanças iniciaram a ser disponibilizadas no sistema. No entanto, é importante ressaltar a influência do evento sobre a entrada de novos usuários no ciclo 2.

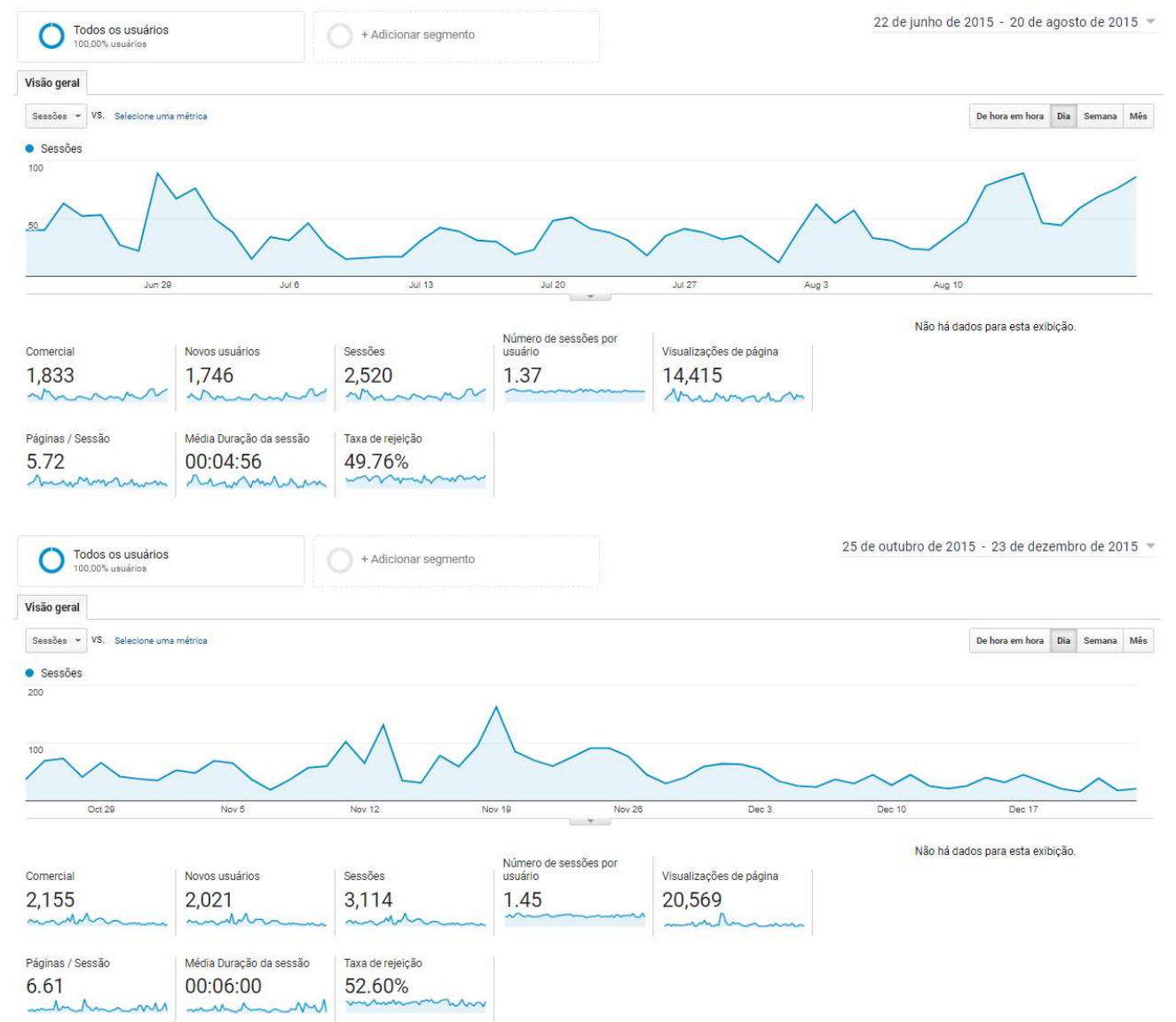

Figura 5.4: Comparação entre os 60 dias finais do ciclo 1 (22/06/2015 - 20/08/2015) e do ciclo 2 (25/10/2015 - 23/12/2015) para a visão geral do Google Analytics.

\section{Reflexão}

As funcionalidades de colaboração foram analisadas por meio dos diários de campo, nos quais os usuários apresentaram emoções positivas aos primeiros contatos com as funcionalidades curtir, notificações e notícias. Além disso, 301 notificações foram registradas de 25 de agosto de 2015 até o fim do ciclo 2, referentes a usuários que passaram a seguir outros (120 notificações), que curtiram uma imagem (173), que curtiram um comentário (6) e de 2 distintivos obtidos por 2 usuários. É importante ressaltar aqui que a quantidade de notificações indica quantas foram geradas a partir de uma atividade realizada por um usuário que é seguido por outros, porém esse comportamento não 
implica que todos os seguidores acessaram a notificação, apenas indica que passou a estar disponível para um seguidor essa notificação.

Para a funcionalidade Curtir, foram contabilizadas 175 curtidas durante o ciclo 2, a partir de 29 usuários, mesmo sendo o ciclo em que foi lançada a funcionalidade. Nenhuma divulgação foi necessária para que os usuários pudessem acessá-la. Contudo, o mesmo não ocorreu com a funcionalidade de distintivos, com apenas 2 distintivos para o ciclo 2. A funcionalidade de notícias mantém apenas as notícias mais atuais, por isso não pode ser monitorada via banco de dados.

Entendemos que a quantidade ínfima de acessos aos distintivos deve-se à dificuldade para alcançar pontos que resultassem nessa recompensa. A preocupação foi maior em recompensar a qualidade das imagens, do que facilitar o ganho de distintivos. Além disso, a regra do jogo não foi explicitamente apresentada aos usuários. Apenas após ganhar um distintivo o usuário tornava-se ciente da importância de ter compartilhado uma imagem de qualidade com o Arquigrafia. Portanto, entendemos que esses dois problemas trouxeram como consequência a não-visibilidade deste elemento de jogo.

Acompanhamos a atualização do quadro de liderança e uma usuária foi subindo no ranking para upload de imagens, até chegar ao primeiro lugar. Foi feito um convite a ela para participar da nossa reunião semanal e perguntamos se o quadro de liderança a influenciou a realizar o upload de imagens e ela disse que sim, porque tem muitas imagens de arquiteturas e viu que poderia chegar ao primeiro lugar, por isso "subiu" as imagens até chegar ao topo do ranking. Também é importante ressaltar que ela prontamente atendeu ao nosso convite para conversarmos sobre o sistema e participar de uma reunião conosco, mostrando seu interesse pelo projeto. A usuária é aluna de arquitetura em uma faculdade privada de São Paulo.

Foram dois pressupostos para o ciclo 2:

1. necessidade de funcionalidades típicas de sistemas colaborativos serem disponibilizadas, de modo que existam meios para se realizar a colaboração, ou seja, funcionalidades relacionadas aos aspectos de comunicação, cooperação e coordenação do Modelo 3C, conforme a Seção 2.1. Esse fato é confirmado pelos diários de campo, pelo aumento na quantidade de comentários e a quantidade de "curtidas" e notificações geradas, uma vez que os elementos colaborativos - notificações e curtir - foram inseridos antes dos elementos de jogo.

2. necessidade de apresentar o feedback das ações aos usuários como meio de aumentar o engajamento. No Ciclo 0 , o feedback sobre a interpretação de imagens possibilitou um aumento significativo do número de interpretações e no ciclo 1 , as notificações também influenciaram o engajamento de usuários, embora de forma mais modesta. No ciclo 2, ao informar o usuário sobre quem passou a segui-lo, ou quem curtiu sua imagem, existe um movimento para também seguir os seguidores ou de curtir conteúdos postados por eles, conforme relato do diário de campo.

Também dois aprendizados foram observados neste ciclo:

1. balanceamento adequado da dificuldade da mecânica de jogo. Entendemos que para o caso do Arquigrafia, ganhar um distintivo por cinco curtidas em uma imagem é algo muito difícil de ser alcançado por um usuário. Além disso, é uma recompensa dependente do usuário possuir seguidores, não sendo uma tarefa que ele pode alcançar de forma independente, isto é, com a autonomia, que é tão importante na motivação intrínseca dos usuários. Com o quadro de liderança ocorre o contrário, o usuário precisa subir imagens e a quantidade de imagens determina a posição do usuário no ranking. No entanto, precisamos confiar que os usuários vão subir imagens relevantes para o tema tratado no sistema. Em particular, a análise das imagens que foram inseridas pelos usuários que estão entre os dez primeiros no quadro de liderança indica que nenhum deles subiu imagens inadequadas.

2. necessidade de apresentar as "regras do jogo" para alcançar objetivos específicos. No caso do distintivo seria melhor não inseri-lo a fazê-lo sem a devida apresentação das regras 
para alcançá-lo. O racional havia sido: além da recompensa do distintivo queremos apresentar uma surpresa positiva ao usuário, indicando que existe uma comunidade acompanhando o conteúdo de qualidade que está sendo compartilhado. No entanto, a surpresa pode nunca ser visualizada, uma vez que o usuário e seus seguidores não sabem que esse "presente" estava disponível.

\subsubsection{Ciclo 3: Implementação de scripts para análise de métricas objetivas}

O ciclo 3 foi realizado entre 04 de janeiro de 2016 e 31 de agosto de 2016 e teve como objetivo a definição de scripts para a análise de métricas objetivas de engajamento. Seus principais resultados foram a compreensão de que um período de inatividade da comunidade pode interferir no engajamento dos usuários e há a necessidade de criar um ambiente automatizado para monitoramento e cálculo das métricas de engajamento.

No fim do ciclo 2, as duas bolsas de desenvolvimento e o contrato com os dois designers finalizaram. Ao longo do ciclo 3, um novo projeto foi escrito e um aluno recém-formado em Análise e desenvolvimento de sistemas foi contratado no fim do ciclo. Portanto, o ciclo 3 iniciou com três e terminou com quatro membros para a equipe de desenvolvimento.

Lembrando que a equipe além de pequena, muda constantemente e é formada por alunos de graduação em sua maioria. Portanto, as atividades são desenvolvidas por alunos que estão aprendendo durante o desenvolvimento do projeto.

\section{Diagnóstico}

Conforme planejado no ciclo 1, seria necessário fornecer meios de extrair as métricas objetivas de engajamento a partir dos registros de ações de usuários, após implementar a primeira versão de funcionalidades colaborativas e de jogos, o que ocorreu no ciclo anterior. Sendo assim, já temos dados suficientes para análise que ainda não foram avaliados estatisticamente, dada a prioridade de disponibilizar os elementos para interação dos usuários.

O código do projeto foi refatorado no ciclo 0 para possibilitar que os novos elementos de colaboração e de jogos fossem inseridos como componentes no sistema, de modo a serem removidos ou inseridos em qualquer momento. Porém, as funcionalidades já existentes foram mantidas como haviam sido implementadas e existia a necessidade de transformar todas as funcionalidades do projeto em componentes, mantendo apenas um núcleo que seria denominado de +Grafia. $\mathrm{O}+$ Grafia será um novo projeto baseado no Arquigrafia que possibilitará o compartilhamento de imagens a partir de quaisquer áreas. Adicionalmente, um tema recorrente nas reuniões semanais e em eventos sobre o projeto, é a necessidade de disponibilizar um aplicativo do Arquigrafia que tornasse possível o compartilhamento de imagens de arquitetura diretamente do local onde o usuário se encontra.

\section{Planejamento}

A Tabela 5.8 apresenta cada item do diagnóstico do ciclo 3 e a ação planejada para solucionálo. A seleção da abordagem de solução foi realizada por meio de reuniões entre equipe, clientes e usuários.

Tabela 5.8: Diagnóstico e Planejamento do Ciclo 3

\begin{tabular}{|c|c|}
\hline Item diagnosticado & Ação planejada \\
\hline $\begin{array}{l}\text { Extrair métricas objetivas de engajamento a } \\
\text { partir dos registros de ações de usuários }\end{array}$ & $\begin{array}{l}\text { 1- criação de scripts SQL e do banco de dados de } \\
\text { análise das métricas objetivas de engajamento }\end{array}$ \\
\hline $\begin{array}{l}\text { Necessidade de disponibilizar uma versão móvel } \\
\text { do Arquigrafia }\end{array}$ & $\begin{array}{l}\text { 2- desenvolvimento de protótipo de alta fidelidade para } \\
\text { o aplicativo móvel do Arquigrafia }\end{array}$ \\
\hline $\begin{array}{l}\text { Transformar todas as funcionalidades do projeto } \\
\text { em componentes }\end{array}$ & 3- refatoração de código \\
\hline Avaliar usabilidade do protótipo para o aplicativo & 4- Teste de usabilidade com usuários \\
\hline
\end{tabular}


A criação de scripts SQL e do banco de dados para análise das métricas objetivas de engajamento depende dos seguintes passos: 1. Criar banco de dados de análise com as colunas que estão armazenadas em cada linha do registro no arquivo .log; 2. Implementar o código para transformar os arquivos .log em arquivos .csv; 3. Implementar o código para transformar os arquivos .csv em arquivos .sql, com cada linha de registro sendo um comando insert do Sql; 4. Importar dados do arquivo Sql criado no banco de dados de análise; 5. Definir scripts Sql para retornar a métrica objetiva de engajamento de acordo com o período e a funcionalidade informada; 6 . Gerar arquivos com as métricas obtidas no formato que será utilizado para os testes estatísticos que serão executados na ferramenta $\mathrm{R}$.

A refatoração de código compreendeu a separação de todas as funcionalidades em componentes, mantendo um núcleo de funcionalidades com usuários, fotos e álbum. Todas as demais funcionalidades serão componentes que podem ser inseridos ou removidos do projeto, o que facilitará a execução de experimentos futuros relacionados à questão de pesquisa I.

\section{Ação}

Foram criadas views no banco de dados para guardar períodos específicos de análise e a partir delas as métricas são recuperadas. O código refatorado com as funcionalidades como componentes está disponível no GitHub do projeto ${ }^{3}$. O monitoramento das ações realizadas durante o ciclo 3 foi realizado conforme o ciclo 2.

Em 18 de fevereiro de 2016, as estagiárias da Biblioteca da FAUUSP, que participavam do estudo com diários de campo, organizaram um Passeio fotográfico do Arquigrafia com os alunos ingressantes no curso de arquitetura e urbanismo. O objetivo foi realizar uma oficina para apresentar o edifício da FAU - Vilanova Artigas - por meio de um passeio fotográfico, que foi finalizado na sessão de materiais iconográficos da biblioteca, apresentando o funcionamento do Arquigrafia e as atividades que são realizadas pelas diversas frentes de trabalho no projeto. O teste de usabilidade sobre o protótipo do aplicativo móvel foi realizado em laboratório no dia 22 de junho de 2016 após uma oficina de atividades com alunos da FAU, com o objetivo de realizarem avaliações de imagens.

\section{Avaliação}

A avaliação da ação Criação de scripts SQL e do banco de dados de análise das métricas objetivas de engajamento foi feita por meio de um estudo exploratório para verificar se os scripts retornavam os dados necessários para a análise estatística das métricas de engajamento na ferramenta R. Para realizar essa avaliação, a primeira funcionalidade de colaboração implementada no sistema, notificação, foi avaliada. Os resultados mostram que o script atendeu ao seu propósito. A avaliação da refatoração do código foi realizada por meio de reuniões com a equipe de desenvolvimento.

Os diários de campo apresentaram alguns problemas com o painel de imagens e tarefas específicas de catalogação no sistema. Contudo, o enfoque da descrição dos diários foi sobre as funcionalidades colaborativas. O contato com os elementos de jogos não foram relatados nos diários. Apenas um diário descreve a interação com a funcionalidade de notícias:

"Ao acessar o Arquigrafia através do acervo fiquei muito feliz ao ver a linha de atualizações, pois facilita o acesso as últimas postagens. Apenas acho que essa linha deveria vir mais no final da página, após as imagens do site".

Apenas 9 participantes da oficina seguiram para o teste de usabilidade. Esses usuários tinham entre 18 e 25 anos, 6 do sexo masculino, todos alunos da graduação da FAU, sendo que 7 deles não conheciam o Arquigrafia. Foram relatados 6 pontos positivos e 14 pontos negativos para o protótipo do aplicativo móvel. Os pontos positivos, em suma, relacionaram-se com a organização da interface, navegação simples e praticidade de uso. Os pontos negativos resumem-se ao sentimento de incompletude em relação à versão disponível na web, uma vez que o protótipo desenvolvido

\footnotetext{
${ }^{3}$ GitHub é uma plataforma de hospedagem de código-fonte com controle de versão, que atualmente possibilita que usuários contribuam com projetos de qualquer lugar do mundo. A url para acesso ao código refatorado é: https://github.com/NAWEB-USP/Arquigrafia-Laravel/tree/master/
} 
continha apenas as funcionalidades básicas, sem a inclusão dos elementos de colaboração e de jogos. O motivo foi entregar rapidamente uma versão disponível para testes com usuários (filosófia de métodos ágeis), antes de ter uma versão completa com todas as funcionalidades para análise. Os resultados foram comentários dos participantes como: "Ainda está muito, alpha..."; ou "Achei a versão para computador bem mais completa e oferece mais possibilidades...".

Aproveitamos o teste para coletar sugestões dos usuários para um aplicativo ideal para o Arquigrafia e compartilhar com os usuários uma dúvida que a equipe de desenvolvimento e de clientes tinha: Inserir ou não o painel de imagens no aplicativo móvel? 5 de 9 responderam não porque o tamanho da imagem seria pequeno e perderia o seu maior valor. No entanto, a diferença foi muito pequena entre os dois grupos. De modo geral, os usuários compararam o aplicativo às funcionalidades do Instagram e sentiram falta das funcionalidades dele no aplicativo do Arquigrafia.

A Figura 5.5 apresenta a comparação entre os 60 dias finais entre ciclo 2 e ciclo 3 para a visão geral do Google Analytics. As oficinas realizadas em fevereiro e junho causaram um impacto positivo na quantidade de usuários que acessaram o sistema durante seus períodos de realização. O teste de usabilidade foi realizado em laboratório sobre o protótipo com apenas 9 usuários e não sobre o sistema em produção. Sendo assim, não afetou as métricas de engajamento. No entanto, a quantidade de usuários (comercial) aumentou em 668 usuários a mais (de 2155 para 2823); e em 728 usuários novos a mais (de 2021 para 2749) em relação ao ciclo anterior, o que parece ser o reflexo das oficinas realizadas neste ciclo.

Entretanto, a análise do final do ciclo 3 compreendeu o mês de férias dos usuários típicos do sistema, que o utilizam para fins de estudo e trabalho, sendo assim, o sistema sofre a queda de acessos durante as férias e fins de semana. Além disso, nenhuma funcionalidade para interação do usuário com o sistema foi disponibilizada ou atualizada neste ciclo. Portanto, para os usuários nenhuma mudança foi apresentada no ciclo 3. Esses motivos somados podem explicar a queda das métricas número de sessões por usuário, visualizações de página, páginas/sessão, média de duração da sessão e o aumento da taxa de rejeição. 


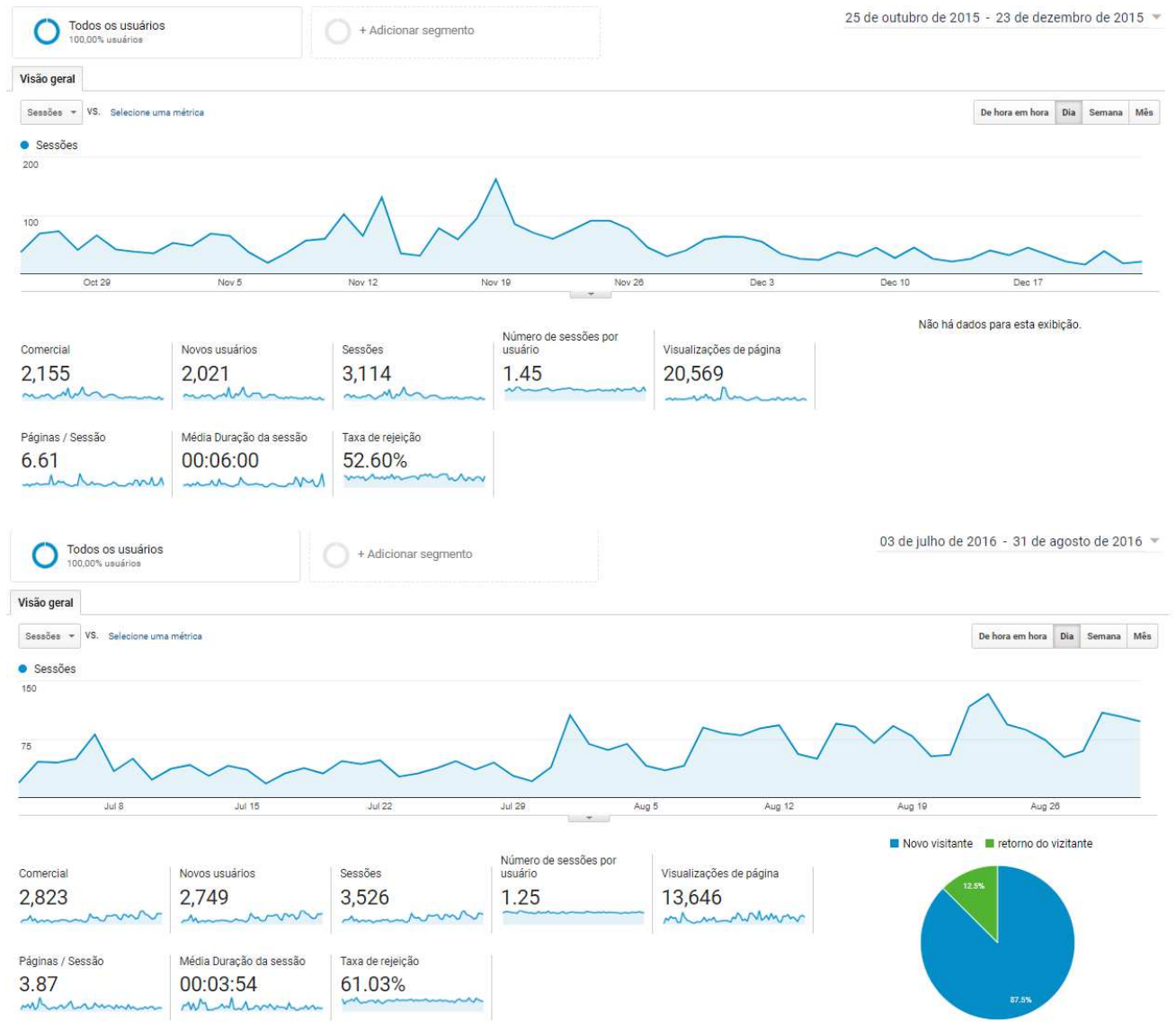

Figura 5.5: Comparação entre os 60 dias finais do ciclo 2 (25/10/2015 - 23/12/2015) e do ciclo 3 (03/07/2016 - 31/08/2016) para a métrica visão geral do Google Analytics.

\section{Reflexão}

As métricas do Google Analytics informam que houve uma redução do engajamento dos usuários com o sistema no ciclo 3 quando comparado com os ciclos 0 a 2 que apresentavam um crescimento contínuo. A oficina de fevereiro foi divulgada na página do Facebook do projeto mas, a oficina de junho não foi divulgada. A falta de atualizações no sistema e na página do Facebook do projeto podem sugerir inatividade da comunidade aos usuários, embora não seja a realidade. A inatividade da comunidade pode reduzir o interesse dos usuários em interagir com o sistema.

No entanto, a partir do monitoramento do banco de dados em produção, percebe-se uma maior interação dos usuários com as funcionalidades de colaboração Curtir uma imagem e Seguir um usuário, para as quais as notificações possibilitam que os usuários acompanhem o movimento dos demais usuários no sistema. Esse movimento parece uma busca por novidades, seguindo usuários que possam estar envolvidos em novas atividades.

Com o estudo exploratório foi possível retornar as métricas de Zichermann et al. [ZC11] para 401.948 registros, de modo a validar a ação de criação de um banco de dados de análise. Porém, o processo de recuperar as métricas por dia de acesso ainda não é totalmente automatizado, porque depende da execução manual de scripts SQL.

Dois aprendizados foram observados no ciclo 3 :

1. um período de poucas atualizações no sistema interfere no engajamento dos usuários, especialmente quando se tem um perfil de usuários exploradores, que entram no sistema para verificar as novidades, buscando serem surpreendidos, conforme relatos dos diários de campo. Além disso, o sistema se apresenta como versão beta, ou seja, o usuário espera que esteja em constante desenvolvimento. O período sem atualizações de desenvolvimento diz respeito ao que é visualizado na comunidade online, contudo fora do ambiente online, a equipe 
estava trabalhando em uma série de atividades que não foram expostas aos usuários. Uma possível solução para esses casos seria apresentar um relato semanal do que a equipe está realizando offline de modo que usuários que encontram-se distantes fisicamente da equipe núcleo de clientes e desenvolvedores do projeto possam acompanhar o desenvolvimento e entender o porquê do período sem melhorias ou novas funcionalidades.

2. necessidade de criar um ambiente totalmente automatizado para cálculo das métricas de engajamento, de modo que as métricas por dia de acesso sejam continuamente registradas sem a necessidade de intervenção para que sejam geradas. Inicialmente, imaginavase que não seria necessário um ambiente com maior profundidade de automatização, pois executar o script SQL por período é relativamente simples, após as ações terem sido registradas em um banco de dados. Contudo, ao precisar isolar efeitos entre elementos de interação diferentes e que foram colocados em períodos distintos, várias mudanças foram necessárias por script, dificultando a geração de um script único que funcione para todos os casos, pois cada elemento envolve ações diferentes que foram inseridas em datas distintas e as análises podem ser realizadas em períodos específicos, diferentes do período de inserção da funcionalidade. Portanto, realizar a automatização em código possibilita inserir uma nova funcionalidade no sistema com os dados necessários para suas futuras análises em vez de adaptar scripts após a inserção de cada funcionalidade. Esse comportamento economiza tempo no momento de realizar as análises estatísticas.

\subsubsection{Ciclo 4: Geração automática de métricas objetivas e definição da $1^{\mathrm{a}}$ versão de abordagem}

O ciclo 4 foi realizado entre 01 de setembro de 2016 e 01 de março de 2017 e teve como objetivo a geração automática de métricas objetivas de engajamento e a execução do experimento de campo online sobre a funcionalidade de notificação. Seu principal resultado foi a definição de uma primeira versão da abordagem para integrar a gamificação com o monitoramento e a avaliação de engajamento de usuários durante o desenvolvimento de uma comunidade online de colaboração aberta.

\section{Diagnóstico}

Assim como ocorreu no ciclo 0, há a necessidade de configurar o registro de ações de usuários, porém agora a partir do aplicativo móvel, antes que o aplicativo seja disponibilizado em produção após as correções de problemas de usabilidade levantados no teste. No ciclo 1 a resposta dos participantes do teste de usabilidade à questão "Do que se trata este sistema?" indicou que boa parte dos usuários enxergavam o Arquigrafia como um banco de dados para imagens de arquitetura, embora todos os esforços de desenvolvimento sejam para criar uma comunidade de membros que colaborem entre si para refletir sobre arquitetura. No ciclo 1 uma série de funcionalidades necessárias ainda estavam em desenvolvimento, portanto, apenas agora é possível apresentar um conjunto de atividades possíveis de serem realizadas no sistema. Por meio de reuniões com usuários, clientes e equipe, entendemos que poderíamos apresentar aos visitantes as novas funcionalidades e como estas se conectam com a filosofia do projeto, como ocorre em páginas de aterrissagem ou páginas de conversão, mais conhecidas como landing pages. O objetivo é converter visitantes em clientes, por exemplo, em e-commerce, ou no caso do Arquigrafia, converter visitantes em usuários ativos do sistema, que criam uma conta e realizam alguma ação, especialmente, ações relacionadas à colaboração.

Adicionalmente, este ciclo dedica-se à implementação da geração automática das métricas de engajamento e a execução de um experimento com a funcionalidade de notificação. A funcionalidade de notificação foi anallisada no estudo exploratório, então existem dados suficientes para comparar resultados e verificar corretude das análises automáticas que seriam realizadas neste ciclo. $\mathrm{O}$ principal objetivo do experimento é a avaliação do processo de análise de engajamento a partir das métricas geradas automaticamente, de modo a avaliar dificuldades, efetividade da automatização e melhorias possíveis. 


\section{Planejamento}

A Tabela 5.9 apresenta cada item do diagnóstico do ciclo 4 e a ação planejada para solucioná-lo.

Tabela 5.9: Diagnóstico e Planejamento do Ciclo 4

\begin{tabular}{ll}
\hline Item diagnosticado & Ação planejada \\
\hline $\begin{array}{l}\text { Necessidade de configurar o registro de ações de } \\
\text { usuários a partir do aplicativo }\end{array}$ & $\begin{array}{l}\text { 1- Diferenciar acessos via o novo aplicativo móvel e via } \\
\text { a aplicação Web no registro de ações de usuários }\end{array}$ \\
$\begin{array}{l}\text { Disponibizar a primeira versão do aplicativo } \\
\text { aplicativo móvel }\end{array}$ & $\begin{array}{l}\text { 3- Desenvolver a landing page do projeto } \\
\text { Apresentar objetivos do projeto na página de } \\
\text { entrada no sistema }\end{array}$ \\
$\begin{array}{l}\text { Necessidade de gerar automaticamente as } \\
\text { métricas de engajamento }\end{array}$ & $\begin{array}{l}\text { 4- Implementar código para geração automática de } \\
\text { métricas de engajamento e criar banco de análise no }\end{array}$ \\
Necessidade de configurar e analisar um & $\begin{array}{l}\text { 5- Executar experimento de campo online sobre a } \\
\text { funcionalidade de notificação. }\end{array}$ \\
experimento piloto com dados do estudo &
\end{tabular}

A ação 1 - Diferenciar acessos via o novo aplicativo móvel e via a aplicação Web no registro de ações de usuários - refere-se a alterar o código de registro de ações de usuários para indicar quando o acesso do usuário é realizado pelo aplicativo ou quando é feito pela aplicação Web.

A ação 4 - Implementar script para geração automática de métricas de engajamento e criar banco de análise no servidor de produção - compreende também a inclusão de um script de execução diária que atualiza o banco de dados de métricas já calculadas com os dados dos registros de ações do dia.

\section{Ação}

Todas as ações planejadas foram realizadas: os logs diferenciam acessos a partir de dispositivos móveis; e uma primeira versão do sistema está disponível para smartphones Android ${ }^{4}$. A landing page do projeto está disponível antes da realização do login em: arquigrafia.org.br. As métricas objetivas de engajamento que antes eram geradas a partir de consultas com queries diretamente no banco de dados, agora são retornadas a partir de códigos Java que calculam as métricas recenticidade, frequência, duração, classificação e viralidade, conforme definição de Zichermann et al. [ZC11] - para cada dia de acesso do usuário e as mantém registradas em um banco de dados de métricas do sistema. A partir da geração automatizada das métricas, o experimento de campo online foi executado sobre a funcionalidade de notificação, o que possibilitou refinar a maneira como as métricas foram analisadas no estudo exploratório de modo a explicitar melhor as diferenças entre cada versão acessada pelo mesmo conjunto de usuários antes e após o acesso à notificação. O monitoramento das ações realizadas durante o ciclo 4 também foi feito como nos ciclos anteriores, porém sem os diários de campo porque os alunos que estavam participando do estudo finalizaram o estágio no projeto.

Em 15 de setembro foi realizado um Encontro do Arquigrafia com intercambistas FAU para compartilhamento de experiências com imagens de arquitetura e plataformas de compartilhamento de imagens. Novos estagiários da biblioteca da FAUUSP, a partir de novembro iniciam atualizações semanais, e em alguns períodos diárias, na página do Facebook do projeto. Durante as reuniões definiu-se que o sistema deveria possibilitar o upload de vídeos e não apenas de imagens. Discussões foram feitas para entender questões de licenças para apresentação de vídeos do Youtube e do Vimeo e a partir deste ciclo, os usuários podem subir vídeos como por exemplo, o processo de uma obra, para serem visualizados no Arquigrafia.

Neste ciclo, uma primeira proposta de abordagem foi construída a partir do estudo da literatura de comunidades de prática, gamificação, engajamento e organizadas dentro do ciclo de vida de

\footnotetext{
${ }^{4}$ https://play.google.com/store/apps/details?id=com.ionicframework.arquigrafiamobile302511\&hl=pt-br
} 
DCU.

\section{Avaliação}

O experimento executado sobre a funcionalidade de notificação, analisada isoladamente, evidenciou aumento estatisticamente significativo das métricas frequência, recenticidade e duração de usuários que a acessaram, considerando os mesmos usuários antes e após o período de acesso à notificação. Além disso, a notificação gerou mudanças no comportamento de usuários, os quais realizaram outras ações após o acesso a uma notificação (viralidade). Contudo, a notificação não gerou efeitos para acessos pelo Facebook e Google+ e para a métrica classificação. Sendo assim, das 5 métricas analisadas, a notificação apresentou efeitos positivos em quatro delas, o que podemos entender que a funcionalidade aumentou o engajamento de usuários em uma comunidade online de colaboração aberta. Mais detalhes estão descritos no artigo 5 da Seção 1.5 [BMR17].

A Figura 5.6 apresenta a comparação entre os 60 dias finais do ciclo 3 e do ciclo 4 para a visão geral do Google Analytics. A quantidade de usuários diminuiu do ciclo 3 para o ciclo 4, conforme métricas comercial (591 usuários a menos), novos usuários (588 usuários a menos) e sessões (518 sessões a menos). Nos ciclos anteriores a quantidade de usuários aumentou após eventos do projeto. Neste ciclo, o último evento foi em 15 de setembro, mas os dois últimos meses do ciclo 4 ocorreram a partir de $1^{\circ}$ de janeiro, aproximadamente após 3 meses e meio, o que pode explicar a diminuição do movimento de novos usuários.

Todas as demais métricas apresentaram resultados melhores quando comparadas com o ciclo anterior. Embora o ciclo 4 tenha apresentado menos usuários, estes visualizaram 4723 páginas a mais, permaneceram mais tempo em cada sessão ( 1 min e 13 seg a mais em média) e acessaram 2,74 páginas a mais por sessão, o que resultou em uma queda da taxa de rejeição de $3.98 \%$, indicando que os usuários estavam mais engajados na interação. Engajamento não é quantidade de usuários, mas sim quão envolvidos eles estão. Uma comunidade pode ter muitos usuários, e não ter nenhum engajado; um participante engajado pode fazer a diferença no engajamento de uma comunidade, uma vez que pode inspirar outros a seguir o seu exemplo. 

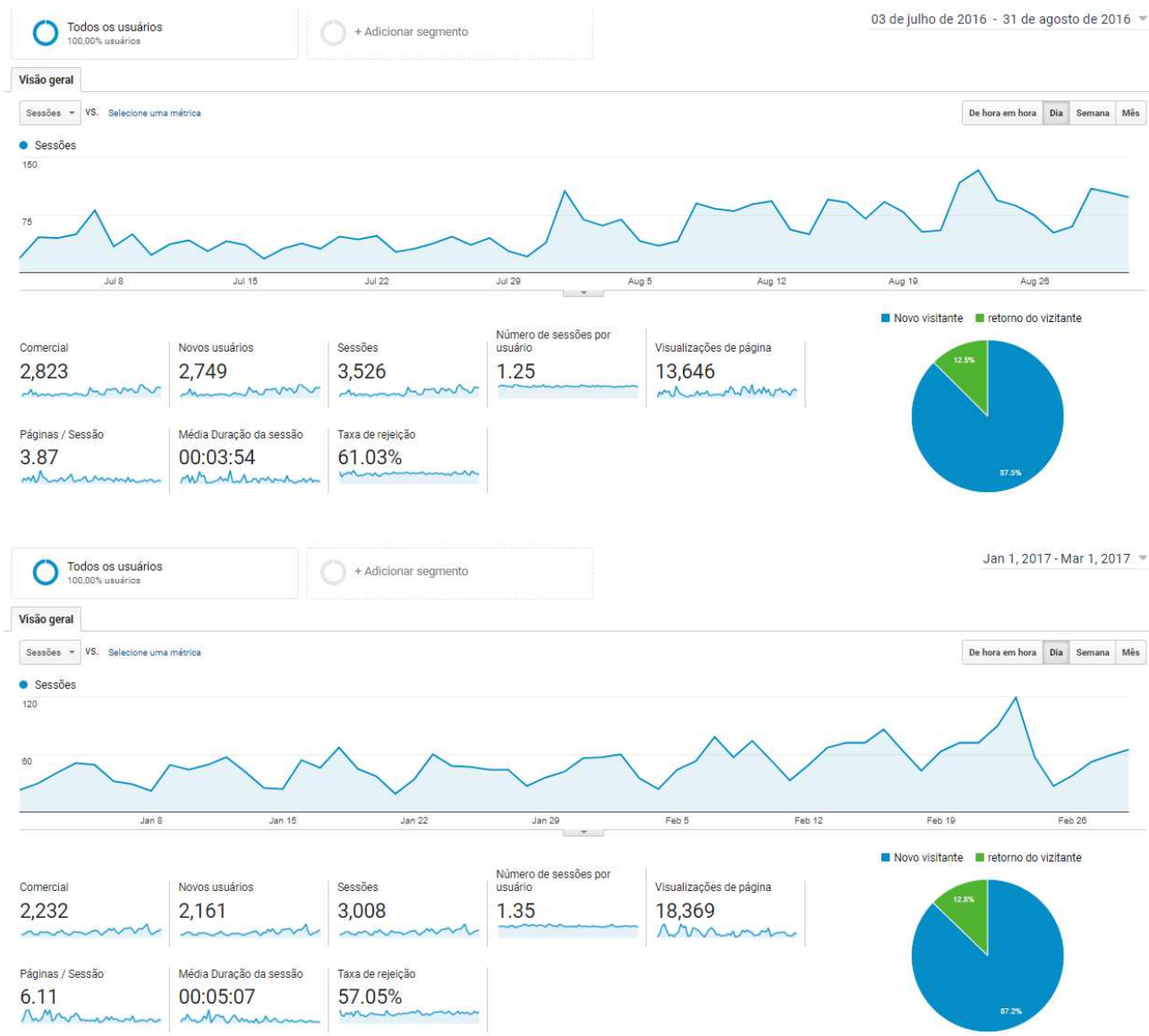

Figura 5.6: Comparação entre os 60 dias finais do ciclo 3 (03/07/2016 - 31/08/2016) e do ciclo 4 (01/01/2017 - 01/03/2017) para a visão geral do Google Analytics.

\section{Reflexão}

Três pressupostos guiaram o ciclo 4:

1. apresentação da filosofia da comunidade. Assim que o usuário acessa pela primeira vez o sistema, ele precisa ser informado sobre o que acontece após realizar cada ação e como ela se conecta com a filosofia da comunidade. Dessa forma, o usuário tem a possibilidade de avaliar se quer ou não participar da atividade. A landing page buscou realizar esse papel.

2. utilização de funções estatísticas apropriadas para cada tipo de análise. Para as análises estatísticas é necessário conhecimento prévio de quais funções utilizar para dados paramétricos ou não-paramétricos, para comparação entre dois grupos, ou entre 3 ou mais grupos, bem como, se os dados vêm a partir dos mesmos usuários em períodos distintos ou se são usuários distintos em um mesmo período. Neste experimento, aplicamos o Shapiro-Wilk normality test para verificar se os dados coletados vinham de uma população normal. Os resultados indicaram que os dados não eram normais, e por esse motivo, para a comparação entre dois períodos para o mesmo conjunto de usuários utilizou-se um teste de hipótese estatística não paramétrico chamado Wilcoxon rank sum test, no formato pareado, indicando que os dados vinham dos mesmos usuários em períodos distintos. O objetivo foi comparar se os resultados dos dois conjuntos eram diferentes para cada métrica em análise, considerando os mesmos usuários.

3. entendimento de que notificação gera efeitos positivos sobre o engajamento. A colaboração é composta pelos 3Cs - Comunicação, Coordenação e Cooperação. A funcionalidade de notificação é a primeira desenvolvida no Arquigrafia relacionada à coordenação, 
porque possibilita o gerenciamento de atividades, recursos e o que as pessoas estão fazendo na comunidade. Sendo assim, a colaboração no Arquigrafia não estava completa antes de incluir elementos dos 3Cs. Diversos estudos descrevem o quanto a notificação é benéfica para o engajamento de usuários com o sistema [Bur05, $\mathrm{CNI}^{+}$03, MP02]. Portanto, como o objetivo é avaliar as métricas utilizadas para medir engajamento, analisar uma funcionalidade em isolamento que a literatura aponta como geradora de maior engajamento, nos ajudaria a entender se as métricas são adequadas para o estudo posterior a ser realizado com elementos de jogos.

Dois aprendizados foram observados no ciclo 4:

1. necessidade de variar as possibilidades de gamificação para abranger perfis de usuários diferentes. Os usuários que curtem imagens e seguem novos usuários continuam a participar do sistema mesmo em um período de poucas atualizações do sistema em produção. Por exemplo, é possível variar as opções de como obter distintivos e crescer no quadro de liderança, de modo a dar destaque aos usuários que têm muitos seguidores ou que postam comentários, aumentando assim a visibilidade deles não apenas para usuários que os seguem, mas para todos os usuários do sistema; e consequentemente, reconhecendo o valor da atividade que eles realizam para a comunidade.

2. associação de dimensões de motivação humana e colaboração com diretrizes de comunidades de prática. A pesquisa da literatura além de ajudar a formar os pressupostos de cada ciclo, direcionando as atividades a serem realizadas, forma também a base para a formação de uma proposta a ser aplicada no Arquigrafia. Esta base será construída sobre um arcabouço teórico baseado em teorias de motivação humana [DR12, DKR99, SDT16]; e o Modelo 3C de colaboração [FRGL05].

O arcabouço teórico relaciona cada dimensão do Modelo 3C com cada dimensão da motivação humana. Portanto, considerando as definições apresentadas no Capítulo 2 temos que: comunicação associa-se com relacionamento; cooperação com competência; e coordenação com autonomia.

Comunicação é realizada com a troca de mensagens; a principal razão porque as pessoas tendem a estar dispostas a realizar comportamentos é o fato de estes serem valorizados por outros indivíduos com quem elas se sentem (ou gostariam de se sentir) conectadas, seja a família, um grupo de pares ou uma sociedade. Isto sugere que a base para facilitar a internalização de um comportamento está em proporcionar uma sensação de pertencimento e conexão entre pessoas, grupos ou culturas, disseminando um objetivo, ou o que na SDT chama-se um senso de relacionamento [RD00a]. Portanto, uma motivação prévia por relacionamento implica em comunicação e a comunicação implica em relacionamento.

Cooperação ocorre por intermédio de operações num espaço compartilhado para a execução das tarefas. Adotar como própria uma meta extrínseca requer que a pessoa sinta-se eficaz com respeito a ela. Assim, Deci e Ryan teorizam que o suporte para a competência facilita a internalização de um comportamento, por exemplo, oferecendo desafios ideais e feedback relevantes, de modo a perceber aprendizado. Portanto, uma motivação prévia por competência em uma comunidade implica em cooperação e a cooperação implica em competência.

De acordo com a abordagem SDT, uma regulação que foi internalizada pode ser somente introjetada, e esse tipo de regulação poderia deixar as pessoas sentirem-se satisfeitas em suas necessidades por competência e relacionamento [RD00a]. No entanto, introjetar uma regulação, e assim ser controlado por ela, não faz com que as pessoas sintam-se autodeterminadas. Elementos de jogos relacionados à motivação extrínseca, podem trazer satisfação ao usuário, e consequentemente aumentar engajamento. Contudo, apenas contextos que suportam autonomia irão produzir a autorregulação integrada. Para internalizar uma regulação e, assim, tornar-se autônomo em relação a ela, as pessoas devem interiormente compreender seu significado e valor [RD00a]. Portanto, elementos de jogos relacionados à motivação intrínseca, 
podem gerar engajamento sustentável por um período de tempo maior do que o que pode ser obtido com elementos de jogos associados a motivação extrínseca, para os quais o engajamento pode ficar restrito à obtenção da recompensa externa.

Coordenação é executada por meio do gerenciamento de pessoas, atividades e recursos; autonomia é o senso de agir de acordo com a vontade e em congruência com seus próprios objetivos, valores e identidade - é a necessidade psicológica básica e parte nuclear da motivação intrínseca. Para tornar a coordenação possível, é necessário perceber a presença dos outros e saber o que está acontecendo, a fim de tomar as decisões adequadas sobre os procedimentos a serem adotados. Esse tipo de informação, conhecido como percepção de grupo, é usado pelos participantes para construir um entendimento sobre os objetos de cooperação e os objetivos das tarefas e do trabalho [GFL03]. Sendo assim, é importante saber o que o grupo já fez, o que está fazendo e o que falta fazer, para decidir com quais atividades contribuir de acordo com objetivos, valores e identidade; inclusive para saber se as atividades do grupo relacionam-se com os objetivos, valores e identidade do indivíduo. Portanto, uma motivação prévia por autonomia implica em coordenação e a coordenação implica em autonomia.

A próxima seção apresenta uma primeira proposta de abordagem, apoiada no arcabouço teórico e em diretrizes de construção de comunidades de prática.

\subsection{Primeira versão da abordagem}

Design Centrado em Usuário (DCU) é definido pela Associação dos Profissionais de Usabilidade (UPA) [UEPA14], como "uma abordagem para projeto que racionaliza o processo de informação sobre as pessoas que usarão o produto. O processo de DCU focaliza em usuários através do planejamento, design e desenvolvimento de um produto". A International Standards Organization (ISO 13407: Human-centred design process) define um processo geral para incluir atividades centradas em humano através do ciclo de vida de desenvolvimento, sem especificar métodos exatos. A Figura 5.7 exibe as principais atividades envolvidas.

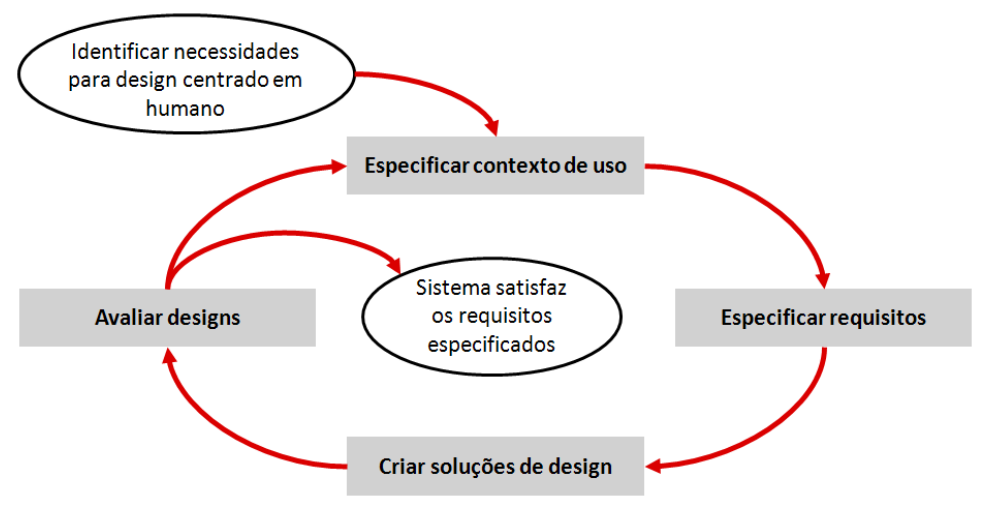

Figura 5.7: Ciclo de vida do DCU [UEPA14].

Identificar necessidades para design centrado em humano, refere-se à identificação da necessidade de usar um processo para design centrado em usuário. Especificar o contexto de uso, refere-se à identificação das pessoas que usarão o produto, o que elas usarão para isto e sob quais condições elas o usarão. Especificar requisitos, refere-se a identificação de requisitos de negócios ou metas de usuários que devem ser cumpridas para que o produto tenha sucesso. Criar soluções de design refere-se aos estágios de construção do design a partir de um conceito bruto até alcançar o design completo. Avaliar designs, considerada a parte mais importante do processo, é realizada idealmente por meio de testes de usabilidade com usuários reais e é tão importante quanto teste de qualidade é para o bom desenvolvimento de software [UEPA14]. 
Para a proposta de abordagem desta pesquisa, considera-se analisar a motivação do usuário sob a perspectiva de Ryan e Deci, ou seja, buscando fornecer autonomia, competência e relacionamento. A gamificação de um sistema deve ser projetada para atender a motivação do usuário, especialmente a motivação intrínseca. Para tal, é preciso compreender quem são os usuários, tanto os atuais quanto os que se almeja alcançar. Nesta proposta essa compreensão é obtida por meio do Design Centrado em usuário.

Também é necessário compreender quais são os objetivos e valores dos usuários típicos, de modo a apresentar conteúdo que possibilite que a autonomia seja experimentada durante o uso do sistema. A percepção de competência depende do indivíduo sentir-se eficaz com respeito a uma meta, a qual deve estar associada a valores, ou competências, que se deseja alcançar. Desafios e feedback relevantes são exemplos de meios para alcançar essa percepção. Proporcionar uma sensação de pertencimento e conexão entre pessoas, grupos ou culturas é o que princípios de comunidades de prática buscam alcançar para sustentar comunidades em torno de práticas e artefatos. O meio para que os relacionamentos aconteçam reflete a necessidade de funcionalidades de colaboração. O contéudo e as funcionalidades que buscam fornecer a percepção de autonomia, competência e relacionamento podem ser associadas a elementos e técnicas de jogos.

A Tabela 5.10 apresenta uma primeira proposta de abordagem estruturada sobre as atividades de Design Centrado em Usuário, com o objetivo de classificar diretrizes distintas para aplicação na prática do processo de desenvolvimento. 
Tabela 5.10: Primeira proposta de abordagem estruturada sobre as atividades de Design Centrado em Usuário.

\begin{tabular}{|c|c|c|c|}
\hline $\begin{array}{l}\text { Especificar contexto de } \\
\text { uso }\end{array}$ & Especificar requisitos & Criar soluções de design & Avaliar designs \\
\hline $\begin{array}{c}(+) \text { Definir objetivos de } \\
\text { negócios [WH12] } \\
(+) \text { Descrever perfil de } \\
\text { usuário [SRP07] } \\
\text { o Novatos ou } \\
\text { Aprendizes } \\
\text { o Casuais ou } \\
\text { Infrequentes } \\
\text { o Frequentes } \\
\text { o Experientes } \\
(+) \text { Descrever perfil de } \\
\text { jogador [Bar96] } \\
\text { o realizadores } \\
\text { o exploradores } \\
\text { o socializadores } \\
\text { o assassinos }\end{array}$ & $\begin{array}{l}\text { (+) Delinear } \\
\text { comportamentos-alvo } \\
\text { [WH12] } \\
\text { 1. Associar com } \\
\text { Relacionamento, } \\
\text { Autonomia e } \\
\text { Competência [RD00a] } \\
(+ \text { Conceber ciclos de atividade } \\
\text { [WH12] } \\
\text { o Definir História } \\
\text { (fantasia) [Sch14] } \\
\text { o Definir Mecânica } \\
\text { (desafio) [Sch14] } \\
\quad \text { Selecionar/Criar } \\
\text { elemento de jogo } \\
\quad \text { Associar com } \\
\text { SDT[DR12, } \\
\text { DKR99, SDT16] }\end{array}$ & $\begin{array}{c}\text { (+) Estética (curiosidade } \\
\text { e imersão) [Sch14] } \\
(+) \text { Implantar as } \\
\text { ferramentas } \\
\text { apropriadas [WH12] } \\
\text { o Tecnologia } \\
\text { [Sch14] } \\
\text { (componentes) } \\
\text { o Monitoramento } \\
\text { de métricas } \\
\text { [ZC11] }\end{array}$ & $\begin{array}{l}(+) \text { Avaliar métricas } \\
\text { objetivas de } \\
\text { engajamento [ZC11] } \\
(+) \text { Avaliar métricas } \\
\text { subjetivas de } \\
\text { engajamento [OT10] } \\
(+) \text { Teste com usuários } \\
\text { [SRP07] } \\
(+) \text { Avaliar Heurísticas de } \\
\text { design [SRP07] }\end{array}$ \\
\hline
\end{tabular}

(+) Não esquecer da diversão [WH12]

o Diversão pesada (Hard fun) [Laz08]

o Diversão fácil (Easy fun)[Laz08]

o Diversão experimental (Experimental fun)[Laz08]

o Diversão social (Social fun)[Laz08]

As atividades de DCU formam uma estrutura na qual conceitos e diretrizes, vindos a partir de áreas distintas, são reunidos. Os seis passos de implantação da gamificação [WH12] descritos na Seção 2.6 fornecem o enfoque sobre o projeto de gamificação. Na fase de especificar contexto de uso do DCU, o passo de implantação da gamificação Definir objetivos de negócio [WH12] é associado aos passos de descrever perfil de usuário do DCU [SRP07] e de descrever perfil de jogador [Bar96]. Essa consideração é relevante porque agora pretende-se entender quem são os usuários sob essas duas perspectivas.

A fase Especificar requisitos é composta dos seguintes passos de implantação da gamificação [WH12]: 1) Delinear comportamentos-alvo; 2) Conceber ciclos de atividade; e 3) Não esquecer da diversão. Para Delinear comportamentos-alvo, pode-se associar a necessidade de percepção de autonomia, competência e relacionamento a comportamentos-alvo que qualquer sistema gamificado precisaria projetar para buscar atender a motivações intrínsecas dos usuários, conforme [RD00a].

O passo Conceber ciclos de atividade contém dois tipos de ciclos de desenvolvimento: ciclos de engajamento e escadas de progressão. Ciclos de engajamento descrevem o que os jogadores fazem, por que fazem e o que o sistema faz em resposta; escadas de progressão fornecem uma macroperspectiva da jornada do jogador, com um nível crescente de desafios. Esse passo faz referência à Tétrade elementar dos jogos descrita na Seção 2.5, pois nesse passo é preciso definir a história e a 
mecânica, que por sua vez, leva à seleção ou à criação do elemento de jogo associado com o processo da Teoria da autodeterminação, de acordo com a Figura 2.2, ou seja, elementos de jogos distintos são necessários para abordar indivíduos com tipos de motivação diferentes.

O passo Não esquecer da diversão é detalhado a partir de Lazzaro [Laz08], no qual a diversão pesada refere-se a desafios ou enigmas; diversão fácil refere-se à diversão casual para espairecer sem sobrecarregar o indivíduo; diversão experimental refere-se a experimentar novas personas ou experiências; e diversão social refere-se aos tipos de diversão que dependem de interação com os outros, mesmo que por meio de competição.

A fase Criar soluções de design é composta pela Estética e o passo Implantar as ferramentas apropriadas. A Estética vem da Tétrade elementar dos jogos [Sch14], com o enfoque sobre a curiosidade e a imersão do usuário no sistema, por enfatizar a mecânica e reforçar ideias da história. O passo Implantar as ferramentas apropriadas [WH12], envolve a Tecnologia da Tétrade elementar dos jogos, que é o meio onde as interações ocorrem e o monitoramento das métricas, conforme [ZC11]. O monitoramento pode ser feito por ferramentas externas ao sistema ou ser desenvolvido internamente, mas antes de disponibilizar aos usuários, é necessário realizar a configuração de um ambiente para coleta de métricas.

A fase Avaliar designs envolve o teste com usuários, a avaliação de heurísticas de design e a avaliação de métricas objetivas e subjetivas de engajamento. As métricas subjetivas são avaliadas por meio de questionários para avaliar motivação e engajamento [OT10]. Na proposta de abordagem desta pesquisa, as métricas objetivas e subjetivas são monitoradas ao longo do desenvolvimento do sistema, de modo que se possa avaliar se as intervenções estão alcançando os resultados desejados. Os atributos de engajamento do modelo de O'Brien e Toms [OT08] podem ser associados a elementos ou técnicas de jogos de acordo com a fase de engajamento. Por exemplo, o ponto de engajamento é a fase na qual uma motivação do usuário deve ser atendida e portanto as considerações apontadas como relevantes para esta pesquisa na seção de motivação podem ser aplicadas. Em outras palavras, quando o usuário entra no sistema, seja a primeira vez ou o retorno, ele deve ser recebido por algo que o remeta a motivação que o conduz a usar o sistema.

A meta específica (atributo de ponto de engajamento), do modelo de O’Brien e Toms [OT08], é associada aos valores, ou competências, que o usuário deseja alcançar e a mudança para o período de engajamento sustentado ocorre quando feedback é fornecido de modo a propiciar a percepção de competência e reconhecimento. A percepção do que acontece em torno do usuário ajuda a mantê-lo engajado, uma vez que fornece meios para que ele saiba o que os demais usuários estão realizando, de modo a poder interagir com eles e passar a realizar atividades de grupos dos quais gostaria de pertencer (relacionamento).

Para a proposta de abordagem desta pesquisa busca-se associar a inserção de gamificação no contexto de desenvolvimento de comunidades de colaboração aberta. Para seguir uma proposta centrada em usuário e que de fato integre as teorias de motivação humana, que formam os principais fundamentos teóricos da gamificação, é necessário considerar o contexto de desenvolvimento antes de inserir elementos de gamificação. A proposta, portanto, baseia-se em princípios para criação e sustentabilidade de comunidades de prática e a associação destes com os elementos de gamificação, tendo como suporte para aplicação no processo de desenvolvimento, o Design Centrado em Usuário.

Como o contexto é o de construção de uma comunidade de prática em ambiente de colaboração aberta, dois pontos precisam ser observados: o sistema precisa fornecer meios para colaboração entre os usuários; e os princípios para cultivar comunidades de prática precisam ser atendidos. A Tabela 5.11 detalha a diretriz Delinear comportamentos-alvo que tem um enfoque sobre o contexto de comunidades de colaboração aberta. 
Tabela 5.11: Detalhamento da diretriz Delinear comportamentos-alvo para comunidades de colaboração aberta

\begin{tabular}{|c|c|c|}
\hline $\begin{array}{l}\text { Diálogo entre membros } \\
\text { (Comunicação) } \\
\text { Relacionamento }\end{array}$ & $\begin{array}{l}\text { Moderação } \\
\text { (Coordenação) } \\
\text { Autonomia }\end{array}$ & $\begin{array}{l}\text { Práticas da comunidade } \\
\text { (Cooperação) } \\
\text { Competência }\end{array}$ \\
\hline $\begin{array}{l}\text { (+) Construir LOCAIS de } \\
\text { reunião flexíveis, extensíveis } \\
\text { [Kim00] } \\
\text { o Abrir um diálogo } \\
\text { entre perspectivas } \\
\text { internas e externas } \\
\text { [WMS02a] } \\
\text { o Desenvolver espaços } \\
\text { da comunidade tanto } \\
\text { públicos quanto } \\
\text { privados [WMS02a] } \\
\text { - } \\
\text { CONDUTA Encorajar } \\
\text { apropriada [Kim00] }\end{array}$ & $\begin{array}{c}\text { (+) Criar PERFIS de membros } \\
\text { significativos e evolutivos } \\
\text { [Kim00] } \\
\text { o Projetar para a } \\
\text { evolução [WMS02a] } \\
\text { o Definir e articular o } \\
\text { seu PROPÓSITO } \\
\text { [Kim00] } \\
\text { o Concentrar no valor } \\
\text { [WMS02a] = } \\
\text { motivação intrínseca } \\
\text { [RD00a] } \\
\text { (+) Projetar para uma variedade } \\
\text { de PAPÉIS [Kim00] } \\
\text { o Convidar diferentes } \\
\text { níveis de participação } \\
\text { [WMS02a] } \\
\text { (+) Desenvolver um forte } \\
\text { programa de LIDERANÇA } \\
\text { [Kim00] }\end{array}$ & $\begin{array}{l}\text { (+) Promover EVENTOS cíclicos } \\
\text { [Kim00]; } \\
\text { (+) Integrar os RITUAIS de vida } \\
\text { da comunidade [Kim00] } \\
\text { o Combinar } \\
\text { familiaridade e } \\
\text { entusiasmo [WMS02a] } \\
\text { o Criar um ritmo para a } \\
\text { comunidade } \\
\text { [WMS02a] } \\
\text { (+) Facilitar a execução de } \\
\text { SUBGRUPOS de membros } \\
\text { [Kim00] }\end{array}$ \\
\hline
\end{tabular}

Os sete princípios propostos por Wenger et al. [WMS02a] para cultivar comunidades de prática e os nove princípios específicos para comunidades online propostos por Kim [Kim00] são associados a comportamentos-alvo de um sistema gamificado para comunidades de colaboração aberta. A associação não indica que cada princípio é um comportamento-alvo em si. Na verdade, o comportamentoalvo pode ser projetado por meio da avaliação desses princípios, os quais, por sua vez, são classificados de acordo com o modelo 3C de colaboração - Comunicação, Coordenação e Cooperação - e a relação deste com as dimensões de motivação intrínseca - Relacionamento, Autonomia e Competência.

Os princípios são classificados de acordo com a busca pela percepção de autonomia, competência ou relacionamento para atender a uma motivação intrínseca do usuário. Cada necessidade psicológica é associada a um dos aspectos do Modelo 3C. Dessa forma, os princípios são de três tipos: 1) Relacionamento que está associado à Comunicação do Modelo $3 \mathrm{C}$ e refere-se a funcionalidades relacionadas a possibilitar o diálogo entre os membros; 2) Autonomia que está associada à Coordenação e refere-se a funcionalidades relacionadas à moderação; e 3) Competência que está associada à Cooperação e refere-se a funcionalidades relacionadas a práticas da comunidade.

Para o relacionamento, associado à comunicação, o princípio para cultivar comunidades de prática Construir locais de reuniões flexíveis, extensíveis foi proposto por Kim [Kim00] e é composto dos seguintes princípios propostos por Wenger et al. [WMS02a]: Abrir um diálogo entre perspectivas internas e externas e Desenvolver espaços da comunidade tanto públicos quanto privados; e do princípio proposto por Kim [Kim00] Encorajar etiqueta apropriada. O princípio Construir locais de reuniões flexíveis, extensíveis refere-se ao desenvolvimento de uma infraestrutura de pequena escala de locais de reunião familiares. Os locais de reunião irão co-evoluir por meio de membros com participação ativa. O princípio Abrir um diálogo entre perspectivas internas e externas requer a perspectiva de pessoas familiarizadas com os tipos de atividades internas e a perspectiva de pessoas de fora da comunidade para ver as possibilidades dentro de seus próprios mecanismos ou na 
adoção de outras ferramentas ou procedimentos. O princípio Desenvolver espaços da comunidade tanto públicos quanto privados tem como meta "orquestrar atividades tanto em espaços públicos quanto privados que usam a força das relações individuais para enriquecer eventos e eventos para fortalecer as relações individuais" [WMS02a]. O princípio Encorajar etiqueta apropriada ressalta que as comunidades precisam estabelecer regras básicas de conduta para os processos de comunicação.

Conforme Dias [Dia08], a "moderação online desenvolve-se como uma atividade reguladora dos processos de organização dos grupos e das aprendizagens realizadas em ambientes virtuais, com particular incidência para as formas de dinamização, gestão e acompanhamento". Sua principal função consiste em "promover o envolvimento dos participantes de forma que o conhecimento por eles construído seja utilizável em novas e diferentes situações" [Tom02a].

Considerando a autonomia, associada à coordenação em uma comunidade online, os seguintes princípios propostos por Kim [Kim00] foram associados a ela: 1) Criar perfis de membros significativos e evolutivos; 2) Projetar para uma variedade de papeis; e 3) Desenvolver um forte programa de liderança. Criar perfis de membros significativos e evolutivos é composto dos seguintes princípios propostos por Wenger et al. [WMS02a]: Projetar para a evolução; concentrar no valor; e do princípio Definir e articular o seu propósito de Kim [Kim00].

Criar perfis de membros significativos e evolutivos refere-se a importância dos perfis porque ajudam a invocar a comunicação entre os membros e a dar à comunidade um senso de história e contexto. Projetar para a evolução, por sua vez, indica que o projeto deve refletir a escalabilidade. Estruturas sociais e organizacionais, como um coordenador da comunidade ou reuniões de resolução de problemas, podem precipitar a evolução de uma comunidade" [WMS02a]. O princípio concentrar no valor indica que as comunidades devem oferecer valor para os membros e sócios potenciais, pois caso contrário não haverá incentivo à participação. Conforme Wenger, o valor pode não ser sempre explicitamente aparente, mas deve crescer ao longo do tempo enquanto a comunidade evolui. Além disso, para conformidade com as teorias de motivação, o valor precisa ser associado à motivação intrínseca dos usuários. O princípio Definir e articular o seu propósito refere-se à importância dos membros entenderem por que e para quem a comunidade está sendo construída, sendo necessário ser explícito por meio do design.

Projetar para uma variedade de papeis de Kim [Kim00] é composto do princípio Convidar pessoas para diferentes níveis de participação de Wenger et al. [WMS02a]. Projetar para uma variedade de papéis refere-se a necessidades diferentes entre novos e antigos membros. Kim indica que estratégias em torno de boas-vindas e para capacitar novos membros são importantes para aqueles em papéis de liderança. O princípio Convidar pessoas para diferentes níveis de participação informa que enquanto os membros que se encontram na periferia da comunidade não podem participar da mesma forma que os membros do núcleo, os membros periféricos ainda ganham insights e conhecimentos por meio desse tipo de participação, por esse motivo todos os membros, independentemente dos níveis de participação, devem ser valorizados. O princípio Desenvolver um forte programa de liderança indica que os líderes comunitários são parte integrante do processo de como recepcionar e orientar membros da comunidade. Kim ressalta que é importante que os líderes sejam suportados nessas atividades vitais para a comunidade [Kim00].

Para competência, associada à cooperação, os seguintes princípios propostos por Kim [Kim00] foram associados: Promover eventos cíclicos; Integrar os rituais de vida da comunidade; e Facilitar a execução de subgrupos de membros. O princípio Promover eventos cíclicos indica que eventos são importantes para inserir ritmo às comunidades, bem como fornecer locais de socialização. Os líderes comunitários podem estabelecer eventos ou incentivar os membros a estabelecerem seus próprios eventos.

O princípio Integrar os rituais de vida da comunidade é composto dos seguintes princípios de Wenger et al. [WMS02a]: Combinar familiaridade e entusiasmo e Criar um ritmo para a comunidade. O princípio Integrar os rituais de vida da comunidade indica que os rituais devem ser estabelecidos em torno de ocorrências importantes (novos membros, membros que saem etc.). O princípio Combinar familiaridade e entusiasmo indica que enquanto as comunidades amadurecem, elas se contentam com maneiras familiares de encontro e conduta. No entanto, as comunidades também precisam de 
desafio e espontaneidade para fornecer uma quebra nas ocorrências diárias [WMS02a]. O princípio Criar um ritmo para a comunidade refere-se ao fato de que "no coração de uma comunidade está uma teia de relacionamentos duradouros entre os membros, mas o ritmo de suas interações é muito influenciado pelo ritmo dos eventos da comunidade" [WMS02a].

Por fim, o princípio Facilitar a execução de subgrupos de membros ressalta que em comunidades de grande escala, os subgrupos são muito importantes enquanto grupos menores, que podem ajudar a estabelecer a fidelidade dos membros e a distinguir sua comunidade das outras. O objetivo dessa organização de princípios de acordo com comportamentos-alvo, portanto, é associar os princípios aos elementos de jogo de modo a dar enfoque ao contexto específico de criação de comunidades de colaboração aberta. Ou seja, os elementos de jogo são inseridos de modo a criar mecânicas ou dinâmicas que favoreçam os princípios de construção de comunidade de prática, que refere-se ao contexto do projeto. A proposta de abordagem preliminar será aplicada nos próximos ciclos da pesquisa-ação no projeto Arquigrafia. O próximo capítulo apresenta os ciclos 5 e 6 , nos quais busca-se implementar uma primeira versão da abordagem proposta neste ciclo. 


\section{Capítulo 6}

\section{Pesquisa-ação: Refinamento da abordagem proposta}

Este capítulo apresenta os ciclos 5 e 6 da pesquisa-ação que buscam aplicar a abordagem proposta no fim do ciclo 4 no contexto do Arquigrafia, por meio da inserção de funcionalidades que representam partes de uma estratégia colaborativa. Um experimento de campo online, um questionário online para coleta de métricas de engajamento subjetivas e uma pesquisa correlacional no período do ciclo 6 foram realizados e possibilitaram refinar a abordagem proposta no que diz respeito ao monitoramento e avaliação de métricas de engajamento durante a inserção de novos elementos colaborativos e de jogos. As reflexões sobre a pesquisa-ação desenvolvida de 05 de janeiro de 2015 a 30 de junho de 2018 ajudaram a refinar a abordagem proposta que será descrita no Capítulo 8 .

\subsection{Refinamento da abordagem proposta no Arquigrafia}

\subsubsection{Ciclo 5: Workshops para instanciação da abordagem}

O ciclo 5 foi realizado entre 02 de março de 2017 e 31 de julho de 2017 e teve como objetivo a instanciação da proposta de abordagem, proposta no ciclo 4, por meio da criação de uma estratégia colaborativa para o contexto do Arquigrafia. Seu principal resultado foi a atualização da proposta de abordagem.

\section{Diagnóstico}

A abordagem para integrar gamificação durante o processo de desenvolvimento, proposta no ciclo anterior, baseia-se na necessidade de criar uma estratégia colaborativa para a comunidade onde elementos de jogos são associados às diretrizes de construção de comunidades de prática e aos elementos de colaboração que atendam aos 3Cs do Modelo de colaboração - comunicação, cooperação e coordenação. Os elementos são projetados para entrar no sistema de forma isolada, de modo que possam ser avaliados quanto aos efeitos causados no engajamento de usuários, buscando reflexões contínuas de como melhorar a interação do usuário com o sistema.

Para desenvolvimento iterativo de uma primeira versão da estratégia, buscou-se analisar diretrizes de construção de comunidades de prática, que estivessem cada uma relacionada a um C de colaboração. Também buscou-se atender a um problema detectado quando alguns usuários enviaram e-mails pedindo para trocar uma informação errada que estava inserida em uma imagem institucional, por exemplo, nome do escritório de arquitetura ou nome do arquiteto responsável; enquanto outros usuários, usaram a área de comentário da imagem para informar que o dado descrito estava errado, informando o dado certo. O Arquigrafia não tinha a opção de um usuário corrigir um problema encontrado em uma imagem até o início do ciclo 5. Entendeu-se, portanto, que a correção e complementação dos dados de uma imagem poderia ser uma funcionalidade de colaboração - do tipo cooperação - que poderia ser construída a partir da primeira proposta de abordagem. 
A refatoração dos componentes relacionados à colaboração e jogos, realizada nos ciclos anteriores, tornou possível separar um núcleo do projeto apenas com os principais componentes do acervo de imagens, excluindo-se os elementos de colaboração e de jogos. Esse núcleo pode ser disponibilizado para que outros acervos possam utilizá-lo para armazenamento e compartilhamento de imagens.

\section{Planejamento}

Definimos um documento de visão geral de como a funcionalidade para completar dados de uma imagem poderia ser projetada de modo a atender o Diálogo entre membros (Comunicação) ou Relacionamento, a Moderação (Coordenação) ou Autonomia e as Práticas da comunidade (Cooperação) ou Competência. A estratégia é sumarizada na Tabela 6.1.

Tabela 6.1: Estratégia colaborativa para a funcionalidade de completude de dados

\begin{tabular}{|c|c|c|c|}
\hline & $\begin{array}{l}\text { Diálogo entre } \\
\text { membros } \\
\text { (Comunicação) } \\
\text { Relacionamento }\end{array}$ & $\begin{array}{l}\text { Moderação } \\
\text { (Coordenação) } \\
\text { Autonomia }\end{array}$ & $\begin{array}{l}\text { Práticas da } \\
\text { comunidade } \\
\text { (Cooperação) } \\
\text { Competência }\end{array}$ \\
\hline Estratégia & $\begin{array}{l}\text { Chat para discussão } \\
\text { entre autor da } \\
\text { imagem e moderador }\end{array}$ & $\begin{array}{l}\text { Definição dos papeis } \\
\text { de Moderador } \\
\text { Júnior, Moderador } \\
\text { Pleno e Moderador } \\
\text { Sênior }\end{array}$ & $\begin{array}{l}\text { Completude de } \\
\text { dados }\end{array}$ \\
\hline $\begin{array}{l}\text { Diretrizes de } \\
\text { comunidade }\end{array}$ & $\begin{array}{l}(+) \text { Construir } \\
\text { LOCAIS de reunião } \\
\text { flexíveis, extensíveis } \\
\text { [Kim00] }\end{array}$ & $\begin{array}{l}(+) \text { Criar PERFIS } \\
\text { de membros } \\
\text { significativos e } \\
\text { evolutivos [Kim00] } \\
(+) \text { Projetar para } \\
\text { uma variedade de } \\
\text { papéis } \\
(+) \text { Desenvolver um } \\
\text { forte programa de } \\
\text { liderança }\end{array}$ & $\begin{array}{l}\text { (+) Integrar os } \\
\text { RITUAIS de vida da } \\
\text { comunidade [Kim00] } \\
(+) \text { Facilitar a } \\
\text { execução de } \\
\text { SUBGRUPOS de } \\
\text { membros }\end{array}$ \\
\hline
\end{tabular}

O papel de moderação foi pensado como um processo para evolução de perfis de membros no ARQUIGRAFIA, de modo a atender três diretrizes de construção de comunidades de prática. O moderador júnior pode contribuir com novas informações ou informações faltantes sobre as arquiteturas presentes nas imagens de outros usuários e de acervos. O moderador pleno passa a ser um conciliador entre as ideias de moderadores júniores e de autores da imagem. O usuário que alcança o papel de moderador sênior passa a ter autonomia para propor perspectivas novas sobre um conjunto de imagens que deseja analisar, inclusive propondo exposições fotográficas com a curadoria de imagens. O moderador sênior exerce também a coordenação de atividades e pessoas, na medida que, pode atribuir imagens para completude de dados e moderação a usuários com esses papéis.

A motivação intrínseca associada à funcionalidade de completude de dados foi definida como a vontade do usuário de contribuir com informações que possui ou tem interesse em pesquisar para compartilhar sobre as arquiteturas presentes nas imagens do sistema, bem como, com informações que desejaria explorar e que não são ainda exibidas pelo sistema.

Os elementos de jogos podem ser associados ao crescimento dos usuários partindo do papel de moderador júnior até alcançar o papel de moderador sênior, onde os pontos serão associados às moderações. Tendo a colaboração como "norte" para a construção da estratégia colaborativa, planejamos definir os requisitos, o design e a mecânica pela qual o usuário alcança objetivos para tornar-se um moderador sênior do sistema por meio de workshops com toda a equipe. No planejamento dos workshops também está a discussão em grupo das duas versões (com e sem gamificação) 
a serem implementadas para realização de experimentos com a funcionalidade.

A Tabela 6.2 resume cada item do diagnóstico do ciclo 5 e a ação planejada para solucioná-lo. A seleção da abordagem de solução foi realizada por meio de reuniões entre equipe, clientes e usuários.

Tabela 6.2: Diagnóstico e Planejamento do Ciclo 5

\begin{tabular}{ll}
\hline Item diagnosticado & Ação planejada \\
\hline Instanciação da primeira versão da abordagem & $\begin{array}{l}\text { 1- Workshop para definição de design, fluxos de } \\
\text { interação e mecânica de jogo para a estratégia } \\
\text { colaborativa definida na Tabela } 6.1 .\end{array}$ \\
Organização de componentes para registro de & $\begin{array}{l}\text { 2- Disponibilização do + Grafia } \\
\text { Usuários, Fotos e Álbuns }\end{array}$ \\
Implementação de parte da abordagem & $\begin{array}{l}\text { 3- Primeira versão da funcionalidade de completude de } \\
\text { dados e de chat. }\end{array}$ \\
Avaliação da primeira implementação & - Teste de usabilidade em laboratório. \\
\hline
\end{tabular}

A ação "Disponibilização do + Grafia" busca compartilhar o núcleo de componentes básicos com acervos de outras áreas. Trata-se, portanto, da difusão pública de um template sobre o qual é possível criar acervos de imagens de outras áreas de conhecimento. A ação " Primeira versão da funcionalidade de completude de dados e de chat" trata das primeiras funcionalidades a serem implementadas a partir dos fluxos de interação definidos nos workshops. A ação "Teste de usabilidade em laboratório" foi projetada para avaliar a percepção dos usuários sobre as funcionalidades implementadas neste ciclo.

\section{Ação}

A ação 1 propiciou a definição de fluxos de interação com usuários, interfaces e mecânicas de jogo a serem utilizadas e até mesmo os termos a serem adotados para comunicação por meio de e-mails e notificações a usuários do sistema. A dinâmica dos workshops foi criada com a colaboração de uma aluna de graduação em Comunicação da ECA-USP. O processo para realização de cada workshop envolveu reuniões presenciais ou remotas anteriores a cada sessão de workshop nas quais era definida a pauta que seria abordada na próxima sessão, cenários de uso e os pôsteres em cartolina com os tópicos de inicialização da discussão. Os pôsteres tiveram o propósito de facilitar a dinâmica e criar um ambiente lúdico, com textos e desenhos coloridos, em que todos podiam colaborar inserindo à mão suas ideias. Também um pôster com questões sem respostas ficava disponível para visualização e toda vez que uma questão era respondida durante as discussões, colocávamos sua resposta no pôster de resultados, inclusive com elementos e mecânica de jogo a ser utilizada descritos de forma sucinta. Ao todo foram realizados quatro workshops.

Como consequência, foi possível definir novos termos que melhor representam a hierarquia de papéis proposta inicialmente, a saber moderador Júnior, moderador Pleno e moderador Sênior. Os novos termos definidos representam os mesmos papéis, mas com uma construção hierárquica mais relevante para o usuário final, são eles: revisor, editor, moderador e curador digital. O revisor corrige problemas nos dados e o editor insere novos dados que ainda não foram apresentados pelo autor e substituem o papel de moderador júnior que compreendia os dois casos. O moderador refere-se ao antigo moderador pleno e o curador digital de exposições fotográficas refere-se ao antigo moderador sênior.

Durante os workshops, a revisão de dados de uma imagem foi projetada como um fluxo de cartões no qual apresentam-se questões sobre os dados da arquitetura presente na imagem para que os usuários possam incluir informações faltantes e/ou revisar informações definidas pelos usuários. Trata-se portanto de um Quiz que contém um cartão, ou página, com uma questão para revisão ou edição de cada atributo de uma imagem, sendo um atributo um campo do formulário de upload de imagem do ARQUIGRAFIA.

As sessões de workshop facilitaram a compreensão de que existiam duas grandes funcionalidades 
que poderiam ser desenvolvidas em momentos distintos: Revisão de dados e Curadoria digital, as quais antes estavam associadas apenas à Completude de dados. A curadoria digital contém a moderação de dados e os papéis moderador e curador digital, e a revisão de dados contém os papéis revisor e editor. As funcionalidades de Revisão de dados e Curadoria digital foram classificadas respectivamente como características de cooperação e coordenação. A funcionalidade de chat está associada à característica de comunicação.

A primeira implementação da revisão de dados foi feita para a versão gamificada e foi disponibilizada no servidor de homologação para que usuários pudessem avaliar no teste de usabilidade. Portanto, esta primeira versão da revisão de dados tratou de um protótipo funcional que apenas será disponibilizado em produção no período de execução do experimento de campo online. A versão não-gamificada distingue-se da gamificada pela remoção dos elementos de jogos, mas contém o mesmo fluxo de interação. Os elementos de jogos definidos foram: pontos, barra de progresso e Jogo duradouro.

Pontos foram exibidos ao usuários como pendentes de aprovação pelo dono da imagem, pois apenas após a aceitação da sugestão fornecida, o usuário poderia receber os pontos. A barra de progresso foi apresentada na versão gamificada indicando quão completos estavam os dados da imagem selecionada. Jogo duradouro é um princípio de projeto de jogo que coloca o jogador em um loop no qual novas ações vão sendo apresentadas sempre que ele finaliza uma ação. Esse elemento de jogo relacionado a princípios e heurísticas de projeto de jogos foi implementado no fim de uma revisão de dados. Sempre que um usuário finaliza uma revisão, três novas imagens relacionadas são apresentadas de modo a facilitar a revisão de novas imagens.

Ainda neste ciclo, ao discutirmos em uma reunião formas melhores de descrever dados de uma imagem no aplicativo do Arquigrafia, pensou-se em utilizar descrição em áudio, para que usuários que encontram-se presentes em frente ou dentro de uma arquitetura (in loco) tivessem uma forma mais rápida de compartilhar informações. O projeto Open Air Museum surgiu dessa necessidade. A ideia principal é possibilitar que usuários disponibilizem informações em áudio sobre a arquitetura que estão visitando, contando histórias do local e compartilhando coordenadas geográficas diretamente ao realizar o upload da imagem. Usuários poderiam, portanto, compartilhar novos dados sobre uma arquitetura via smartphones e os demais usuários do projeto poderiam acessar os áudios descrevendo tais arquiteturas quando estivessem presentes no local de sua construção. $\mathrm{O}$ artigo 7 da Seção 1.5 apresenta mais detalhes deste projeto.

Para a ação "Disponibilização do + Grafia", foi criado um projeto no GitHub para difusão pública do + Grafia, a partir do entendimento conjunto da equipe (IME, FAU e ECA) de que o núcleo de componentes básicos, composto pelo código para registro de Usuários, Fotos e Álbuns, é comum a quaisquer tipos de acervos e pode constituir-se como suporte à construção de acervos digitais de áreas distintas. Os componentes do ARQUIGRAFIA relacionados à colaboração ou à gamificação são personalizações do sistema que podem ser aplicadas de acordo com o contexto do acervo. A partir da refatoração da estrutura do código, foi possível organizar o projeto em dois núcleos: componentes básicos ou funcionais, componentes de colaboração e componentes de gamificação. O código refatorado foi portanto denominado + Grafia e foi disponibilizado no GitHub do Núcleo de Pesquisa em Ambientes Colaborativos na Web (NAWEB-USP) ${ }^{1}$.

O novo projeto Open Air Museum e a sua conexão com o Arquigrafia foram apresentados no I Workshop do Instituto Nacional de Ciência e Tecnologia (INCT) no período entre 10 e 12 de abril de 2017. O seminário RITe (REPRESENTAÇÕES: IMAGINÁRIO E TECNOLOGIA) ocorreu nos dias 25 e 26 de maio de 2017 e também contou com apresentações e discussões sobre os dois projetos por meio de mesas-redondas. O teste de usabilidade em laboratório foi executado em 26 de junho de 2017.

\footnotetext{
${ }^{1}$ https://github.com/NAWEB-USP/MaisGrafia
} 


\section{Avaliação}

De modo geral, os participanes do teste reportaram uma série de sugestões para melhorar o fluxo de navegação, por exemplo, incluir link de acesso ao chat do autor da imagem no fim de cada cartão de sugestão/revisão para que o revisor/editor pudesse entrar em contato com o autor da imagem; ou tornar evidente que o moderador terá um papel de resolução de conflitos, precisando pesquisar a informação certa quando houver divergência entre autor e revisor/editor. Usuários também apontaram que não estava claro que as sugestões eram armazenadas mesmo que abandonassem o cartão sem concluir a visualização de todas as questões. Todas os problemas foram corrigidos pela equipe de desenvolvimento.

As melhorias que foram identificadas no teste de usabilidade, passíveis de serem corrigidas rapidamente foram aplicadas ao sistema pela equipe de desenvolvimento neste mesmo ciclo. A funcionalidade de chat foi priorizada para correção e disponibilizada em produção neste ciclo após as correções de usabilidade, uma vez que ela não era enfoque do experimento, pois seria disponibilizada da mesma forma para usuários das duas versões.

A Figura 6.1 apresenta a comparação entre os 60 dias finais do ciclo 4 e do ciclo 5. Embora o teste de usabilidade tenha sido realizado durante o período de análise do ciclo 5 , ele ocorreu no ambiente de homologação porque a funcionalidade de revisão de dados ainda não está disponível em produção, portanto, não afetou os resultados da análise apresentada na Figura 6.1. Houve uma melhora nas métricas comercial (315 usuários a mais), novos usuários (273 novos usuários) e sessões (108 sessões a mais), quando comparadas com o ciclo anterior. Os eventos realizados entre abril e junho podem ser o motivo para o aumento destas métricas, pois estão relacionadas ao maior número de visitantes.

No entanto, a taxa de rejeição aumentou em 4.65\%, a média de duração da sessão reduziu 1 min e 37 segundos, com uma diminuição de 1625 páginas em relação ao ciclo anterior. A única funcionalidade que foi disponibilizada em produção neste ciclo foi o chat, por esse motivo o sistema ficou aproximadamente quatro meses sem atualizações. Além disso, o período de fim do ciclo contém o mês de julho ou período de férias. Esses podem ser os principais motivos para a queda de engajamento de usuários.

Contudo, quando observamos os resultados obtidos para um período de análise que também compreende o mês de julho, o final do Ciclo 3 (de 03 de julho de 2016 a 31 de agosto de 2016) percebemos que o ciclo 5 apresentou resultados superiores aos obtidos no ciclo 3 . O ciclo 5 apresentou 16744 visualizações de páginas com 5,34 páginas/sessão, enquanto o ciclo 3 apresentou 13646 visualizações de páginas com 3,87 páginas/sessão. No entanto, o ciclo 5 teve menos usuários (2547) quando comparado com o ciclo 3 (2823 usuários). Portanto, mesmo com 276 usuários a menos do que o ciclo 3, no ciclo 5 os usuários visualizaram 3098 páginas a mais, com 1,47 páginas a mais por sessão. 


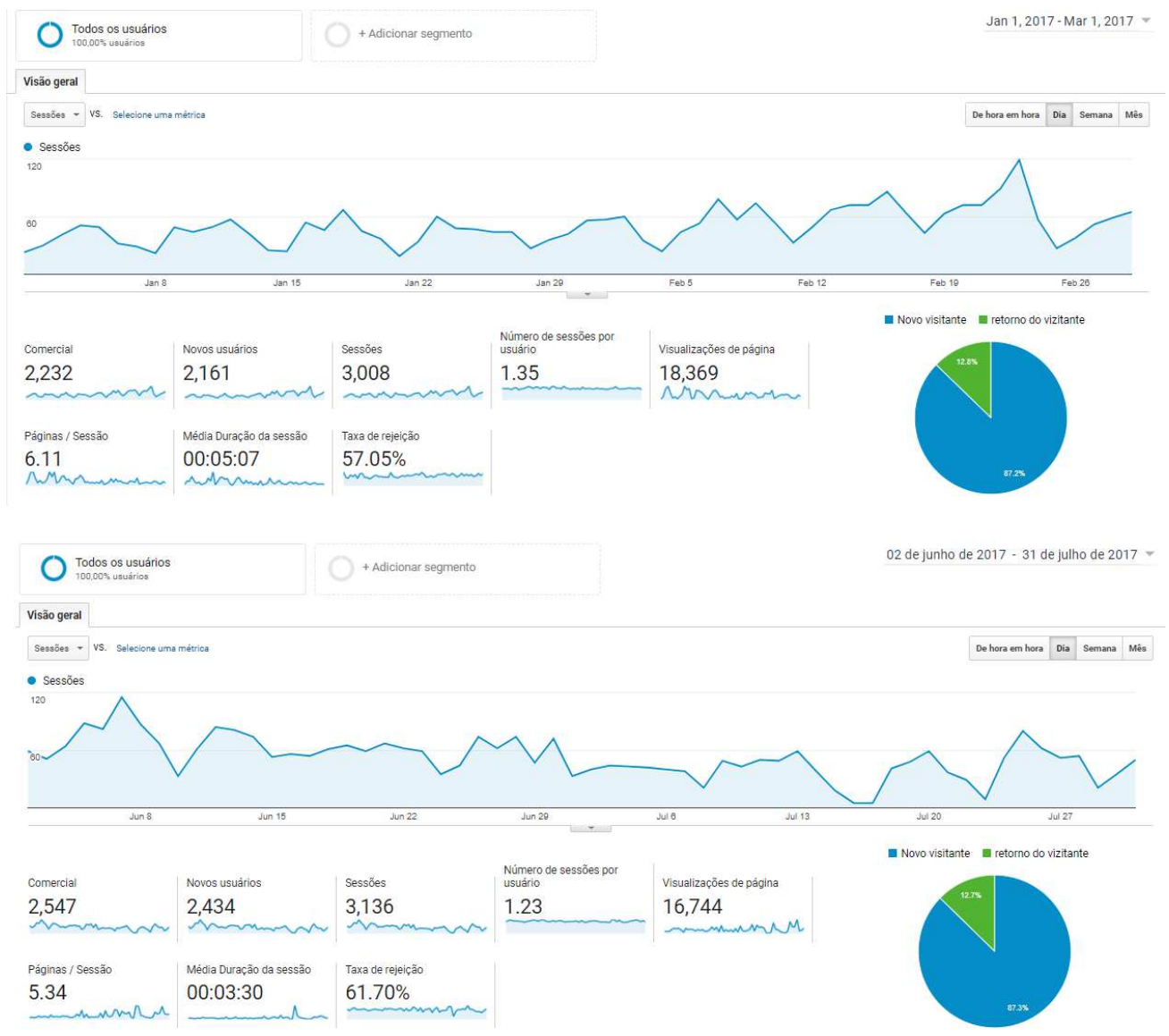

Figura 6.1: Comparação entre os 60 dias finais do ciclo 4 (01/01/2017-01/03/2017) e do ciclo 5 (02/06/2017 - 31/07/2017) para a visão geral do Google Analytics.

\section{Reflexão}

Um pressuposto guiou o ciclo 5: a produção colaborativa da mecânica dos elementos de jogos para as funcionalidades de revisão de dados e curadoria digital. A mecânica de jogos é uma fase complexa de se planejar e a colaboração vinda de diversas perspectivas distintas ajudou a definir de forma iterativa e "divertida" a mecânica a ser implementada.

O aprendizado do ciclo 5 foi: a inclusão das 3 dimensões da prática de uma comunidade na abordagem de integração. As discussões nos workshops, que resultaram na divisão da Completude de dados em Revisão de dados e Curadoria digital, possibilitaram voltar à proposta de abordagem e analisar como as diretrizes haviam sido classificadas. Nesse processo notou-se a relação com as dimensões da prática que antes não haviam sido incluídas no arcabouço teórico.

Uma motivação prévia por relacionamento implica em comunicação e a comunicação implica em relacionamento. Contudo, comunidades de prática residem em torno de pessoas engajadas em certas ações ou ideias comuns, ou engajamento mútuo. Portanto, uma motivação prévia por relacionamento implica em comunicação e a comunicação implica em engajamento mútuo que por sua vez, implica em relacionamento.

Uma motivação prévia por competência implica em cooperação e a cooperação implica em competência. A cooperação ocorre sobre um repertório compartilhado. O repertório de uma comunidade de prática inclui rotinas, palavras, ferramentas, maneiras de fazer as coisas, histórias, gestos, símbolos, gêneros, ações ou conceitos que a comunidade tem produzido ou adotado no curso de sua existência. Portanto, uma motivação prévia por competência implica em cooperação e a cooperação implica em repertório compartilhado, que por sua vez, implica em competência.

Uma motivação prévia por autonomia implica em coordenação e a coordenação implica em autonomia. Wenger declara a importância do empreendimento conjunto ser constantemente renegociado 
pelos membros individuais, ou seja, de acordo com a autonomia dos membros. O empreendimento conjunto vai além das metas estabelecidas, como declaração da missão ou objetivos, e cria responsabilidade mútua entre os participantes. Portanto, uma motivação prévia por autonomia implica em coordenação e a coordenação implica em empreendimento conjunto, que por sua vez, implica em autonomia. A Figura 6.2 apresenta o arcabouço teórico que reúne os construtos das teorias de motivação humana, colaboração e comunidades de prática.

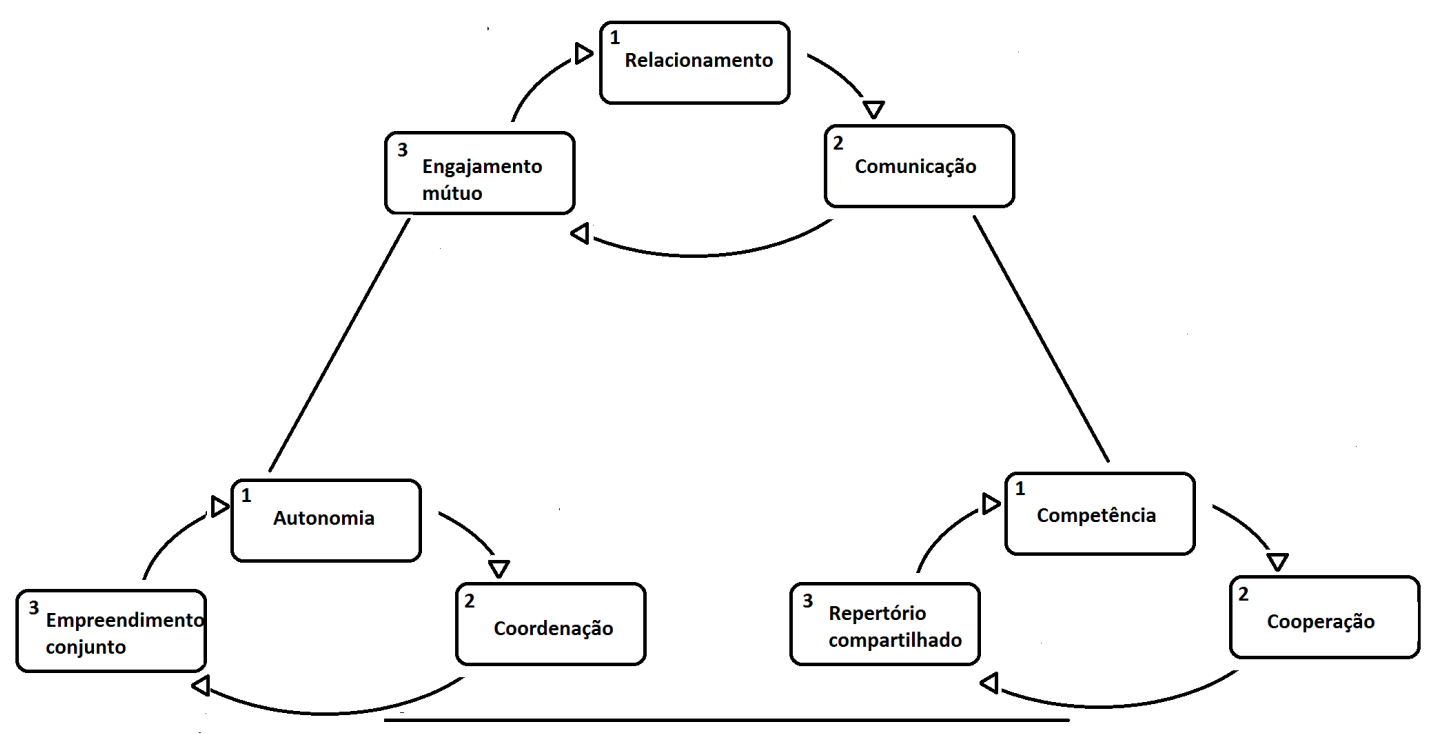

Figura 6.2: Arcabouço teórico: Motivação e colaboração em práticas compartilhadas.

A numeração de 1 a 3 na Figura 6.2 indica que a necessidade psicológica (relacionamento, competência ou autonomia) é o início do processo (1); o que implica em 2, um aspecto da colaboração (comunicação, cooperação ou coordenação), que no contexto de comunidades, implica em 3, ou uma dimensão da prática compartilhada (engajamento mútuo, repertório compartilhado ou empreendimento conjunto).

Na proposta de abordagem, a diretriz Encorajar CONDUTA apropriada [Kim00] foi alterada para coordenação em vez de comunicação, pois regula o comportamento dos membros da comunidade; e a diretriz Facilitar a execução de SUBGRUPOS de membros [Kim00] foi alterada para comunicação em vez de cooperação, uma vez que propicia o relacionamento que pode gerar cooperação. Essa percepção veio à tona a partir da funcionalidade de chat, que possibilita que usuários criem subgrupos para conversação e está relacionada à comunicação. A Tabela 6.3 apresenta as mudanças na proposta de abordagem. 
Tabela 6.3: Proposta de abordagem: Delinear comportamentos-alvo para comunidades de colaboração aberta

\begin{tabular}{lll}
\hline $\begin{array}{l}\text { Diálogo entre membros } \\
\text { (Comunicação) }\end{array}$ & $\begin{array}{l}\text { Moderação } \\
\text { (Coordenação) }\end{array}$ & $\begin{array}{l}\text { Práticas da comunidade } \\
\text { (Cooperação) }\end{array}$ \\
Relacionamento & Autonomia & Competência \\
Engajamento mútuo & Empreendimento conjunto & Repertório compartilhado \\
\hline
\end{tabular}

(+) Construir LOCAIS de reunião flexíveis, extensíveis [Kim00]

o Abrir um diálogo entre perspectivas internas e externas [WMS02a]

o Desenvolver espaços da comunidade tanto públicos quanto privados [WMS02a]

(+) Facilitar a execução de SUBGRUPOS de membros [Kim00]
(+) Criar PERFIS de membros significativos e evolutivos [Kim00]

o Projetar para a evolução [WMS02a]

o Definir e articular o seu PROPÓSITO [Kim00]

o Concentrar no valor [WMS02a] = motivação intrínseca [RD00a]

(+) Projetar para uma variedade de PAPÉIS [Kim00]

o Convidar diferentes níveis de participação [WMS02a]

$(+)$ Desenvolver um forte programa de LIDERANÇA [Kim00]

$(+)$ Encorajar CONDUTA apropriada [Kim00]
(+) Promover EVEnTOS cíclicos [Kim00];

(+) Integrar os RITUAIS de vida da comunidade [Kim00]

o Combinar familiaridade e entusiasmo [WMS02a]

o Criar um ritmo para a comunidade [WMS02a]

Portanto, a estratégia no contexto do Arquigrafia foi alterada conforme Tabela 6.4 abaixo.

Tabela 6.4: Estratégia colaborativa para a funcionalidade de completude de dados

\begin{tabular}{|c|c|c|c|}
\hline & $\begin{array}{l}\text { Diálogo entre } \\
\text { membros } \\
\text { (Comunicação) } \\
\text { Relacionamento } \\
\text { Engajamento } \\
\text { mútuo }\end{array}$ & $\begin{array}{l}\text { Moderação } \\
\text { (Coordenação) } \\
\text { Autonomia } \\
\text { Empreendimento } \\
\text { conjunto }\end{array}$ & $\begin{array}{l}\text { Práticas da } \\
\text { comunidade } \\
\text { (Cooperação) } \\
\text { Competência } \\
\text { Repertório } \\
\text { compartilhado }\end{array}$ \\
\hline Estratégia & $\begin{array}{l}\text { Chat para discussão } \\
\text { entre autor da } \\
\text { imagem, revisor, } \\
\text { editor, moderador e } \\
\text { curador }\end{array}$ & $\begin{array}{l}\text { Definição dos papeis } \\
\text { de revisor, editor, } \\
\text { moderador e curador }\end{array}$ & $\begin{array}{l}\text { Revisão de dados e } \\
\text { Curadoria digital }\end{array}$ \\
\hline $\begin{array}{l}\text { Diretrizes de } \\
\text { comunidade }\end{array}$ & $\begin{array}{l}(+) \text { Construir } \\
\text { LOCAIS de reunião } \\
\text { flexíveis, extensíveis } \\
\text { [Kim00] } \\
(+) \text { Facilitar a } \\
\text { execução de } \\
\text { SUBGRUPOS de } \\
\text { membros }\end{array}$ & $\begin{array}{l}(+) \text { Criar PERFIS } \\
\text { de membros } \\
\text { significativos e } \\
\text { evolutivos [Kim00] } \\
(+) \text { Projetar para } \\
\text { uma variedade de } \\
\text { papéis } \\
(+) \text { Desenvolver um } \\
\text { forte programa de } \\
\text { liderança }\end{array}$ & $\begin{array}{l}(+) \text { Integrar os } \\
\text { RITUAIS de vida da } \\
\text { comunidade [Kim00] }\end{array}$ \\
\hline
\end{tabular}




\subsubsection{Ciclo 6: Experimento com gamificação e Refinamento da abordagem}

O ciclo 6 foi realizado entre 01 de agosto de 2017 e 30 de junho de 2018 e teve como objetivo a realização de um experimento de campo online com a aplicação de um questionário para coleta de métricas subjetivas de engajamento sobre a funcionalidade de revisão de dados nas versões gamificada e não-gamificada. Seu principal resultado foi o refinamento da abordagem por meio das lições aprendidas após a análise de experimento e questionário.

\section{Diagnóstico}

As melhorias sugeridas a partir do teste de usabilidade em laboratório que não foram corrigidas no ciclo anterior, precisam ser corrigidas antes da disponibilização da funcionalidade de revisão de dados em produção. O objetivo é executar um experimento de campo online com as duas versões da funcionalidade em um mesmo período de tempo.

A proposta de abordagem descrita na Tabela 5.10 no fim do ciclo 4, apresenta a avaliação de engajamento com métricas objetivas a partir das métricas definidas por Zichermann and Cunningham [ZC11] e métricas subjetivas definidas por O'Brien e Toms [OT10]. As métricas subjetivas possibilitam avaliar a percepção do usuário sobre o seu engajamento com o sistema. Para o experimento de campo online, as métricas objetivas são calculadas a partir do registro de logs de ações de usuários e as métricas subjetivas precisam ser coletadas por meio da aplicação de um questionário online após a execução do experimento.

Para disponibilizar a revisão de dados aos usuários, também se faz necessário inserir o registro desta ação nos logs de ações do sistema e atualizar o código de geração de métricas para considerar também a nova funcionalidade e os elementos de colaboração e de jogos associados a ela.

Os workshops iterativos realizados no ciclo anterior tornaram possível a construção colaborativa de uma mecânica de jogo para a versão gamificada da funcionalidade de curadoria. Portanto, um protótipo pode ser definido para a evolução dos papeis de moderador e curador e uma primeira versão da mecânica de moderação pode ser implementada.

\section{Planejamento}

A Tabela 6.5 apresenta cada item do diagnóstico do ciclo 6 e a ação planejada para solucioná-lo.

Tabela 6.5: Diagnóstico e Planejamento do Ciclo 6

\begin{tabular}{ll}
\hline Item diagnosticado & Ação planejada \\
\hline Definir a execução de experimento e questionário & $\begin{array}{l}\text { 1- Definição do protocolo do experimento de campo } \\
\text { online e do questionário baseado na Escala de } \\
\text { Engajamento de Usuário para a funcionalidade de } \\
\text { revisão de dados } \\
\text { 2- Configuração de ambiente para apresentar de forma } \\
\text { aleatória as versões com e sem gamificação aos usuários }\end{array}$ \\
$\begin{array}{l}\text { Necessidade de avaliar funcionalidade gamificada } \\
\text { e não-gamificada no mesmo período }\end{array}$ & $\begin{array}{l}\text { Cumprimento de pré-requisitos para do código de geração de métricas } \\
\text { monitoramento e avaliação de engajamento de } \\
\text { nova funcionalidade }\end{array}$ \\
$\begin{array}{l}\text { Definição de lógica de moderação } \\
\text { Avaliar engajamento com métodos mistos } \\
\text { (métricas subjetivas e objetivas) }\end{array}$ & $\begin{array}{l}\text { 4- Implementação inicial de mecânica de moderação } \\
\text { e aplicação do questionário }\end{array}$ \\
$\begin{array}{l}\text { Tunce pré-execução do experimento } \\
\text { funcionalidade, usabilidade, versões distintas e }\end{array}$ & \\
$\begin{array}{l}\text { questionário) } \\
\text { Prototipação das versões gamificada e do experimento }\end{array}$ \\
não-gamificada da curadoria
\end{tabular}

Em paralelo com este planejamento, foi aberto um edital do programa Mobilidade Santander em meados de julho de 2017 para doutorandos realizarem um período de pesquisa em centros 
de excelência em outros países, visando o aprimoramento da sua formação e a intensificação da internacionalização dos programas de pós-graduação da USP. Aproveitamos esta oportunidade para enviar uma proposta de pesquisa para configuração e execução das ações 1 e 5 com a supervisão de uma grande especialista na área de enjamento: Dra. Heather L. O'Brien, que definiu o modelo de engajamento de usuários [OT08], perspectivas teóricas sobre engajamento [O'B16] e o instrumento para avaliação de métricas subjetivas de engajamento na versão longa [OT10] e na versão curta [OCH18].

\section{Ação}

A proposta enviada ao programa Mobilidade Santander foi aprovada, sendo assim, o experimento de campo online e o questionário foram configurados durante o período de pesquisa na University of British Columbia, sob a supervisão da professora Heather L. O'Brien (de setembro a dezembro de 2017). Durante o período, reuniões semanais com o grupo de pesquisa possibilitaram entender como diversas pesquisas de engajamento estavam ocorrendo e como se relacionavam e refinar os protocolos para execução do experimento e do questionário.

Em particular, o planejamento inicial de aplicar o questionário com a versão longa das métricas descritas no artigo de 2010 de O'Brien e Toms [OT10], foi atualizada para aplicar a versão curta que estava em desenvolvimento e que foi publicado em 2018 por O'Brien, Cairns e Hall [OCH18]. A versão longa tem como base 6 dimensões de engajamento - atenção focada, usabilidade percebida, apelo estético, endurability, novidade e envolvimento sentido - e utiliza-se de 31 itens para o questionário. A versão curta baseia-se em 4 dimensões de engajamento - atenção focada, usabilidade percebida, apelo estético e recompensa - e utiliza-se de 12 itens para o questionário, o que se adequa bem a estudos onde se necessita de uma frequência maior de medições ou que dependem de participação voluntária.

A funcionalidade de revisão de dados foi apresentada para o grupo de pesquisa, que sugeriu mudanças no design e na apresentação dos pontos: deixá-los mais visíveis. Em reuniões por videoconferência, foi possível atualizar o desenvolvedor, estagiário do projeto, com as sugestões, que foram então corrigidas antes da execução do experimento.

Para execução do experimento, foi necessário utilizar uma ferramenta para disponibilizar as duas versões da funcionalidade de revisão de dados por meio de um algoritmo que aleatoriamente seleciona uma das versões para um usuário e a partir do primeiro acesso a uma delas, garante que o usuário sempre acessará a mesma versão. Selecionamos a ferramenta Google Optimize para esse fim por ser gratuita e atender bem ao que precisávamos. Foi necessária a inclusão de algumas linhas de código para a chamada ao experimento configurado na ferramenta e a associação de cada versão a um identificador (id). As duas versões da revisão de dados estão disponíveis no Apêndice A. O código de geração de métricas foi atualizado para considerar a nova funcionalidade e seus elementos de jogos, que foram inseridos na versão gamificada.

O experimento de campo online foi executado no período entre 16 de novembro de 2017 e 05 de de dezembro de 2017, após sua execução o questionário online para recuperação da percepção do usuário sobre seu engajamento com o sistema foi enviado apenas aos 73 usuários que acessaram o sistema nesse período. Destes, 18 responderam ao questionário. Alunas da FAU, estagiárias do projeto, realizaram dois posts no Facebook, nos dias 17 e 19 de novembro de 2017, para convidar os usuários a conhecer a nova funcionalidade de revisão de dados. E-mails com o convite foram enviados para todos os usuários.

Foram realizados estudos mais aprofundados sobre o protótipo da curadoria digital a partir de um novo grupo de três estagiários de design da FAUUSP. Em $1^{\circ}$ de março de 2018 ocorreu uma Oficina do Arquigrafia com alunos da FAUUSP, durante a Semana dos Bixos 2018, que contou com 110 pessoas interessadas, conforme registro do convite inserido na página do Facebook do projeto em 17 de fevereiro de 2018. A oficina apresentou o Arquigrafia para os alunos ingressantes do curso de arquitetura e urbanismo e realizou atividades que dependiam do cadastro do participante no sistema, além de solicitar que baixassem o aplicativo para Android, de modo a realizar um passeio fotográfico. Em 23 de maio de 2018, ocorreu o evento Conversas no Ateliê - Representações: 
reflexões, pesquisas e experimentações, que foi também divulgado na página do Facebook do projeto. Neste ciclo iniciou-se um trabalho pela equipe da FAUUSP de apresentar temas semanais na página do Facebook do projeto, convidando os usuários a compartilhar imagens de um estilo ou tema específico de arquitetura e urbanismo. Nos dias 07 e 08 de junho de 2018 ocorreu o IV Seminário Representações: Imaginário e Tecnologia (RITE) em que o Arquigrafia e resultados sobre estudos de engajamento no projeto foram apresentados, com uma mesa-redonda sobre o tema.

\section{Avaliação}

Os principais resultados do experimento de campo online são descritos no artigo 9 da Seção 1.5. Em suma, o experimento apresenta como principal resultado o fato de que a métrica Ações teve um papel importante na compreensão do comportamento exploratório dos usuários durante o período do experimento. Apenas acessos ao elemento de jogo barra de progresso foram contabilizados durante o período do experimento, enquanto que o acesso à visualização de pontos obtidos e à página de Jogo duradouro não foram registradas. Descobrimos que os usuários que acessaram a Barra de progresso realizaram o maior número de ações, e o grupo de usuários com as maiores pontuações de engajamento autorrelatados executou a maior parte das ações. Como trabalho futuro, seria possível investigar cada ação realizada pelos usuários com notas baixas, médias e altas de acordo com os percentis da Escala de Engajamento de Usuários, versão curta de O’Brien et al. [OCH18] (UES, a partir do acrônimo em inglês) para entender melhor o porquê de mais ações realizadas em um grupo de usuários conduzirem a notas menores na UES, enquanto que mais ações em outro grupo de usuários conduziram a notas altas na UES. Nessa análise, usuários com notas médias apresentavam menor nota quanto mais ações realizaram, enquanto que para usuários com nota alta o contrário ocorreu.

Além disso, ações diferentes, por exemplo, avaliações de imagens versus acesso ao quadro de liderança, podem indicar uma quantidade variável de esforço e reflexão colocada na tarefa. Isso pode resultar em diferentes categorias de ação com base na quantidade de esforço, no conhecimento existente, na experiência e no elemento de interação do usuário acessado (por exemplo, elementos de design colaborativo ou de jogos). O isolamento de ações e de elementos de interação do usuário pode melhorar a análise dos efeitos reais de uma intervenção no sistema sobre o engajamento do usuário.

A análise do experimento de campo online sobre a funcionalidade de revisão de dados indicou que as ações dos usuários poderiam informar melhor como o engajamento ocorreu com cada tipo de elemento de interação: elementos de projeto de jogos, elementos funcionais ou elementos colaborativos; e esses dados poderiam ser correlacionados com os resultados a partir da percepção dos usuários sobre o engajamento deles com o sistema. Por esse motivo, uma pesquisa correlacional foi executada para aprofundamento da análise.

Para realizar esta análise, levou-se em consideração que ações de usuários estão relacionadas a elementos de interação de usuário com o sistema. Categorizar ações de usuários de acordo com os elementos de interação acessados pode nos ajudar a compreender melhor o engajamento. Harnad [Har17] definiu que cognição é categorização, pois atribuir termos a categorias tem um papel importante na comunicação [YJML11]. Existem muitos elementos de interação de usuário de acordo com o domínio de um software. A análise realizada considerou os elementos relacionados a comunidades online de colaboração aberta, especificamente, elementos colaborativos e elementos funcionais, e os relacionados à gamificação ou elementos de jogos. A Tabela 6.6 fornece um sumário da definição de cada elemento de interação de usuário que foi abordado na pesquisa correlacional executada neste ciclo. 
Tabela 6.6: Definição de cada tipo de elemento de interação de usuário abordado nesta pesquisa.

\begin{tabular}{|l|l|}
\hline $\begin{array}{l}\text { Tipo de elemento } \\
\text { de interação de usuário }\end{array}$ & Definição \\
\hline $\begin{array}{l}\text { Elementos de jogo } \\
\text { (gamificação) }\end{array}$ & $\begin{array}{l}\text { Elementos que pertencem a um dos cinco } \\
\text { níveis de elementos de projeto de jogo [DDKN11] }\end{array}$ \\
\hline $\begin{array}{l}\text { Elementos colaborativos } \\
\text { (colaboração) }\end{array}$ & $\begin{array}{l}\text { Elementos que fornecem suporte à } \\
\text { colaboração [FRG } 08, \text { GFL03] }\end{array}$ \\
\hline $\begin{array}{l}\text { Elementos funcionais } \\
\text { (função) }\end{array}$ & $\begin{array}{l}\text { Elementos relacionados a requisitos } \\
\text { funcionais [RGK90] }\end{array}$ \\
\hline
\end{tabular}

Como definido por Deterding et al. [DDKN11], elementos de jogo consideram: 1) padrões de projeto de interface de jogo; 2) padrões e mecânicas de projeto de jogo; 3) princípios e heurísticas de projeto de jogo; 4) modelos de jogo; e 5) métodos de projeto de jogo. Como argumentado por Fuks et al. $\left[\mathrm{FRG}^{+} 08\right]$, elementos colaborativos podem ser relacionados a uma das seguintes dimensões do Modelo 3C de Colaboração: 1) Comunicação; 2) Coordenação; e 3) Cooperação.

Os requisitos funcionais especificam funções que os sistemas devem ser aptos a realizar [RGK90]. Em nosso estudo, elementos de jogo e elementos colaborativos não são definidos como elementos funcionais, embora eles tenham requisitos funcionais. Portanto, todos os elementos que não foram categorizados como de jogos ou colaborativos foram classificados como funcionais. Além disso, segundo o dicionário Michaelis, função é uma "ação natural e própria de qualquer coisa (aparelho, dispositivo, artefato, órgão etc.)"; ou ainda, é o "uso a que alguma coisa se destina; emprego, serventia, utilidade". Sendo assim, tratamos como elementos funcionais àqueles relacionados com o uso principal que deu origem ao Arquigrafia, ou seja, possibilitar que pessoas interessadas em imagens de arquitetura tenham acesso a um acervo rico e seleto de imagens, de valor histórico, que antes estavam apenas disponíveis a quem visitasse pessoalmente a biblioteca da FAUUSP.

Ao analisar cada ação dos 18 usuários que responderam ao questionário do experimento online, percebemos um padrão entre tempos de reação dos grupos de usuários com notas baixas, médias e altas. Ao investigar na literatura, percebemos que o tempo de reação [MRGH99, $\mathrm{SDH}^{+}$04, $\mathrm{RMA}^{+}$97] está intimamente relacionado com o engajamento dos usuários com uma tarefa, indicando que ele pode estar realizando ações com a mente distraída quando respondendo muito rapidamente a eventos repetitivos. No contexto do Arquigrafia definimos o tempo de reação dos usuários como o intervalo entre duas ações consecutivas, uma vez que o usuário executou uma ação, recebeu uma resposta do sistema e realizou outra ação como reação à resposta do sistema. As ações foram analisadas de acordo com Maximal Repeating Patterns (MRPs) [SE91] para encontrar as ações recorrentes dos usuários e definir as táticas de uso de grupos de usuários, buscando encontrar padrões. Os MRPs identificam a sequência mais longa de ações que é repetida pelo menos uma vez em todo o conjunto de dados [SE91].

Os principais resultados da pesquisa correlacional foram publicados no artigo de número 10 da Seção 1.5 do Capítulo 1. Em suma, nossos resultados revelaram que o conjunto de ações recorrentes do usuário, combinado com o tempo médio de reação, pode informar o engajamento do usuário mais do que a frequência de ações sozinhas. As ações do usuário podem ser ativas, como a realização de avaliações ou uploads de imagens ou passivas, como a realização de buscas ou downloads. Usuários engajados contribuem para a comunidade do sistema (acesso ativo) e/ou para atingir seus próprios objetivos (acesso passivo). Ambos são guiados por um objetivo específico que implica uma motivação preexistente, reforçando a ideia de que a motivação orientada por objetivos orienta o engajamento mais do que a exploração do sistema sem objetivos específicos, o que pode explicar porque uma grande quantidade de ações repetidas não indica que os usuários estavam envolvidos quando as realizaram.

Além disso, os resultados mostram diferenças nas táticas de uso e na distribuição de acesso a cada elemento de interação do usuário para usuários com alta, média e baixa pontuação na UES. Os elementos funcionais contribuíram para um maior engajamento dos usuários com alta pontuação na UES, e correlações moderadas crescentes foram encontradas entre a pontuação de usabilidade 
percebida e os elementos de projeto de jogos, especificamente a Barra de progresso. Nossos resultados podem ser úteis para análises adicionais das ações do usuário para entender melhor o que determina o engajamento do usuário e para isolar os efeitos de cada elemento de interação do usuário com o sistema.

A Figura 6.3 apresenta uma redução das métricas do ciclo 5 para o ciclo 6 , com exceção da taxa de rejeição e do número de sessões por usuário, que apresentaram uma melhoria sutil. Este ciclo contém quatro eventos relacionados ao projeto, o que historicamente marca uma maior quantidade de acessos de novos usuários durante os eventos, dada a divulgação destes. No entanto, a última atualização no sistema ocorreu em 16 de novembro de 2017 e o período dos 60 dias finais do ciclo 6 compreendeu maio e junho de 2018, ou seis meses sem alterações no sistema.

Entretanto, desde que as métricas Novo visitante e Retorno do visitante passaram a ser apresentadas na visão geral do Google Analytics no ciclo 3, esta foi a primeira vez que a porcentagem de visitantes sai de aproximadamente $12 \%$ (12,5\% no ciclo $3,12,8 \%$ no ciclo 4 e $12,7 \%$ no ciclo 5 ) para alcançar 14,5\%. Embora ainda seja uma pequena diferença, se consideramos que engajamento não diz respeito à quantidade de usuários e que os dados retornados pela visão geral do Google Analytics dizem respeito aos visitantes, independente de serem ou não usuários registrados, podemos perceber que os resultados podem ser diferentes se filtrarmos os dados apenas para usuários logados no sistema. A pesquisa correlacional que será apresentada no próximo capítulo, busca compreender o engajamento por meio desse filtro.

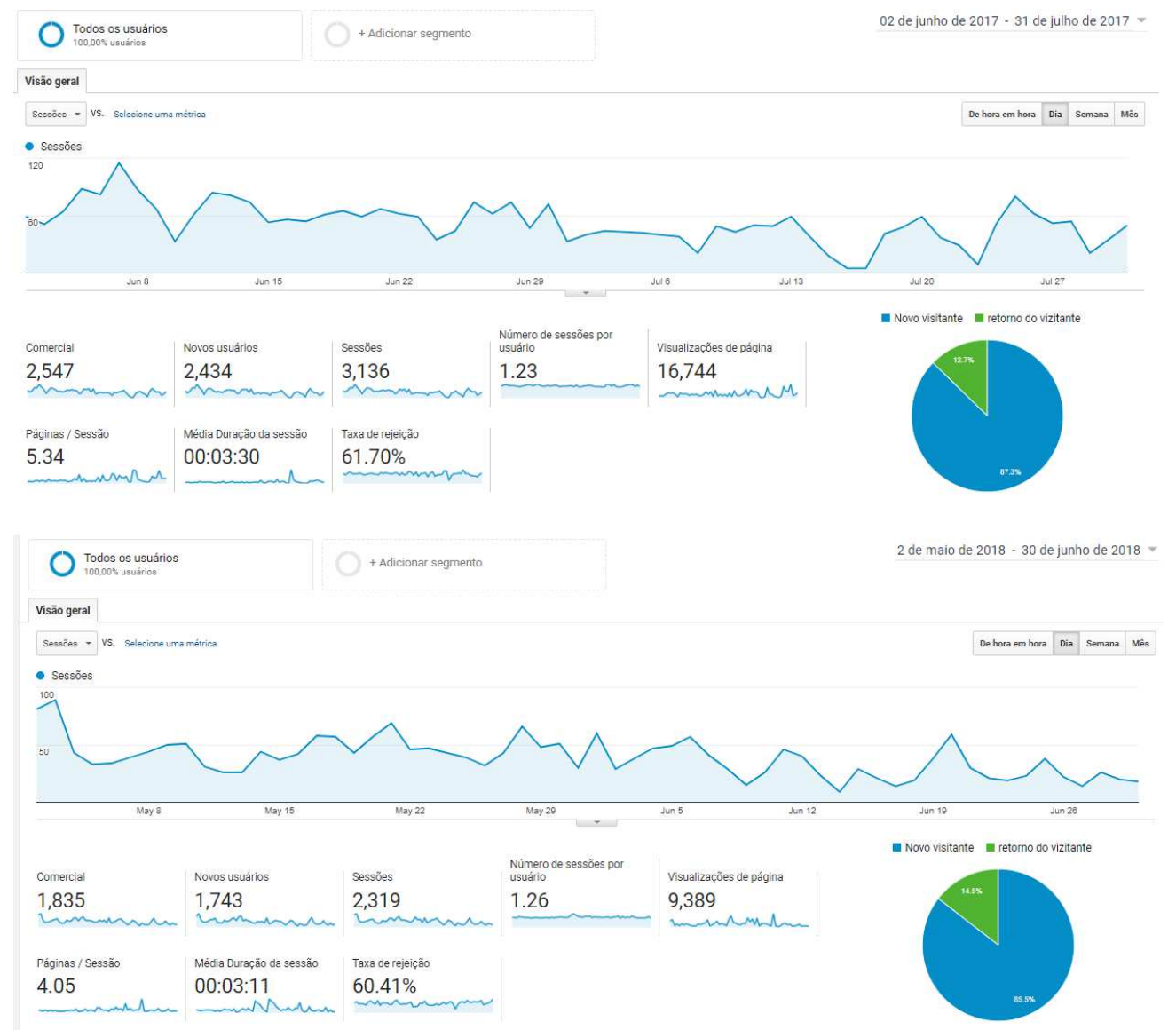

Figura 6.3: Comparação entre os 60 dias finais do ciclo $5(02 / 06 / 2017$ - 31/07/2017) e do ciclo 6 (02/05/2018 - 30/06/2018) para a visão geral do Google Analytics.

\section{Reflexão}

Um pressuposto guiou o ciclo 6: análise integrada de métricas objetivas e subjetivas de engajamento. As análises descritas nos artigos 9 e 10 tornaram mais clara a "fotografia" do 
engajamento real dos usuários que acessaram o sistema porque cruzaram informações dos dois tipos de métricas.

Os aprendizados relativos ao ciclo 6 dizem respeito a como monitorar e planejar a avaliação de métricas de engajamento durante o desenvolvimento de comunidades online. As revisões de dados começaram a ser realizadas com maior frequência a partir de janeiro de 2018. Esse comportamento nos levou a compreender que: 1) o período do teste não foi adequado, muito próximo do Natal e a duração foi muito curta. Contudo, planejamos esse período para obter feedback dos resultados da análise a partir da Prof ${ }^{a}$ Heather O'Brien durante o período de pesquisa na UBC, de modo a realimentar a proposta de abordagem para monitoramento e avaliação de engajamento; e 2) a funcionalidade de revisão de dados depende de conhecimentos específicos sobre arquitetura e por isso dependia de um perfil ainda mais específico de usuários do Arquigrafia, como biblioteconomistas e curadores de acervos, que possuem um olhar clínico para catalogação e curadoria de objetos. Sendo assim, o teste em um curto período de tempo, poderia ser mais eficiente se fosse direcionado para esse perfil de usuários, especialmente convidando aqueles que costumam realizar esse tipo de atividade no domínio de imagens de arquitetura em outras plataformas como Wikipedia ou Wikimedia.

Foram observados 10 aprendizados no ciclo 6 :

1. não é possível avaliar funcionalidades novas e que dependem de pesquisas ou estudos por parte do usuário, como a revisão de dados, em períodos curtos de disponibilização do experimento em produção. No contexto do Arquigrafia, levou aproximadamente 2 meses para começar a surtir os primeiros efeitos. No entanto, aguardar dois meses para saber se uma funcionalidade foi eficaz ou não na melhora do engajamento não é uma opção durante o período de desenvolvimento.

2. atividades que dependem de habilidades específicas de usuários precisam ser executadas em laboratório com métricas subjetivas de engajamento, de modo a obter resultados em curto período de tempo. Nesse caso, é preciso dar enfoque ao perfil específico que melhor se adeque ao novo tipo de atividade. Esse novo perfil pode inclusive ser um novo perfil de usuário que ainda não era considerado como usuário típico do sistema.

O enfoque sobre métricas subjetivas de engajamento para experimentos em laboratório, advém do fato que o grande valor da análise de métricas objetivas de engajamento decorre da análise do comportamento do usuário em seu contexto real de uso. Em um teste realizado em laboratório, o usuário receberá atividades específicas para realizar em um período de tempo determinado, sendo assim não é o seu real engajamento com o sistema, e sim um artificial. Mas, as métricas subjetivas de engajamento referem-se à percepção do usuário, em relação à sua atenção focada, à usabilidade percebida, o apelo estético da interface e a recompensa que o usuário sentiu ao conseguir finalizar uma atividade proposta. Portanto, são dimensões que o usuário consegue avaliar no primeiro contato. O convite a usuários pertencentes a novos perfis também pode servir como um meio de divulgação do projeto.

3. necessidade de identificar quais novas funcionalidades podem não pertencer ao escopo de habilidades ou interesses dos atuais membros do projeto. A revisão de dados exige além de conhecimentos específicos de arquitetura e urbanismo, também conhecimentos de como pesquisar, catalogar e organizar dados de acervos. Somados a esses conhecimentos, exige também a motivação do usuário em compartilhá-los, seja para treinar seus conhecimentos e consequentemente reforçá-los, seja para contribuir com a comunidade do sistema. É uma atividade, portanto, que pode ser desenvolvida para promover aprendizado para usuários.

4. análise da correlação de cada ação realizada com cada métrica de engajamento e não apenas da quantidade de ações realizadas como é medido pela métrica Ações. Esse entendimento decorreu do fato de mais ações em um grupo resultarem em notas menores na Escala de Engajamento de Usuário, enquanto mais ações em outro grupo de usuários resultou em notas mais altas. Sendo assim, o conjunto de ações acessado interferiu diretamente na percepção que o usuário teve do sistema e por isso é preciso saber como cada 
ação afetou o engajamento. As correlações ajudam a entender se os efeitos foram positivos ou negativos sobre o engajamento.

5. categorização das ações dos usuários de acordo com os tipos de elementos de interação acessados para realizar a ação: elementos colaborativos, elementos de projeto de jogos e elementos funcionais.

6. análise de engajamento por meio do cruzamento entre as ações recorrentes dos usuários combinadas com o tempo médio de reação do usuário a cada ação. Essa análise pode informar melhor o engajamento do usuário do que apenas a frequência de ações sozinhas.

7. análise das táticas de uso com MRPs como uma forma de melhor compreender os padrões de ação por grupo de usuários com notas baixas, médias e altas a partir da UES.

8. aplicação do mesmo tipo de análise utilizado para avaliar métricas subjetivas de engajamento com notas baixas, médias e altas a partir da UES, para avaliar as notas baixas, médias e altas para cada métrica objetiva de engajamento. Portanto, refere-se a análise da distribuição de acessos a cada tipo de elemento de interação do usuário de acordo com as notas baixas, médias e altas para cada métrica objetiva de engajamento.

9. análise de notas baixas, médias e altas a partir da UES para realizar a pesquisa correlacional entre tipos de elementos de interação acessados ou entre elementos de interação em isolamento.

10. personalizações de acordo com cada grupo de usuários que possui táticas de uso específicas e tipos de elementos de interação mais utilizados. Por exemplo, apresentar uma versão gamificada para um grupo que respondeu melhor a elementos de jogos e uma versão não-gamificada para um grupo onde o contrário aconteceu.

\subsection{Reflexão sobre os 7 ciclos de pesquisa-ação no Arquigrafia}

O período sem novidades, como visto em outros ciclos, pode resultar em redução das métricas de engajamento analisadas. Esse comportamento é especialmente verdadeiro em comunidades, que necessitam de eventos cíclicos que possibilitam que usuários reengajem-se com o sistema. No caso de comunidades onlines, esses eventos cíclicos precisam ser fomentados por atividades colaborativas no próprio sistema com passos bem definidos, objetivos a serem alcançados e o reconhecimento para quem os cumprir. Nesse sentido, elementos de jogos, como apresentados pela pontificação, podem ser adequados para motivar extrinsecamente usuários ainda não motivados.

Conforme Ryan e Deci [RD00a], a motivação extrínseca, refere-se a fazer alguma coisa porque ela conduz a um resultado separado. Contudo, quando esse resultado é alcançado, o interesse pela atividade finaliza a menos que novos objetivos sejam propostos. Porém, no caso de comunidades de prática, onde espera-se compartilhar conhecimento, os resultados separados precisam ser muito bem projetados para que não se criem mecanismos para manter usuários realizando ações no sistema que não interessam a comunidade núcleo e muito menos agregam conhecimento ao usuário.

Para a interação com o sistema ser inerentemente interessante ou agradável, ela precisa atender às necessidades psicológicas do ser humano, ou as necessidades inatas para a competência, autonomia e relacionamento, que se referem à satisfação de uma pessoa ao realizar uma tarefa. Nesse caso, a interação agrega valor ao usuário que interage com o sistema. Dessa forma, as atividades de valor para equipe nuclear, que formou a comunidade, devem ser associadas ao atendimento de necessidades inatas do usuário, assim ambos lados se beneficiam.

A estratégia colaborativa proposta visava atender a essas necessidades para construção de comunidades de prática baseada em motivação intrínseca, o que é discutido na literatura sobre a 
teoria de gamificação, mas pouco aplicada na prática, ou quando aplicada, os passos para executála não são informados. Nesta pesquisa buscamos apresentar os passos de inserção de pontificação, de monitoramento das métricas de engajamento e de instanciação de uma proposta de abordagem no contexto do Arquigrafia.

No entanto, apenas uma parte da estratégia foi implementada devido à redução da equipe de desenvolvimento para apenas 1 desenvolvedor no ciclo 5 e a necessidade de inserir os elementos de forma isolada para que os experimentos pudessem ser realizados. Sendo assim, foi implementada apenas parte da estratégia colaborativa, que no entanto teve o projeto de design de interface desenvolvido por completo pela equipe de três designers.

A inserção de parte da estratégia é necessária para avaliar engajamento resultante a partir de cada nova funcionalidade, inclusive, essa é uma boa prática para ir disponibilizando software funcionando para avaliação dos usuários, conforme filosofia ágil. Porém, o tempo não pode ser muito longo para inclusão de todos os elementos de uma mesma estratégia. Dois caminhos podem ocorrer aqui. Se possui uma equipe pequena, é possível realizar o desenvolvimento da segunda funcionalidade durante o período de avaliação da primeira. Se a equipe é grande, diversos elementos podem ser desenvolvidos em paralelo com o objetivo de disponibilizar simultaneamente aos usuários os elementos que fazem parte de uma mesma estratégia colaborativa por meio de versões distintas que serão direcionadas aleatoriamente aos usuários que acessam o sistema. Em qualquer caso, para obter resultados em curto período de tempo, o experimento em laboratório pode ser executado.

A partir da análise da Figura 6.4 percebemos que o acesso de visitantes do Arquigrafia sofreu uma redução ao longo de três anos de monitoramento. No entanto, a duração média da sessão aumentou em 1 minuto. A distribuição de acessos ocorre de forma mais regular no ciclo 6 do que no pré-ciclo 0 em que um pico de acesso ocorre em meados de 08 de novembro de 2014 e a partir de 13 de dezembro de 2014 reduz substancialmente. Contudo, é importante ressaltar que o período de análise influencia bastante esse tipo de avaliação, pois podem ser os meses com menor acesso do ciclo 6 sendo comparados com os meses de maior acesso do pré-ciclo 0. 

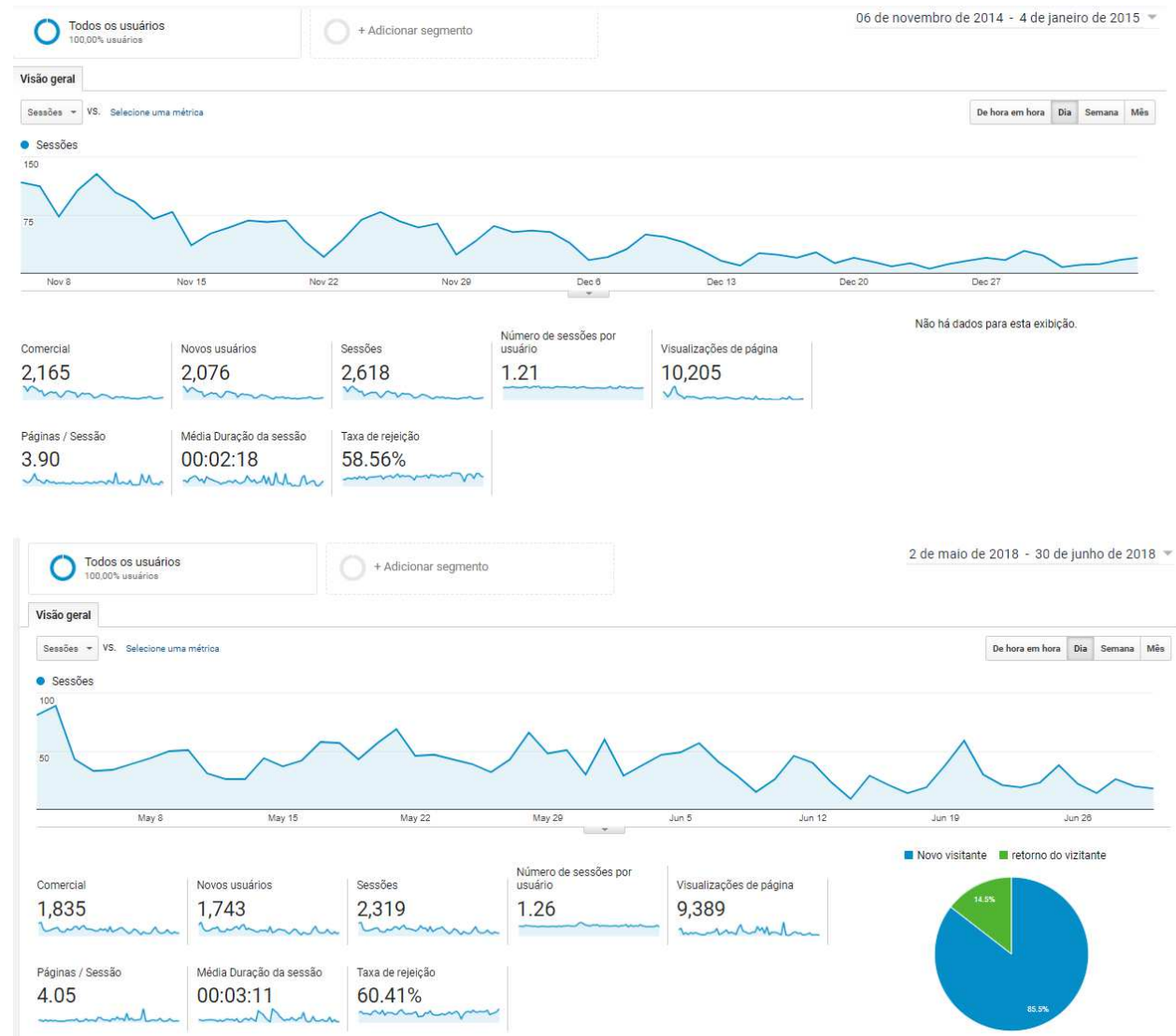

Figura 6.4: Comparação entre os 60 dias finais do Pré-Ciclo $0(06 / 11 / 2014$ - 04/01/2015) e do ciclo 6 (02/05/2018 - 30/06/2018) para a visão geral do Google Analytics.

Por esse motivo, acrescentamos a análise ano a ano de 2014 a 2017 na Figura 6.5 com o objetivo de diluir o efeito de períodos de maior ou menor acesso ao longo de 1 ano. O ano de 2018 não foi incluído porque a pesquisa-ação finalizou em 30 de junho de 2018.

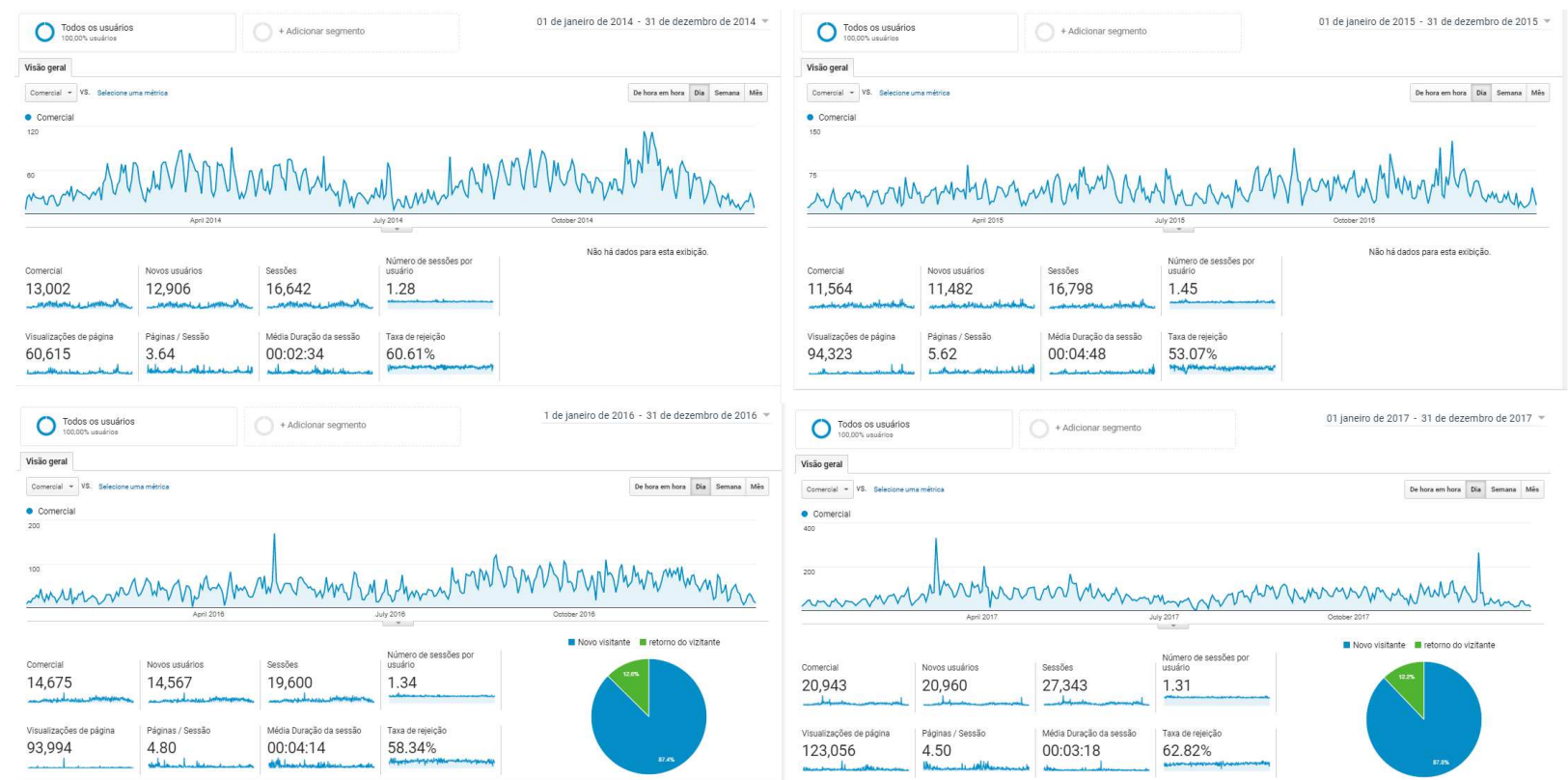

Figura 6.5: Comparação de 2014 a 2017 para a visão geral do Google Analytics.

A análise de 2014 a 2017 evidencia melhoria das métricas monitoradas, e deixa claro o fato de que o ano com maior frequência de alterações no sistema (2015) apresenta os melhores resultados 
para as métricas número de sessões por usuário, páginas por sessão, média de duração da sessão e taxa de rejeição. Enquanto que o ano com maior quantidade de eventos (2017) apresenta os melhores resultados para as métricas comercial, novos usuários, sessões e visualizações de páginas. Portanto, eventos influenciam no interesse de novos usuários, enquanto que mudanças no sistema afetam o comportamento do usuário durante a interação.

Por fim, desde seu lançamento em 2011 até 31 de dezembro de 2014 (4 anos), o Arquigrafia apresentou 581 usuários cadastrados; 936 imagens a partir de 71 usuários; 4518 imagens a partir de 2 acervos; 75 comentários a partir de 25 usuários; 292 álbuns a partir de 228 usuários; e 42 interpretações de imagens a partir de 20 usuários. A Tabela 6.7 apresenta os dados de produção para o ciclo 6 .

Tabela 6.7: Dados do sistema em produção para o ciclo 6

\begin{tabular}{ll}
\hline Dados & Quantidade \\
\hline Usuários & 3728 cadastrados \\
Imagens & 3787 imagens a partir de 295 usuários \\
& 9448 imagens a partir de 3 acervos \\
Comentários & 169 comentários a partir de 63 usuários \\
Álbuns & 491 álbuns a partir de 345 usuários \\
& 8 álbuns a partir de 2 acervos \\
Interpretações de imagens & 1327 a partir de 189 usuários \\
Notificaçôes & 1656, sendo 398 de seguir um usuário, \\
& 1147 de curtir uma imagem, 34 de curtir \\
& um comentário, 41 de comentário \\
& postado, 8 de obtenção de distintivos, 21 \\
de sugestões recebidas e 7 de sugestões \\
Curtir & aceitas \\
Distintivos & 1182 a partir de 158 usuários \\
Chat & 8 para 8 usuários \\
Revisões de dados & 45 mensagens a partir de 12 usuários \\
\hline
\end{tabular}

De 2015 até 30 de junho de 2018 (3 anos e meio), o Arquigrafia apresentou 3728 usuários cadastrados; 3787 imagens a partir de 295 usuários; 9448 imagens a partir de 3 acervos; 169 comentários a partir de 63 usuários; 491 álbuns a partir de 345 usuários; 8 álbuns a partir de 2 acervos; e 1327 interpretações de imagens a partir de 189 usuários. Além das novas funcionalidades que foram criadas ao longo dos ciclos que ainda não existiam em 2015: notificações, curtir, distintivos, chat e revisão de dados. Foram 3147 novos usuários ou um aumento de 541,65\%, com 2851 novas imagens cadastradas por usuários ou um aumento de 304,59\% e 1285 novas interpretações de imagens que correspondem a um aumento de 3059,52\%. Portanto, concluímos que as mudanças realizadas durante os ciclos de pesquisa-ação apresentaram efeitos positivos sobre o engajamento do usuário com o sistema.

Porém, ainda não ficou claro se houve melhora do engajamento a partir do acesso aos elementos de jogo. O próximo capítulo apresenta a pesquisa quantitativa não-experimental que busca responder a QPI e o Capítulo 8 apresentará, por fim, os resultados dos Capítulos 5, 6 e 7 para responder a QPII. 


\section{Capítulo 7}

\section{Pesquisa correlacional e causal-comparativa sobre dados de 2015 a 2018}

Zichermann e Cunningham [ZC11] informaram que nenhuma métrica pode sozinha medir engajamento de forma satisfatória, o que também é reforçado pelo modelo de engajamento de O'Brien e Toms [OT08]. Para monitorar o engajamento de usuários no Arquigrafia, entre 14 de junho de 2015 e 30 de junho de 2018, utilizamos um conjunto com oito métricas objetivas, dentre elas, cinco foram definidas por Zichermann e Cunningham - recenticidade, frequência, duração, viralidade e classificação -, descritas no Capítulo 2.

A métrica frequência foi monitorada em dois níveis: quantidade média de sessões de usuário por dia e a quantidade de dias de acesso em um período. Para distingui-los, foram denominadas as métricas frequência e ndias, respectivamente. As métricas frequência e duração são calculadas sobre cada sessão de usuário. Uma sessão de usuário foi definida em 600 segundos, uma vez que a métrica "Duração média da sessão" coletada pelo Google Analytics configurado para o Arquigrafia, informa que $90 \%$ das sessões de usuário do sistema ocorrem dentro de 600 segundos ou 10 minutos. Portanto, para frequência e duração, é contabilizada uma sessão se a próxima ação do usuário, em relação à última do mesmo dia, estiver dentro de um intervalo de 10 minutos entre uma ação e outra. Caso contrário, uma nova sessão é contabilizada.

A partir de novembro de 2017, passamos a monitorar também a métrica Ações e a métrica Tempo de reação. A métrica Ações, conforme relatada por Iacovides et al. [ $\mathrm{ICM}^{+}$15] e Hamari [Ham17], indica a quantidade de ações realizadas pelo usuário no período em análise. Por fim, a métrica Tempo de reação apresenta a diferença média em segundos entre uma ação e outra realizada pelo usuário, ou duas ações consecutivas. O interesse por essa métrica surgiu a partir do conhecimento dos estudos de Smallwood et al. [SDH $\left.{ }^{+} 04\right]$.

Esses pesquisadores da área de psicologia, relataram engajamento e desengajamento em tarefas durante o Teste de resposta à atenção sustentada (Sustained Attention to Response Test (SART)) [MR05]. SART é um teste de laboratório projetado para medir lapsos de atenção. Nele os participantes visualizam um monitor de computador e precisam pressionar uma tecla de resposta após cada apresentação, exceto para um dígito (no-go digit), para o qual nenhuma resposta deve ser informada. Os pesquisadores realizaram experimentos para investigar a relação entre a experiência subjetiva do participante e os lapsos de atenção. Os resultados sugeriram que durante a atenção sustentada, as pessoas experimentam o pensamento não relacionado com a tarefa (Task Unrelated Thought (TUT)), que corresponde a um desengajamento a partir de uma mente distraída da tarefa [SDH ${ }^{+}$04, SOH03]. TUT [SOH03] e lapsos de atenção são atribuídos a situações de tédio e preocupação $\left[\mathrm{RMA}^{+} 97, \mathrm{SDH}^{+}\right.$04]. No contexto do SART e sob condições de baixa probabilidade de alvo, os tempos de reação mais curtos foram relacionados à distração mais significativa e insensibilidade à tarefa. Robertson et al. [RMA ${ }^{+}$97] apóiam essa afirmação ao relatar que o fenômeno "Oops", associado a erros, sugere que a detecção de erros tende a redirecionar a atenção para a tarefa, resultando 
em um tempo de reação mais lento para encontrar a resposta correta.

Contudo, geralmente associa-se maior engajamento de usuários ao aumento de certos comportamentos como frequência de cliques [EK17]. No entanto, em estudos no contexto de ações de busca, que são muito comuns no contexto de GLAMs, como o Arquigrafia, existe evidência que os usuários mais engajados realizavam menos ações de busca [OL13], e ao contrário, quando os usuários estavam frustrados exibiam mais comportamentos de busca [EK17, OL13, FA09]. Por esse motivo, incluímos o tempo de reação dos usuários para avaliar como eles se relacionam com o engajamento ou frustração dos usuários com o sistema. A Tabela 7.1 apresenta um sumário de como as métricas objetivas de engajamento - do tipo comportamental - são calculadas no Arquigrafia, a partir da coleta do registro de ações de usuários.

Tabela 7.1: Métricas de engajamento objetivas do tipo comportamental utilizadas para monitoramento e análise do engajamento do Arquigrafia ao longo de três anos (2015-2018).

\begin{tabular}{|c|c|c|}
\hline Métrica & Descrição & Cálculo \\
\hline $\begin{array}{l}\text { Frequência } \\
\text { (frequency) }\end{array}$ & $\begin{array}{l}\text { Média de sessões do usuário por } \\
\text { dia de acesso ao sistema }\end{array}$ & $\begin{array}{l}\text { SOMA(sessões de usuário por dia)/Qtde. de dias de acesso } \\
\text { de cada usuário para período considerado }\end{array}$ \\
\hline $\begin{array}{l}\text { Recenticidade } \\
\text { (recency) }\end{array}$ & $\begin{array}{l}\text { Tempo em dias entre último e } \\
\text { penúltimo dia de acesso }\end{array}$ & $\begin{array}{l}\text { Último dia de acesso - Penúltimo dia de acesso para } \\
\text { período considerado }\end{array}$ \\
\hline $\begin{array}{l}\text { Duração } \\
(\text { duration })\end{array}$ & $\begin{array}{l}\text { Tempo médio de uso do sistema } \\
\text { para cada usuário }\end{array}$ & $\begin{array}{l}\text { SOMA(tempo médio em segundos de sessões de usuários } \\
\text { por dia)/Qtde. de dias de acesso de cada usuário para } \\
\text { período considerado }\end{array}$ \\
\hline $\begin{array}{l}\text { Viralidade } \\
\text { (virality) }\end{array}$ & $\begin{array}{l}\text { Acessos a partir de usuários } \\
\text { influenciados por outros }\end{array}$ & $\begin{array}{l}\text { SOMA(acessos de usuários a partir de posts no Facebook, } \\
\text { Google+ ou a partir de notificações do sistema geradas para } \\
\text { usuários que seguem outros durante período considerado) }\end{array}$ \\
\hline $\begin{array}{l}\text { Classificação } \\
\text { (ratings) }\end{array}$ & $\begin{array}{l}\text { Classificações de conteúdo em } \\
\text { termos de qualidade, quantidade } \\
\text { ou ambas realizadas por usuários }\end{array}$ & SOMA(Comentários + Likes para período considerado) \\
\hline Ações (actions) & $\begin{array}{l}\text { Quantidade de ações realizadas } \\
\text { pelo usuário }\end{array}$ & $\begin{array}{l}\text { SOMA(ações realizadas pelo usuário para período } \\
\text { considerado) }\end{array}$ \\
\hline $\begin{array}{l}\text { Tempo de } \\
\text { reação (reaction } \\
\text { time) }\end{array}$ & $\begin{array}{l}\text { Diferença média em segundos entre } \\
\text { uma ação e outra realizada pelo } \\
\text { usuário, ou duas ações consecutivas }\end{array}$ & $\begin{array}{l}\text { SOMA(diferenças de acesso em segundos entre uma ação e } \\
\text { outra de um mesmo dia)/Qtde. de acessos de cada usuário } \\
\text { para período considerado (removendo o primeiro acesso de } \\
\text { cada dia para o qual não é possível calcular a diferença) }\end{array}$ \\
\hline Ndias (ndays) & $\begin{array}{l}\text { Quantidade de dias de acesso de } \\
\text { cada usuário }\end{array}$ & $\begin{array}{l}\text { SOMA(dias de acesso de cada usuário para período } \\
\text { considerado) }\end{array}$ \\
\hline
\end{tabular}

Para realizar a pesquisa, levou-se em consideração que ações de usuários estão relacionadas a elementos de interação de usuário com o sistema, conforme resultado do ciclo 6 da pesquisa-ação. Portanto, utilizamos a classificação definida na Tabela 6.6 para realizar análises com elementos de jogos (gamificação), elementos colaborativos (colaboração) e elementos funcionais (função).

As próximas seções apresentam as análises correlacionais e causais-comparativas sobre as métricas objetivas, as ações realizadas pelos usuários e os tipos de elementos acessados, bem como, a evolução das métricas ao longo dos três anos de monitoramento.

\subsection{Evolução do engajamento de usuários de 2015 a 2018}

A Figura 7.1 apresenta o monitoramento das métricas de 2015 a 2018. Os anos de 2015 e 2018 apresentam 6 meses de monitoramento: 14 de junho de 2015 a 31 de dezembro de 2015; e 01 de janeiro de 2018 a 30 de junho de 2018, respectivamente. Os anos de 2016 e 2017 apresentam as métricas monitoradas para o ano inteiro: de 01 de janeiro a 31 de dezembro de 2016 e 2017, respectivamente. 
A métrica ndias não foi inserida porque ela considera a quantidade de dias de acesso em um período e para esse gráfico são apresentadas as atividades por dia de acesso. As métricas ações, classificação e viralidade apresentam a soma dessas atividades no dia para todos os usuários e as demais métricas apresentam a média para todos os usuários que acessaram no dia. O maior pico de acessos ocorreu em 2016 durante uma oficina de atividades com alunos da FAU, para realizarem avaliações de imagens e na sequência participarem de um teste de usabilidade sobre o protótipo do aplicativo móvel que estava em desenvolvimento.

De um modo geral, todos os picos de atividades representam eventos do projeto que são divulgados no Facebook, bem como, por e-mail aos usuários cadastrados. Exemplos de eventos são atividades com ingressantes do curso de Arquitetura e Urbanismo da FAU, entrada de novas funcionalidades no sistema e a realização de testes de usabilidade. A métrica recenticidade aumentou como efeito de ser inicializada com 0 (zero). Nesse caso, o fato da recenticidade ser maior, indica que: 1) mais usuários antigos voltaram a acessar em um determinado período; e 2) esses usuários antigos não acessavam por um período de tempo.
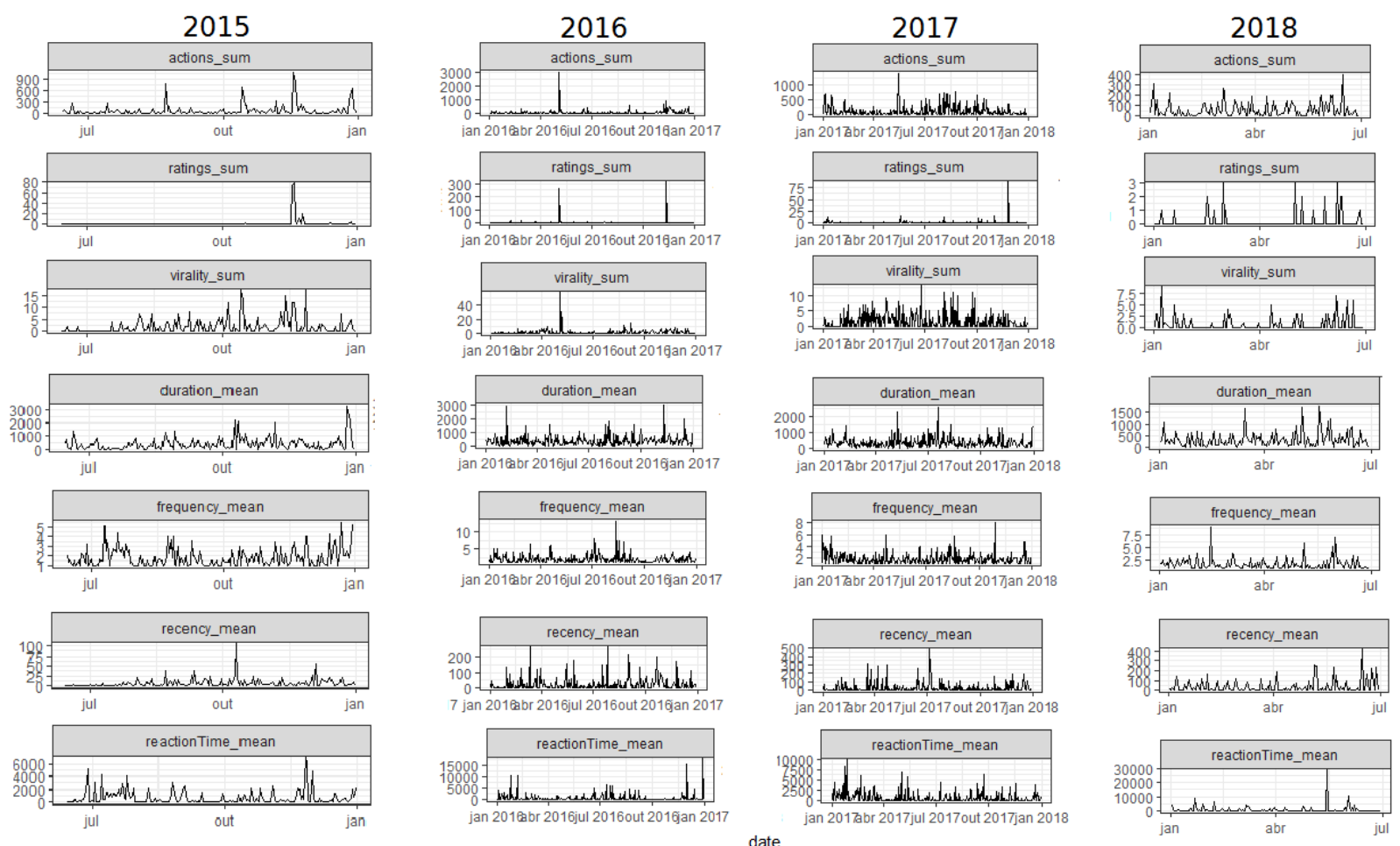

Figura 7.1: Monitoramento de métricas objetivas de engajamento do Arquigrafia ano a ano entre $14 / 06 / 2015$ e $30 / 06 / 2018$.

O monitoramento por registro de ações de usuários (logs) iniciou em 14 de junho de 2015. Por esse motivo, não temos dados para o período de 01 de janeiro de 2011 a 13 de junho de 2015. Contudo, no Ciclo 0 descrito no Capítulo 5, são apresentados dados do Google Analytics e do banco de dados em produção que evidenciam crescimento na quantidade de usuários e ações realizadas no sistema entre 2011 e 2018. A partir do monitoramento com logs, inicia-se um período de intenso desenvolvimento e atualizações no sistema que começam a ser disponibilizadas a partir de 23 de junho de 2015 com a entrada do elemento de notificação e finaliza em 23 de dezembro de 2015. Após esse período, atividades de desenvolvimento relativas às análises das métricas foram desenvolvidas paralelamente com o desenvolvimento da primeira versão do aplicativo móvel Android, disponível em setembro de 2016, e o desenvolvimento de uma landing page, disponível em dezembro de 2016. Em 31 de julho de 2017, foi disponibilizada a funcionalidade de chat e melhorias no aplicativo móvel; e em 16 de novembro de 2017 foi disponibilizada a funcionalidade de Revisão de dados em duas versões - com e sem gamificação - para realização de um experimento de campo online. Após 
essa data, nenhuma nova funcionalidade foi inserida no sistema e apenas correções pontuais foram realizadas.

Portanto, o período de maior intensidade de mudanças no sistema compreendeu 23 de junho de 2015 a 23 de dezembro de 2015; setembro e dezembro de 2016; e julho e novembro de 2017. Em 2015, existiam atualizações semanais com melhorias e novas funcionalidades no sistema. A partir de 2016, as mudanças foram pontuais aos meses citados. O período de mudanças contínuas e intensas, reflete um aumento em todas as métricas, com respeito a picos de acesso e maior distribuição e intensidade de acessos ao longo do período. Oito meses sem alterações significantes no sistema (entre janeiro e agosto de 2016) representam uma diminuição gradativa na intensidade de ações de usuários, embora ainda existam picos que estão relacionados a eventos do projeto que sustentam acessos até que ocorram novas mudanças. A intensidade de ações volta a aumentar lentamente a partir de dezembro de $2016 \mathrm{com}$ a entrada da landing page e intensifica-se novamente a partir de 26 de junho de 2017 quando um teste de usabilidade em laboratório marca um pico de atividades que é mantido após a divulgação no Facebook de atualizações da landing page e melhorias no aplicativo Android.

De junho a novembro de 2017 ocorre o movimento mais intenso de usuários distintos realizando ações no sistema. A partir de dezembro de 2017, existe uma nova queda nas métricas, com uma leve recuperação nos meses de janeiro e fevereiro de 2018, mantendo uma melhor distribuição de ações por dia de acesso do que ocorreu entre junho e dezembro de 2015 e de janeiro a junho de 2016, embora menor do que em 2017.

É importante ressaltar que na análise das métricas do Google Analytics apresentada nas seções sobre avaliação dos ciclos da pesquisa-ação, no Capítulo 5, a intensidade de acessos segue o mesmo comportamento do que é apresentado neste capítulo, embora o Google Analytics considere acessos de quaisquer usuários, independentemente de serem usuários logados ou visitantes, enquanto a análise deste capítulo considera apenas acessos de usuários logados.

Contudo, o engajamento de usuários com cada ação foi distinto ao longo do tempo. A Figura 7.2 apresenta o engajamento de usuários para 22 ações dentre 25 monitoradas que tiveram as métricas ação e duração diferentes de zero. As três ações monitoradas que tiveram a métrica ação ou a métrica duração igual a zero foram: rejeitar sugestão de usuário, visualizar pontos obtidos após sugestão de dados para imagens e acesso ao jogo duradouro após sugestão de dados ${ }^{1}$.

\footnotetext{
${ }^{1}$ As três ações com a métrica ação ou a métrica duração igual a zero foram inseridas em 16 de novembro de 2017 e até 30 de junho de 2018 ainda não tinham acessos registrados a elas. Essas ações estão relacionadas com a revisão de dados de uma foto inserida por usuários privados. Mais detalhes sobre a inserção da funcionalidade de revisão de dados e a diferença de acessos a versões com e sem elementos de jogos estão disponíveis no artigo 9 da Seção 1.5 .
} 


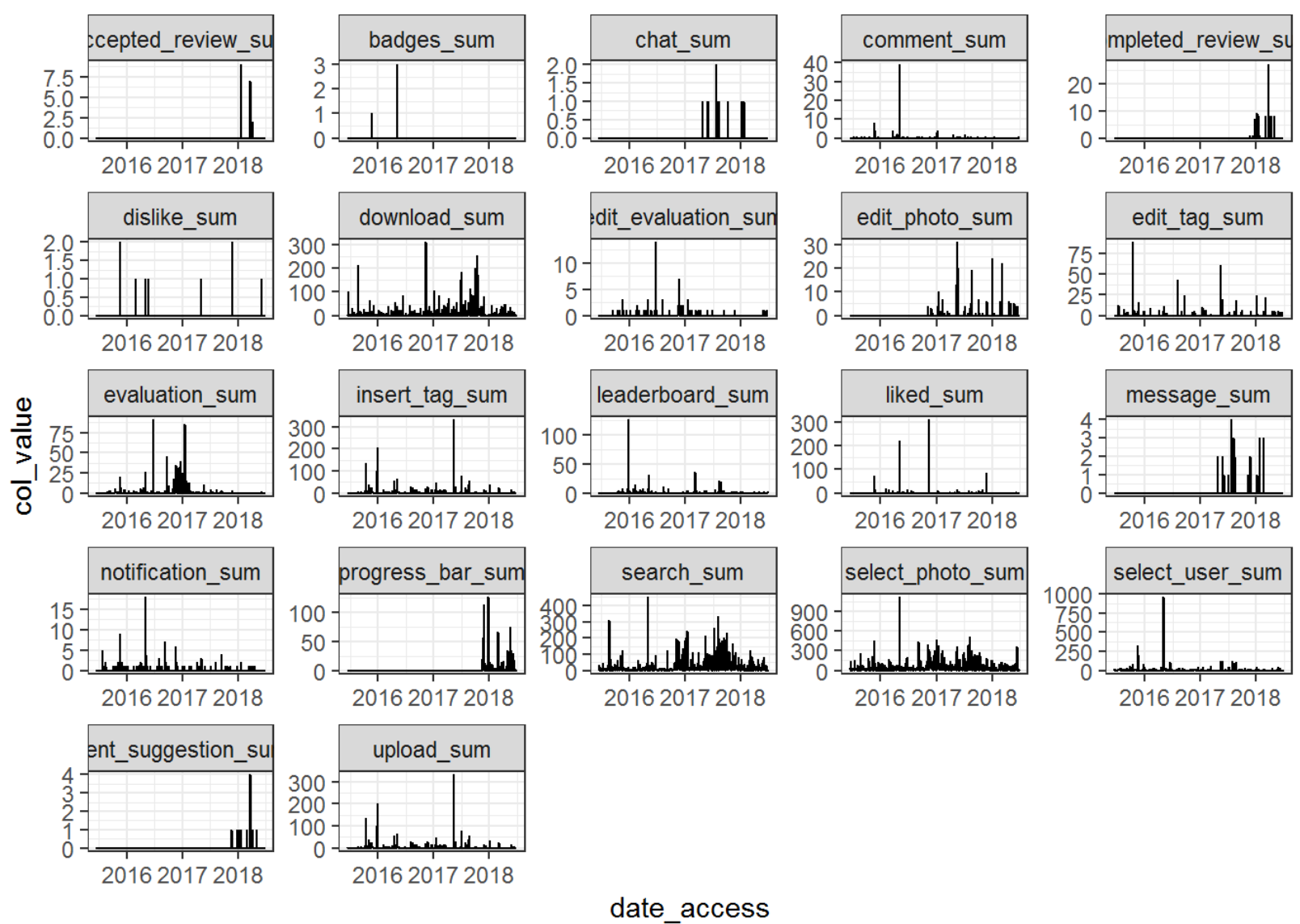

Figura 7.2: Monitoramento de cada ação ao longo do período entre 14/06/2015 e 30/06/2018.

Das 22 ações, 11 tiveram acima de 75 acessos por dia. São elas: Edição de tag e Avaliação de imagem que atingiram picos de 75 acessos por dia; Acesso ao quadro de liderança e Acesso à barra de progresso (progress bar) com picos de 100 acessos por dia; Download, Inserção de tag, Like e Upload de imagem com picos de 300 acessos por dia; Busca com pico de 400 acessos por dia; Seleção de imagem e Seleção de usuário com picos próximos de 1000 acessos por dia. Essas foram, portanto, as ações que mais foram realizadas ao longo dos três anos de monitoramento do Arquigrafia. Dentre elas, quatro ações foram relacionadas a elementos funcionais: Download, Busca, Seleção de imagem e Seleção de usuário, que por sua vez, foram as ações mais realizadas pelos usuários do sistema, e, são ações passivas de consumo de dados, em vez de ativamente colaborar com novos dados ou informações. Cinco ações foram relacionadas a elementos colaborativos: Edição de tag, Avaliação de imagem, Inserção de tag, Like e Upload de imagem; e duas ações foram relacionadas a elementos de projeto de jogos: Acesso ao quadro de liderança e Acesso à barra de progresso.

Portanto, os resultados indicam que houve um aumento do engajamento durante o período em que existiram alterações no sistema e eventos do projeto e que a maior parte das ações realizadas referem-se a consumo de dados. A visão geral descrita nesta seção serviu de filtro para as análises que serão apresentadas nas próximas seções.

\subsection{Pesquisa correlacional}

A pesquisa correlacional busca avaliar a relação entre variáveis [GMA06]. A pesquisa correlacional no Arquigrafia busca compreender como as ações, tipos de elementos de interação ou conjuntos de elementos de interação distintos, acessados pelos usuários, correlacionam-se com as métricas de engajamento resultantes.

Para 2243 usuários distintos, que acessaram o sistema entre 2015 e 2018, foram selecionados apenas os usuários que realizaram ações no sistema (além de simplesmente logar) e tiveram duração 
média de sessões diferente de zero. Após esse filtro, métricas coletadas a partir de 1591 usuários distintos foram analisadas. Sete correlações foram realizadas sobre os dados desses usuários. São elas:

1. Correlação entre ações independentes acessadas pelos usuários e cada métrica objetiva;

2. Correlação entre tipos de elementos de interação de usuário acessados e cada métrica objetiva;

3. Correlação entre acessos apenas a elementos funcionais e cada métrica objetiva;

4. Correlação entre acessos ao conjunto de elementos funcionais e de jogo e cada métrica objetiva;

5. Correlação entre acessos ao conjunto de elementos funcionais e de colaboração (um dos 3Cs) e cada métrica objetiva;

6. Correlação entre acessos ao conjunto de elementos funcionais, de jogo e de colaboração (um dos $3 \mathrm{Cs}$ ) e cada métrica objetiva; e

7. Correlação entre acessos ao conjunto de elementos funcionais, de jogo e de Comunicação, Coordenação e Cooperação (todos os 3Cs de Colaboração) e cada métrica objetiva.

A correlação 1 verifica se existem correlações significativas entre a quantidade de acessos a cada uma das 22 ações apresentadas na Figura 7.2 e cada uma das 8 métricas objetivas de engajamento. A correlação 2 verifica se existem correlações significativas entre a quantidade de acessos a cada tipo de elemento - funcional, de jogo ou de colaboração - e cada métrica objetiva de engajamento. As correlações de 3 a 6 referem-se aos cruzamentos possíveis para acessos aos tipos de elementos de interação: apenas elementos funcionais, apenas elementos de jogos, apenas elementos de colaboração, conjunto funcionais + jogo, conjunto funcionais + colaboração, conjunto funcionais + jogo + colaboração e conjunto jogo + colaboração. Contudo, não existiram acessos apenas a elementos de jogos e ao conjunto jogo + colaboração; e somente 2 acessos foram contabilizados apenas a elementos de colaboração. Portanto, a análise foi restrita aos demais cruzamentos citados, nos quais, sempre existe o acesso a elementos funcionais. O objetivo foi verificar se existiam correlações significativas entre cada métrica objetiva de engajamento e acessos a apenas um desses conjuntos.

Adicionalmente, foi feita uma distinção entre acessos a qualquer elemento de colaboração e acessos a elementos que compreendem todos os 3Cs de colaboração - Comunicação, Coordenação e Cooperação. A correlação 7 trata desta distinção, tendo como objetivo compará-la com a correlação 6 e verificar se existem diferenças entre acessos a todos os elementos de colaboração ou apenas a alguns na correlação positiva ou negativa com as métricas objetivas.

A função da ferramenta $\mathrm{R}$ para calcular o coeficiente de correlação de classificação de Spearman (Spearman's rank correlation coeficient) foi utilizada para medir a força da relação entre duas variáveis - ou as 7 correlações descritas acima - isto é, medir o tamanho de efeito entre elas. Esta função foi selecionada porque os dados não são paramétricos, conforme teste de normalidade de Shapiro-Wilk (Shapiro-Wilk normality test). A Tabela 7.2 foi extraída de [Muk12] e apresenta diretrizes para interpretação do rho, ou o coeficiente de correlação de classificação de Spearman que se baseia em [Muk12, HWJ03].

Tabela 7.2: Diretrizes para interpretação do rho ou coeficiente de correlação de classificação de Spearman a partir de [Muk12].

\begin{tabular}{ll}
\hline Tamanho da correlação & Interpretação \\
\hline 0.90 a $1.0(-0.90$ a -1.0$)$ & Correlação positiva (negativa) muito alta \\
0.70 a $0.90(-0.70$ a -0.90$)$ & Correlação positiva (negativa) alta \\
0.50 a $0.70(-0.50$ a -0.70$)$ & Correlação positiva (negativa) moderada \\
0.30 a $0.50(-0.30$ a -0.50$)$ & Correlação positiva (negativa) baixa \\
0.00 a $0.30(0.00$ a -0.30$)$ & Correlação insignificante \\
\hline \hline
\end{tabular}


Para todas as análises estatísticas, consideramos o $p$-value $<0.05$ para definir os resultados como estatisticamente significativos. O intervalo de confiança de $95 \%$ para os coeficientes encontrados para cada correlação foi apresentado, e, para interpretar os resultados, consideramos o menor efeito apresentado para cada intervalo. As próximas subseções apresentam os resultados e a discussão para cada uma das sete correlações.

\subsubsection{Ações independentes X métricas objetivas}

Para facilitar a visualização das correlações para cada uma dentre as 22 ações realizadas por 1591 usuários, os resultados foram divididos em duas tabelas. A Tabela 7.3 apresenta as correlações para as métricas objetivas de engajamento: Frequência, Recenticidade, Duração e Viralidade. A Tabela 7.4 apresenta as correlações para as métricas: Ações, Ndias, Tempo de reação e Classificação. Os acessos a cada uma das ações foram contabilizados independentemente das demais ações que o usuário possa ter realizado, portanto, não foram acessos exclusivos a essas ações.

A métrica Frequência apresentou correlações positivas baixas com as seguintes ações: Seleção de imagem, Busca, Upload de imagem e Inserção de tag. Os intervalos de confiança para o rho dessas ações mantiveram as correlações como positivas baixas, no limite superior; e no limite inferior, apenas a ação Seleção de imagem manteve a correlação positiva baixa com intervalo de confiança (IC) de 95\%. A métrica Recenticidade apresentou correlações positivas baixas com as seguintes ações: Seleção de imagem, Busca, Seleção de usuário, Upload de imagem e Inserção de tag. Os intervalos de confiança para o rho dessas ações mantiveram as correlações como positivas baixas, no limite superior; e no limite inferior, apenas as ações Seleção de imagem e Seleção de usuário mantiveram a correlação positiva baixa com IC de $95 \%$.

A métrica Duração apresentou correlações positivas moderadas com as seguintes ações: Seleção de imagem e Busca; e apresentou correlações positivas baixas com as ações: Upload de imagem e Inserção de tag. Os intervalos de confiança para o rho dessas ações mantiveram a ação de Seleção de imagem como correlação positiva moderada e a busca diminuiu para correlação positiva baixa para o limite inferior do intervalo. No limite inferior do intervalo, Upload de imagem e Inserção de tag passam a não apresentar correlação significativa com IC de 95\%. A métrica Viralidade não apresentou correlações significativas com nenhuma das 22 ações.

A métrica Ações apresentou correlações positivas altas com as seguintes ações: Seleção de imagem e Busca; apresentou correlações positivas baixas com as ações: Download, Seleção de usuário, Like, Upload de imagem, Inserção de tag e Edição de tag. Os intervalos de confiança para o rho dessas ações mantiveram as correlações positivas altas das ações Seleção de imagem e Busca; e as correlações positivas baixas das ações Download, Seleção de usuário, Upload de imagem e Inserção de tag. A métrica Ndias apresentou correlações positivas baixas com as seguintes ações: Seleção de imagem, Busca, Seleção de usuário, Upload de imagem, Inserção de tag e Edição de tag. Com os intervalos de confiança de 95\%, apenas as ações Seleção de imagem, Seleção de usuário, Upload de imagem e Inserção de tag mantiveram as correlações positivas baixas com a métrica Ndias.

A métrica Tempo de reação apresentou correlações positivas baixas com a ação Seleção de imagem, Upload de imagem e Inserção de tag, contudo dentro do IC de 95\%, apenas a ação Seleção de imagem manteve a correlação positiva baixa. A métrica Classificação apresentou correlação positiva muito alta com a ação Like; correlação positiva moderada com a ação Comentário; e correlações positivas baixas com as ações: Seleção de imagem, Seleção de usuário, Avaliação de imagem, Upload de imagem, Inserção de tag e Notificação. Os intervalos de confiança para o rho dessas ações mantiveram a correlação positiva muito alta com a ação Like; diminuíram para correlação positiva baixa com a ação Comentário; e apenas as ações Seleção de usuário e Avaliação de imagem mantiveram-se com correlações positivas baixas para o IC de $95 \%$. 
Tabela 7.3: Correlações com Spearman's rank correlation rho entre ações independentes acessadas pelos usuários e cada métrica objetiva (2015 a 2018) - Recorte com as métricas Frequência, Recenticidade, Duração e Viralidade.

\begin{tabular}{|c|c|c|c|c|}
\hline $\begin{array}{l}22 \text { Ações } \\
\text { Indep. }\end{array}$ & $\begin{array}{l}\text { Freq. } \\
\text { IC }(95 \%)\end{array}$ & $\begin{array}{l}\text { Recentic. } \\
\text { IC }(95 \%)\end{array}$ & $\begin{array}{l}\text { Duração } \\
\text { IC }(95 \%)\end{array}$ & $\begin{array}{l}\text { Viral. } \\
\text { IC }(95 \%)\end{array}$ \\
\hline Download & $\begin{array}{l}0.16(3.76 \mathrm{e}-11) \\
0.11-0.21\end{array}$ & $\begin{array}{l}0.21(<2.2 \mathrm{e}-16) \\
0.15-0.25\end{array}$ & $\begin{array}{l}0.24(<2.2 \mathrm{e}-16) \\
0.20-0.28\end{array}$ & $\begin{array}{l}0.24(<2.2 \mathrm{e}-16) \\
0.18-0.29\end{array}$ \\
\hline $\begin{array}{l}\text { Seleção de } \\
\text { imagem }\end{array}$ & $\begin{array}{l}\mathbf{0 . 4 5}(<2.2 \mathrm{e}-16) \\
0.41-0.49\end{array}$ & $\begin{array}{l}\mathbf{0 . 4 3}(<2.2 \mathrm{e}-16) \\
0.39-0.47\end{array}$ & $\begin{array}{l}\mathbf{0 . 6 2}(<2.2 \mathrm{e}-16) \\
0.58-0.65\end{array}$ & $\begin{array}{l}0.24(<2.2 \mathrm{e}-16) \\
0.19-0.28\end{array}$ \\
\hline Busca & $\begin{array}{l}\mathbf{0 . 3 3}(<2.2 \mathrm{e}-16) \\
0.28-0.37\end{array}$ & $\begin{array}{l}\mathbf{0 . 3 2}(<2.2 \mathrm{e}-16) \\
0.27-0.36\end{array}$ & $\begin{array}{l}\mathbf{0 . 5 0}(<2.2 \mathrm{e}-16) \\
0.46-0.54\end{array}$ & $\begin{array}{l}0.20(2.548 \mathrm{e}-16) \\
0.15-0.25\end{array}$ \\
\hline $\begin{array}{l}\text { Seleção de } \\
\text { usuário }\end{array}$ & $\begin{array}{l}0.28(<2.2 \mathrm{e}-16) \\
0.23-0.33\end{array}$ & $\begin{array}{l}\mathbf{0 . 3 9}(<2.2 \mathrm{e}-16) \\
0.34-0.44\end{array}$ & $\begin{array}{l}0.18(2.129 \mathrm{e}-13) \\
0.13-0.23\end{array}$ & $\begin{array}{l}0.02(0.3543) \\
-0.03-0.07\end{array}$ \\
\hline Comentário & $\begin{array}{l}0.10(1.342 \mathrm{e}-05) \\
0.05-0.15\end{array}$ & $\begin{array}{l}0.12(1.169 \mathrm{e}-06) \\
0.06-0.18\end{array}$ & $\begin{array}{l}0.12(9.778 \mathrm{e}-07) \\
0.08-0.15\end{array}$ & $\begin{array}{l}0.14(1.442 \mathrm{e}-08) \\
0.07-0.20\end{array}$ \\
\hline $\begin{array}{l}\text { Avaliação de } \\
\text { imagem }\end{array}$ & $\begin{array}{l}0.23(<2.2 \mathrm{e}-16) \\
0.18-0.28\end{array}$ & $\begin{array}{l}0.20(5.849 \mathrm{e}-16) \\
0.14-0.25\end{array}$ & $\begin{array}{l}0.19(1.063 \mathrm{e}-15) \\
0.16-0.23\end{array}$ & $\begin{array}{l}0.11(1.944 \mathrm{e}-06) \\
0.05-0.17\end{array}$ \\
\hline Like & $\begin{array}{l}0.20(4.119 \mathrm{e}-16) \\
0.15-0.24\end{array}$ & $\begin{array}{l}0.19(8.961 \mathrm{e}-15) \\
0.14-0.24\end{array}$ & $\begin{array}{l}0.22(<2.2 \mathrm{e}-16) \\
0.18-0.26\end{array}$ & $\begin{array}{l}0.14(8.3 \mathrm{e}-09) \\
0.08-0.20\end{array}$ \\
\hline $\begin{array}{l}\text { Upload de } \\
\text { imagem }\end{array}$ & $\begin{array}{l}\mathbf{0 . 3 3}(<2.2 \mathrm{e}-16) \\
0.28-0.38\end{array}$ & $\begin{array}{l}\mathbf{0 . 3 5}(<2.2 \mathrm{e}-16) \\
0.29-0.39\end{array}$ & $\begin{array}{l}\mathbf{0 . 3 1}(<2.2 \mathrm{e}-16) \\
0.27-0.34\end{array}$ & $\begin{array}{l}0.09(0.0002678) \\
0.03-0.14\end{array}$ \\
\hline $\begin{array}{l}\text { Edição de } \\
\text { imagem }\end{array}$ & $\begin{array}{l}0.18(6.306 \mathrm{e}-14) \\
0.13-0.22\end{array}$ & $\begin{array}{l}0.18(3.795 \mathrm{e}-14) \\
0.13-0.23\end{array}$ & $\begin{array}{l}0.14(1.329 \mathrm{e}-08) \\
0.10-0.17\end{array}$ & $\begin{array}{l}0.04(0.09318) \\
-0.01-0.10\end{array}$ \\
\hline $\begin{array}{l}\text { Inserção de } \\
\text { tag }\end{array}$ & $\begin{array}{l}\mathbf{0 . 3 3}(<2.2 \mathrm{e}-16) \\
0.28-0.38\end{array}$ & $\begin{array}{l}\mathbf{0 . 3 5}(<2.2 \mathrm{e}-16) \\
0.29-0.40\end{array}$ & $\begin{array}{l}\mathbf{0 . 3 1}(<2.2 \mathrm{e}-16) \\
0.27-0.34\end{array}$ & $\begin{array}{l}0.09(0.0002285) \\
0.03-0.14\end{array}$ \\
\hline $\begin{array}{l}\text { Edição de } \\
\text { tag }\end{array}$ & $\begin{array}{l}0.26(<2.2 \mathrm{e}-16) \\
0.21-0.30\end{array}$ & $\begin{array}{l}0.28(<2.2 \mathrm{e}-16) \\
0.23-0.32\end{array}$ & $\begin{array}{l}0.18(2.282 \mathrm{e}-13) \\
0.14-0.22\end{array}$ & $\begin{array}{l}0.10(2.499 \mathrm{e}-05) \\
0.04-0.16\end{array}$ \\
\hline Dislike & $\begin{array}{l}0.10(4.227 \mathrm{e}-05) \\
0.04-0.14\end{array}$ & $\begin{array}{l}0.06(0.008008) \\
0.01-0.10\end{array}$ & $\begin{array}{l}0.05(0.04185) \\
0.01-0.07\end{array}$ & $\begin{array}{l}0.06(0.01045) \\
-0.005-0.12 \\
\end{array}$ \\
\hline $\begin{array}{l}\text { Edit. aval. } \\
\text { imagem }\end{array}$ & $\begin{array}{l}0.13(3.498 \mathrm{e}-08) \\
0.08-0.18\end{array}$ & $\begin{array}{l}0.12(6.542 \mathrm{e}-07) \\
0.06-0.17\end{array}$ & $\begin{array}{l}0.14(1.857 \mathrm{e}-08) \\
0.10-0.17\end{array}$ & $\begin{array}{l}0.10(2.983 \mathrm{e}-05) \\
0.03-0.17\end{array}$ \\
\hline Notificação & $\begin{array}{l}0.13(3.933 \mathrm{e}-08) \\
0.09-0.18\end{array}$ & $\begin{array}{l}0.19(1.13 \mathrm{e}-14) \\
0.13-0.23\end{array}$ & $\begin{array}{l}0.09(0.0001189) \\
0.05-0.13\end{array}$ & $\begin{array}{l}0.22(<2.2 \mathrm{e}-16) \\
0.16-0.27\end{array}$ \\
\hline $\begin{array}{l}\text { Acesso/ } \\
\text { Chat }\end{array}$ & $\begin{array}{l}0.06(0.005719) \\
0.02-0.10\end{array}$ & $\begin{array}{l}0.09(0.0002984) \\
0.04-0.12\end{array}$ & $\begin{array}{l}0.009(0.695) \\
-0.01-0.02\end{array}$ & $\begin{array}{l}0.04(0.08472) \\
-0.02-0.10\end{array}$ \\
\hline $\begin{array}{l}\text { Envio/ } \\
\text { mensagem }\end{array}$ & $\begin{array}{l}0.07(0.001582) \\
0.04-0.11\end{array}$ & $\begin{array}{l}0.10(1.424 \mathrm{e}-05) \\
0.06-0.14\end{array}$ & $\begin{array}{l}0.02(0.335) \\
-0.003-0.04 \\
\end{array}$ & $\begin{array}{l}0.05(0.03911) \\
-0.02-0.11\end{array}$ \\
\hline $\begin{array}{l}\text { Envio/ } \\
\text { sugestão }\end{array}$ & $\begin{array}{l}0.08(0.0005054) \\
0.05-0.12\end{array}$ & $\begin{array}{l}0.08(0.0008215) \\
0.03-0.11\end{array}$ & $\begin{array}{l}0.03(0.1799) \\
0.001-0.06\end{array}$ & $\begin{array}{l}0.08(0.0009442) \\
0.01-0.14\end{array}$ \\
\hline $\begin{array}{l}\text { Sugestão } \\
\text { aceita }\end{array}$ & $\begin{array}{l}0.06(0.01026) \\
0.02-0.09\end{array}$ & $\begin{array}{l}0.07(0.002548) \\
0.03-0.11\end{array}$ & $\begin{array}{l}0.005(0.8242) \\
-0.006-0.02\end{array}$ & $\begin{array}{l}0.0002(0.9917) \\
-0.03-0.05\end{array}$ \\
\hline $\begin{array}{l}\text { Revisão } \\
\text { completa }\end{array}$ & $\begin{array}{l}0.08(0.000506) \\
0.05-0.12\end{array}$ & $\begin{array}{l}0.08(0.0008258) \\
0.03-0.12\end{array}$ & $\begin{array}{l}0.03(0.1799) \\
-0.0001-0.06\end{array}$ & $\begin{array}{l}0.08(0.0009512) \\
0.01-0.14\end{array}$ \\
\hline Distintivo & $\begin{array}{l}0.02(0.4151) \\
-0.02-0.07\end{array}$ & $\begin{array}{l}0.02(0.2598) \\
-0.02-0.07\end{array}$ & $\begin{array}{l}0.04(0.104) \\
0.01-0.07\end{array}$ & $\begin{array}{l}0.07(0.001793) \\
0.02-0.12\end{array}$ \\
\hline $\begin{array}{l}\text { Quadro/ } \\
\text { liderança }\end{array}$ & $\begin{array}{l}0.18(1.128 \mathrm{e}-13) \\
0.13-0.22\end{array}$ & $\begin{array}{l}0.24(<2.2 \mathrm{e}-16) \\
0.19-0.29\end{array}$ & $\begin{array}{l}0.14(6.087 \mathrm{e}-09) \\
0.10-0.18\end{array}$ & $\begin{array}{l}0.15(6.139 \mathrm{e}-10) \\
0.09-0.21\end{array}$ \\
\hline $\begin{array}{l}\text { Barra/ } \\
\text { progresso }\end{array}$ & $\begin{array}{l}0.04(0.09358) \\
-0.009-0.09\end{array}$ & $\begin{array}{l}0.10(5.407 \mathrm{e}-05) \\
0.04-0.15\end{array}$ & $\begin{array}{l}0.04(0.07824) \\
0.002-0.08\end{array}$ & $\begin{array}{l}-0.04(0.05718) \\
-0.08-0.0006\end{array}$ \\
\hline
\end{tabular}


Tabela 7.4: Correlações com Spearman's rank correlation rho entre ações independentes acessadas pelos usuários e cada métrica objetiva (2015 a 2018) - Recorte com as métricas Ações, Ndias, Tempo de reação e Classificação.

\begin{tabular}{|c|c|c|c|c|}
\hline $\begin{array}{l}22 \text { Ações } \\
\text { Indep. }\end{array}$ & $\begin{array}{l}\text { Ações } \\
\text { IC }(95 \%)\end{array}$ & $\begin{array}{l}\text { Ndias } \\
\text { IC }(95 \%)\end{array}$ & $\begin{array}{l}\text { Tempo/Reação } \\
\text { IC }(95 \%)\end{array}$ & $\begin{array}{l}\text { Classif. } \\
\text { IC }(95 \%)\end{array}$ \\
\hline Download & $\begin{array}{l}\mathbf{0 . 4 4}(<2.2 \mathrm{e}-16) \\
0.40-0.48\end{array}$ & $\begin{array}{l}0.22(<2.2 \mathrm{e}-16) \\
0.16-0.27\end{array}$ & $\begin{array}{l}0.07(0.003877) \\
0.01-0.11\end{array}$ & $\begin{array}{l}0.04(0.05371) \\
-0.002-0.10\end{array}$ \\
\hline $\begin{array}{l}\text { Seleção de } \\
\text { imagem }\end{array}$ & $\begin{array}{l}\mathbf{0 . 8 9}(<2.2 \mathrm{e}-16) \\
0.87-0.90\end{array}$ & $\begin{array}{l}\mathbf{0 . 4 7}(<2.2 \mathrm{e}-16) \\
0.42-0.51\end{array}$ & $\begin{array}{l}\mathbf{0 . 3 5}(<2.2 \mathrm{e}-16) \\
0.31-0.40\end{array}$ & $\begin{array}{l}\mathbf{0 . 3 3}(<2.2 \mathrm{e}-16) \\
0.29-0.36\end{array}$ \\
\hline Busca & $\begin{array}{l}\mathbf{0 . 7 5}(<2.2 \mathrm{e}-16) \\
0.72-0.77\end{array}$ & $\begin{array}{l}\mathbf{0 . 3 4}(<2.2 \mathrm{e}-16) \\
0.29-0.39\end{array}$ & $\begin{array}{l}0.23(<2.2 \mathrm{e}-16) \\
0.18-0.28\end{array}$ & $\begin{array}{l}0.23(<2.2 \mathrm{e}-16) \\
0.19-0.28\end{array}$ \\
\hline $\begin{array}{l}\text { Seleção de } \\
\text { usuário }\end{array}$ & $\begin{array}{l}\mathbf{0 . 3 6}(<2.2 \mathrm{e}-16) \\
0.32-0.41\end{array}$ & $\begin{array}{l}\mathbf{0 . 4 4}(<2.2 \mathrm{e}-16) \\
0.39-0.48\end{array}$ & $\begin{array}{l}0.24(<2.2 \mathrm{e}-16) \\
0.19-0.29\end{array}$ & $\begin{array}{l}\mathbf{0 . 3 5}(<2.2 \mathrm{e}-16) \\
0.30-0.41\end{array}$ \\
\hline Comentário & $\begin{array}{l}0.18(1.202 \mathrm{e}-13) \\
0.13-0.22\end{array}$ & $\begin{array}{l}0.15(8.915 \mathrm{e}-10) \\
0.09-0.21\end{array}$ & $\begin{array}{l}0.10(3.451 \mathrm{e}-05) \\
0.06-0.14\end{array}$ & $\begin{array}{l}\mathbf{0 . 5 2}(<2.2 \mathrm{e}-16) \\
0.46-0.58\end{array}$ \\
\hline $\begin{array}{l}\text { Avaliação de } \\
\text { imagem }\end{array}$ & $\begin{array}{l}0.29(<2.2 \mathrm{e}-16) \\
0.25-0.33\end{array}$ & $\begin{array}{l}0.24(<2.2 \mathrm{e}-16) \\
0.18-0.30\end{array}$ & $\begin{array}{l}0.19(2.488 \mathrm{e}-15) \\
0.15-0.23\end{array}$ & $\begin{array}{l}\mathbf{0 . 3 9}(<2.2 \mathrm{e}-16) \\
0.31-0.47\end{array}$ \\
\hline Like & $\begin{array}{l}\mathbf{0 . 3 3}(<2.2 \mathrm{e}-16) \\
0.29-0.36\end{array}$ & $\begin{array}{l}0.23(<2.2 \mathrm{e}-16) \\
0.17-0.29\end{array}$ & $\begin{array}{l}0.17(4.525 \mathrm{e}-12) \\
0.13-0.21\end{array}$ & $\begin{array}{l}\mathbf{0 . 9 5}(<2.2 \mathrm{e}-16) \\
0.92-0.97\end{array}$ \\
\hline $\begin{array}{l}\text { Upload de } \\
\text { imagem }\end{array}$ & $\begin{array}{l}\mathbf{0 . 4 4}(<2.2 \mathrm{e}-16) \\
0.40-0.47\end{array}$ & $\begin{array}{l}\mathbf{0 . 3 9}(<2.2 \mathrm{e}-16) \\
0.33-0.44\end{array}$ & $\begin{array}{l}\mathbf{0 . 3 3}(<2.2 \mathrm{e}-16) \\
0.29-0.36\end{array}$ & $\begin{array}{l}\mathbf{0 . 3 3}(<2.2 \mathrm{e}-16) \\
0.26-0.39\end{array}$ \\
\hline $\begin{array}{l}\text { Edição de } \\
\text { imagem }\end{array}$ & $\begin{array}{l}0.22(<2.2 \mathrm{e}-16) \\
0.19-0.26\end{array}$ & $\begin{array}{l}0.22(<2.2 \mathrm{e}-16) \\
0.17-0.28\end{array}$ & $\begin{array}{l}0.17(3.701 \mathrm{e}-12) \\
0.13-0.20\end{array}$ & $\begin{array}{l}0.17(2.435 \mathrm{e}-12) \\
0.08-0.25\end{array}$ \\
\hline $\begin{array}{l}\text { Inserção de } \\
\text { tag }\end{array}$ & $\begin{array}{l}\mathbf{0 . 4 4}(<2.2 \mathrm{e}-16) \\
0.40-0.47\end{array}$ & $\begin{array}{l}\mathbf{0 . 3 9}(<2.2 \mathrm{e}-16) \\
0.33-0.44\end{array}$ & $\begin{array}{l}\mathbf{0 . 3 2}(<2.2 \mathrm{e}-16) \\
0.29-0.36\end{array}$ & $\begin{array}{l}\mathbf{0 . 3 3}(<2.2 \mathrm{e}-16) \\
0.27-0.40\end{array}$ \\
\hline $\begin{array}{l}\text { Edição de } \\
\text { tag }\end{array}$ & $\begin{array}{l}\mathbf{0 . 3 2}(<2.2 \mathrm{e}-16) \\
0.28-0.35\end{array}$ & $\begin{array}{l}\mathbf{0 . 3 3}(<2.2 \mathrm{e}-16) \\
0.28-0.38\end{array}$ & $\begin{array}{l}0.24(<2.2 \mathrm{e}-16) \\
0.20-0.27\end{array}$ & $\begin{array}{l}0.24(<2.2 \mathrm{e}-16) \\
0.15-0.31\end{array}$ \\
\hline Dislike & $\begin{array}{l}0.09(6.936 \mathrm{e}-05) \\
0.05-0.13\end{array}$ & $\begin{array}{l}0.08(0.0006129) \\
0.02-0.13\end{array}$ & $\begin{array}{l}0.07(0.004645) \\
0.01-0.10\end{array}$ & $\begin{array}{l}0.23(<2.2 \mathrm{e}-16) \\
0.15-0.30\end{array}$ \\
\hline $\begin{array}{l}\text { Edit. aval. } \\
\text { imagem }\end{array}$ & $\begin{array}{l}0.19(1.997 \mathrm{e}-15) \\
0.15-0.23\end{array}$ & $\begin{array}{l}0.16(5 \mathrm{e}-11) \\
0.10-0.22\end{array}$ & $\begin{array}{l}0.11(1.035 \mathrm{e}-05) \\
0.07-0.14\end{array}$ & $\begin{array}{l}0.26(<2.2 \mathrm{e}-16) \\
0.17-0.35\end{array}$ \\
\hline Notificação & $\begin{array}{l}0.22(<2.2 \mathrm{e}-16) \\
0.17-0.26\end{array}$ & $\begin{array}{l}0.23(<2.2 \mathrm{e}-16) \\
0.17-0.29\end{array}$ & $\begin{array}{l}0.14(1.597 \mathrm{e}-08) \\
0.09-0.18\end{array}$ & $\begin{array}{l}\mathbf{0 . 3 2}(<2.2 \mathrm{e}-16) \\
0.23-0.40\end{array}$ \\
\hline $\begin{array}{l}\text { Acesso/ } \\
\text { Chat }\end{array}$ & $\begin{array}{l}0.08(0.0003905) \\
0.04-0.12\end{array}$ & $\begin{array}{l}0.12(1.25 \mathrm{e}-06) \\
0.06-0.16\end{array}$ & $\begin{array}{l}0.08(0.001014) \\
0.04-0.11\end{array}$ & $\begin{array}{l}0.12(9.703 \mathrm{e}-07) \\
0.02-0.20\end{array}$ \\
\hline $\begin{array}{l}\text { Envio/ } \\
\text { mensagem }\end{array}$ & $\begin{array}{l}0.10(2.311 \mathrm{e}-05) \\
0.05-0.14\end{array}$ & $\begin{array}{l}0.14(1.86 \mathrm{e}-08) \\
0.08-0.18\end{array}$ & $\begin{array}{l}0.07(0.002072) \\
0.03-0.11\end{array}$ & $\begin{array}{l}0.13(1.522 \mathrm{e}-07) \\
0.02-0.21\end{array}$ \\
\hline $\begin{array}{l}\text { Envio/ } \\
\text { sugestão }\end{array}$ & $\begin{array}{l}0.10(2.139 \mathrm{e}-05) \\
0.06-0.14\end{array}$ & $\begin{array}{l}0.11(2.228 \mathrm{e}-06) \\
0.05-0.17\end{array}$ & $\begin{array}{l}0.10(2.354 \mathrm{e}-05) \\
0.06-0.13\end{array}$ & $\begin{array}{l}0.13(2.883 \mathrm{e}-08) \\
0.04-0.22\end{array}$ \\
\hline $\begin{array}{l}\text { Sugestão } \\
\text { aceita }\end{array}$ & $\begin{array}{l}0.07(0.00368) \\
0.03-0.10\end{array}$ & $\begin{array}{l}0.08(0.001053) \\
0.03-0.12\end{array}$ & $\begin{array}{l}0.05(0.0272) \\
0.01-0.08\end{array}$ & $\begin{array}{l}0.06(0.006835) \\
-0.01-0.15\end{array}$ \\
\hline $\begin{array}{l}\text { Revisão } \\
\text { completa }\end{array}$ & $\begin{array}{l}0.10(2.141 \mathrm{e}-05) \\
0.06-0.14\end{array}$ & $\begin{array}{l}0.11(2.242 \mathrm{e}-06) \\
0.05-0.16\end{array}$ & $\begin{array}{l}0.10(2.355 \mathrm{e}-05) \\
0.06-0.13\end{array}$ & $\begin{array}{l}0.13(2.918 \mathrm{e}-08) \\
0.03-0.21\end{array}$ \\
\hline Distintivo & $\begin{array}{l}0.06(0.009169) \\
0.03-0.10\end{array}$ & $\begin{array}{l}0.04(0.07922) \\
-0.02-0.10\end{array}$ & $\begin{array}{l}0.02(0.2382) \\
-0.02-0.06\end{array}$ & $\begin{array}{l}0.13(3.807 \mathrm{e}-08) \\
0.07-0.20\end{array}$ \\
\hline $\begin{array}{l}\text { Quadro/ } \\
\text { liderança }\end{array}$ & $\begin{array}{l}0.27(<2.2 \mathrm{e}-16) \\
0.22-0.30\end{array}$ & $\begin{array}{l}0.29(<2.2 \mathrm{e}-16) \\
0.24-0.35\end{array}$ & $\begin{array}{l}0.19(1.537 \mathrm{e}-14) \\
0.15-0.23\end{array}$ & $\begin{array}{l}0.26(<2.2 \mathrm{e}-16) \\
0.18-0.34\end{array}$ \\
\hline $\begin{array}{l}\text { Barra/ } \\
\text { progresso }\end{array}$ & $\begin{array}{l}0.13(1.089 \mathrm{e}-07) \\
0.09-0.17\end{array}$ & $\begin{array}{l}0.08(0.0006648) \\
0.02-0.13\end{array}$ & $\begin{array}{l}0.07(0.001612) \\
0.03-0.12\end{array}$ & $\begin{array}{l}0.04(0.07041) \\
-0.01-0.10\end{array}$ \\
\hline
\end{tabular}

Portanto, para 1591 usuários, com intervalo de confiança de 95\% e p-value $<0.05$ 


\section{temos:}

- Métrica Frequência: correlação positiva baixa com a ação Seleção de imagem.

- Métrica Recenticidade: correlação positiva baixa com as ações Seleção de imagem e Seleção de usuário.

- Métrica Duração: correlação positiva moderada com a ação Seleção de imagem; e correlação positiva baixa com a ação Busca.

- Métrica Viralidade: não apresentou correlações significativas.

- Métrica Ações: correlação positiva alta com as ações Seleção de imagem e Busca; e correlação positiva baixa com as ações Download, Seleção de usuário, Upload de imagem e Inserção de tag.

- Métrica Ndias: correlação positiva baixa com as ações Seleção de imagem, Seleção de usuário, Upload de imagem e Inserção de tag.

- Métrica Tempo de reação: correlação positiva baixa com a ação Seleção de imagem.

- Métrica Classificação: correlação positiva muito alta com a ação Like; correlação positiva baixa com as ações Comentário, Seleção de usuário e Avaliação de imagem.

Nesta primeira análise, a ação Seleção de imagem destaca-se por apresentar efeitos positivos sobre as métricas Frequência, Recenticidade, Duração, Ndias, Ações e Tempo de reação. Para a métrica Ações apresentou correlação positiva alta, indicando que a ação mais realizada pelos usuários durante os três anos de monitoramento foi a seleção de imagem, ou, um comportamento exploratório de visualização de imagens do acervo, o que também explica a ação de Busca apresentar correlação positiva alta com a métrica Ações. A métrica Classificação representa ações relacionadas à classificação de conteúdo do sistema, ou Comentários e Like no caso do Arquigrafia. A correlação positiva muito alta com a ação Like indica que esta ação compreende a maior parte das ações de classificação no projeto.

O fato das ações Seleção de imagem e Busca serem as mais utilizadas indica que usuários do Arquigrafia exploram o sistema por meio da navegação livre e aleatória, selecionando imagens que são apresentadas na Home, e, por meio da busca, que também os direciona para a seleção de imagens que são retornadas como resultado. A seleção de imagem apresentou picos e maior intensidade de acessos do que a busca, o que representa um fato positivo, que indica que as buscas retornaram imagens e os usuários passaram a navegar sobre elas. Essa informação pode ser evidenciada pelo picos de acesso em junho de 2016 com 400 acessos à busca e no mesmo período apresentam-se 900 acessos à seleção de imagem.

\subsubsection{Tipos de elementos de interação $\mathrm{X}$ métricas objetivas}

A partir da análise anterior, não foi possível compreender qual é o peso de cada tipo de elemento de interação do usuário - colaboração, jogo ou funcional - sobre as métricas objetivas de engajamento. Por esse motivo, as 22 ações apresentadas na Figura 7.2 e nas Tabelas 7.3 e 7.4 foram agrupadas para serem contabilizadas como acessos a cada tipo de elemento de interação.

As ações relacionadas a elementos funcionais foram: Download, Seleção de imagem, Busca e Seleção de usuário. A busca web colaborativa é definida como um tipo de elemento de colaboração $\left[\mathrm{MOC}^{+} 11\right]$, uma vez que a cada nova busca, algoritmos para aprendizado de máquina geram recomendações de busca baseadas nos resultados que outros usuários encontraram para buscas similares. No entanto, no caso do Arquigrafia, ainda não temos algoritmos de recomendação para a busca implementados no sistema. Portanto, a busca apenas retorna resultados ao usuário, sem armazenar dados que possam ajudar em buscas posteriores. Por esse motivo, a classificamos dentro de elementos funcionais. 
As ações relacionadas a elementos colaborativos foram: Comentário, Avaliação de imagem, Like, Upload de imagem, Edição de imagem, Inserção de tag, Edição de tag, Dislike, Editar avaliação de imagem, Notificação, Acesso ao Chat, Envio de mensagem, Envio de sugestão para imagem, Revisão de sugestão aceita pelo autor e Revisão completa de uma imagem. As ações relacionadas a elementos de jogos foram: Visualização de distintivo, Visualizar o Quadro de liderança e Visualizar a Barra de progresso da foto. A Tabela 7.5 apresenta a correlação entre os tipos de elementos de interação de usuário que foram acessados durante os três anos de monitoramento e cada métrica objetiva.

Tabela 7.5: Correlações com Spearman's rank correlation rho entre tipos de elementos de interação de usuário acessados e cada métrica objetiva de engajamento monitorada ao longo de três anos (2015 a 2018).

\begin{tabular}{|l|l|l|l|}
\hline $\begin{array}{l}\text { Métricas } \\
\text { objetivas }\end{array}$ & Funcionais - rho (p) & $\begin{array}{l}\text { Colaborativos - rho (p) } \\
\text { IC }(95 \%)\end{array}$ & $\begin{array}{l}\text { Jogo - rho }(95 \%) \\
\text { IC }(95 \%)\end{array}$ \\
\hline Frequência & $\mathbf{0 . 4 6}(<2.2 \mathrm{e}-16)$ & $\mathbf{0 . 3 6}(<2.2 \mathrm{e}-16)$ & $0.15(6.033 \mathrm{e}-10)$ \\
& $0.41-0.50$ & $0.31-0.40$ & $0.10-0.20$ \\
\hline Recenticidade & $\mathbf{0 . 4 8}(<2.2 \mathrm{e}-16)$ & $0.34(<2.2 \mathrm{e}-16)$ & $0.23(<2.2 \mathrm{e}-16)$ \\
& $0.44-0.52$ & $0.28-0.39$ & $0.18-0.28$ \\
\hline Duração & $\mathbf{0 . 6 3}(<2.2 \mathrm{e}-16)$ & $\mathbf{0 . 3 6}(<2.2 \mathrm{e}-16)$ & $0.13(7.602 \mathrm{e}-08)$ \\
& $0.60-0.66$ & $0.32-0.41$ & $0.09-0.17$ \\
\hline Viralidade & $0.22(<2.2 \mathrm{e}-16)$ & $0.10(1.149 \mathrm{e}-05)$ & $0.06(0.006994)$ \\
& $0.17-0.26$ & $0.05-0.16$ & $0.01-0.12$ \\
\hline Classificação & $0.32(<2.2 \mathrm{e}-16)$ & $\mathbf{0 . 6 2}(<2.2 \mathrm{e}-16)$ & $0.21(<2.2 \mathrm{e}-16)$ \\
& $0.27-0.36$ & $0.58-0.66$ & $0.14-0.27$ \\
\hline Ações & $\mathbf{0 . 9 7}(<2.2 \mathrm{e}-16)$ & $\mathbf{0 . 5 0}(<2.2 \mathrm{e}-16)$ & $0.28(<2.2 \mathrm{e}-16)$ \\
& $0.96-0.98$ & $0.46-0.53$ & $0.24-0.32$ \\
\hline Ndias & $\mathbf{0 . 5 2}(<2.2 \mathrm{e}-16)$ & $\mathbf{0 . 3 8}(<2.2 \mathrm{e}-16)$ & $0.26(<2.2 \mathrm{e}-16)$ \\
& $0.48-0.56$ & $0.32-0.43$ & $0.20-0.32$ \\
\hline Tempo de reação & $\mathbf{0 . 3 7}(<2.2 \mathrm{e}-16)$ & $0.32(<2.2 \mathrm{e}-16)$ & $0.18(2.422 \mathrm{e}-14)$ \\
& $0.32-0.41$ & $0.28-0.36$ & $0.14-0.23$ \\
\hline
\end{tabular}

Esta correlação considera o acesso a qualquer um dos tipos de elementos, independente do usuário ter acessado outros elementos em conjunto ou não. A partir das diretrizes de interpretação apresentadas na Tabela 7.2, nota-se que todas as correlações foram positivas, o que indica que quanto maior o acesso a um tipo de elemento, maior foi a sua pontuação para cada métrica objetiva, mesmo para a métrica recenticidade. Isso indica que usuários que realizaram muitas ações, retornam ao sistema mesmo após um longo período sem acesso, ou recenticidade maior. Adicionalmente, os resultados de $p$-value foram todos estatisticamente significativos, dada a quantidade de usuários considerados na análise: 1591 usuários.

O acesso a elementos de jogos não resultou em correlação com as métricas objetivas de engajamento. $\mathbf{O}$ acesso a elementos colaborativos apresentou correlação positiva moderada com as métricas objetivas Ações e Classificação; e correlação positiva baixa com as métricas frequência, recenticidade, duração, ndias e tempo de reação; e apenas para a métrica viralidade não houve correlação. Considerando o intervalo de confiança de $95 \%$, o acesso a elementos colaborativos manteve a correlação positiva moderada com a métrica Classificação e a métrica Ações passou para uma correlação positiva baixa, acompanhando as métricas Frequência, Duração e Ndias.

O acesso a elementos funcionais foi o único que apresentou correlação positiva muito alta com a métrica Ações, o que indica que a maioria das ações realizadas pelos usuários nos três anos de monitoramento foram relacionadas a elementos funcionais. As métricas duração e ndias apresentaram correlação positiva moderada; e as métricas frequência, recenticidade, classificação e tempo de reação apresentaram correlação positiva baixa com o acesso a elementos funcionais. Assim como ocorreu com elementos colaborativos, apenas a métrica viralidade não apresentou correlação. Considerando o intervalo de confiança de $95 \%$, elementos funcionais mantiveram correlação positiva 
muito alta com a métrica Ações; correlação positiva moderada com a métrica duração; e correlação positiva baixa com as métricas ndias, frequência, recenticidade e tempo de reação.

Portanto, para 1591 usuários, com intervalo de confiança de $95 \%$ e p-value $<0.05$ temos:

- Elementos de jogos: Não apresentaram correlação significante com as métricas objetivas de engajamento;

- Elementos colaborativos: Correlação positiva moderada com a métrica Classificação; e correlação positiva baixa com as métricas Ações, Frequência, Duração e Ndias.

- Elementos funcionais: Correlação positiva muito alta com a métrica Ações; correlação positiva moderada com a métrica Duração; e correlação positiva baixa com as métricas Ndias, Frequência, Recenticidade e Tempo de Reação.

A falta de correlação entre o acesso a elementos de jogos e as métricas objetivas pode indicar que o acesso a esses elementos não interferiu no engajamento de usuários. Contudo, o acesso a conjuntos de elementos pode gerar resultados diferentes do que os obtidos para um único tipo de elemento. Existe também a necessidade de filtrar apenas os usuários que acessaram tipos de elementos específicos, sem acessar os demais, e realizar a análise apenas para esse conjunto sem diluí-lo nos dados de 1591 usuários, para os quais o peso dos elementos funcionais é maior do que o peso dos demais elementos e, portanto, não fica claro o que ocorreu com os usuários que acessaram elementos de jogos ou de colaboração. A próxima subseção analisa os dados por meio desses filtros.

\subsubsection{Conjuntos de elementos de interação $\mathrm{X}$ métricas objetivas}

A Tabela 7.6 apresenta as correlações entre métricas objetivas de engajamento e cada conjunto possível de elementos de interação que foram acessados pelos usuários. 1132 usuários acessaram apenas elementos funcionais (Func); 91 usuários acessaram apenas elementos funcionais e de jogo (Func + Jog); 10 usuários acessaram todos os tipos de elementos, inclusive todos os elementos de colaboração - comunicação, coordenação e cooperação - 3Cs (Func + Jog $+3 \mathrm{C}$ ); 82 usuários acessaram elementos funcionais, de jogo e de colaboração (Func $+\mathrm{Jog}+\mathrm{Col}$ ), sendo que este último foi contabilizado se pelo menos um elemento dos 3 Cs foi acessado; e 284 usuários acessaram apenas elementos funcionais e de colaboração (Func $+\mathrm{Col}$ ). Sendo assim, as métricas foram comparadas apenas entre usuários que estavam no mesmo conjunto, de modo a entender o comportamento dos usuários de cada grupo.

Ao separar os acessos aos elementos nesses conjuntos, foi possível perceber o porquê das ações relacionadas a elementos funcionais possuírem um peso superior em todas as análises anteriores: dos 1591 usuários, 1132 acessaram apenas elementos funcionais, o que corresponde a $71.15 \%$ dos usuários que acessaram o sistema com ações e duração diferentes de zero.

Para análise do conjunto Func $+\mathrm{Jog}+3 \mathrm{C}$, as ações Comentário, Acesso ao Chat e Envio de mensagem foram relacionadas à comunicação; a ação Notificação foi relacionada à coordenação; e as ações Avaliação de imagem, Like, Upload de imagem, Edição de imagem, Inserção de tag, Edição de tag, Dislike, Editar avaliação de imagem, Envio de sugestão para imagem, Revisão de sugestão aceita pelo autor e Revisão completa de uma imagem foram relacionas à cooperação. Para classificar as ações de acordo com os 3Cs de colaboração, usamos como base o artigo de Oliveira e Gerosa [DOG11]. 
Tabela 7.6: Correlações com Spearman's rank correlation rho entre acessos a conjuntos de elementos de interação de usuário e cada métrica objetiva de engajamento (de 14 de junho de 2015 a 30 de junho de 2018).

\begin{tabular}{|l|l|l|l|l|l|}
\hline $\begin{array}{l}\text { Métri } \\
\text { cas }\end{array}$ & Func & Func + Jog & Func + Col & $\begin{array}{l}\text { Func }+ \text { Jog }+ \text { Col } \\
\text { IC }(95 \%)\end{array}$ & $\begin{array}{l}\text { Func }+ \text { Jog }+3 \mathrm{C} \\
\text { IC }(95 \%)\end{array}$ \\
\hline Freq. & $0.35(<2.2 \mathrm{e}-16)$ & $0.37(0.000219)$ & $0.36(2.092 \mathrm{e}-10)$ & $0.38(0.0003445)$ & $0.44(0.2042)$ \\
& $0.29-0.40$ & $0.16-0.55$ & $0.26-0.45$ & $0.15-0.56$ & $-0.47-0.96$ \\
\hline Rec. & $\mathbf{0 . 3 7}(<2.2 \mathrm{e}-16)$ & $0.38(0.0001368)$ & $\mathbf{0 . 4 0}(7.461 \mathrm{e}-13)$ & $0.12(0.2459)$ & $-0.006(1)$ \\
& $0.32-0.42$ & $0.18-0.57$ & $0.30-0.50$ & $-0.09-0.36$ & $-0.91-0.73$ \\
\hline Dur. & $\mathbf{0 . 6 1}(<2.2 \mathrm{e}-16)$ & $\mathbf{0 . 6 0}(3.049 \mathrm{e}-10)$ & $\mathbf{0 . 4 2}(7.594 \mathrm{e}-14)$ & $0.26(0.01725)$ & $0.09(0.8114)$ \\
& $0.57-0.65$ & $0.43-0.72$ & $0.31-0.51$ & $0.04-0.47$ & $-0.64-0.85$ \\
\hline Vir. & $0.18(9.749 \mathrm{e}-10)$ & $0.20(0.05669)$ & $0.13(0.02004)$ & $\mathbf{0 . 6 4}(4.15 \mathrm{e}-11)$ & $0.56(0.09579)$ \\
& $0.12-0.23$ & $-0.006-0.38$ & $0.01-0.25$ & $0.48-0.76$ & $0.01-0.84$ \\
\hline Clas. & $\mathrm{NA}$ & $\mathrm{NA}$ & $0.17(0.002917)$ & $\mathbf{0 . 5 5}(7.68 \mathrm{e}-08)$ & $-0.17(0.625)$ \\
& $\mathrm{NA}$ & $\mathrm{NA}$ & $0.04-0.28$ & $0.37-0.69$ & $-0.91-0.59$ \\
\hline Ações & $\mathbf{1}(<2.2 \mathrm{e}-16)$ & $\mathbf{1}(<2.2 \mathrm{e}-16)$ & $\mathbf{1}(<2.2 \mathrm{e}-16)$ & $\mathbf{1}(<2.2 \mathrm{e}-16)$ & $\mathbf{1}(<2.2 \mathrm{e}-16)$ \\
& $1-1$ & $1-1$ & $1-1$ & $1-1$ & $1-1$ \\
\hline Ndias & $\mathbf{0 . 3 9}(<2.2 \mathrm{e}-16)$ & $0.43(1.422 \mathrm{e}-05)$ & $\mathbf{0 . 5 2}(<2.2 \mathrm{e}-16)$ & $\mathbf{0 . 7 8}(<2.2 \mathrm{e}-16)$ & $\mathbf{0 . 9 2}(0.0001302)$ \\
& $0.34-0.44$ & $0.25-0.60$ & $0.42-0.60$ & $0.65-0.86$ & $0.55-1.0$ \\
\hline Reaç. & $0.29(<2.2 \mathrm{e}-16)$ & $0.21(0.03954)$ & $0.26(4.992 \mathrm{e}-06)$ & $0.23(0.03707)$ & $0.17(0.632)$ \\
& $0.24-0.35$ & $0.02-0.40$ & $0.14-0.38$ & $0.009-0.43$ & $-0.70-0.89$ \\
\hline
\end{tabular}

Considerando os intervalos de confiança de 95\%, com p-value $<0.05$, e o mesmo método de análise descrito nas seções anteriores, temos as seguintes correlações aos acessos a:

- Elementos Funcionais (Func): Correlação positiva baixa com Recenticidade e Ndias; Correlação positiva moderada com Duração; e Correlação positiva muito alta com Ações.

- Elementos Funcionais + Jogo (Func+Jog): Correlação positiva baixa com Duração; e Correlação positiva muito alta com Ações.

- Elementos Funcionais + Colaboração $(\mathrm{Func}+\mathrm{Col})$ : Correlação positiva baixa com Recenticidade, Duração e Ndias; e Correlação positiva muito alta com Ações.

- Elementos Funcionais + Jogo + Colaboração $(F u n c+J o g+C o l)$ : Correlação positiva baixa com Viralidade e Classificação; Correlação positiva moderada com Ndias; e Correlação positiva muito alta com Ações.

- Elementos Funcionais + Jogo $+3 \mathrm{Cs}($ Func + Jog $+3 \mathrm{C})$ : Correlação positiva moderada com Ndias; e Correlação positiva muito alta com Ações.

A métrica Ações apresentou correlações positivas muito altas com todos os conjuntos, indicando que a quantidade de ações associadas aos acessos a cada conjunto de elementos corresponde às ações totais dos usuários de cada conjunto. Apenas os acessos a elementos Funcionais + Jogo + Colaboração (Func + Jog + Col) e a elementos Funcionais + Jogo +3 Cs $($ Func + Jog $+3 \mathrm{C}$ ) resultaram em correlação positiva moderada com Ndias, o que indica que os dois conjuntos possuem os usuários que mais acessaram o sistema durante os três anos. Adicionalmente, apenas os acessos a Func + Jog + Col apresentaram correlações positivas significativas com viralidade e classificação. Portanto, ao analisar os elementos de jogos, acessados em conjunto com outros elementos, é possível vê-los causando efeitos positivos sobre algumas métricas objetivas. Mas, ainda não comparamos esses resultados entre valores obtidos para cada métrica em cada conjunto e entre conjuntos, de modo a verificar se de fato existem diferenças significativas entre eles, uma vez que cada conjunto possui uma quantidade diferente de usuários. A próxima seção trata dessa análise. 


\subsection{Pesquisa causal-comparativa}

A pesquisa causal-comparativa visa analisar causas e efeitos entre conjuntos de dados. A próximas subseções apresentam a pesquisa causal-comparativa entre conjuntos de elementos, entre conjuntos por métrica e entre ações mais acessadas.

\subsubsection{Pesquisa causal-comparativa entre conjuntos de elementos}

Para todas as métricas objetivas, é possível calcular os níveis alto, médio e baixo de acordo com os percentis: $<=1^{\circ}$ quartil $(25 \%)$ ou nível baixo; $>1^{\circ}$ quartil e $<=3^{\circ}$ quartil $(75 \%)$ ou nível médio; e $>3^{\circ}$ quartil ou nível alto. Esse tipo de análise foi apresentado por O'Brien e Lebow [OL13] para pontuações na escala Likert para análise de métricas subjetivas coletadas por meio de questionários aos usuários. Aplicamos o mesmo tipo de análise para as métricas objetivas de engajamento, coletadas via registro de ações de usuários, para comparar a quantidade de elementos acessados, de cada conjunto apresentado nas correlações 3 a 7 da seção anterior, e o nível alcançado para cada métrica. Para complementar essa análise, comparamos os resultados obtidos para cada métrica objetiva entre todos os conjuntos.

Para realizar essas comparações, o Teste de soma de classificação de Kruskal-Wallis (KruskalWallis rank sum test) foi aplicado por meio da ferramenta R. Este teste foi selecionado porque os dados não são paramétricos, conforme teste de normalidade de Shapiro-Wilk (Shapiro-Wilk normality test), e, dois ou mais conjuntos precisam ser comparados para verificar se existem diferenças entre eles. Para todas as análises estatísticas, consideramos o p-value $<0.05$ para definir os resultados como estatisticamente significativos e apresentamos tamanhos de efeito Epsilon-squared para as comparações com Kruskal.

Estatísticas de tamanho de efeito para o Teste de Kruskal-Wallis fornecem o grau pelo qual um grupo tem dados com classificações maiores do que outro grupo. Elas estão relacionadas com a probabilidade do valor de um grupo ser maior do que o valor de outro grupo. Ao contrário de $p$ value, tamanhos de efeito não são afetados pelo tamanho da amostra. Para interpretar o tamanho de efeito, utilizamos diretrizes apresentadas por [Coh88, KW04]: $>=0.01$ e $<0.06$ para efeito pequeno; $>=0.06$ e $<0.15$ para efeito médio; e $>=0.15$ para efeito grande. Um tamanho de efeito igual a 1 indica que as medições para um grupo são inteiramente maiores do que para outro grupo. As próximas subseções apresentam os resultados e a discussão para cada uma das comparações com o teste de Kruskal-Wallis.

\section{Níveis alcançados para cada métrica por conjunto}

A Tabela 7.7 apresenta os níveis baixo, médio e alto para cada métrica objetiva. Os níveis foram usados para comparar a quantidade de elementos acessados em cada conjunto e o nível alcançado para cada métrica.

Tabela 7.7: Níveis Alto, Médio e Baixo alcançados para cada métrica objetiva de engajamento.

\begin{tabular}{|l|l|l|l|}
\hline $\begin{array}{l}\text { Métrica } \\
\text { Objetiva }\end{array}$ & $\begin{array}{l}\text { Nível } \\
\text { Baixo }\end{array}$ & $\begin{array}{l}\text { Nível } \\
\text { Médio }\end{array}$ & $\begin{array}{l}\text { Nível } \\
\text { Alto }\end{array}$ \\
\hline Frequência & $<=1.0$ & $>1.0 \mathrm{e}<=2.0$ & $>2.0$ \\
\hline Recenticidade & $<=0$ & $>0 \mathrm{e}<=1.33$ & $>1.33$ \\
\hline Duração & $<=73.5$ & $>73.5 \mathrm{e}<=448.5$ & $>448.5$ \\
\hline Viralidade & $<=0$ & $>0 \mathrm{e}<=1.0$ & $>1.0$ \\
\hline Classificação & $<=0$ & NA & $>0$ \\
\hline Ações & $<=3$ & $>3 \mathrm{e}<=29$ & $>29$ \\
\hline Ndias & $<=1$ & $>1 \mathrm{e}<=2$ & $>2$ \\
\hline Tempo de reação & $<=15.35$ & $>15.35 \mathrm{e}<=163.20$ & $>163.20$ \\
\hline
\end{tabular}


As Figuras 7.3 a 7.10 apresentam as comparações entre a quantidade de elementos acessados em cada conjunto para cada nível alcançado por métrica em análise. A divisão em oito figuras foi necessária para facilitar a visualização dos dados. Após cada figura apresentamos a tabela que descreve os dados apresentados na figura que a antecede.
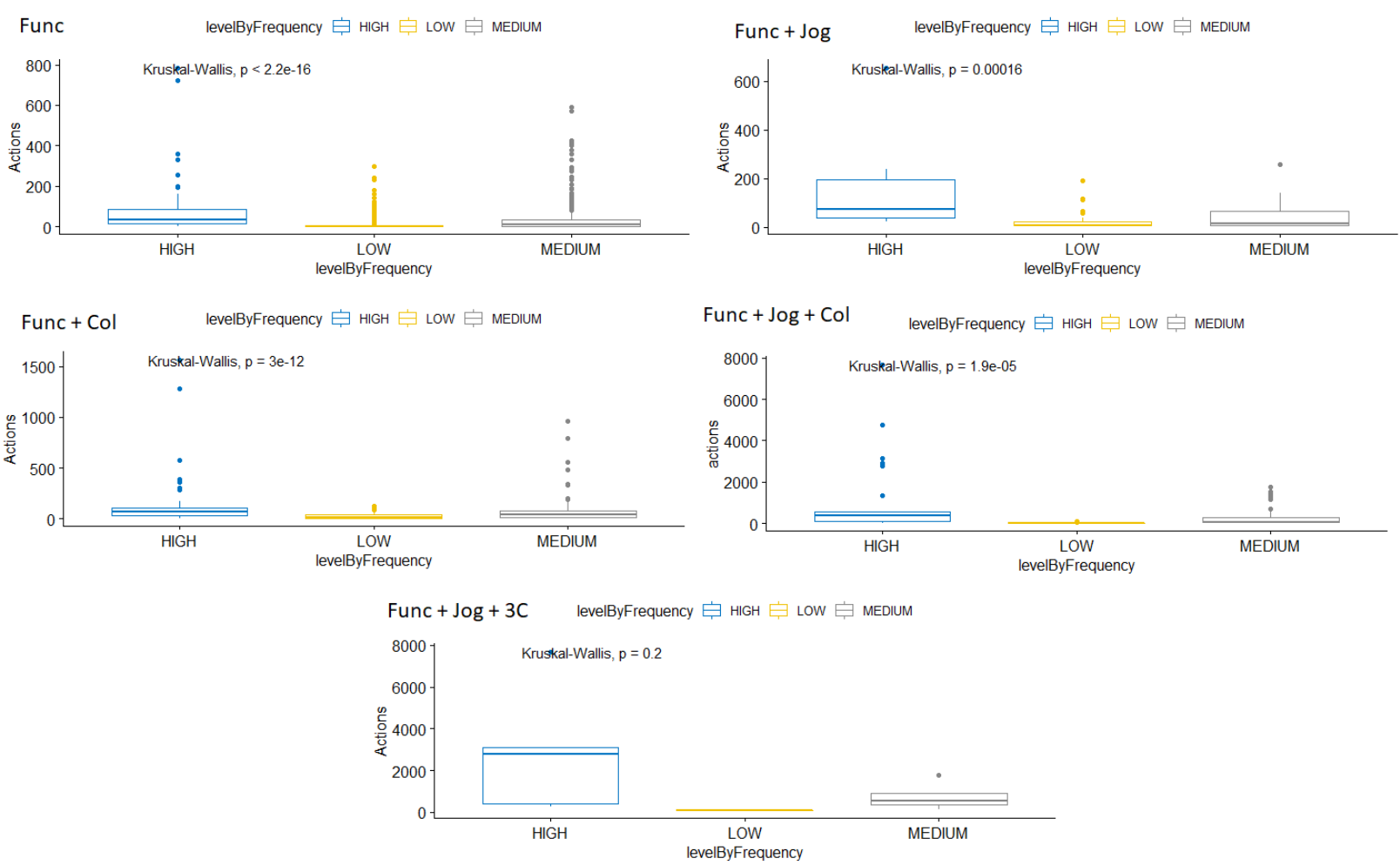

Figura 7.3: Comparação dos conjuntos a partir dos níveis Alto, Médio e Baixo alcançados para a métrica Frequência.

Tabela 7.8: Descrição dos dados apresentados na Figura 7.3.

\begin{tabular}{|l|l|l|l|l|l|l|l|}
\hline Conjunto & Nível por & Min. & $1^{\circ} \mathrm{Qu}$. & Mediana & Média & $3^{\circ} \mathrm{Qu}$. & Máx. \\
& Métrica & & & & & & \\
\hline Func & Frequência Baixa & 1 & 2 & 3 & 9.55 & 7 & 296 \\
& Frequência Média & 1 & 3 & 9 & 44.36 & 32 & 590 \\
& Frequência Alta & 1 & 15.50 & 32 & 84.07 & 84 & 785 \\
\hline Func + Jog & Frequência Baixa & 2 & 5 & 8 & 20.62 & 22.50 & 189 \\
& Frequência Média & 2 & 6 & 13 & 46.36 & 66 & 256 \\
& Frequência Alta & 21 & 37.25 & 74 & 148.60 & 196 & 655 \\
\hline Func + Col & Frequência Baixa & 2 & 6 & 12.50 & 25.27 & 36.75 & 127 \\
& Frequência Média & 3 & 15 & 37 & 73.8 & 79.5 & 962 \\
& Frequência Alta & 5 & 28 & 67 & 141.6 & 110 & 1565 \\
\hline \multirow{5}{*}{ Func + Jog + Col } & Frequência Baixa & 4 & 12.25 & 18 & 27.20 & 29 & 86 \\
& Frequência Média & 7 & 38.5 & 73 & 291.6 & 273 & 1757 \\
& Frequência Alta & 11 & 115 & 380 & 1102 & 567 & 7682 \\
\hline Func + Jog $+3 \mathrm{C}$ & Frequência Baixa & 86 & 86 & 86 & 86 & 86 & 86 \\
& Frequência Média & 125 & 380.8 & 535 & 738 & 892.2 & 1757 \\
& Frequência Alta & 262 & 421 & 2782 & 2854 & 3124 & 7682 \\
\hline
\end{tabular}

Dentre os usuários com frequência alta ( $>2$ sessões por dia em média) e acesso ao conjunto Func + Jog $+3 \mathrm{C}, 50 \%$ dos usuários - regiões entre $1^{\circ}$ e $3^{\circ}$ quartil - realizaram entre 421 e 3124 
ações. Além disso, este conjunto apresentou a maior quantidade de elementos acessados por usuário; tendo apenas um usuário com frequência baixa (ou 1 sessão por dia) que acessou 86 ações e ainda assim foi o maior número de elementos acessados para o valor mínimo quando comparado com os demais conjuntos. Func $+\mathrm{Jog}+3 \mathrm{C}$ também foi o conjunto com a maior variabilidade de quantidade de elementos acessados relacionados ao nível alto de frequência para $50 \%$ dos usuários. Para todos os conjuntos, quanto maior o número de ações realizadas, maior foi o nível de frequência alcançado.
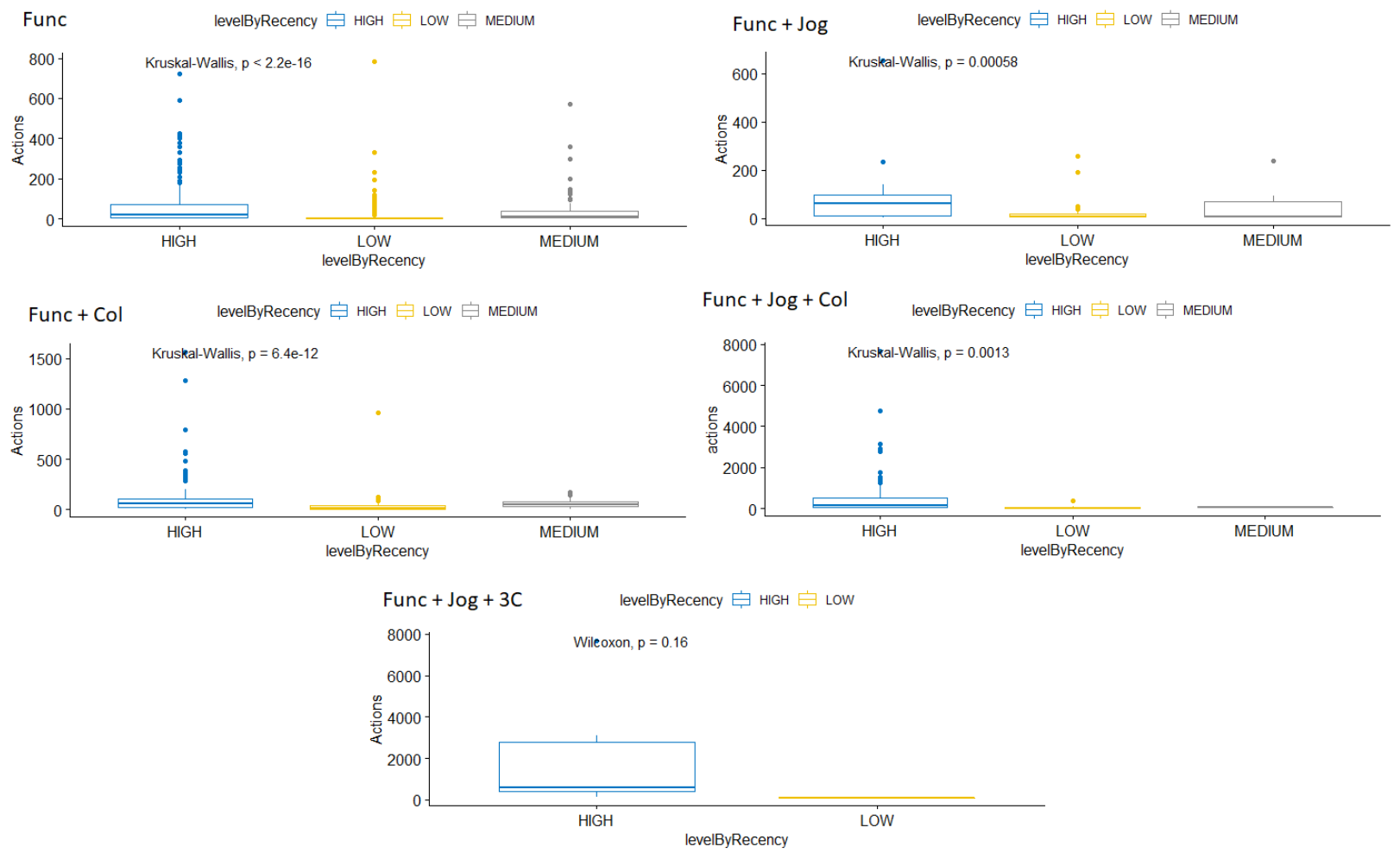

Figura 7.4: Comparação dos conjuntos a partir dos níveis Alto, Médio e Baixo alcançados para a métrica Recenticidade.

Tabela 7.9: Descrição dos dados apresentados na Figura 7.4.

\begin{tabular}{|l|l|l|l|l|l|l|l|}
\hline Conjunto & $\begin{array}{l}\text { Nível por } \\
\text { Métrica }\end{array}$ & Min. & $1^{\circ} \mathrm{Qu}$. & Mediana & Média & $3^{\circ} \mathrm{Qu}$. & Máx. \\
\hline Func & Recenticidade Baixa & 1 & 2 & 3 & 10.28 & 8 & 785 \\
& Recenticidade Média & 1 & 4 & 10 & 43.05 & 37.25 & 570 \\
& Recenticidade Alta & 1 & 5 & 18 & 66.05 & 72.75 & 721 \\
\hline Func + Jog & Recenticidade Baixa & 2 & 5 & 8 & 20.24 & 17.50 & 256 \\
& Recenticidade Média & 5 & 6 & 6.5 & 58.67 & 70.75 & 236 \\
& Recenticidade Alta & 2 & 11.75 & 61 & 77.83 & 95.50 & 655 \\
\hline Func + Col & Recenticidade Baixa & 2 & 7 & 15 & 34.81 & 37.25 & 962 \\
& Recenticidade Média & 7 & 27 & 47 & 56.3 & 74 & 169 \\
& Recenticidade Alta & 3 & 22 & 55 & 116 & 108 & 1565 \\
\hline Func + Jog + Col & Recenticidade Baixa & 4 & 14.75 & 29 & 65.50 & 62 & 360 \\
& Recenticidade Média & 12 & 33.50 & 51 & 44.43 & 56.50 & 68 \\
& Recenticidade Alta & 7 & 44 & 159 & 624.1 & 522 & 7682 \\
\hline Func + Jog + 3C & Recenticidade Baixa & 86 & 86 & 86 & 86 & 86 & 86 \\
& Recenticidade Média & NA & NA & NA & NA & NA & NA \\
& Recenticidade Alta & 125 & 421 & 604 & 1914 & 2782 & 7682 \\
\hline
\end{tabular}


Para a métrica Recenticidade, também temos a relação maior número de ações realizadas, maior recenticidade para todos os conjuntos, assim como ocorreu com frequência. O conjunto Func + Jog $+3 \mathrm{C}$ destacou-se novamente por ter apenas um usuário com recenticidade baixa $(<=0$ ou apenas um dia de acesso em média) e todos os demais usuários com recenticidade alta $(>1.33$ dia de acesso), todos os demais conjuntos apresentaram acessos relacionados aos três níveis de recenticidade, destacando o conjunto Func $+\mathrm{Jog}+\mathrm{Col}$ com a maior quantidade de ações relacionadas à recenticidade alta, após o conjunto Func $+\mathrm{Jog}+3 \mathrm{C}$.
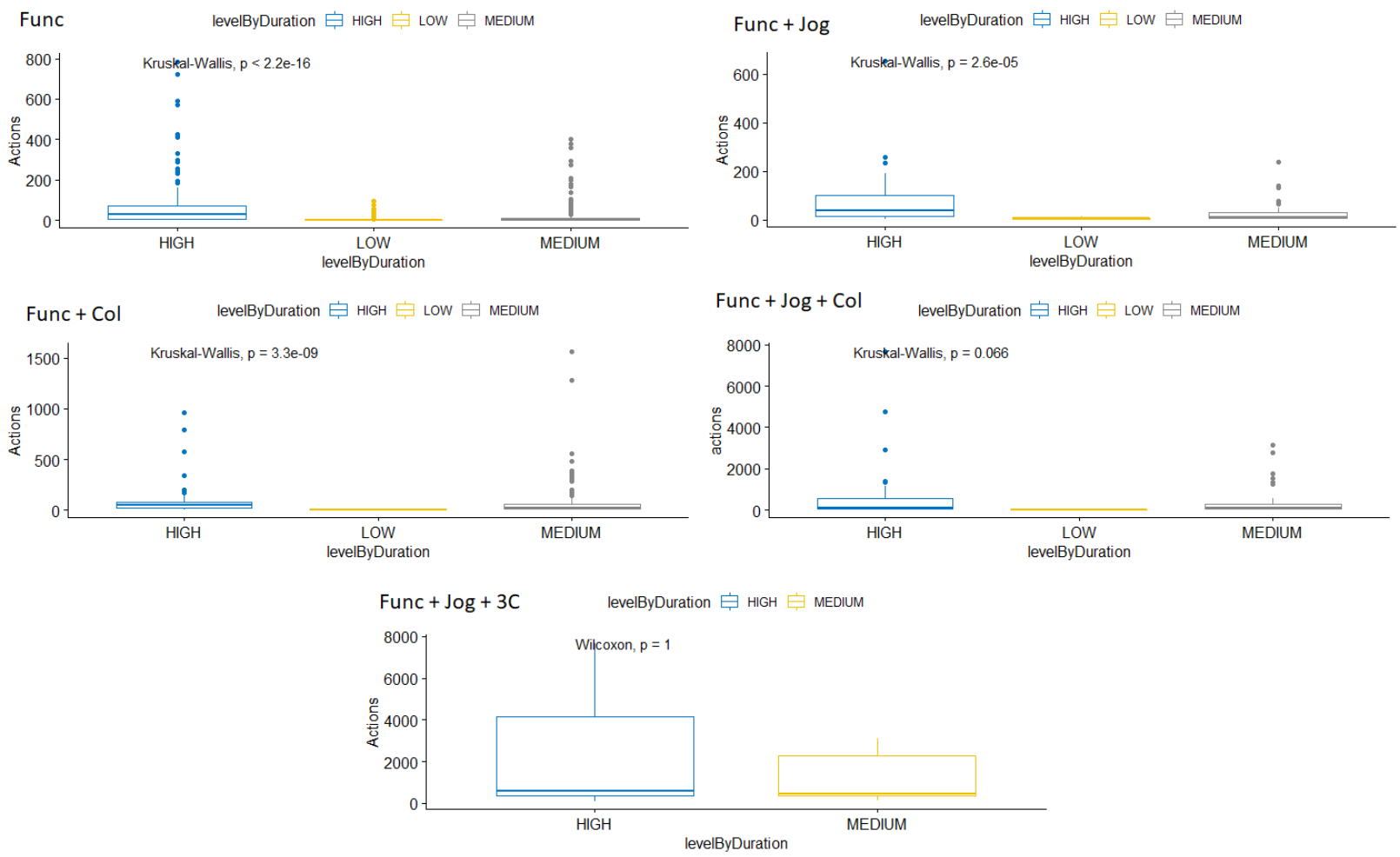

Figura 7.5: Comparação dos conjuntos a partir dos níveis Alto, Médio e Baixo alcançados para a métrica Duração.

Tabela 7.10: Descrição dos dados apresentados na Figura 7.5.

\begin{tabular}{|l|l|l|l|l|l|l|l|}
\hline Conjunto & $\begin{array}{l}\text { Nível por } \\
\text { Métrica }\end{array}$ & Min. & $1^{\circ} \mathrm{Qu}$. & Mediana & Média & $3^{\circ} \mathrm{Qu}$. & Máx. \\
\hline Func & Duração Baixa & 1 & 1 & 2 & 3.45 & 3 & 95 \\
& Duração Média & 1 & 3 & 5 & 16.5 & 13 & 404 \\
& Duração Alta & 1 & 8 & 29 & 68.27 & 74.25 & 785 \\
\hline Func + Jog & Duração Baixa & 2 & 3 & 5 & 5.61 & 7 & 13 \\
& Duração Média & 2 & 6 & 11 & 28.04 & 28.50 & 236 \\
& Duração Alta & 3 & 13 & 36 & 87.27 & 98.75 & 655 \\
\hline Func + Col & Duração Baixa & 2 & 3 & 5 & 6.25 & 8.25 & 16 \\
& Duração Média & 2 & 8 & 22 & 73.52 & 56 & 1565 \\
& Duração Alta & 3 & 24 & 50 & 72.43 & 79.00 & 962.00 \\
\hline Func + Jog + Col & Duração Baixa & 7 & 10.25 & 13.5 & 13.5 & 16.75 & 20 \\
& Duração Média & 6 & 33.5 & 115 & 367.9 & 275 & 3124 \\
& Duração Alta & 4 & 39 & 96 & 733.8 & 561 & 7682 \\
\hline Func + Jog + 3C & Duração Baixa & NA & NA & NA & NA & NA & NA \\
& Duração Média & 125 & 341.5 & 466 & 1277 & 2270 & 3124 \\
& Duração Alta & 86 & 345 & 604 & 2791 & 4143 & 7682 \\
\hline
\end{tabular}


Para a métrica Duração, temos a quantidade mais proeminente de ações relacionadas à duração baixa ( $<=73.5$ segundos por sessão em média) apenas no conjunto Func, o que se relacionado com os estudos de Smallwood et al. [SDH ${ }^{+}$04], pode indicar mais ações realizadas com pouca atenção ou menor engajamento com a tarefa, o que ocorre em situações de tédio ou preocupação [RMA ${ }^{+} 97$, $\mathrm{SDH}^{+}$04]. Em contrapartida, o conjunto Func $+\mathrm{Jog}+3 \mathrm{C}$ não apresentou ações relacionadas à duração baixa e grande parte das ações relacionou-se com duração alta ( $>448.5$ segundos). Os conjuntos Func + Jog + Col e Func + Jog apresentaram uma quantidade maior de ações relacionadas à duração alta do que o conjunto Func $+\mathrm{Col}$, no qual a distribuição de ações relacionadas às durações alta e baixa é similar. A relação maior número de ações realizadas, maior duração média ocorreu em todos os conjuntos.
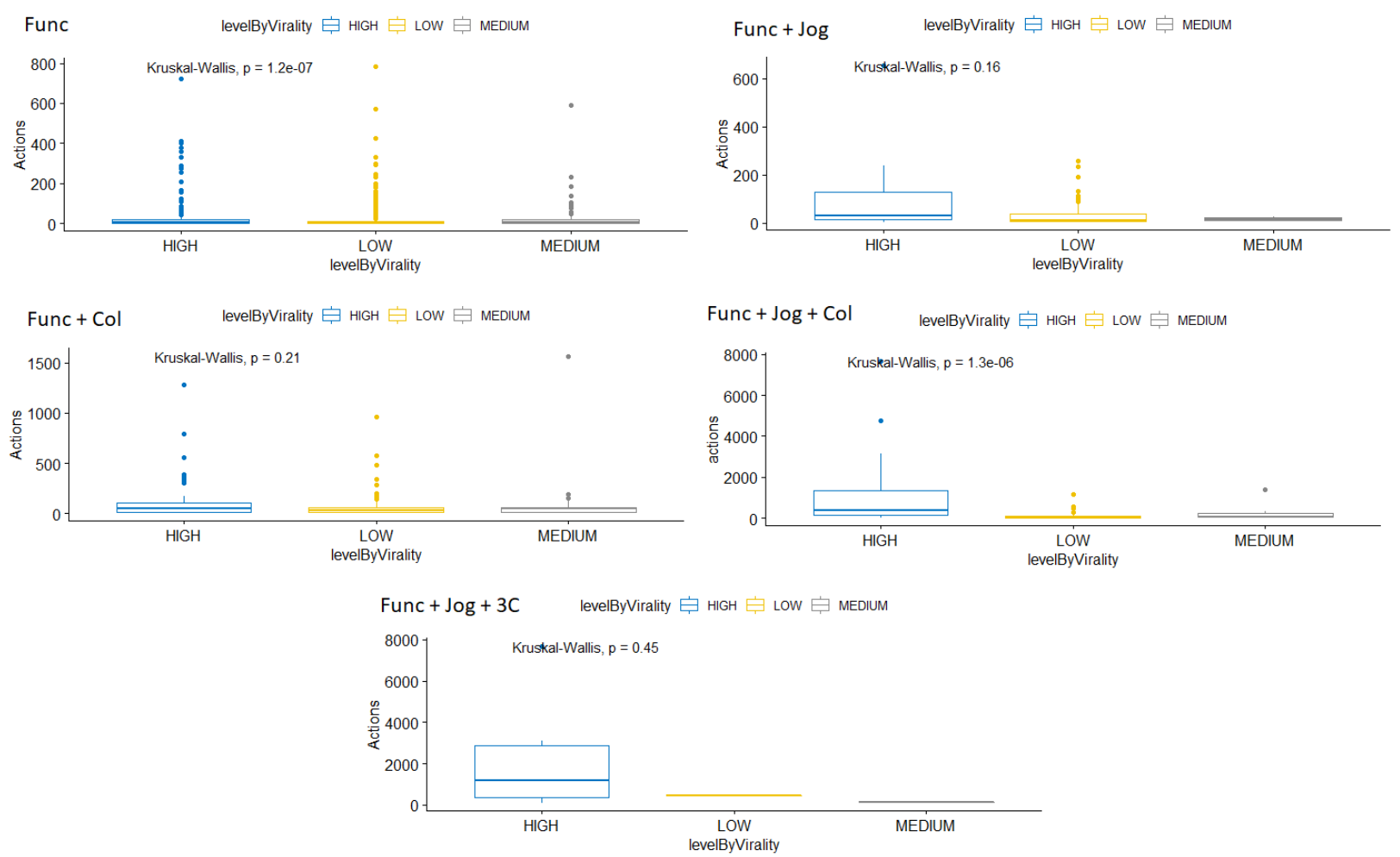

Figura 7.6: Comparação dos conjuntos a partir dos níveis Alto, Médio e Baixo alcançados para a métrica Viralidade. 
Tabela 7.11: Descrição dos dados apresentados na Figura 7.6.

\begin{tabular}{|l|l|l|l|l|l|l|l|}
\hline Conjunto & $\begin{array}{l}\text { Nível por } \\
\text { Métrica }\end{array}$ & Min. & $1^{\circ} \mathrm{Qu}$. & Mediana & Média & $3^{\circ}$ Qu. & Máx. \\
\hline Func & Viralidade Baixa & 1 & 2 & 4 & 17.34 & 10 & 785 \\
& Viralidade Média & 1 & 2 & 4 & 30.82 & 18.50 & 590 \\
& Viralidade Alta & 1 & 3 & 7 & 35.4 & 20 & 721 \\
\hline Func + Jog & Viralidade Baixa & 2 & 5 & 11 & 32.18 & 37 & 256 \\
& Viralidade Média & 8 & 11 & 14 & 16 & 20 & 26 \\
& Viralidade Alta & 4 & 14 & 30 & 115.8 & 128 & 655 \\
\hline Func + Col & Viralidade Baixa & 2 & 12 & 28 & 52.69 & 61 & 962 \\
& Viralidade Média & 3 & 12 & 47 & 110.8 & 61 & 1565 \\
& Viralidade Alta & 3 & 9.25 & 50 & 113.30 & 107.50 & 1276 \\
\hline Func + Jog + Col & Viralidade Baixa & 4 & 23.5 & 41 & 120.8 & 105.8 & 1142 \\
& Viralidade Média & 7 & 41.5 & 63 & 225.7 & 215 & 1388 \\
& Viralidade Alta & 13 & 163 & 380 & 1044 & 1348 & 7682 \\
\hline Func + Jog $+3 \mathrm{C}$ & Viralidade Baixa & 466 & 466 & 466 & 466 & 466 & 466 \\
& Viralidade Média & 125 & 125 & 125 & 125 & 125 & 125 \\
& Viralidade Alta & 86 & 381.2 & 1180 & 2090 & 2868 & 7682 \\
\hline
\end{tabular}

Para a métrica Viralidade, o conjunto Func é o que apresenta a quantidade de ações mais equilibrada entre os níveis de viralidade, o que fica evidente pela quantidade máxima de elementos acessados relacionados à viralidade baixa (785) e viralidade alta (721). A métrica viralidade é a primeira a não apresentar a quantidade máxima de ações relacionada ao maior nível alcançado na métrica. Para os acessos apenas a elementos funcionais (conjunto Func), a viralidade baixa ficou relacionada à quantidade máxima de ações; e para o conjunto Func + Col, a viralidade média ficou relacionada à quantidade máxima de ações. Contudo, considerando a quantidade média de elementos acessados em cada conjunto, a relação maior quantidade de elementos acessados, maior nível alcançado na métrica é mantida para os conjuntos Func, Func $+\mathrm{Col}$ e Func $+\mathrm{J}$ og + Col. Para os conjuntos Func + Jog e Func + Jog $+3 \mathrm{C}$, a viralidade média esteve relacionada com a menor quantidade de elementos acessados. Contudo, apenas um usuário esteve relacionado à viralidade baixa e outro à viralidade média no conjunto Func $+\mathrm{Jog}+3 \mathrm{C}$, todos os demais foram relacionadas à viralidade alta. Os conjuntos Func + Jog, Func + Jog + Col e Func + Jog $+3 \mathrm{C}$ foram os que tiveram a maior proporção de ações relacionadas à viralidade alta ( $>1$ acesso por posts no Facebook, Google + ou por clicar em uma notificação). 

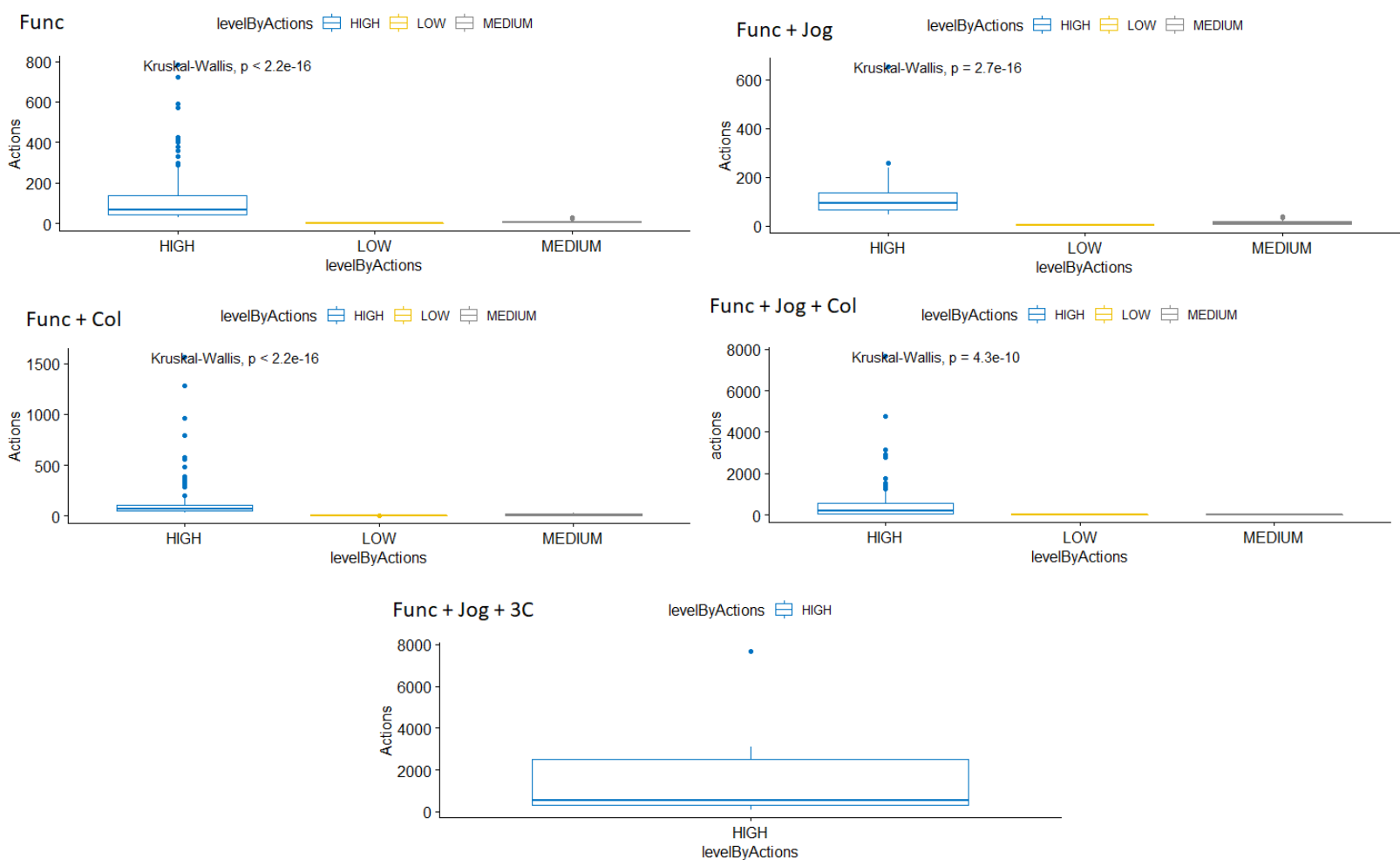

Figura 7.7: Comparação dos conjuntos a partir dos níveis Alto, Médio e Baixo alcançados para a métrica Ações.

Tabela 7.12: Descrição dos dados apresentados na Figura 7.7.

\begin{tabular}{|l|l|l|l|l|l|l|l|}
\hline Conjunto & $\begin{array}{l}\text { Nível por } \\
\text { Métrica }\end{array}$ & Min. & $1^{\circ} \mathrm{Qu}$. & Mediana & Média & $3^{\circ} \mathrm{Qu}$. & Máx. \\
\hline Func & Ações Baixa & 1 & 1 & 2 & 1.87 & 2 & 3 \\
& Ações Média & 4 & 5 & 8 & 9.89 & 13 & 29 \\
& Ações Alta & 30 & 41.75 & 66.50 & 118.40 & 136.80 & 785 \\
\hline Func + Jog & Ações Baixa & 2 & 3 & 4 & 3.89 & 5 & 6 \\
& Ações Média & 5 & 7 & 11 & 13.86 & 18 & 37 \\
& Ações Alta & 44 & 64 & 92 & 132.5 & 134 & 655 \\
\hline Func + Col & Ações Baixa & 2 & 3 & 3 & 2.81 & 3 & 3 \\
& Ações Média & 4 & 7 & 12 & 13.65 & 19 & 29 \\
& Ações Alta & 30 & 49.25 & 66.50 & 124.40 & 108 & 1565 \\
\hline Func + Jog + Col & Ações Baixa & 4 & 4 & 4 & 4 & 4 & 4 \\
& Ações Média & 6 & 12.25 & 19 & 18.89 & 25.75 & 35 \\
& Ações Alta & 30 & 69 & 175 & 653.8 & 541.5 & 7682 \\
\hline Func + Jog $+3 \mathrm{CC}$ & Ações Baixa & NA & NA & NA & NA & NA & NA \\
& Ações Média & NA & NA & NA & NA & NA & NA \\
& Ações Alta & 86 & 301.8 & 535 & 1731 & 2526 & 7682 \\
\hline
\end{tabular}

Para a métrica Ações, a relação maior quantidade de ações, maior nível alcançado é necessária, uma vez que esta métrica mede a quantidade de ações realizadas pelo usuário no período. O conjunto Func + Jog $+3 \mathrm{C}$ destaca-se por apresentar apenas o nível alto para a métrica ações ( $>29$ ações). Func $+\operatorname{Jog}+$ Col vem em seguida, com apenas um usuário com ações de nível baixo e todos os demais com níveis alto e médio. 

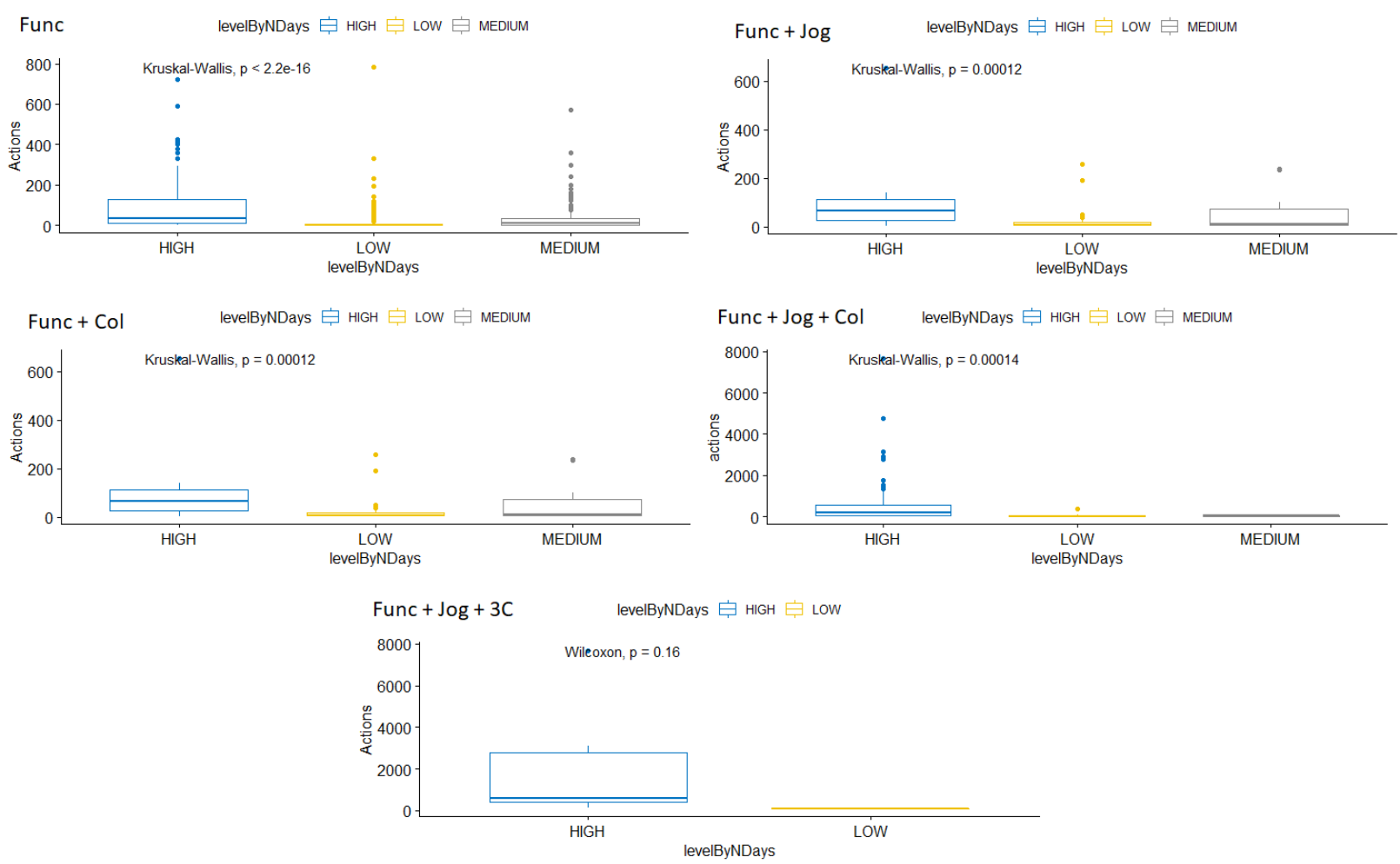

Figura 7.8: Comparação dos conjuntos a partir dos níveis Alto, Médio e Baixo alcançados para a métrica NDias.

Tabela 7.13: Descrição dos dados apresentados na Figura 7.8.

\begin{tabular}{|l|l|l|l|l|l|l|l|}
\hline Conjunto & $\begin{array}{l}\text { Nível por } \\
\text { Métrica }\end{array}$ & Min. & $1^{\circ} \mathrm{Qu}$. & Mediana & Média & $3^{\circ} \mathrm{Qu}$. & Máx. \\
\hline Func & NDias Baixa & 1 & 2 & 3 & 10.28 & 8 & 785 \\
& NDias Média & 1 & 3 & 9 & 33.15 & 33 & 570 \\
& NDias Alta & 1 & 9 & 36 & 98.59 & 128 & 721 \\
\hline Func + Jog & NDias Baixa & 2 & 5 & 8 & 20.24 & 17.50 & 256 \\
& NDias Média & 2 & 6 & 11 & 50.42 & 73.50 & 236 \\
& NDias Alta & 4 & 24 & 66 & 101.7 & 113 & 655 \\
\hline Func + Col & NDias Baixa & 2 & 7 & 15 & 34.81 & 37.25 & 962 \\
& NDias Média & 3 & 18 & 28.50 & 40.20 & 53.75 & 147 \\
& NDias Alta & 5 & 48.5 & 77.5 & 150.3 & 133.8 & 1565 \\
\hline Func + Jog + Col & NDias Baixa & 4 & 14.75 & 29 & 65.5 & 62 & 360 \\
& NDias Média & 16 & 27.5 & 40.5 & 45.25 & 56.25 & 96 \\
& NDias Alta & 7 & 56.75 & 183 & 672.30 & 562.50 & 7682 \\
\hline Func + Jog + 3C & NDias Baixa & 86 & 86 & 86 & 86 & 86 & 86 \\
& NDias Média & NA & NA & NA & NA & NA & NA \\
& NDias Alta & 125 & 421 & 604 & 1914 & 2782 & 7682 \\
\hline
\end{tabular}

Para a métrica NDias, a quantidade máxima de ações não esteve relacionada ao maior nível alcançado para ndias (ou maior quantidade de dias de acesso), apenas para o conjunto Func. Contudo, considerando a média de ações, todos os conjuntos apresentaram a relação maior nível alcançado para ndias, maior quantidade de ações realizadas. Apenas o conjunto $\mathrm{Func}+\mathrm{Jog}+3 \mathrm{C}$ não possui nível médio de ndias e apenas um usuário esteve relacionado ao nível baixo de ndias, enquanto todos os demais foram relacionados ao nível alto $(>=3$ dias de acesso). O conjunto Func foi o que apresentou a maior quantidade de acessos relacionados ao nível baixo de ndias (apenas 1 dia de 
acesso).
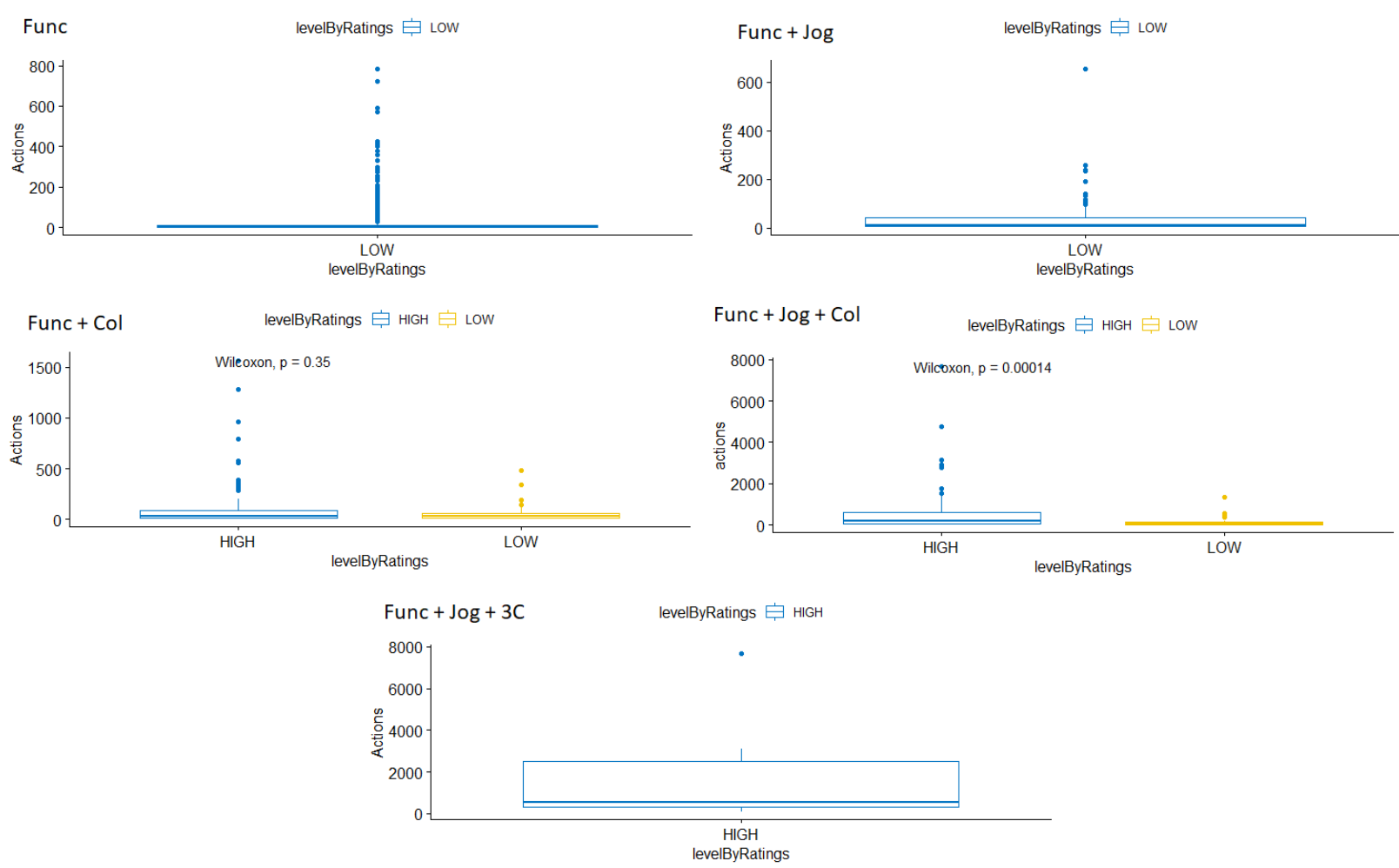

Figura 7.9: Comparação dos conjuntos a partir dos níveis Alto, Médio e Baixo alcançados para a métrica Classificação.

Tabela 7.14: Descrição dos dados apresentados na Figura 7.9.

\begin{tabular}{|l|l|l|l|l|l|l|l|}
\hline Conjunto & $\begin{array}{l}\text { Nível por } \\
\text { Métrica }\end{array}$ & Min. & $1^{\circ} \mathrm{Qu}$. & Mediana & Média & $3^{\circ} \mathrm{Qu}$. & Máx. \\
\hline Func & Classificação Baixa & 1 & 2 & 4 & 21.65 & 13 & 785 \\
& Classificação Média & NA & NA & NA & NA & NA & NA \\
& Classificação Alta & NA & NA & NA & NA & NA & NA \\
\hline Func + Jog & Classificação Baixa & 2 & 6 & 11 & 41.76 & 40.50 & 655 \\
& Classificação Média & NA & NA & NA & NA & NA & NA \\
& Classificação Alta & NA & NA & NA & NA & NA & NA \\
\hline Func + Col & Classificação Baixa & 2 & 12 & 30.50 & 45.87 & 61 & 481 \\
& Classificação Média & NA & NA & NA & NA & NA & NA \\
& Classificação Alta & 3 & 10 & 31.50 & 103.40 & 88.25 & 1565 \\
\hline Func + Jog + Col & Classificação Baixa & 4 & 19.5 & 36 & 146.9 & 145.2 & 1350 \\
& Classificação Média & NA & NA & NA & NA & NA & NA \\
& Classificação Alta & 6 & 61.75 & 177 & 736.70 & 594.80 & 7682 \\
\hline Func + Jog + 3C & Classificação Baixa & NA & NA & NA & NA & NA & NA \\
& Classificação Média & NA & NA & NA & NA & NA & NA \\
& Classificação Alta & 86 & 301.8 & 535 & 1731 & 2526 & 7682 \\
\hline
\end{tabular}

Para a métrica Classificação, onde a quantidade de comentários e likes é contabilizada, os conjuntos Func e Func + Jog não apresentam ações relacionadas à colaboração e portanto apenas alcançaram nível baixo para esta métrica, com 0 acesso relacionado à classificação. Para os demais conjuntos não existiram ações relacionadas com o nível médio de classificação. Os conjuntos Func + Col e Func + Jog + Col apresentaram apenas níveis alto e baixo para classificação, com uma 
distribuição similar de ações entre os níveis para Func $+\mathrm{Col}$ considerando a mediana. Apenas o conjunto Func + Jog $+3 \mathrm{C}$ apresentou somente o nível alto $(>=1$ comentário ou like) para a métrica classificação.
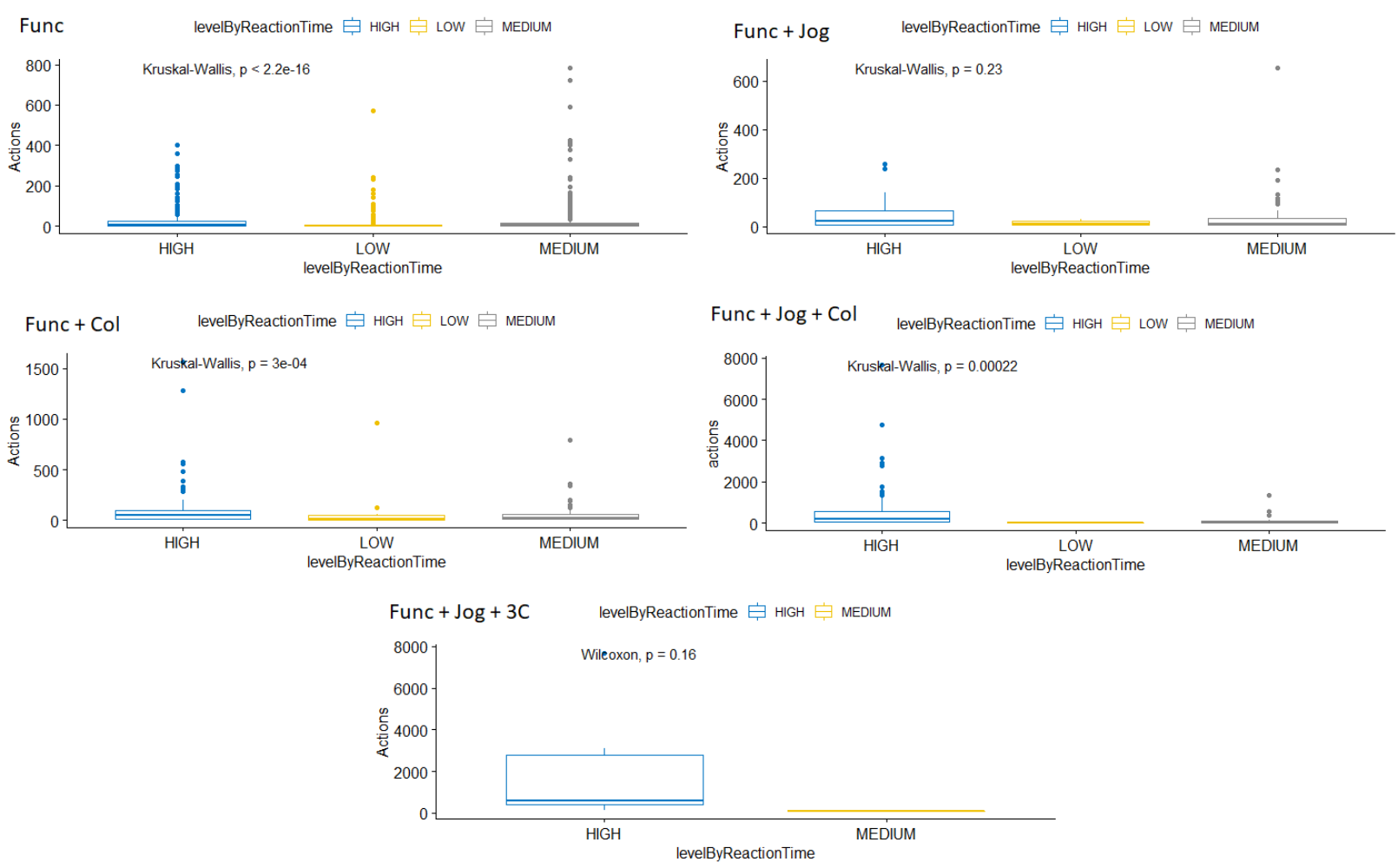

Figura 7.10: Comparação dos conjuntos a partir dos níveis Alto, Médio e Baixo alcançados para a métrica Tempo de reação.

Tabela 7.15: Descrição dos dados apresentados na Figura \%.10.

\begin{tabular}{|l|l|l|l|l|l|l|l|}
\hline Conjunto & Nível por & Min. & $1^{\circ}$ Qu. & Mediana & Média & $3^{\circ}$ Qu. & Máx. \\
& Métrica & & & & & & \\
\hline Func & Tempo de reação Baixa & 1 & 1 & 3 & 11.33 & 6 & 570 \\
& Tempo de reação Média & 1 & 2 & 5 & 23.78 & 15 & 785 \\
& Tempo de reação Alta & 1 & 3 & 6 & 34.29 & 25 & 403 \\
\hline Func + Jog & Tempo de reação Baixa & 2 & 5.25 & 9.5 & 13 & 21.50 & 30 \\
& Tempo de reação Média & 2 & 5.75 & 9.5 & 46.46 & 31.75 & 655 \\
& Tempo de reação Alta & 2 & 7 & 21 & 47.86 & 64 & 256 \\
\hline Func + Col & Tempo de reação Baixa & 2 & 4 & 13 & 112.1 & 46 & 962 \\
& Tempo de reação Média & 2 & 9 & 25 & 45.76 & 54.75 & 790 \\
& Tempo de reação Alta & 3 & 16 & 53 & 106 & 99.5 & 1565 \\
\hline Func + Jog + Col & Tempo de reação Baixa & 20 & 20 & 20 & 20 & 20 & 20 \\
& Tempo de reação Média & 4 & 20.75 & 35.00 & 126.60 & 83.75 & 1348 \\
& Tempo de reação Alta & 7 & 56.5 & 191 & 695 & 544.5 & 7682 \\
\hline Func + Jog $+3 \mathrm{C}$ & Tempo de reação Baixa & NA & NA & NA & NA & NA & NA \\
& Tempo de reação Média & 86 & 86 & 86 & 86 & 86 & 86 \\
& Tempo de reação Alta & 125 & 421 & 604 & 1914 & 2782 & 7682 \\
\hline
\end{tabular}

Para a métrica Tempo de reação, o conjunto Func apresentou a distribuição mais similar entre ações por nível alcançado. Os conjuntos Func e Func + Jog tiveram a quantidade máxima de ações relacionadas ao nível médio de tempo de reação $(>15.35$ e $<=163.20$ segundos entre 
duas ações consecutivas de um mesmo dia). O comportamento contrário ocorreu para Func $+\mathrm{Col}$ e Func + Jog $+3 \mathrm{C}$ para os quais a quantidade mínima de ações esteve relacionada ao nível médio de tempo de reação. Contudo, apenas o conjunto Func $+\mathrm{Jog}+3 \mathrm{C}$ não apresentou nível baixo de tempo de reação e teve apenas um usuário com nível médio, com todos os demais com nível alto de tempo de reação ( $>163.20$ segundos). O conjunto Func + Jog $+\mathrm{Col}$ apresentou apenas um usuário relacionado com nível baixo de tempo de reação e todos os demais entre níveis médio e alto, com predominância do nível alto. O conjunto Func + Col foi o único em que nível médio de tempo de reação foi relacionado com a menor quantidade de média e de máxima de ações realizadas. Para a análise apresentada nesta seção, até o momento, o conjunto Func + Jog $+3 \mathrm{C}$ apresentou os usuários mais engajados com o sistema e o conjunto Func apresentou os usuários menos engajados. É importante ressaltar que engajamento não diz respeito à maior quantidade de usuários acessando um sistema ou uma funcionalidade e sim a como foi o comportamento dos usuários que acessaram o sistema ou funcionalidade, ainda que sejam poucos usuários.

Para verificar se existiram diferenças estatisticamente significativas para os níveis alcançados em cada métrica por conjunto, a Tabela 7.16 apresenta os resultados para a comparação entre a quantidade de elementos acessados por nível alcançado - baixo, médio e alto (BMA) - de cada métrica objetiva para cada um dos cinco conjuntos. Por exemplo, para a métrica frequência e acesso apenas ao conjunto de elementos funcionais (Func), compara-se a lista de quantidade de elementos funcionais acessados na qual o nível da frequência resultou em alto, versus a lista de quantidade de elementos funcionais acessados na qual o nível da frequência resultou em médio, versus a lista de quantidade de elementos funcionais acessados na qual o nível da frequência resultou em baixo. A comparação das três listas de quantidade de elementos funcionais por nível da métrica frequência, é apresentada pelos valores de chi-squared de Kruskal Wallis, de p-value e do tamanho de efeito Epsilon-squared para essa comparação. O mesmo é aplicado para a métrica frequência e cada um dos demais conjuntos. Em seguida, aplica-se o mesmo tipo de análise para a próxima métrica, até analisar os níveis alcançados para cada uma das métricas em cada um dos conjuntos.

Dentre as comparações, apenas para as métricas classificação no conjunto Func $+\mathrm{Col}$ e duração no conjunto Func + Jog $+3 \mathrm{C}$ não existiram efeitos significativos para a quantidade de elementos acessados de acordo com o nível alcançado para essas métricas. Para as métricas viralidade e tempo de reação em Func + Jog; viralidade e classificação em Func + Col; duração em Func + Jog + Col; e frequência, recenticidade, duração, viralidade, ndias e tempo de reação em Func $+\mathrm{Jog}+3 \mathrm{C}$ não existiram resultados estatisticamente significativos, embora tenham apresentado tamanhos de efeito de pequenos a grandes. Isso ocorre porque o resultado de p-value é muito sensível ao tamanho da amostra, enquanto tamanhos de efeito não são.

Portanto, para p-value e tamanho de efeito Epsilon-squared estatisticamente significativos temos que a comparação para a quantidade de elementos acessados por nível alcançado em cada métrica resultou em:

- Conjunto Func: efeito pequeno para a métrica viralidade; efeito médio para as métricas recenticidade e tempo de reação; e efeito grande para as métricas frequência, duração, ações e ndias.

- Conjunto Func + Jog: efeito grande para as métricas frequência, recenticidade, duração, ações e ndias.

- Conjunto Func + Col: efeito pequeno para a métrica tempo de reação; efeito médio para a métrica duração; e efeito grande para as métricas frequência, recenticidade, ações e ndias.

- Conjunto Func + Jog + Col: efeitos grandes para as métricas frequência, recenticidade, viralidade, classificação, ações, ndias e tempo de reação.

- Conjunto Func + Jog $+3 \mathrm{C}$ : não apresentou resultados estatisticamente significativos, dado o tamanho da amostra deste conjunto (10 usuários), contudo, apresentou tamanhos de efeito grandes para cinco dentre seis métricas comparadas; e para as duas métricas em que não se 
Tabela 7.16: Resultados do Teste de Kruskal Wallis com tamanho de efeito Epsilon-squared ( $\epsilon \hat{2})$ para a comparação entre a quantidade de elementos acessados por nivel alcançado - baixo, médio e alto (BMA) de cada métrica para cada conjunto.

\begin{tabular}{|c|c|c|c|c|c|}
\hline Obj. & $\begin{array}{l}\text { Func } \\
(\mathrm{p}) \\
\epsilon \hat{2}\end{array}$ & $\begin{array}{l}\text { Func }+ \text { Jog } \\
\text { (p) } \\
\epsilon \hat{2}\end{array}$ & $\begin{array}{l}\text { Func }+ \text { Col } \\
\text { (p) } \\
\epsilon \hat{2}\end{array}$ & $\begin{array}{l}\text { Func }+ \text { Jog }+ \text { Col } \\
\text { (p) } \\
\epsilon \hat{2}\end{array}$ & $\begin{array}{l}\text { Func }+ \text { Jog }+3 \text { C } \\
\text { (p) } \\
\epsilon \hat{2}\end{array}$ \\
\hline $\begin{array}{l}\text { Freq. } \\
\text { BxMxA }\end{array}$ & $\begin{array}{l}170.21 \\
(<2.2 \mathrm{e}-16) \\
\mathbf{0 . 1 5}\end{array}$ & $\begin{array}{l}17.466 \\
(0.0001611) \\
\mathbf{0 . 1 9}\end{array}$ & $\begin{array}{l}53.035 \\
(3.045 \mathrm{e}-12) \\
\mathbf{0 . 1 8}\end{array}$ & $\begin{array}{l}21.704 \\
(1.937 \mathrm{e}-05) \\
\mathbf{0 . 2 6}\end{array}$ & $\begin{array}{l}3.24 \\
(0.1979) \\
\mathbf{0 . 3 6}\end{array}$ \\
\hline $\begin{array}{l}\text { Rec. } \\
\text { BxMxA }\end{array}$ & $\begin{array}{l}160.41 \\
(<2.2 \mathrm{e}-16) \\
0.14\end{array}$ & $\begin{array}{l}14.916 \\
(0.0005768) \\
\mathbf{0 . 1 6}\end{array}$ & $\begin{array}{l}51.538 \\
(6.438 \mathrm{e}-12) \\
\mathbf{0 . 1 8}\end{array}$ & $\begin{array}{l}13.304 \\
(0.001292) \\
\mathbf{0 . 1 6}\end{array}$ & $\begin{array}{l}2.4545 \\
(0.1172) \\
\mathbf{0 . 2 7}\end{array}$ \\
\hline $\begin{array}{l}\text { Duração } \\
\text { BxMxA }\end{array}$ & $\begin{array}{l}386.09 \\
(<2.2 \mathrm{e}-16) \\
\mathbf{0 . 3 4}\end{array}$ & $\begin{array}{l}21.125 \\
(2.587 \mathrm{e}-05) \\
\mathbf{0 . 2 3}\end{array}$ & $\begin{array}{l}39.062 \\
(3.295 \mathrm{e}-09) \\
0.13\end{array}$ & $\begin{array}{l}5.4273 \\
(0.06629) \\
0.06\end{array}$ & $\begin{array}{l}0.012987 \\
(0.9093) \\
0.001\end{array}$ \\
\hline $\begin{array}{l}\text { Vir. } \\
\text { BxMxA }\end{array}$ & $\begin{array}{l}31.811 \\
(1.237 \mathrm{e}-07) \\
0.02\end{array}$ & $\begin{array}{l}3.6989 \\
(0.1573) \\
0.04\end{array}$ & $\begin{array}{l}3.1668 \\
(0.2053) \\
0.01\end{array}$ & $\begin{array}{l}27.104 \\
(1.301 \mathrm{e}-06) \\
\mathbf{0 . 3 3}\end{array}$ & $\begin{array}{l}1.5818 \\
(0.4534) \\
\mathbf{0 . 1 7}\end{array}$ \\
\hline $\begin{array}{l}\text { Clas. } \\
\text { BxMxA }\end{array}$ & $\begin{array}{l}\mathrm{NA} \\
\mathrm{NA} \\
\mathrm{NA}\end{array}$ & $\begin{array}{l}\text { NA } \\
\text { NA } \\
\text { NA }\end{array}$ & $\begin{array}{l}0.88351 \\
(0.3472) \\
0.003 \\
\end{array}$ & $\begin{array}{l}14.604 \\
(0.0001327) \\
\mathbf{0 . 1 8}\end{array}$ & $\begin{array}{l}\mathrm{NA} \\
\mathrm{NA} \\
\mathrm{NA}\end{array}$ \\
\hline $\begin{array}{l}\text { Ações } \\
\text { BxMxA }\end{array}$ & $\begin{array}{l}959.08 \\
(<2.2 \mathrm{e}-16) \\
\mathbf{0 . 8 4}\end{array}$ & $\begin{array}{l}71.668 \\
(2.739 \mathrm{e}-16) \\
\mathbf{0 . 7 9}\end{array}$ & $\begin{array}{l}219.31 \\
(<2.2 \mathrm{e}-16) \\
\mathbf{0 . 7 7}\end{array}$ & $\begin{array}{l}43.133 \\
(4.302 \mathrm{e}-10) \\
\mathbf{0 . 5 3}\end{array}$ & $\begin{array}{l}\text { NA } \\
\text { NA } \\
\text { NA }\end{array}$ \\
\hline $\begin{array}{l}\text { Ndias } \\
\text { BxMxA }\end{array}$ & $\begin{array}{l}185.43 \\
(<2.2 \mathrm{e}-16) \\
\mathbf{0 . 1 6}\end{array}$ & $\begin{array}{l}18.037 \\
(0.0001212) \\
\mathbf{0 . 2}\end{array}$ & $\begin{array}{l}72.1 \\
(<2.2 \mathrm{e}-16) \\
\mathbf{0 . 2 5}\end{array}$ & $\begin{array}{l}17.798 \\
(0.0001365) \\
\mathbf{0 . 2 2}\end{array}$ & $\begin{array}{l}2.4545 \\
(0.1172) \\
\mathbf{0 . 2 7}\end{array}$ \\
\hline $\begin{array}{l}\text { TReação } \\
\text { BxMxA }\end{array}$ & $\begin{array}{l}77.96 \\
(<2.2 \mathrm{e}-16) \\
0.06\end{array}$ & $\begin{array}{l}2.9706 \\
(0.2264) \\
0.03 \\
\end{array}$ & $\begin{array}{l}16.236 \\
(0.0002981) \\
0.05\end{array}$ & $\begin{array}{l}16.808 \\
(0.000224) \\
\mathbf{0 . 2 0} \\
\end{array}$ & $\begin{array}{l}2.4545 \\
(0.1172) \\
\mathbf{0 . 2 7}\end{array}$ \\
\hline
\end{tabular}

aplicou a comparação - classificação e ações - todas as ações foram associadas ao nível alto das duas métricas.

Os tamanhos de efeito encontrados indicam que a quantidade de elementos acessados de cada conjunto de fato diferiu significativamente por nível alcançado em cada métrica. A próxima seção apresenta a comparação entre conjuntos para valores obtidos em cada métrica objetiva de engajamento.

\subsubsection{Pesquisa causal-comparativa entre conjuntos por métrica}

As Figuras 7.3 a 7.10 verificaram se existiam diferenças no nível alcançado para cada métrica de acordo com a quantidade de elementos acessados em cada conjunto, portanto comparou-se os níveis alcançados dentro de um mesmo conjunto sem compará-lo com os demais conjuntos. A Figura 7.11 trata da análise entre conjuntos, apresentando a comparação dos resultados obtidos para cada métrica objetiva entre os cinco conjuntos. Por exemplo, para a métrica Frequência, compara-se a lista de valores obtidos para frequência no conjunto Func, versus a lista de valores obtidos para frequência no conjunto Func + Jog, versus a lista de valores obtidos para frequência no conjunto Func + Col, versus a lista de valores obtidos para frequência no conjunto Func + Jog + Col, versus a lista de valores obtidos para frequência no conjunto Func $+\mathrm{J}$ og $+3 \mathrm{C}$. Repete-se o mesmo tipo de comparação para cada métrica. 

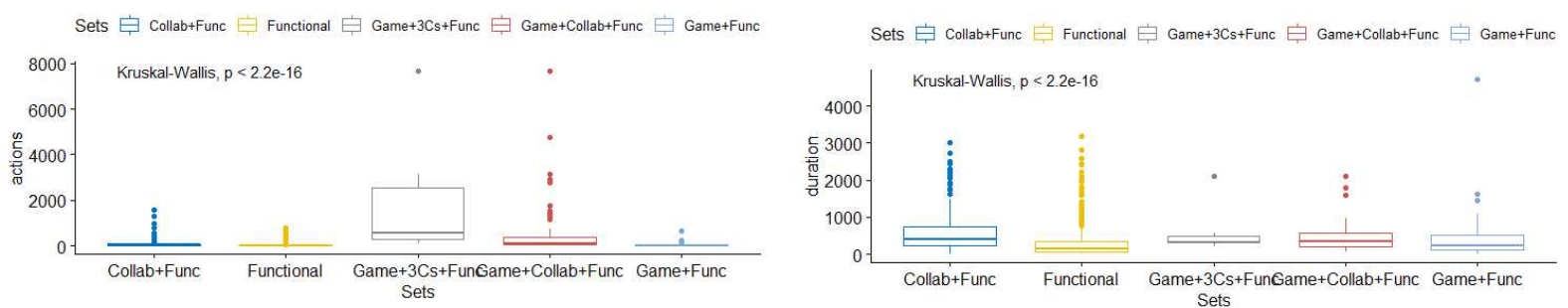

Sets 白 Collab+Func 也 Functional 由 Game+3Cs+Func 白 Game+Collab+Func 由 Game+Func

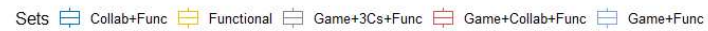
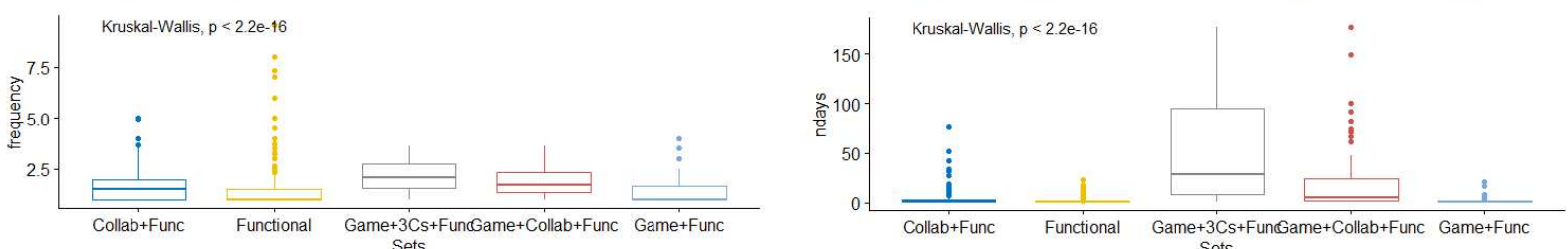

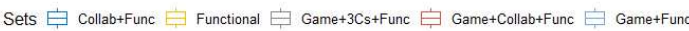

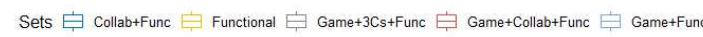
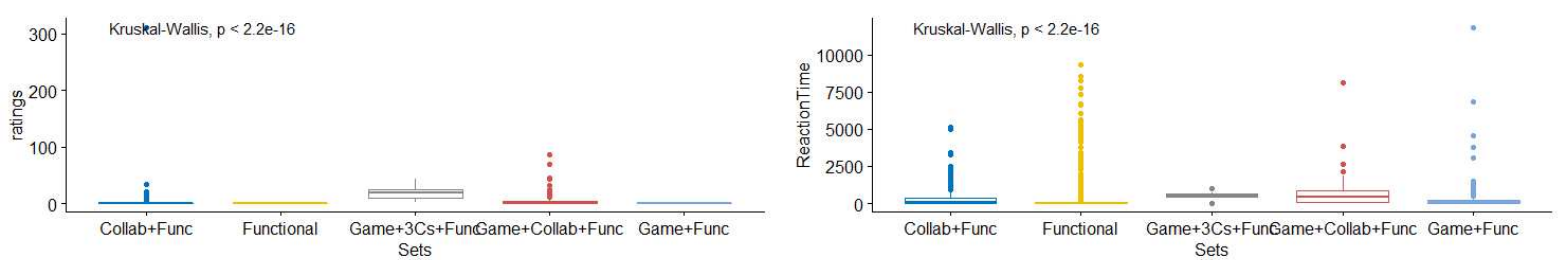

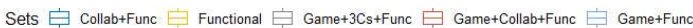

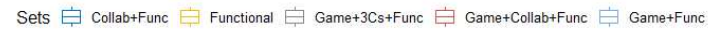
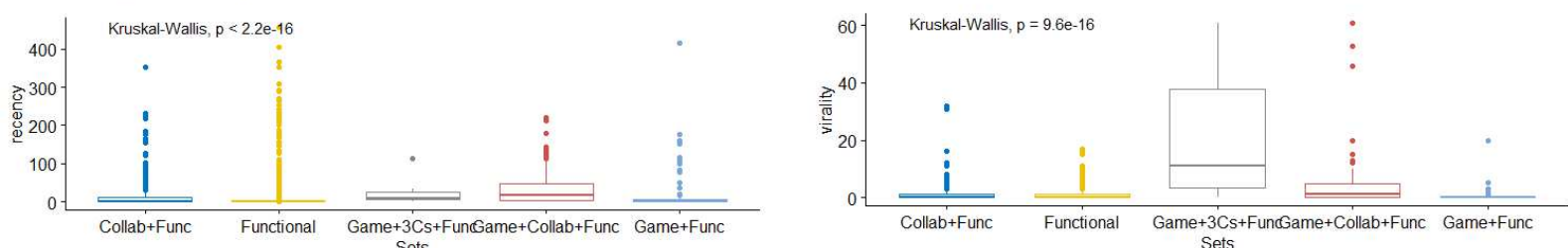

Figura 7.11: Comparação das métricas objetivas entre conjuntos a partir do Teste de Kruskal-Wallis. 
Tabela 7.17: Descrição dos dados apresentados na Figura 7.11.

\begin{tabular}{|c|c|c|c|c|c|c|c|}
\hline Métrica & Conjunto & Min. & $1^{\circ} \mathrm{Qu}$. & Mediana & Média & $3^{\circ} \mathrm{Qu}$ & Máx. \\
\hline \multirow[t]{5}{*}{ Freq. } & Func & 1 & 1 & 1 & 1.32 & 1.5 & 9.5 \\
\hline & Func + Jog & 1 & 1 & 1 & 1.39 & 1.68 & 4 \\
\hline & Func $+\mathrm{Col}$ & 1 & 1 & 1.5 & 1.73 & 2 & 5 \\
\hline & Func + Jog + Col & 1 & 1.3 & 1.69 & 1.88 & 2.34 & 3.62 \\
\hline & Func + Jog $+3 \mathrm{C}$ & 1 & 1.5 & 2.08 & 2.16 & 2.73 & 3.62 \\
\hline \multirow[t]{5}{*}{ Rec. } & Func & 0 & 0 & 0 & 11.46 & 0 & 458.5 \\
\hline & Func + Jog & 0 & 0 & 0 & 21.65 & 5.9 & 415 \\
\hline & Func $+\mathrm{Col}$ & 0 & 0 & 0.5 & 20.91 & 11.52 & 352 \\
\hline & Func + Jog + Col & 0 & 3.4 & 16.28 & 38.39 & 45.79 & 220.5 \\
\hline & Func + Jog $+3 \mathrm{C}$ & 0 & 5.3 & 7.3 & 22 & 24.98 & 114.5 \\
\hline \multirow[t]{5}{*}{ Duração } & Func & 0.5 & 49.75 & 139.20 & 264.10 & 331 & 3192 \\
\hline & Func + Jog & 1 & 109.8 & 225 & 398.9 & 502.5 & 4725 \\
\hline & Func + Col & 8 & 225.6 & 393.8 & 578.5 & 743.9 & 3016 \\
\hline & Func + Jog + Col & 45.17 & 206.4 & 335.9 & 446.7 & 569 & 2111 \\
\hline & Func + Jog $+3 \mathrm{C}$ & 214.9 & 311.1 & 328.3 & 529.4 & 479.6 & 2111 \\
\hline \multirow[t]{5}{*}{ Vir. } & Func & 0 & 0 & 0 & 0.71 & 1 & 17 \\
\hline & Func + Jog & 0 & 0 & 0 & 0.57 & 0 & 20 \\
\hline & Func $+\mathrm{Col}$ & 0 & 0 & 0 & 1.06 & 1 & 32 \\
\hline & Func + Jog + Col & 0 & 0 & 1 & 4.97 & 4.75 & 61 \\
\hline & Func + Jog $+3 \mathrm{C}$ & 0 & 3.5 & 11 & 20.40 & 37.75 & 61 \\
\hline \multirow[t]{5}{*}{ Clas. } & Func & 0 & 0 & 0 & 0 & 0 & 0 \\
\hline & Func + Jog & 0 & 0 & 0 & 0 & 0 & 0 \\
\hline & Func + Col & 0 & 0 & 0 & 2.71 & 1 & 311 \\
\hline & Func + Jog + Col & 0 & 0 & 1 & 6.68 & 4.75 & 87 \\
\hline & Func + Jog $+3 \mathrm{C}$ & 2 & 9.75 & 18.5 & 18.7 & 25 & 43 \\
\hline \multirow[t]{5}{*}{ Ações } & Func & 1 & 2 & 4 & 21.65 & 13 & 785 \\
\hline & Func + Jog & 2 & 6 & 11 & 41.76 & 40.5 & 655 \\
\hline & Func $+\mathrm{Col}$ & 2 & 11 & 31 & 70.18 & 71.25 & 1565 \\
\hline & Func + Jog + Col & 4 & 35.75 & 102.5 & 506.5 & 385.20 & 7682 \\
\hline & Func + Jog $+3 \mathrm{C}$ & 86 & 301.8 & 535 & 1731 & 2526 & 7682 \\
\hline \multirow[t]{5}{*}{ Ndias } & Func & 1 & 1 & 1 & 1.53 & 1 & 23 \\
\hline & Func + Jog & 1 & 1 & 1 & 2.07 & 2 & 21 \\
\hline & Func $+\mathrm{Col}$ & 1 & 1 & 2 & 3.4 & 3 & 76 \\
\hline & Func + Jog + Col & 1 & 2 & 5.5 & 20.17 & 24.5 & 177 \\
\hline & Func + Jog $+3 \mathrm{C}$ & 1 & 8.75 & 29 & 59.2 & 95.75 & 177 \\
\hline \multirow[t]{5}{*}{ TReação } & Func & 0.37 & 12 & 27.85 & 306.8 & 106.1 & 9349 \\
\hline & Func + Jog & 9 & 21.13 & 51.27 & 510.5 & 220.5 & 11860 \\
\hline & Func $+\mathrm{Col}$ & 3.5 & 37.29 & 85.12 & 367.4 & 376.5 & 5159 \\
\hline & Func + Jog + Col & 14.52 & 81.84 & 412.2 & 667.8 & 841.5 & 8095 \\
\hline & Func + Jog $+3 \mathrm{C}$ & 19.73 & 455.1 & 511 & 527.1 & 636.9 & 967.2 \\
\hline
\end{tabular}

A Figura 7.11 evidencia que os usuários que realizaram a maior parte das ações do sistema durante os três anos de monitoramento foram os que acessaram todos os tipos de elementos, com o maior número de ações sendo apresentado para os acessos a partir de usuários do conjunto Func + Jog +3 C. Essa informação torna-se mais clara ao analisar a Tabela

Para a métrica duração, o conjunto Func $+\mathrm{Jog}+3 \mathrm{C}$ apresentou a menor variabilidade entre $1^{\circ}$ e $3^{\circ}$ quartil, uma vez que a duração mínima (214.9 segundos foi superior ao valor mínimo de todos os demais conjuntos. A menor duração média foi a do conjunto Func e a maior duração média foi a do conjunto Func + Col. Para a métrica frequência, a maior quantidade de sessões por dia de 
acesso ocorreu para o conjunto Func (9.5 sessões de até 10 minutos por dia de acesso) e a menor quantidade ocorreu para os conjuntos Func $+\mathrm{Jog}+\mathrm{Col}$ e Func $+\mathrm{Jog}+3 \mathrm{C}$. No entanto, considerando a média de frequência por dia de acesso, ocorre exatamente o contrário.

Para métrica ndias, as maiores quantidades de dias de acesso foram apresentadas pelos conjuntos Func + Jog + Col e Func + Jog $+3 \mathrm{C}$, porém com valores superiores para $1^{\circ}$ quartil, mediana, média e $3^{\circ}$ quartil para Func $+\mathbf{J o g}+3 \mathrm{C}$. Os conjuntos com menores quantidades de dias de acesso foram Func e Func + Jog, com os menores valores para média e $3^{\circ}$ quartil no conjunto Func. Assim como ocorreu para as métricas ações e frequência, ndias teve média superior para o conjunto Func $+\mathrm{Col}$ em relação ao conjunto Func + Jog.

Para a métrica classificação, a maior quantidade de comentários e likes vieram a partir dos acessos aos conjuntos Func + Jog + Col e Func $+\mathbf{J o g}+3 \mathrm{C}$, considerando mediana, média e $3^{\circ}$ quartil, embora a quantidade máxima tenha sido alcançada no conjunto Func $+\mathrm{Col}$ por um outlier. Contudo, Func + Jog $+3 \mathrm{C}$ é o conjunto com a maior média para classificação. Para a métrica tempo de reação, os maiores valores obtidos para valor mínimo, $1^{\circ}$ quartil e mediana foram apresentados no conjunto Func $+\mathrm{J}$ og $+3 \mathrm{C}$, enquanto que os menores valores estiveram no conjunto Func. Os maiores valores de média e $3^{\circ}$ quartil foram apresentados no conjunto Func $+\mathbf{J}$ og + Col. O maior valor de tempo de reação foi apresentado por um outlier no conjunto Func + Jog. A menor variabilidade de tempo de reação entre $1^{\circ}$ e $3^{\circ}$ quartil foi apresentada pelo conjunto Func $+\mathrm{Jog}+3 \mathrm{C}$.

Para valores máximos de recenticidade, a menor recenticidade foi apresentada pelo conjunto Func + Jog $+3 \mathrm{C}$, seguido do conjunto Func + Jog + Col. Para o cojunto Func, $75 \%$ dos usuários acessaram apenas uma vez (ou recenticidade igual a zero), dado que neste conjunto $75 \%$ dos usuários acessaram apenas em 1 dia, conforme $3^{\circ}$ quartil da métrica ndias. Os maiores valores de média e $3^{\circ}$ quartil de recenticidade foram apresentados pelo conjunto $\mathrm{Func}+\mathrm{Jog}+\mathrm{Col}$, seguido do conjunto Func + Jog $+3 \mathrm{C}$, o que indica que são os dois conjuntos em que mais usuários retornaram ao sistema, mesmo após um período longo sem acesso. Para a métrica viralidade, o conjunto Func $+\mathrm{Jog}+3 \mathrm{C}$ destaca-se como o conjunto a partir do qual ocorreu a maior quantidade de acessos via posts do Facebook, Google+ ou após clicar em notificações. Para o conjunto Func ocorreu o contrário.

Por meio da análise comparativa dos conjuntos para valores obtidos em cada métrica, mais uma vez percebe-se a diferença entre os conjuntos Func + Jog $+3 \mathrm{C}$ e Func. Além disso, foi possível notar que o conjunto Func $+\mathrm{Col}$ apresentou resultados melhores quando comparado com o conjunto Func + Jog, o que pode sugerir que elementos de jogo não associados a elementos de colaboração podem não gerar o engajamento almejado e nesse caso seria preferível incluir apenas elementos de colaboração.

Em todas as comparações, os dois conjuntos que apresentaram os usuários mais engajados, segundo as métricas observadas, foram Func $+\mathrm{Jog}+3 \mathrm{C}$ e Func $+\mathrm{Jog}+\mathrm{Col}$, especialmente os usuários do conjunto Func + Jog $+3 \mathrm{C}$, os quais são bons candidatos a usuários influenciadores que podem engajar mais usuários na interação com o sistema. Para verificar se existiram diferenças estatisticamente significativas entre os conjuntos, a Tabela 7.18 apresenta os valores para chi-squared de Kruskal-Wallis, p-value (p) e tamanho de efeito $(\epsilon \hat{2})$ para a comparação dos conjuntos para cada métrica objetiva.

A comparação entre os conjuntos com o Teste de Kruskal-Wallis apresentou diferenças estatisticamente significativas entre os conjuntos para todas as métricas. A métrica viralidade foi a única com tamanho de efeito pequeno; as métricas frequência, recenticidade, duração e tempo de reação apresentaram tamanhos de efeito médio; e as métricas classificação, ações e ndias apresentaram efeitos grandes para a comparação entre conjuntos. A existência de tamanhos de efeito de pequenos a grandes, com $p$-value significativo $(<0.05$ em todos os casos), indica que os valores alcançados para as métricas diferiram significativamente entre os conjuntos, com conjuntos apresentando valores maiores do que outros. Em particular, o tamanho de efeito grande para a métrica ndias indica que existiram conjuntos que foram capazes de sustentar o engajamento do usuário por mais dias do que outros, e a partir da Figura 7.11 e da Tabela 7.17, sabemos que esses conjuntos foram Func $+\mathrm{Jog}+3 \mathrm{C}$ e Func $+\mathbf{J}$ og + Col.

Portanto, foi possível notar que o acesso a elementos de jogos, associados a elementos de co- 
Tabela 7.18: Resultados da comparação de métricas objetivas entre os cincos conjuntos a partir do Teste de Kruskal-Wallis.

\begin{tabular}{|l|l|}
\hline Métrica & Comparação dos 5 Conjuntos (p-value) \\
Obj. & $\epsilon \hat{2}$ \\
\hline Freq. & $209.57(<2.2 \mathrm{e}-16)$ \\
& 0.13 \\
\hline Rec. & $236.39(<2.2 \mathrm{e}-16)$ \\
& 0.14 \\
\hline Duração & $218.63(<2.2 \mathrm{e}-16)$ \\
& 0.13 \\
\hline Vir. & $76.496(9.613 \mathrm{e}-16)$ \\
& 0.04 \\
\hline Clas. & $717.33(<2.2 \mathrm{e}-16)$ \\
& $\mathbf{0 . 4 4}$ \\
\hline Ações & $440.92(<2.2 \mathrm{e}-16)$ \\
& $\mathbf{0 . 2 7}$ \\
\hline Ndias & $302.9(<2.2 \mathrm{e}-16)$ \\
& $\mathbf{0 . 1 9}$ \\
\hline TReação & $194.36(<2.2 \mathrm{e}-16)$ \\
& 0.12 \\
\hline
\end{tabular}

laboração e funcionais, foi relacionado com os melhores resultados para as métricas objetivas de engajamento, e o acesso a elementos de jogos associados apenas a elementos funcionais, embora ainda tenha apresentado melhores resultados do que acessos apenas a elementos funcionais, ainda apresenta resultados inferiores quando comparado com o acesso a elementos funcionais e de colaboração. Esses resultados sugerem que elementos de jogo resultam em maior engajamento de usuário quando relacionados a elementos de colaboração. No entanto, estamos comparando conjuntos de elementos sem isolar os efeitos obtidos para ações individuais. Esta análise é apresentada na próxima seção.

\subsubsection{Pesquisa causal-comparativa entre ações mais acessadas}

Foram comparadas as métricas objetivas para as duas ações mais acessadas de cada tipo de elemento de interação, segundo a Figura 7.2. As ações selecionadas para comparação foram as que apresentaram maiores picos de acessos e maior distribuição de acessos ao longo do tempo para cada tipo de elemento de interação. Para elementos funcionais, foram selecionadas as ações Seleção de imagem e Busca.

Para elementos de colaboração, foram selecionadas as ações Like e Upload de imagem. A ação Inserção de tag apresentou picos de acesso iguais aos de Upload de imagem (300), contudo esta é uma ação dependente do Upload, pois é necessário realizá-lo primeiro, portanto, a ação de Upload foi priorizada para análise. Adicionalmente, as ações Edição de tag e Avaliação de imagem, embora apresentem picos de acesso menores (75) do que a ação Like, possuem uma distribuição de acessos maior. No entanto, Edição de tag e Avaliação de imagem foram atividades realizadas em eventos específicos com alunos da FAU-USP, que correspondem aos períodos de maior intensidade de acessos a essas ações. Por esse motivo, Like foi selecionada para análise, uma vez que apresentou picos de 300 acessos e não esteve relacionada diretamente com eventos específicos do sistema. Para elementos de jogos, foram selecionadas as ações Visualizar o Quadro de liderança e Visualizar a Barra de progresso da imagem. A ação Visualização de distintivo teve poucos acessos e os elementos Pontos e Jogo duradouro não foram acessados.

Dentre as ações selecionadas, 1331 usuários acessaram a ação Seleção de imagem; 1118 usuários acessaram a ação Busca; 225 usuários acessaram a ação Upload de imagem; 154 usuários acessaram 
a ação Like; 99 usuários acessaram a ação Visualizar a Barra de progresso da imagem; e 78 usuários acessaram a ação Visualizar o Quadro de liderança. A Figura 7.12 apresenta a comparação entre as seis principais ações acessadas e cada métrica objetiva de engajamento, de acordo com o Teste de Kruskal-Wallis.
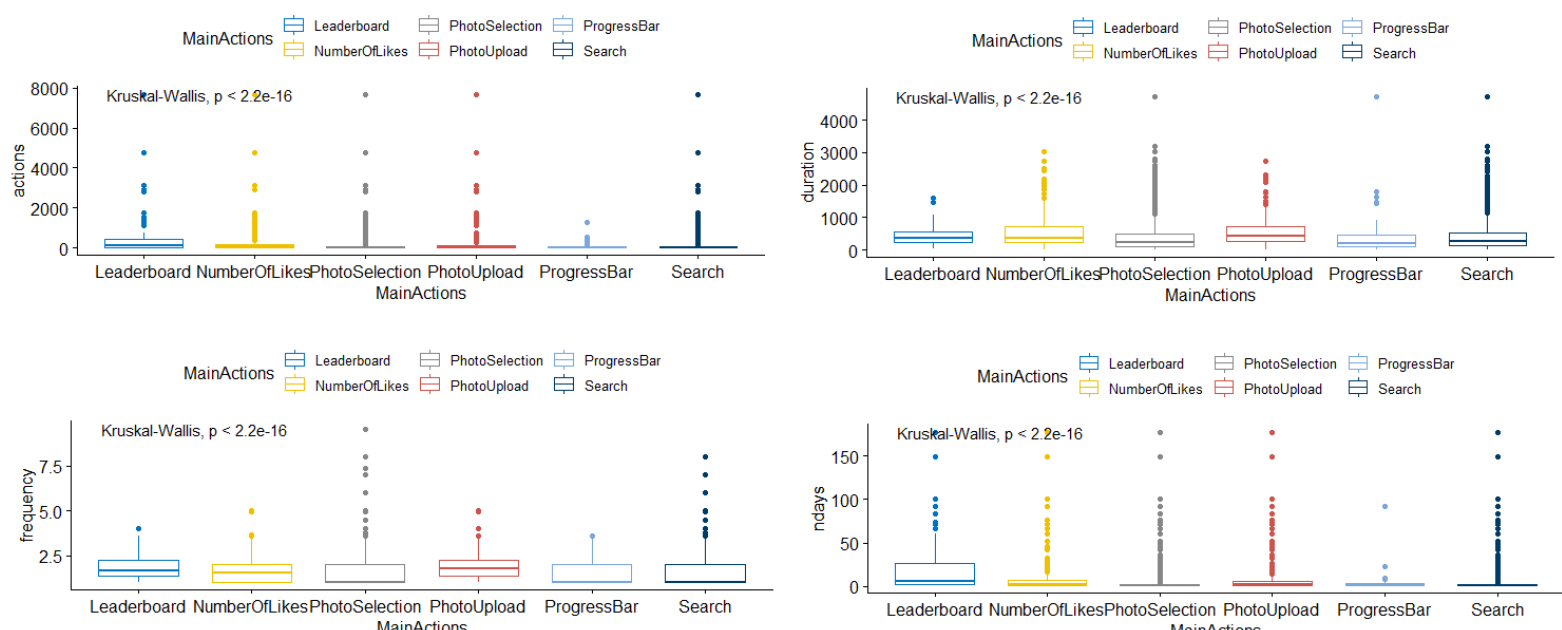

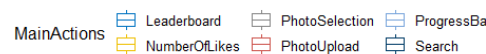

MainActions 追 Leaderboard 审 PhotoSelection ProgressBar
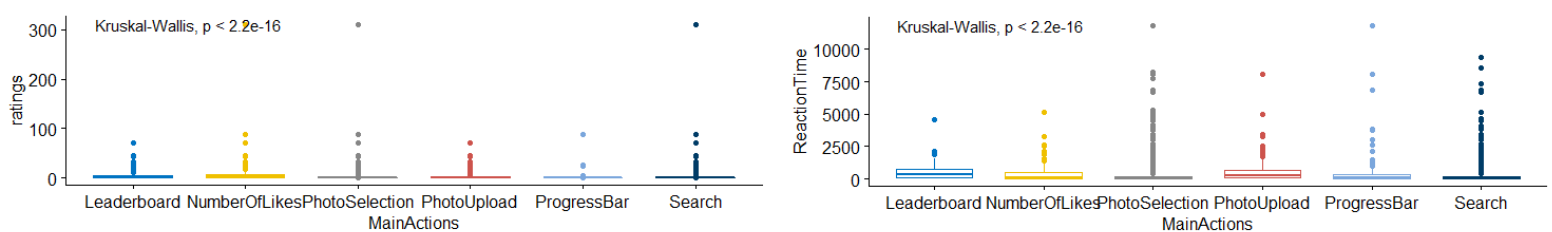

MainActions Leaderboard PhotoSelection ProgressBa

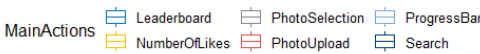
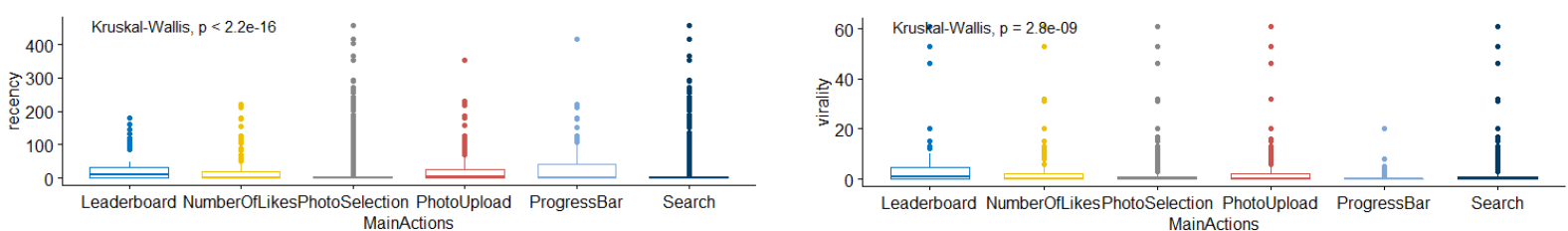

Figura 7.12: Comparação das principais ações acessadas a partir do Teste de Kruskal-Wallis para cada métrica objetiva de engajamento. 
Tabela 7.19: Descrição dos dados apresentados na Figura 7.12.

\begin{tabular}{|c|c|c|c|c|c|c|c|}
\hline Métrica & $\begin{array}{l}\text { Ação } \\
\text { Principal }\end{array}$ & Min. & $1^{\circ} \mathrm{Qu}$. & Mediana & Média & $3^{\circ} \mathrm{Qu}$. & Máx. \\
\hline \multirow[t]{6}{*}{ Freq. } & Sel. Imagem & 1 & 1 & 1 & 1.48 & 2 & 9.56 \\
\hline & Busca & 1 & 1 & 1 & 1.49 & 2 & 8 \\
\hline & Like & 1 & 1 & 1.51 & 1.73 & 2 & 5 \\
\hline & Upload & 1 & 1.33 & 1.77 & 1.87 & 2.23 & 5 \\
\hline & Q.Liderança & 1 & 1.33 & 1.67 & 1.82 & 2.25 & 4 \\
\hline & B.Progresso & 1 & 1 & 1 & 1.48 & 2 & 3.62 \\
\hline \multirow[t]{6}{*}{ Rec. } & Sel. Imagem & 0 & 0 & 0 & 16.17 & 2.5 & 458.5 \\
\hline & Busca & 0 & 0 & 0 & 16.99 & 3.62 & 458.5 \\
\hline & Like & 0 & 0 & 1.25 & 22.09 & 19.97 & 220.5 \\
\hline & Upload & 0 & 0 & 4.59 & 28.31 & 26.94 & 352 \\
\hline & Q.Liderança & 0 & 1 & 10.94 & 27.46 & 30.33 & 179.7 \\
\hline & B.Progresso & 0 & 0 & 0 & 34.26 & 42.46 & 415 \\
\hline \multirow[t]{6}{*}{ Duração } & Sel. Imagem & 1 & 105.5 & 237 & 383.4 & 502.7 & 4725 \\
\hline & Busca & 1 & 121 & 259.4 & 406.9 & 523 & 4725 \\
\hline & Like & 8 & 217.1 & 374.5 & 593.6 & 734.8 & 3016 \\
\hline & Upload & 12.8 & 261.7 & 414.8 & 568.7 & 703 & 2731 \\
\hline & Q.Liderança & 45.17 & 229.7 & 358.2 & 449.3 & 572.1 & 1598 \\
\hline & B.Progresso & 1 & 117.2 & 214.9 & 376.9 & 447.2 & 4725 \\
\hline \multirow[t]{6}{*}{ Vir. } & Sel. Imagem & 0 & 0 & 0 & 1.14 & 1 & 61 \\
\hline & Busca & 0 & 0 & 0 & 1.23 & 1 & 61 \\
\hline & Like & 0 & 0 & 0 & 3.17 & 2 & 61 \\
\hline & Upload & 0 & 0 & 0 & 2.52 & 2 & 61 \\
\hline & Q.Liderança & 0 & 0 & 1 & 5.12 & 4.5 & 61 \\
\hline & B.Progresso & 0 & 0 & 0 & 0.68 & 0 & 20 \\
\hline \multirow[t]{6}{*}{ Clas. } & Sel. Imagem & 0 & 0 & 0 & 0.99 & 0 & 311 \\
\hline & Busca & 0 & 0 & 0 & 1.15 & 0 & 311 \\
\hline & Like & 1 & 1 & 2 & 8.44 & 7 & 311 \\
\hline & Upload & 0 & 0 & 0 & 3.05 & 2 & 70 \\
\hline & Q.Liderança & 0 & 0 & 0 & 5.34 & 3.75 & 70 \\
\hline & B.Progresso & 0 & 0 & 0 & 1.57 & 0 & 87 \\
\hline \multirow[t]{6}{*}{ Ações } & Sel. Imagem & 1 & 4 & 10 & 66.88 & 39 & 7682 \\
\hline & Busca & 1 & 5 & 13 & 77.94 & 47.75 & 7682 \\
\hline & Like & 3 & 19 & 56 & 295.6 & 160.5 & 7682 \\
\hline & Upload & 3 & 24 & 56 & 237.2 & 115 & 7682 \\
\hline & Q.Liderança & 5 & 27.25 & 97 & 524.60 & 412.5 & 7682 \\
\hline & B.Progresso & 2 & 6 & 14 & 60.23 & 48.50 & 1251 \\
\hline \multirow[t]{6}{*}{ Ndias } & Sel. Imagem & 1 & 1 & 1 & 3.15 & 2 & 177 \\
\hline & Busca & 1 & 1 & 1 & 3.43 & 2 & 177 \\
\hline & Like & 1 & 1 & 2 & 11.35 & 7 & 177 \\
\hline & Upload & 1 & 1 & 2 & 9.87 & 6 & 177 \\
\hline & Q.Liderança & 1 & 2 & 6 & 20.95 & 26.5 & 177 \\
\hline & B.Progresso & 1 & 1 & 1 & 3.23 & 3 & 92 \\
\hline \multirow[t]{6}{*}{ TReação } & Sel. Imagem & 1.5 & 18.71 & 48.79 & 300.2 & 189.1 & 11860 \\
\hline & Busca & 1.91 & 18.63 & 47.69 & 273.2 & 167.7 & 9349 \\
\hline & Like & 7.11 & 35.55 & 108.1 & 407.7 & 528.2 & 5159 \\
\hline & Upload & 19.06 & 67.13 & 224.4 & 520.9 & 670.1 & 8095 \\
\hline & Q.Liderança & 11.1 & 78.54 & 336.5 & 523.6 & 718.7 & 4558 \\
\hline & B.Progresso & 9 & 23.05 & 57.2 & 627.8 & 374.9 & 11860 \\
\hline
\end{tabular}


É possível notar que as quantidades máximas apresentadas em todas as métricas indicam que um mesmo usuário foi responsável pelos maiores valores para diversas ações. Portanto, vamos considerar apenas as médias e valores interquartis por métrica.

Para a métrica ações, a maior quantidade de ações representada nos valores mínimo, $1^{\circ}$ quartil, mediana, média e $3^{\circ}$ quartil foram alcançadas por usuários que acessaram o quadro de liderança; e em segundo lugar por usuários que acessaram Like, considerando a média. A menor quantidade de ações foi relacionada com usuários que acessaram a ação Seleção de imagem, considerando $1^{\circ}$ quartil, mediana e $3^{\circ}$ quartil. Contudo, considerando a média, a menor quantidade de ações foi relacionada com o acesso à barra de progresso. Contudo, para as métricas que representam somas (viralidade, classificação, ação e ndias), a ação Acesso à barra de progresso está em desvantagem pois foi inserida no sistema a partir de 16 de novembro, enquanto que as demais estão disponíveis desde 2015. Mesmo assim, é possível notar que a diferença na quantidade média de ações para acesso à barra de progresso (60.23) e seleção de imagem (66.88) é muito pequena, mesmo com a última estando presente no sistema por um período mais longo de tempo.

Para a métrica duração, a maior duração para a média e $3^{\circ}$ quartil foi relacionada com o acesso à ação Like, contudo o acesso ao quadro de liderança apresentou o maior valor mínimo de duração (45.17 segundos). Os menores valores para mediana, média e $3^{\circ}$ quartil foram relacionados ao acesso à barra de progresso. Para a métrica frequência, houve pouca diferença entre as ações, pois entre valor mínimo e $3^{\circ}$ quartil existiu uma variação entre 1 e 2.25 sessões por dia. As ações que mais se destacaram foram Upload e Acesso ao quadro de liderança.

Para a métrica ndias, a ação mais sustentável, em termos de quantidade de dias de acesso, foi a ação Acesso ao quadro de liderança, com os maiores para $1^{\circ}$ quartil, mediana, média e $3^{\circ}$ quartil. Embora o acesso à barra de progresso tenha sido a última dentre as ações consideradas nesta análise a entrar no sistema, ela ainda tem valores superiores aos encontrados para a ação Seleção de imagem para média e $3^{\circ}$ quartil.

Para a métrica classificação, a ação Like foi a que mais se destacou com uma média de 8.44 comentários ou likes realizados; em seguida, a ação Acesso ao quadro de liderança ficou em segundo lugar com uma média de 5.34 comentários ou likes. A menor média foi relacionada com a ação Seleção de imagem. Para a métrica tempo de reação, os maiores valores para $1^{\circ}$ quartil, mediana e $3^{\circ}$ quartil foram encontrados para a ação Acesso ao quadro de liderança, enquanto a maior média de tempo de reação foi relacionada à ação Visualizar a Barra de progresso da imagem; e o maior valor mínimo foi relacionado à ação Upload. Os menores valores de $1^{\circ}$ quartil, mediana, média e $3^{\circ}$ quartil para tempo de reação foram associados à ação de Busca. Esse comportamento está de acordo com as pesquisas de [RMA $\left.{ }^{+} 97, \mathrm{SDH}^{+} 04\right]$, nas quais o tempo de reação mais curto foi relacionado à distração mais significativa e insensibilidade à tarefa, onde lapsos de atenção são atribuídos a situações de tédio e preocupação; e às pesquisas de [EK17, OL13, FA09], onde usuários frustrados exibiam mais comportamentos de busca, ou menor tempo de reação entre uma busca e outra.

Para a métrica recenticidade, a única ação que teve como $1^{\circ}$ quartil um dia entre o último e o penúltimo acesso foi a ação Acesso ao quadro de liderança, que também apresentou o maior valor para mediana; e os maiores valores para média e $3^{\circ}$ quartil foram encontrados para a ação Visualizar a Barra de progresso da imagem. Os menores valores para média e $3^{\circ}$ quartil foram relacionados à ação Seleção de imagem. Valores menores de recenticidade são associados a um retorno mais breve ao sistema, o que é positivo. Contudo, no caso da ação Seleção de imagem, sabemos que a menor recenticidade diz respeito a poucos acessos no sistema, dado que ela apresenta os menores valores para a métrica ndias.

Para a métrica viralidade, apenas a ação Acesso ao quadro de liderança tem como mediana 1 acesso via posts de Facebook, Google + ou notificação, todas as demais ações apresentam valores mínimo, $1^{\circ}$ quartil e mediana iguais a zero. Os maiores valores para média e $3^{\circ}$ quartil foram associados à ação Acesso ao quadro de liderança; e os menores valores à ação Visualizar a Barra de progresso da imagem, que nesse caso está em desvantagem por ser disponibilizada no sistema anos após às demais ações.

Portanto, nessa última análise entendemos que as ações individuais influenciam de formas dife- 
rentes cada métrica, sendo que algumas ações possuem um peso maior sobre métricas específicas. Contudo, dentre as seis ações mais acessadas do sistema, uma ação teve destaque quando comparada com às demais: a ação Acesso ao quadro de liderança. Em contrapartida, a que teve menores resultados foi a ação Seleção de imagem. Para verificar se existiram diferenças estatisticamente significativas para as comparações dos valores obtidos para cada métrica por ação acessada, realizamos o Teste de Kruskal Wallis. A Tabela 7.20 apresenta os resultados.

Tabela 7.20: Resultados da comparação das métricas objetivas entre as seis principais ações a partir do Teste de Kruskal-Wallis.

\begin{tabular}{|l|l|}
\hline Métrica & Comparação das 6 Ações Mais Acessadas (p-value) \\
Obj. & $\epsilon \hat{2}$ \\
\hline Freq. & $148.15(<2.2 \mathrm{e}-16)$ \\
& 0.04 \\
\hline Rec. & $\begin{array}{l}192.14(<2.2 \mathrm{e}-16) \\
0.06\end{array}$ \\
\hline Duração & $\begin{array}{l}118.92(<2.2 \mathrm{e}-16) \\
0.03\end{array}$ \\
\hline Vir. & $\begin{array}{l}48.542(2.753 \mathrm{e}-09) \\
0.01\end{array}$ \\
\hline Clas. & $\begin{array}{l}738.76(<2.2 \mathrm{e}-16) \\
\mathbf{0 . 2 4}\end{array}$ \\
\hline Ações & $327.98(<2.2 \mathrm{e}-16)$ \\
& 0.10 \\
\hline Ndias & $268.89(<2.2 \mathrm{e}-16)$ \\
& 0.08 \\
\hline TReação & $189.66(<2.2 \mathrm{e}-16)$ \\
& 0.06 \\
\hline
\end{tabular}

Existiram tamanhos de efeito estatisticamente significativos de pequenos a grandes para todas as comparações. As métricas frequência, duração e viralidade apresentaram tamanhos de efeito pequenos; as métricas recenticidade, ações, ndias e tempo de reação apresentaram tamanhos de efeito médios; e a métrica classificação apresentou tamanho de efeito grande para a comparação entre as ações. Sabemos que a ação Visualizar o Quadro de liderança foi a que mais se destacou para todas as métricas cujos efeitos foram médios e a ação Like foi a que se destacou para classificação.

\subsection{Resposta da QPI}

A análise de 25 ações distintas, retornou 22 ações que foram utilizadas por usuários do sistema. Para o caso específico de elementos de jogos, as ações Visualizar o Quadro de liderança e Visualizar a barra de progresso da imagem, associadas aos elementos de jogos Quadro de liderança e Barra de progresso, respectivamente, estavam entre as ações mais utilizadas. No entanto, um elemento de jogo não teve acessos suficientes para realizar análises estatísticas (distintivos) e dois elementos de jogos não foram acessados (Pontos e Jogo duradouro). Sendo assim, não causaram impacto sobre o comportamento dos usuários durante o lançamento (pontualmente) e também não geraram engajamento sustentando ao longo do tempo. Contudo, o desafio de projetar uma mecânica que não fosse muito fácil para garantir a qualidade do acervo e nem muito difícil que desmotivasse os usuários a realizá-la foi o motivo principal do baixo impacto desses elementos. A primeira versão dos distintivos implementada só retornava um distintivo caso o usuário recebesse 5 likes para seus comentários. Contudo, a comunidade ainda estava em uma fase inicial e receber 5 likes por um comentário não foi algo fácil de ser alcançado.

A maioria dos usuários apenas acessou a revisão de dados, mas não realizou sugestões para inserção de novos dados ou correção dos existentes, o que possibilitaria que tivessem contato com 
os elementos de projeto de jogos Jogo duradouro e Pontos. A interação com a revisão de dados dependia da vontade de compartilhar conhecimentos sobre a arquitetura representada, caso o usuário os tivesse. Portanto, o desafio ainda era difícil demais para ser alcançado em um curto período de tempo.

O elemento Barra de progresso causou um impacto positivo sobre o engajamento, uma vez que seus usuários realizaram o maior número de ações durante o período do experimento controlado online executado durante a pesquisa-ação (vide Ciclo 7 da pesquisa-ação), cujos detalhes são descritos no artigo 8 da Seção 1.5. Neste experimento também notou-se que os usuários que definiram seu engajamento como alto na Escala de Engajamento de Usuários (do acrônimo em inglês UES) foram os mesmos que realizam mais ações no sistema. Além disso, foram encontradas correlações positivas moderadas entre a pontuação definida pelos usuários no questionário para usabilidade percebida e o acesso ao elemento de jogo barra de progresso. Portanto, pontualmente a barra de progresso afetou tanto a percepção de usabilidade quanto a exploração do sistema.

A comparação entre as ações mais acessadas, apresentada na seção anterior, mostrou que a ação Visualizar a barra de progresso da imagem retornou resultados positivos quando comparada com ações que estão a mais tempo no sistema, como a ação Seleção de imagem. Contudo, nota-se que esses resultados pontuais não foram suficientes para sustentar o engajamento dos usuários, uma vez que na média eles acessaram o sistema apenas por três dias.

A ação que mais engajou usuários dentre as seis mais acessadas foi a ação Visualizar o quadro de liderança, com diferenças estatisticamente significativas para as comparações entre todas as ações. Além disso, esta foi a ação relacionada com o maior valor alcançado para as métricas viralidade, ações e ndias, e esteve dentre as ações com maior valor para as demais métricas.

Ao cruzarmos os dados entre os períodos de maior quantidade de uploads e avaliações de imagens, que são as atividades relacionadas ao crescimento do usuário no quadro de liderança, percebe-se que são os mesmos períodos nos quais ocorrem picos de atividades para a ação Visualizar o Quadro de liderança, o que demonstra que as atividades aconteceram sequencialmente. Entende-se, portanto, que o quadro de liderança foi o único elemento que manteve um engajamento sustentado, tendo portanto cumprido seu papel de engajar usuários não apenas pontualmente, mas por um período de tempo sustentado, uma vez que na média seus usuários acessaram o sistema por vinte dias, com $75 \%$ dos usuários tendo acessado o sistema por até 26 dias. A ação Seleção de imagem que está disponível desde o início do registro de logs em 14 de junho de 2015, retornou três dias de acesso em média para seus usuários, com $75 \%$ deles tendo acessado por até dois dias.

As análises correlacionais possibilitaram também compreender que o peso dos elementos funcionais foi sempre superior para correlações do que para outros elementos porque $71.15 \%$ dos usuários que acessaram o sistema, com ações e duração diferentes de zero, acessaram apenas elementos funcionais. Ao filtrar as análises para comparar usuários apenas dentro de cada conjunto, foi possível perceber correlações estatisticamente significativas entre as métricas objetivas de engajamento e elementos de jogos associados a outros elementos, especialmente nos conjuntos Func $+\mathrm{Jog}+\mathrm{Col}$ e Func + Jog +3 C. Também foi possível perceber que embora a maior parte dos usuários tenha acessado apenas elementos funcionais, estes foram os usuários menos engajados com o sistema.

A comparação dos níveis alto, médio e baixo alcançados para cada métrica objetiva em cada conjunto, também evidenciou efeitos estatisticamente significativos para a quantidade de elementos acessados e o nível alcançado por métrica, que indicou que mais elementos acessados foram associados a níveis mais altos alcançados para cada métrica. O mesmo ocorreu quando comparando os valores de cada métrica entre os conjuntos. Em particular, essa análise evidenciou que: 1) os elementos de jogos relacionados a elementos funcionais e de colaboração apresentaram resultados positivos de engajamento, especialmente para acessos relacionados a todos os 3Cs de colaboração; e 2) o acesso a elementos funcionais e de jogo embora tenha sido associado a melhores resultados de engajamento do que o acesso a apenas elementos funcionais, ainda apresentou resultado inferior do que o obtido para o acesso a elementos funcionais e de colaboração. Estes resultados indicam que gamificação resultou em maior engajamento quando associada a elementos de colaboração.

Portanto, respondendo à QPI - "O uso de elementos de jogos aumenta o engajamento 
em uma comunidade online de colaboração aberta no domínio de GLAMs?" - podemos responder: Sim, para acesso a elementos de jogos associados a elementos de colaboração e funcionais, especialmente quando acessados elementos relacionados aos 3Cs de colaboração, bem como para o acesso apenas a um elemento de jogo quando este tiver o nível de dificuldade e feedback adequados ao conhecimento e necessidades dos usuários. No caso do Arquigrafia, este elemento foi o Quadro de liderança, que trouxe efeitos estatisticamente significativos para o engajamento dos usuários que o acessaram.

Conclui-se que o design e a mecânica envolvida em cada elemento de jogo são fundamentais para alcançar resultados positivos ou negativos com respeito ao engajamento de usuários. Mas, é possível melhorar o engajamento com o uso de elementos de jogos bem projetados e adequados aos objetivos de cada sistema. Em particular, a mecânica é mais eficaz quando associada aos objetivos de colaboração do sistema, isto é, associando elementos de jogos a elementos de colaboração. 


\section{Capítulo 8}

\section{Proposta de integração da gamificação com o monitoramento e avaliação de engajamento}

Em seu artigo sobre a prática da teoria [WT13], Wenger descreve que teoria social contribui para o conhecimento produzindo perspectivas, que podem ser usadas para dar sentido ao mundo, o que implica uma relação complexa entre teoria e prática. Como diversas perspectivas podem coexistir, elas montam um quebra-cabeças de peças interativas, em vez de uma teoria substituir outra. Portanto, conforme Wenger, cada teoria precisa apresentar sua localização no quebra-cabeças, possibilitando uma abordagem plug-and-play para a combinação de teorias relacionadas.

Arcabouço teórico é uma estrutura que orienta a pesquisa, baseando-se em uma teoria formal selecionada (ou teorias) que sustenta o pensamento do pesquisador com relação a como ele entende e planeja pesquisar um tópico, bem como os conceitos e definições dessa teoria que são relevantes para o tópico [GO14].

Por meio da abordagem plug-and-play [WT13], o arcabouço teórico desta tese associa as teorias de motivação humana [DR12, DKR99, SDT16]; a teoria para desenvolvimento de comunidades de prática [WMS02b, WTdL11], especialmente, as dimensões de uma prática compartilhada; e o Modelo 3C de colaboração [FRGL05].

Comunidades de prática, ainda conforme Wenger, apresentam fases de desenvolvimento com estágios definidos. Cada estágio possui seus desafios, e a partir desse entendimento, é possível projetar gamificação em uma comunidade baseada em motivação intrínseca. A Seção 8.1 aborda as fases e estágios, bem como o plano de trabalho típico de cada estágio de vida de uma comunidade, de modo a relacioná-los na Seção 8.2 com a proposta de abordagem, respondendo a QPII. Por fim, um enfoque da abordagem sobre o domínio de GLAMs é apresentado na Seção 8.2.2.

\subsection{Construção de comunidades de prática}

No livro "Cultivando comunidades de práticas", Wenger et al. [WMS02b] apresentam cinco estágios de desenvolvimento de comunidades de prática inseridos em três fases de vida, que representam o ciclo de vida de uma comunidade de prática:

1. formação: nesta fase redes iniciais são descobertas, terreno comum é formado e relacões são formadas. A chamada inicial (informal) é geralmente centrada em torno da geração de valor. A fase de formação é composta pelos estágios potencial e adesão:

- potencial (potential): refere-se ao surgimento de networking dispersos, com potencial para conexões importantes; e

- adesão (coalescing): os indivíduos se conectam e aderem a uma comunidade. 
2. integração: nesta fase existe um enfoque sobre tópicos particulares e a admissão de novos membros. São desenvolvidos métodos e ferramentas únicos para a comunidade. Novas ideias são continuamente bem-vindas enquanto a comunidade evolui. A fase de integração é composta pelos estágios maturidade e administração:

- maturidade (maturing): refere-se aos ciclos de baixa e alta atividades; e

- administração (stewardship): neste estágio são realizadas atividades para manter os conhecimentos e práticas da comunidade.

3. transformação: a fase de transformação indica o encerramento das atividades ou a formação de clubes sociais ou outras comunidades derivadas. Isso pode significar que a comunidade tornouse redundante, ou esta fase marca o início de uma nova comunidade. Outras possibilidades incluem a fusão com outras comunidades ou se tornar institucionalizado como uma unidade formal. A fase de transformação contém o estágio de transformação e trata-se de um retorno ao estágio de adesão ou o encerramento da comunidade.

A Tabela 8.1 apresenta um resumo com o problema principal, o problema de domínio-chave, o problema de comunidade-chave, o problema de prática-chave, a solução e os papeis-chave envolvidos em cada estágio de desenvolvimento de uma comunidade de prática. A tabela foi definida com base nas páginas 70 a 112 do livro de Wenger et al. [WMS02b]. O estágio de transformação não foi inserido na tabela, pois é um estágio que não possui um plano de trabalho próprio, uma vez que seu principal objetivo é definir se a comunidade retorna a um estágio anterior de adesão ou se encerra as atividades da comunidade. As informações na tabela que foram marcadas com itálico referem-se a um entendimento da pesquisadora a partir da leitura que não foi definido explicitamente no livro. 
Tabela 8.1: Resumo de cada estágio de desenvolvimento de uma comunidade de prática a partir de Wenger et al. [WMS02b].

\begin{tabular}{|c|c|c|c|c|}
\hline & Potencial & Adesão & Maturidade & Administração \\
\hline $\begin{array}{l}\text { Problema } \\
\text { Principal }\end{array}$ & $\begin{array}{l}\text { Encontrar terreno comum } \\
\text { suficiente entre membros } \\
\text { para que eles se sintam } \\
\text { conectados e vejam o valor } \\
\text { de compartilhar insights, } \\
\text { histórias e técnicas. }\end{array}$ & $\begin{array}{l}\text { Gerar energia } \\
\text { suficiente para a } \\
\text { comunidade se unir: } \\
\text { membros precisam } \\
\text { encontrar valor em } \\
\text { participar. }\end{array}$ & $\begin{array}{l}\text { Tornar claro o enfoque, } \\
\text { papel e fronteiras da } \\
\text { comunidade. }\end{array}$ & $\begin{array}{l}\text { Sustentar seu "momentum" } \\
\text { ou força de movimento } \\
\text { (embalo) através das } \\
\text { mudanças naturais em suas } \\
\text { práticas, membros, } \\
\text { tecnologia e relacionamento } \\
\text { com a organização. }\end{array}$ \\
\hline $\begin{array}{l}\text { O que } \\
\text { energiza a } \\
\text { comuni- } \\
\text { dade? }\end{array}$ & $\begin{array}{l}\text { Descobrir que outras } \\
\text { pessoas enfrentam } \\
\text { problemas similares, } \\
\text { compartilham uma paixão } \\
\text { para os mesmos tópicos, }\end{array}$ & $\begin{array}{l}\text { Construir relações, } \\
\text { confiança e uma } \\
\text { consciência de seus } \\
\text { interesses e } \\
\text { necessidades }\end{array}$ & $\begin{array}{l}\text { Perceber um senso de } \\
\text { identidade e maior } \\
\text { confiança no valor do } \\
\text { domínio da comunidade. }\end{array}$ & $\begin{array}{l}\text { Perceber um forte senso de } \\
\text { propriedade do dominio } \\
\text { (corpo de conhecimento) } \\
\text { com a receptividade a novas } \\
\text { pessoas e ideias. }\end{array}$ \\
\hline
\end{tabular}

possuem dados, ferramentas

e abordagens que podem

contribuir e existem

insights valiosos que podem

aprender uns com os outros.

\begin{tabular}{ll}
\hline Problema & Definir o escopo do domínio \\
de domínio- & com os interesses reais dos \\
chave & membros alinhados com \\
& problemas importantes da \\
& organização como um todo: \\
& definir o foco da \\
& comunidade.
\end{tabular}

\begin{tabular}{ll}
\hline Problema & Encontrar pessoas que já \\
de & formam uma rede ou grupo \\
comunidade- & sobre o assunto e ajudá-las \\
chave & a imaginar como a rede \\
& aumentada e o \\
& compartilhamento de \\
& conhecimento poderiam ser \\
& valiosos: identificar e \\
& construir relações entre \\
& membros.
\end{tabular}

Estabelecer o valor

de compartilhar

conhecimento sobre

o domínio.
Definir seu papel na organização e sua relação com outros domínios.
Manter a relevância do domínio e encontrar uma voz na organização.

\begin{tabular}{ll}
\hline Problema & Identificar necessidades de \\
de prática- & conhecimentos comuns: \\
chave & identificar tópicos e projetos \\
& que seriam interessantes \\
& para os membros.
\end{tabular}

Solução
Desenvolver relações

e confiança suficiente para discutir problemas de prática genuinamente recorrentes.
Gerenciar a fronteira da comunidade que não é mais uma rede de profissionais amigos: definir novas e mais amplas fronteiras, assegurando que a comunidade não se distraia de sua proposta principal (núcleo).
Manter o tom e enfoque intelectual da comunidade animado e engajado.

Descobrir
especificamente qual
conhecimento deve
ser compartilhado e
como.

\section{Descobrir}

conhecimento deve como.
Organizar e administrar o

conhecimento da

comunidade: identificar

lacunas de conhecimento e ser sistemático na definição da prática-núcleo.
Incube e entregue valor imediato: equilibre a necessidade de desenvolver relações e confiança com a necessidade de demonstrar o valor da comunidade.

\begin{tabular}{lll}
\hline $\begin{array}{l}\text { Papeis- } \\
\text { chave }\end{array}$ & Coordenadores da & Coordenadores da \\
& comunidade, líderes da & comunidade, pessoal \\
& organização e & de suporte e \\
membros-núcleo da & membros-núcleo da \\
& comunidade. & comunidade.
\end{tabular}

Concentre-se e expanda: equilibre foco e crescimento da comunidade, preservando relações, entusiasmo e confiança, mantendo interações de ajuda, enquanto sistematiza suas práticas.

Coordenadores da comunidade, pessoal de suporte, membros-núcleo da comunidade e bibliotecário da comunidade.
Manter a comunidade na vanguarda com conhecimento de ponta.

Propriedade e abertura: equilibre senso de propriedade do domínio com o influxo de novas ideias, abordagens e relacionamentos, o que envolve ativamente solicitá-los e novas lideranças.

Coordenadores da
comunidade, pessoal de suporte, membros-núcleo da comunidade e bibliotecário da comunidade. 
Em todos os estágios, os coordenadores da comunidade são fundamentais para a "sáude" da comunidade, usando um termo que é mencionado no livro, sendo portanto o papel que mais se envolve nas soluções dos problemas de cada estágio. O coordenador precisa ser apaixonado pelo tópico da comunidade, ter domínio da área e visualizar a comunidade como meio importante de conexões. Membros-núcleo são os papeis que mais participam da discussão das práticas e da construção do corpo de conhecimento ("Body of Knowledge - BoK"). O pessoal de suporte colabora com o coordenador e membros-núcleo na disseminação das práticas, por meio de mentorias a novatos, e o bibliotecário desenvolve e fornece acesso a conhecimento, ferramentas e diretrizes do domínio da comunidade. A partir desse entendimento, Wenger et al. definiram um plano de trabalho para cada estágio de uma comunidade.

O estágio 1 é composto do seguinte plano de trabalho típico relativo ao planejamento da comunidade: i) Definir intenção principal da comunidade; ii) Definir o domínio e identificar problemas de engajamento; iii) Construir um caso para ação; iv) Identificar potenciais coordenadores e líderes de pensamento; v) Entrevistar membros potenciais; vi) Conectar membros da comunidade; e vii) Criar um projeto preliminar para a comunidade. Portanto, o estágio 1 busca atingir um equilíbrio entre descobrir as redes naturais e imaginar o valor de enriquecer as relações. Neste estágio não existe ainda um ambiente online para a comunidade.

O estágio 2 é composto do seguinte plano de trabalho típico relativo à nutrição da comunidade: i) Construir um caso para associação; ii) Lançar a comunidade; iii) Iniciar eventos e espaços da comunidade; iv) Legitimar coordenadores da comunidade; v) Construir conexões entre membrosnúcleo; vi) Encontrar ideias, insights e práticas que valem a pena compartilhar; vii) Documentar judiciosamente; viii) Identificar oportunidades para fornecer valor; e ix) Engajar gerentes. O estágio 2 , portanto, busca nutrir relações fortes, duradouras, enquanto ao mesmo tempo rapidamente demonstra o valor da comunidade. Neste estágio a comunidade online é lançada. No fim do estágio de adesão, a comunidade demonstrou que é viável. Está instalada, funcionando e tem uma boa chance de sobrevivência.

O estágio 3 é composto do seguinte plano de trabalho típico relativo ao amadurecimento da comunidade: i) Identificar lacunas em conhecimento e desenvolver uma agenda de aprendizagem; ii) Definir o papel da comunidade na organização; iii) Redefinir fronteiras da comunidade; iv) Criar rotinas para requisitos e processo de entrada de membros; v) Medir o valor da comunidade; vi) Manter um enfoque de ponta (estado da arte); e vii) Construir e organizar um repositório de conhecimento.

O estágio 4 é composto do seguinte plano de trabalho típico relativo à sustentabilidade do momentum (força de movimento): i) Institucionalizar a voz da comunidade; ii) Rejuvenescer a comunidade; iii) Realizar um workshop de renovação; iv) Recrutar ativamente novas pessoas para membros-núcleo; v) Desenvolver nova liderança; vi) Fornecer mentoria a novos membros; e vii) Procurar relações e referências fora da organização (benchmarking).

O estágio 5 é um retorno ao estágio 2 (incubação) ou a compreensão de encerramento da comunidade. Para chegar a compreensão de qual caminho escolher, é preciso uma discussão com os membros. Se a decisão de encerrar a comunidade for tomada, Wenger et al. relatam a importância de fechar a comunidade com um senso de resolução, encontrando uma maneira de viver em memória ou na forma de um legado, de modo a honrar as constribuições dos membros e o conhecimento construído.

O desafio de comunidades mais maduras, a partir do estágio 3, é afiar seu enfoque enquanto crescem, equilibrando um senso de propriedade do domínio com a abertura a novas ideias. Comunidades alternam períodos de estabilidade relativa com períodos de maiores descobertas. Se existe confiança e respeito, e um senso comum forte de direção, as tensões de cada estágio podem ser expressões temporárias da vivacidade de comunidades. 


\subsection{Resposta da QPII: Proposta de abordagem}

A partir do plano de trabalho típico de cada estágio de uma comunidade de prática, a Tabela 8.2 apresenta a classificação de cada item do plano de trabalho como um de dois passos para implantar gamificação dentre seis propostos por Werbach e Hunter [WH12]: Definir objetivos de negócio ou Delinear (delimitar) comportamentos-alvo. Estes, por sua vez, foram classificados como Especificar contexto de uso e Especificar requisitos, respectivamente, que correspondem a duas fases de Design Centrado em Usuário (DCU). As atividades Criar soluções de design e Avaliar designs permanecem como foram descritas na Tabela 5.10.

A proposta de abordagem relaciona conceitos-chave desta pesquisa: engajamento, gamificação e comunidades de colaboração aberta, este último podendo ser decomposto em comunidades de prática e modelo de colaboração. A classificação de acordo com as fases do DCU tem o objetivo de fornecer uma perspectiva da prática para os conceitos, ideias e teorias; em outras palavras, em que momento durante o desenvolvimento eles podem ser aplicados.

A Tabela 6.3 apresenta os princípios de construção de comunidades de prática classificados de acordo com o Modelo 3C e as dimensões da prática e da motivação humana como projeto de um comportamento-alvo. Mas, ainda não apresenta quais comportamentos-alvo podem ser gamificados no desenvolvimento de uma comunidade online de colaboração aberta.

Os itens de plano de trabalho de cada estágio de vida da comunidade, foram então classificados como Definir objetivos de negócio e Delinear comportamentos-alvo. Definir objetivos de negócio, conforme Werbach e Hunter [WH12], significa definir metas de desempenho específicas para o sistema gamificado, como aumentar a retenção de clientes, construir a fidelidade à marca ou melhorar a produtividade dos funcionários. Delinear comportamentos-alvo significa definir comportamentos concretos e específicos, como por exemplo: "publique um comentário em um fórum de discussão".

Portanto, comportamento-alvo diz respeito a uma atividade que pode ser projetada por meio da gamificação em uma comunidade online. Enquanto que objetivo de negócio refere-se a uma atividade do coordenador da comunidade e de membros-núcleo, que não é inserida no ambiente online, podendo ser executada inteiramente offline.

Relacionando esses entendimentos à construção de comunidades online, temos que comportamentosalvo podem ser projetados de acordo com o estágio de vida da comunidade. Sendo assim, no estágio 1 que trata apena de planejamento da comunidade, os itens de plano de trabalho foram todos classificados como objetivos de negócio; entendendo a comunidade como parte do negócio.

Para o estágio 2, os seguintes comportamentos-alvo podem ser enfoque do projeto de gamificação: [i] Construir um caso para associação; [iv] Legitimar coordenadores da comunidade; [v] Construir conexões entre membros-núcleo e [vi] Encontrar ideias, insights e práticas que valem a pena compartilhar. Construir um caso para associação refere-se a construir um caso com duas vertentes: o benefício de contribuir e o valor do aprendizado a partir da experiência dos demais membros [WMS02b].

Conforme Wenger, contribuir nesse estágio adiciona visibilidade e reputação e também está relacionado à motivação intrínseca do indivíduo: satisfação em ajudar seus pares, fazer sua marca no campo, ou ainda a contribuição pode ajudar-lhe a dar enfoque e articular seus pensamentos. Legitimar coordenadores da comunidade diz respeito à reconhecer e recompensar publicamente desde cedo, e por isso no ambiente online, o trabalho de coordenação, que é fundamental para a sobrevivência da comunidade.

Construir conexões entre membros-núcleo pode ocorrer tanto offline quanto online, e refere-se ao recrutamento e envolvimento de membros periféricos até que seja formado um grupo-núcleo coeso. Esse processo de envolvimento de membros no grupo núcleo pode ser gamificado. Encontrar ideias, insights e práticas que valem a pena compartilhar é uma busca da coordenação e membros-núcleo que pode ser potencializada ao abrir para ideias, insights e práticas a partir da comunidade, de modo que membros núcleo possam refletir sobre práticas que podem fornecer valor ao domínio. Sendo assim, também é um comportamento que pode ser projetado com gamificação. 
Tabela 8.2: Proposta de abordagem reformulada para considerar o enfoque de cada estágio da comunidade: recorte sobre atividades Especificar contexto de uso e Especificar requisitos.

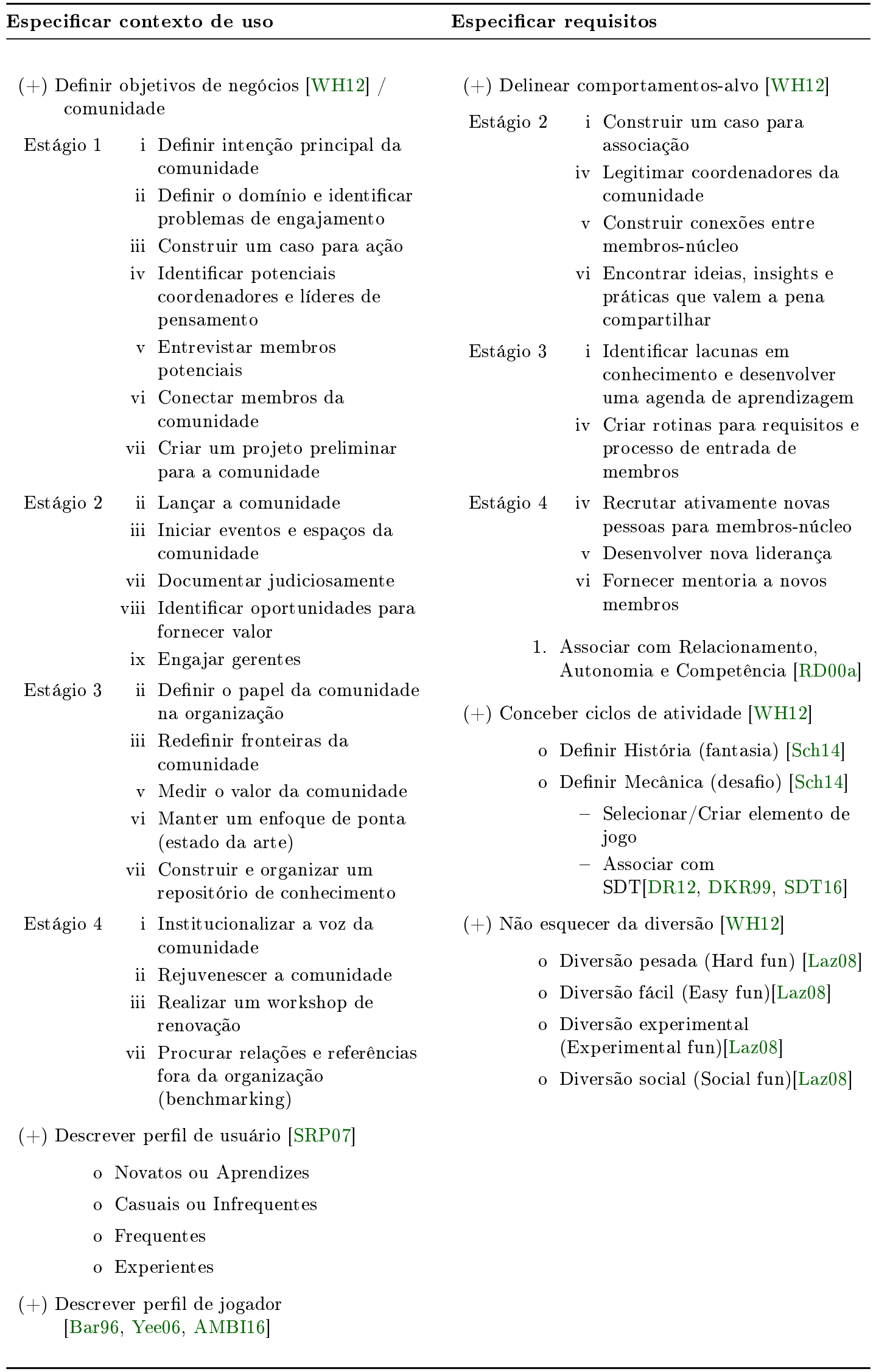

Para o estágio 3, temos os seguintes comportamentos-alvo: [i] Identificar lacunas em conheci- 
mento e desenvolver uma agenda de aprendizagem; e [iv] Criar rotinas para requisitos e processo de entrada de membros. Identificar lacunas em conhecimento é uma atividade realizada pela coordenação e membros-núcleo da comunidade, mas o desenvolvimento de uma agenda de aprendizagem pode ser explorado no ambiente online com enfoque sobre a evolução de aprendizagem do membro em relação ao domínio da prática e à construção de um corpo de conhecimento sobre o domínio. Para isso, é necessário administrar conhecimento produzido pela comunidade e formular guidelines para membros novatos evoluirem em um processo de aprendizagem.

Essa evolução de aprendizado, com reconhecimento após cumprimento de um marco, ou reforço sobre competência alcançada e a construção de autonomia na área de domínio, ao passar de nível e por meio de relacionamentos de ajuda entre membros criam um ambiente onde membro aprende e contribui e comunidade constrói conhecimento.

Criar rotinas para requisitos e processo de entrada de membros diz respeito a criar um ambiente de relacionamento entre membros seniôres e novatos. Portanto, o aprendizado de membros-núcleo passa para membros-seniôres que podem recepcionar a entrada de novos membros, apresentando a proposta da comunidade, história, escopo e normas de interação. O processo pode ser gamificado, na medida que, os membros atuais podem ser convidados a recepcionar novatos a partir de um nível de contribuição que comprove certas competências. Dessa forma, recompensa-se o aprendizado do membro atual e cria-se relações entre membros experientes e recém-chegados.

Para o estágio 4, temos os comportamentos-alvo: [iv] Recrutar ativamente novas pessoas para membros-núcleo; [v] Desenvolver nova liderança; e [vi] Fornecer mentoria a novos membros. Recrutar ativamente novas pessoas para membros-núcleo no estágio 4 decorre do fato que comunidades evoluem ao longo do tempo e enquanto o enfoque da comunidade muda, membros-núcleo que eram interessados no assunto que deu origem à comunidade, podem não ter mais interesse nos assuntos que movem a comunidade nesse estágio.

Portanto, o processo de envolvimento de novos membros ao grupo-núcleo é importante para a sustentabilidade da comunidade e pode ser gamificado em um processo de evolução de papeis. Este processo culmina no desenvolvimento de novas lideranças, que também pode ser feito pela rotação de membros-núcleo, por exemplo, por meio de períodos definidos na liderança ou eleições periódicas, de modo a revigorar e renovar a liderança. Essa atividade é proposta por Wenger no contexto de redução da energia da comunidade, sendo necessária a renovação de ideias.

Por fim, Fornecer mentoria a novos membros refere-se a ensinar práticas e disseminar conhecimento da comunidade para membros novatos ou júniores. O objetivo é tirar a carga de membrosnúcleo passando a mentoria para membros-seniôres, o que assim como ocorre com a recepção de membros, é uma atividade que pode ser projetada com gamificação.

Os comportamentos-alvo são distintos em cada estágio de vida da comunidade e entendemos que a gamificação - buscando motivar intrinsecamente usuários e ter uma comunidade sustentável pode ser executada sobre esses comportamentos-alvo. A escolha de qual comportamento gamificar em cada estágio depende do problema que é mais crítico para o contexto de cada comunidade e a área de domínio. No entanto, os itens do plano de trabalho de cada estágio de vida de uma comunidade podem ser executados sequencialmente, segundo Wenger et al..

Para finalizar, buscamos relacionar essa proposta de abordagem com os pressupostos e lições aprendidas com a pesquisa-ação. A Tabela 8.3 apresenta os pressupostos que guiaram o desenvolvimento de cada ciclo da pesquisa-ação. Os pressupostos são decorrentes do estudo da literatura em busca de soluções para os problemas diagnosticados em cada ciclo. Para integrar os pressupostos com os estágios de vida da comunidade, apresentamos uma classificação inicial do estágio de vida da comunidade a partir do qual cada pressuposto pode ser abordado na construção de uma comunidade online e também a sua classificação dentro das fases de Design Centrado em Usuário (DCU). 
Tabela 8.3: Pressupostos de cada ciclo a partir do estudo da literatura.

\begin{tabular}{|c|c|c|c|c|}
\hline Id & Ciclo & Pressuposto & Fase DCU & $\begin{array}{l}\text { Estágio da } \\
\text { comunidade }\end{array}$ \\
\hline 1 & Ciclo 0 & $\begin{array}{l}\text { Pré-requisito para avaliação de engajamento: inserção } \\
\text { de registros de ações de usuários }\end{array}$ & $\begin{array}{l}\text { Especificar } \\
\text { requisitos }\end{array}$ & Estágio 1 \\
\hline 2 & Ciclo 0 & $\begin{array}{l}\text { Priorização do desenvolvimento de funcionalidades } \\
\text { relacionadas às práticas da comunidade }\end{array}$ & $\begin{array}{l}\text { Especificar } \\
\text { requisitos }\end{array}$ & Estágio 2 \\
\hline 3 & Ciclo 0 & $\begin{array}{l}\text { Necessidade de melhorar a usabilidade para aumentar o } \\
\text { engajamento dos usuários }\end{array}$ & $\begin{array}{l}\text { Especificar } \\
\text { requisitos }\end{array}$ & Estágio 2 \\
\hline 4 & Ciclo 1 & $\begin{array}{l}\text { Para realizar análises dos efeitos de elementos de jogo } \\
\text { ou de colaboração é necessário inseri-los isoladamente } \\
\text { no sistema }\end{array}$ & $\begin{array}{l}\text { Criar soluções } \\
\text { de design }\end{array}$ & Estágio 2 \\
\hline 5 & Ciclo 2 & $\begin{array}{l}\text { Necessidade de funcionalidades típicas de sistemas } \\
\text { colaborativos serem disponibilizadas no sistema, de } \\
\text { modo que existam meios para se realizar a colaboração }\end{array}$ & $\begin{array}{l}\text { Especificar } \\
\text { requisitos }\end{array}$ & Estágio 2 \\
\hline 6 & Ciclo 2 & $\begin{array}{l}\text { Necessidade de apresentar o feedback das ações aos } \\
\text { usuários como meio de aumentar o engajamento }\end{array}$ & $\begin{array}{l}\text { Especificar } \\
\text { requisitos }\end{array}$ & Estágio 2 \\
\hline 7 & Ciclo 4 & Apresentação da filosofia da comunidade & $\begin{array}{l}\text { Especificar } \\
\text { requisitos }\end{array}$ & Estágio 3 \\
\hline 8 & Ciclo 4 & $\begin{array}{l}\text { Utilização de funções estatísticas apropriadas para cada } \\
\text { tipo de análise }\end{array}$ & $\begin{array}{l}\text { Avaliar } \\
\text { designs }\end{array}$ & Estágio 2 \\
\hline 9 & Ciclo 4 & $\begin{array}{l}\text { Elementos de notificação geram efeitos positivos sobre o } \\
\text { engajamento }\end{array}$ & $\begin{array}{l}\text { Especificar } \\
\text { requisitos }\end{array}$ & Estágio 2 \\
\hline 10 & Ciclo 5 & $\begin{array}{l}\text { Produção colaborativa (workshop) da mecânica dos } \\
\text { elementos de jogo }\end{array}$ & $\begin{array}{l}\text { Especificar } \\
\text { requisitos }\end{array}$ & Estágio 2 \\
\hline 11 & Ciclo 6 & $\begin{array}{l}\text { Análise integrada de métricas objetivas e subjetivas de } \\
\text { engajamento }\end{array}$ & $\begin{array}{l}\text { Avaliar } \\
\text { designs }\end{array}$ & Estágio 2 \\
\hline
\end{tabular}

A Tabela 8.4 apresenta os resultados de pesquisa obtidos durante os sete ciclos de pesquisa-ação, e assim como ocorre com os pressupostos, para cada lição aprendida apresenta-se o estágio de vida da comunidade a partir do qual cada lição pode ser abordada e a fase do DCU em que se pode aplicar a lição. 
Tabela 8.4: Resultados de pesquisa obtidos durante a pesquisa-ação.

\begin{tabular}{|c|c|c|c|c|}
\hline Id & Ciclo & Aprendizado & Fase DCU & $\begin{array}{l}\text { Estágio da } \\
\text { comunidade }\end{array}$ \\
\hline 1 & Ciclo 0 & $\begin{array}{l}\text { Necessidade de coletar/monitorar continuamente dados } \\
\text { qualitativos da interação }\end{array}$ & $\begin{array}{l}\text { Avaliar } \\
\text { designs }\end{array}$ & Estágio 2 \\
\hline 2 & Ciclo 0 & $\begin{array}{l}\text { Inserções/alterações de funcionalidades geram efeitos no } \\
\text { engajamento de usuários }\end{array}$ & $\begin{array}{l}\text { Avaliar } \\
\text { designs }\end{array}$ & Estágio 2 \\
\hline 3 & Ciclo 1 & $\begin{array}{l}\text { Necessidade de analisar o fluxo de ações de usuários que } \\
\text { acessaram as funcionalidades cujas métricas de } \\
\text { engajamento estão sob análise }\end{array}$ & $\begin{array}{l}\text { Avaliar } \\
\text { designs }\end{array}$ & Estágio 2 \\
\hline 4 & Ciclo 2 & $\begin{array}{l}\text { Balanceamento adequado da dificuldade da mecânica de } \\
\text { jogo }\end{array}$ & $\begin{array}{l}\text { Especificar } \\
\text { requisitos }\end{array}$ & Estágio 2 \\
\hline 5 & Ciclo 2 & $\begin{array}{l}\text { Apresentar as "regras do jogo" para alcançar objetivos } \\
\text { específicos }\end{array}$ & $\begin{array}{l}\text { Especificar } \\
\text { requisitos }\end{array}$ & Estágio 2 \\
\hline 6 & Ciclo 3 & $\begin{array}{l}\text { Períodos de poucas atualizações no sistema (melhorias } \\
\text { ou novas funcionalidades) interfere negativamente no } \\
\text { engajamento dos usuários, especialmente em versão beta }\end{array}$ & $\begin{array}{l}\text { Avaliar } \\
\text { designs }\end{array}$ & Estágio 2 \\
\hline 7 & Ciclo 3 & $\begin{array}{l}\text { Necessidade de criar um ambiente totalmente } \\
\text { automatizado para cálculo das métricas de engajamento }\end{array}$ & $\begin{array}{l}\text { Avaliar } \\
\text { designs }\end{array}$ & Estágio 1 \\
\hline 8 & Ciclo 4 & $\begin{array}{l}\text { Variar as possibilidades de gamificação para abranger } \\
\text { perfis de usuários diferentes }\end{array}$ & $\begin{array}{l}\text { Especificar } \\
\text { requisitos }\end{array}$ & Estágio 2 \\
\hline 9 & Ciclo 4 & $\begin{array}{l}\text { Associação de dimensões de motivação humana e } \\
\text { colaboração com diretrizes de comunidades de prática: } \\
\text { primeira versão de arcabouço teórico e da proposta de } \\
\text { abordagem }\end{array}$ & $\begin{array}{l}\text { Especificar } \\
\text { contexto de } \\
\text { uso }\end{array}$ & Estágio 1 \\
\hline 10 & Ciclo 5 & $\begin{array}{l}\text { Inclusão das } 3 \text { dimensões da prática de uma comunidade } \\
\text { na abordagem de integração e refinamento da proposta }\end{array}$ & $\begin{array}{l}\text { Especificar } \\
\text { contexto de } \\
\text { uso }\end{array}$ & Estágio 1 \\
\hline 11 & Ciclo 6 & $\begin{array}{l}\text { Não é possível avaliar funcionalidades novas e que } \\
\text { dependem de pesquisas ou estudos por parte do usuário, } \\
\text { como a revisão de dados, em períodos curtos de } \\
\text { disponibilização do experimento em produção }\end{array}$ & $\begin{array}{l}\text { Avaliar } \\
\text { designs }\end{array}$ & Estágio 2 \\
\hline 12 & Ciclo 6 & $\begin{array}{l}\text { Atividades que dependem de habilidades específicas de } \\
\text { usuários precisam ser executadas em laboratório com } \\
\text { métricas subjetivas de engajamento para resultado em } \\
\text { curto período de tempo (enfoque no perfil de usuário } \\
\text { típico de acordo com a nova atividade) }\end{array}$ & $\begin{array}{l}\text { Avaliar } \\
\text { designs }\end{array}$ & Estágio 2 \\
\hline 13 & Ciclo 6 & $\begin{array}{l}\text { Avaliar se novas funcionalidades estão dentro do escopo } \\
\text { de habilidades e interesses dos atuais membros da } \\
\text { comunidade }\end{array}$ & $\begin{array}{l}\text { Especificar } \\
\text { contexto de } \\
\text { uso }\end{array}$ & Estágio 2 \\
\hline 14 & Ciclo 6 & $\begin{array}{l}\text { Analisar a correlação de cada ação realizada com cada } \\
\text { métrica de engajamento }\end{array}$ & $\begin{array}{l}\text { Avaliar } \\
\text { designs }\end{array}$ & Estágio 2 \\
\hline 15 & Ciclo 6 & $\begin{array}{l}\text { Categorizar as ações dos usuários de acordo com os } \\
\text { tipos de elementos de interação acessados: elementos } \\
\text { colaborativos, elementos de projeto de jogos e elementos } \\
\text { funcionais }\end{array}$ & $\begin{array}{l}\text { Avaliar } \\
\text { designs }\end{array}$ & Estágio 2 \\
\hline 16 & Ciclo 6 & $\begin{array}{l}\text { Analisar o engajamento por meio do cruzamento entre } \\
\text { as ações recorrentes dos usuários combinadas com o } \\
\text { tempo médio de reação do usuário a cada ação pode } \\
\text { informar melhor o engajamento do usuário do que } \\
\text { apenas a frequência de ações sozinha }\end{array}$ & $\begin{array}{l}\text { Avaliar } \\
\text { designs }\end{array}$ & Estágio 2 \\
\hline 17 & Ciclo 6 & $\begin{array}{l}\text { Analisar as táticas de uso com MRPs como uma forma } \\
\text { de melhor compreender os padrões de ação por grupo de } \\
\text { usuários com notas baixas, médias e altas a partir da } \\
\text { UES }\end{array}$ & $\begin{array}{l}\text { Avaliar } \\
\text { designs }\end{array}$ & Estágio 2 \\
\hline 18 & Ciclo 6 & $\begin{array}{l}\text { Analisar a distribuição de acessos a cada tipo de } \\
\text { elemento de interação do usuário de acordo com as } \\
\text { notas baixas, médias e altas para cada métrica objetiva } \\
\text { de engajamento }\end{array}$ & $\begin{array}{l}\text { Avaliar } \\
\text { designs }\end{array}$ & Estágio 2 \\
\hline 19 & Ciclo 6 & $\begin{array}{l}\text { Analisar as notas baixas, médias e altas a partir da UES } \\
\text { para realizar a pesquisa correlacional entre tipos de } \\
\text { elementos de interação acessados ou entre elementos de } \\
\text { interação em isolamento }\end{array}$ & $\begin{array}{l}\text { Avaliar } \\
\text { designs }\end{array}$ & Estágio 2 \\
\hline 20 & Ciclo 6 & $\begin{array}{l}\text { Personalizar o sistema de acordo com cada grupo de } \\
\text { usuários que possui táticas de uso específicas }\end{array}$ & $\begin{array}{l}\text { Especificar } \\
\text { requisitos }\end{array}$ & Estágio 2 \\
\hline
\end{tabular}


Ao abordar os estágios de vida da comunidade na proposta de abordagem é possível notar que a evolução da comunidade se dá por meio da gestão de conhecimento, tanto a partir do indivíduo, que precisa entender como o seu conhecimento atual pode contribuir com a comunidade, e como acompanhar a evolução de seu conhecimento a partir da colaboração, quanto a partir da coordenação, membros-núcleo, pessoal de suporte da comunidade e bibliotecários. Estes precisam gerir conhecimento gerado, de modo a construir um corpo de conhecimento sólido sobre um assunto, e tornar possível a evolução do indivíduo e da comunidade, tornando-a sustentável a longo prazo. Nesse contexto, há construção de significado e valor para seus membros em todos os níveis de participação. A Tabela 8.5 apresenta esse entendimento no detalhamento da diretriz Delinear comportamentos-alvo.

Tabela 8.5: Proposta de abordagem: Delinear comportamentos-alvo para comunidades de colaboração aberta

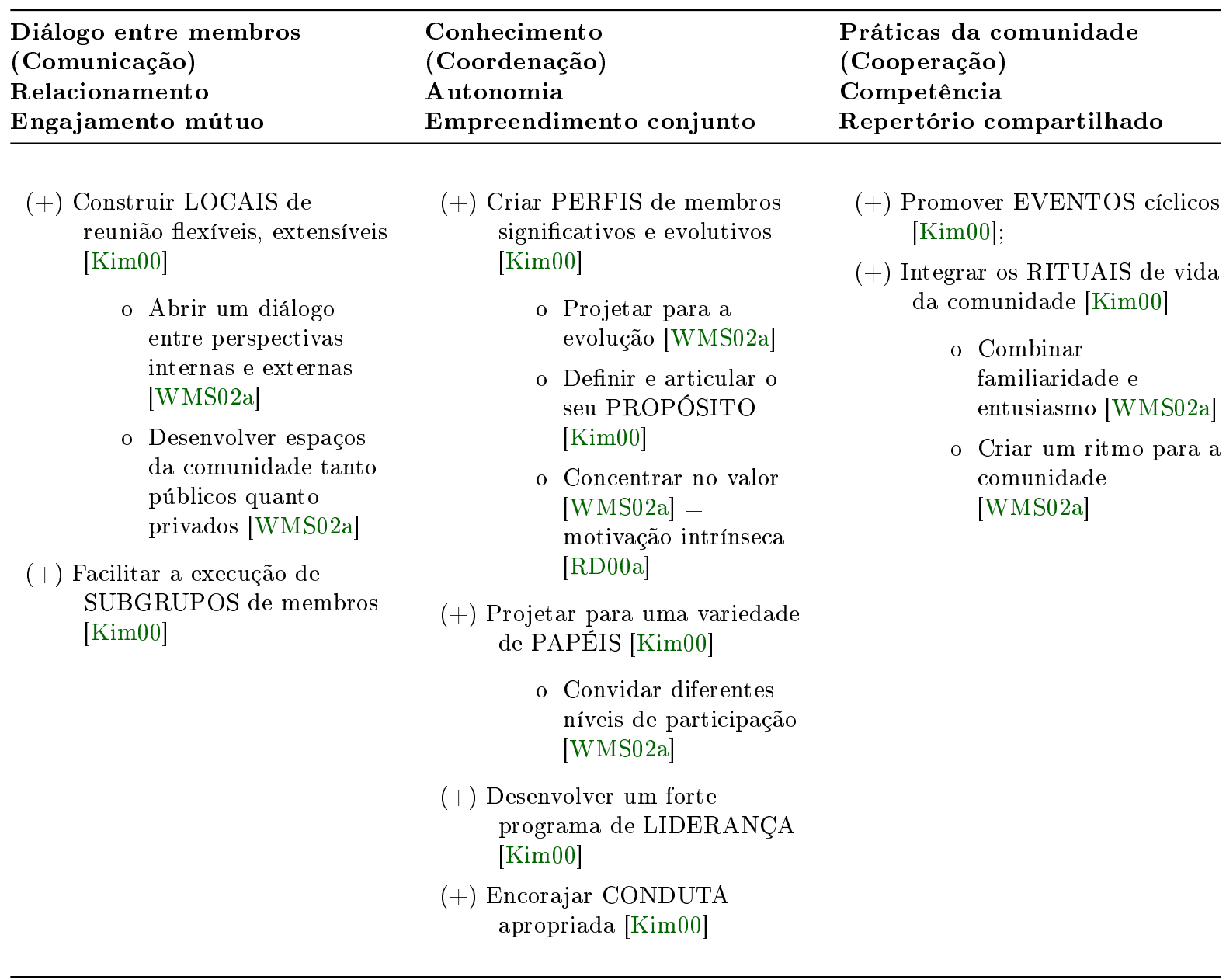

A mudança refere-se a relacionar a coordenação, não mais à moderação, mas sim ao conhecimento, no sentido de que a coordenação a partir do indivíduo e da comunidade, deve possibilitar gestão de conhecimento. A moderação está inserida na coordenação, mas o valor ou significado da coordenação reside em compartilhar conhecimento. O indivíduo precisa entender como contribuir a partir de seu conhecimento atual e evoluir seu conhecimento na comunidade; e a comunidade precisa administrar conhecimento para tornar-se sustentável ao longo dos ciclos de vida.

\subsubsection{DCU ágil}

Por ser um processo cíclico, e a compreensão do usuário ser central, as diretrizes e passos descritos na proposta de abordagem são classificados de acordo com as fases do DCU, sendo assim, indicam o momento que podem ser consideradas no desenvolvimento de software. A Figura 8.1 exibe o ciclo 
de DCU ágil proposto por Sy [Sy07] que integra tanto as atividades de design de interação, quanto as de desenvolvimento em apenas um único ciclo, exibindo a interação das atividades.

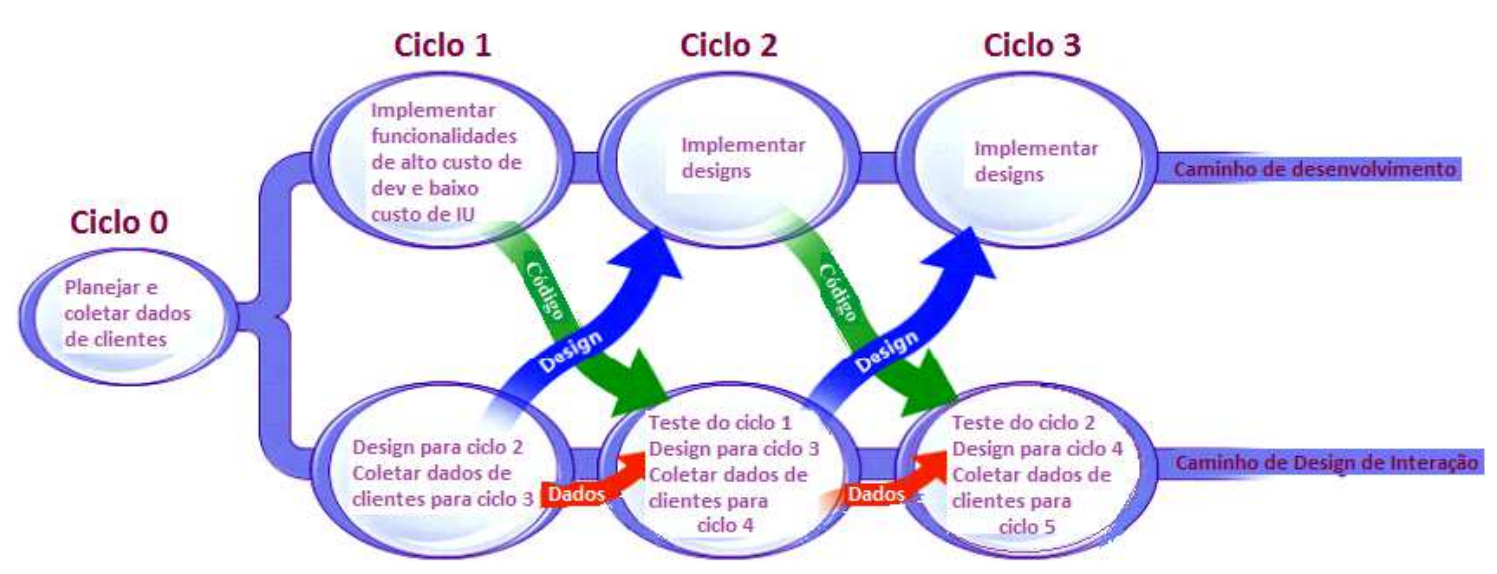

Figura 8.1: Ciclo do DCU ágil [Sy07].

As fases de vida do DCU são executadas de maneira cíclica em cada ciclo. Dessa forma, temos o estágio 1 de vida da comunidade, associado ao ciclo 0 de DCU ágil. Os resultados obtidos no ciclo 0, ou a compreensão das diretrizes relacionadas ao passo Definir objetivos de negócios, classificado na fase Especificar contexto de uso de DCU, tornam-se entradas para dois caminhos que serão executados em paralelo: desenvolvimento e design de interação. O objetivo é atender a primeira diretriz do passo Delinear comportamentos-alvo, classificado na fase Especificar requisitos de DCU no estágio 2 de vida da comunidade: Construir um caso para associação. A comunidade é implementada com os resultados oriundos das diretrizes do ciclo 0, que são os dados de entrada para a construção de um caso para associação.

Portanto, o ciclo 1 de DCU ágil para o caminho de desenvolvimento refere-se ao desenvolvimento back-end, com alguns poucos elementos de interface sobre o caso para associação, enquanto para o caminho de design refere-se ao protótipo do caso para associação e o levantamento de dados de usuário para o próximo comportamento-alvo Legitimar coordenadores da comunidade. As diretrizes de construção de comunidades de prática estão enumeradas indicando a ordem que podem ser implementadas. Para cada fase do DCU, existem atividades fixas a serem desenvolvidas em todos os ciclos, e atividades específicas do estágio de vida da comunidade.

\subsubsection{Enfoque sobre o domínio de GLAMs}

Um comportamento-alvo em uma comunidade online de colaboração aberta, como descrito na seção anterior, é projetado a partir de princípios de construção de comunidades de prática, classificados de acordo com Modelo 3C, dimensões da prática e da motivação humana, conforme Tabela 6.3. Porém, assim como foi descrito nos Ciclos 5 e 6 da pesquisa-ação, é preciso instanciar de acordo com o domínio da prática compartilhada na comunidade.

Essa instanciação, denominamos na pesquisa-ação de uma estratégia colaborativa. Portanto, um dos comportamentos-alvo de um estágio de vida da comunidade é selecionado para desenvolvimento e a prática da comunidade, que diz respeito à competência adquirida pelos membros (motivação), que ocorre por meio de cooperação (modelo 3C) relaciona-se com a área de domínio da comunidade. Temos então duas perspectivas: a de desenvolvimento da comunidade (comportamento-alvo), apresentada na Tabela 8.2, e a de resolução de um problema da área de domínio da comunidade (estratégia colaborativa).

No contexto de GLAMs, existem atividades que são comumente solicitadas aos usuários. Mia Ridge define crowdsourcing em patrimônio cultural como "a solicitação ao público para auxílio em 
tarefas significativas que contribuam para um objetivo compartilhado, significativo ou interesse de pesquisa relacionado a coleções ou conhecimento sobre patrimônio cultural" [Rid16]. Oomen e Aroyo [OA11] estudaram as motivações e design de vários projetos de crowdsourcing em GLAMs e apresentaram uma classificação com seis tipos principais de iniciativas nesse contexto, as quais são apresentadas na Tabela 8.6.

Tabela 8.6: Classificação de iniciativas de crowdsourcing em GLAMs traduzida a partir da pesquisa de Oomen e Aroyo [OA11].

\begin{tabular}{ll}
\hline $\begin{array}{l}\text { Tipo de } \\
\text { crowdsourcing }\end{array}$ & Definição \\
\hline Correção & $\begin{array}{l}\text { Convite de usuários para corrigir e/ou transcrever } \\
\text { saídas de processos de digitalização. }\end{array}$ \\
\hline Contextualização & $\begin{array}{l}\text { Adição de conhecimento contextual a objetos, por exemplo, } \\
\text { por contar histórias, ou escrever artigos ou páginas de wiki } \\
\text { com dados contextuais. }\end{array}$ \\
\hline $\begin{array}{l}\text { Completude de } \\
\text { coleção }\end{array}$ & $\begin{array}{l}\text { Busca ativa de objetos adicionais para serem } \\
\text { incluídos em uma exposição ou coleção Web. }\end{array}$ \\
\hline Classificação & $\begin{array}{l}\text { Coleta de metadados descritivos relacionados aos } \\
\text { objetos em uma coleção. Tagueamento social é um } \\
\text { exemplo bem conhecido. }\end{array}$ \\
\hline Co-curadoria & $\begin{array}{l}\text { Uso de inspiração/expertise de curadores } \\
\text { não-profissionais para criar exposições na Web. }\end{array}$ \\
\hline Crowdfunding & $\begin{array}{l}\text { Cooperação coletiva de pessoas que agregam } \\
\text { dinheiro e outros recursos juntas para } \\
\text { suportar esforços iniciados por outros. }\end{array}$ \\
\hline
\end{tabular}

As iniciativas apresentadas na Tabela 8.6 são as práticas mais comumente divulgadas ao público para participação no contexto de GLAMs e constituem portanto as práticas que possibilitam cooperação entre membros nesse contexto. As práticas que possibilitam cooperação atualmente no Arquigrafia estão inseridas nas iniciativas acima citadas, por esse motivo, o Arquigrafia pode ser definido como uma comunidade online de colaboração aberta no domínio de uma GLAM sobre arquitetura e urbanismo. A Figura 8.2 apresenta o relacionamento entre os estágios no modelo de ciclo de vida de conteúdo digital e os tipos de crowdsourcing mais comuns em GLAMs, de acordo com Oomen e Aroyo [OA11]. 


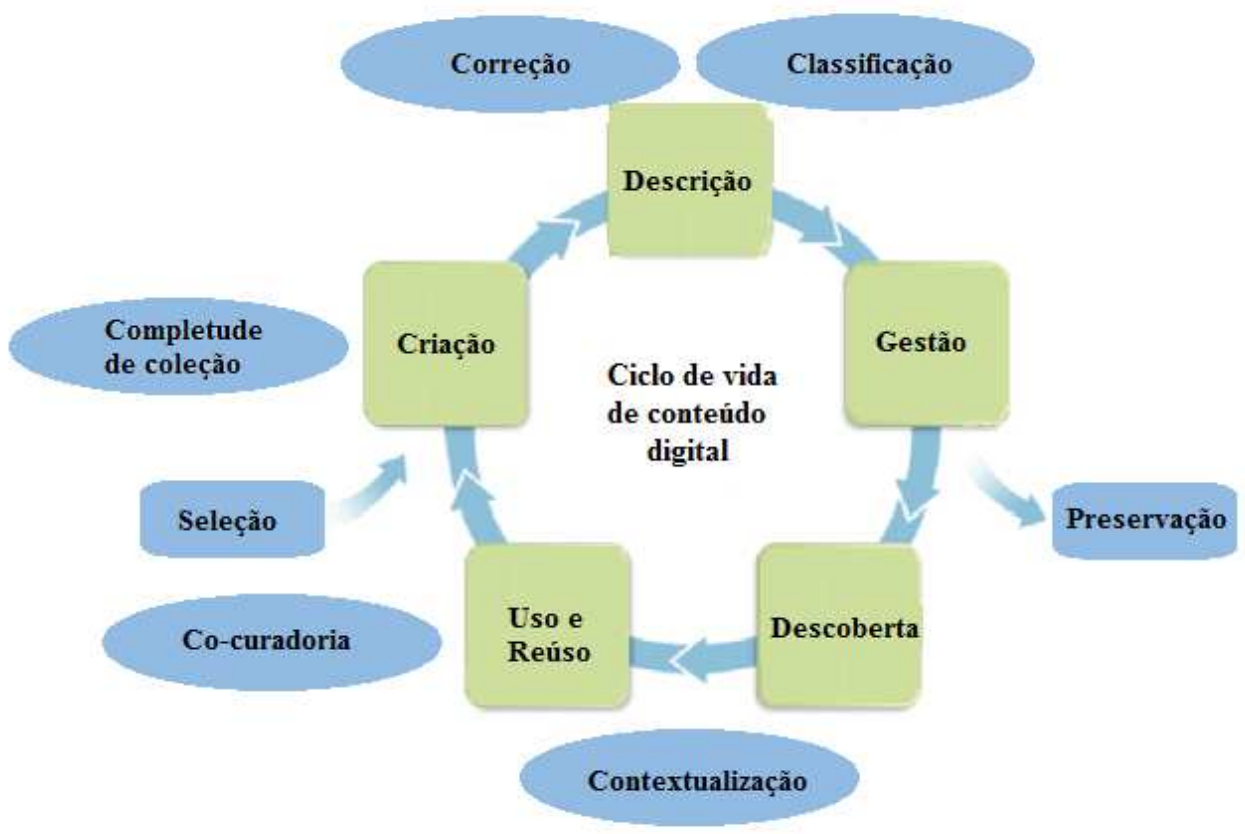

Figura 8.2: Ciclo de vida de conteúdo digital e crowdsourcing a partir de Oomen e Aroyo [OA11].

Relacionando os comportamentos-alvo para sustentabilidade de uma comunidade de prática com estratégias colaborativas no contexto de GLAMs, a partir do ciclo de vida de conteúdo digital, temos o seguinte recorte a partir da coluna Especificar requisitos da Tabela 8.2.

- $(+)$ Delinear comportamentos-alvo [WH12]

Estágio 2 i Construir um caso para associação - Estratégia colaborativa: Completude de coleção, correção e classificação

iv Legitimar coordenadores da comunidade

v Construir conexões entre membros-núcleo

vi Encontrar ideias, insights e práticas que valem a pena compartilhar

Estágio 3 i Identificar lacunas em conhecimento e desenvolver uma agenda de aprendizagem Estratégia colaborativa: Contextualização e co-curadoria

iv Criar rotinas para requisitos e processo de entrada de membros

Estágio 4 iv Recrutar ativamente novas pessoas para membros-núcleo: crowdfunding

v Desenvolver nova liderança

vi Fornecer mentoria a novos membros

No estágio 2 da comunidade, é preciso entregar valor rápido para assegurar a adesão de novos membros. Atividades de fácil contribuição por parte dos usuários precisam ser priorizadas nesse estágio. Essa necessidade está de acordo com o ciclo de vida de conteúdo digital, no qual as atividades de mais fácil contribuição são realizadas antes de atividades que envolvem maior reflexão e compreensão do domínio.

Portanto, a partir do estágio 2, construir um caso para associação de membros em uma comunidade, pode iniciar com umas das três tarefas: Complementar coleção; Tarefas de correção e transcrição; ou classificação. Dentro da proposta de abordagem, essas são as tarefas que podem gerar maior motivação para usuários típicos engajarem-se com o sistema e portanto a gamificação pode ser aplicada sobre elas, para potencializar o engajamento. No estágio 2, devido a necessidade de entrega rápida de valor, podem ser utilizadas mecânicas associadas 
a motivação extrínseca, porque usuários estão buscando o valor/utilidade do sistema, e feedback/recompensa rápida por suas contribuições é uma maneira de engajá-los na comunidade.

A partir do estágio 3, usuários apenas continuarão participando da comunidade se perceberem que ela traz benefícios para sua evolução pessoal, aprendizagem e auto-confiança na área de domínio. Por esse motivo, mecânicas que envolvem a evolução de níveis de papéis de acordo com aprendizados obtidos pelo sistema, podem gerar melhores resultados. Tais mecânicas precisam ser associadas a atividades que exigem maior habilidade, o que implica em desafio de aprendizagem e recompensa para um nível superior, de acordo com o cumprimento da tarefa. Os níveis de evolução de papéis são requisitos para seleção de usuários que podem ser chamados para fornecer mentorias a usuários novatos; participarem do grupo de membrosnúcleo, de modo a evoluírem para futuras lideranças de acordo com competências adquiridas no domínio; e obter recompensa da comunidade às contribuições realizadas.

No caso do Arquigrafia, a evolução de práticas relacionadas a GLAMs sobre arquitetura e urbanismo, precisa ser o enfoque para que a comunidade que encontra-se atualmente no estágio de maturidade (estágio 3), possa evoluir para o estágio 4. A compreensão de que o Arquigrafia encontra-se no estágio 3 decorre de que no fim do estágio de adesão (estágio 2), a comunidade demonstra que é viável, pois está instalada, funcionando e tem uma boa chance de sobrevivência. Adicionalmente, o Arquigrafia encontra-se em um período caracterizado por ciclos de baixa e alta atividades, o que pode ser confirmado na reflexão dos ciclos de pesquisa-ação. Tal caracterização é típica do estágio 3 do ciclo de vida de comunidades.

A estratégia colaborativa apresentada no ciclo 4, tendo sua primeira parte implementada (revisão de dados) e a segunda parte prototipada (curadoria digital), nos ciclos 5 e 6 , buscou atender ao comportamento-alvo Identificar lacunas em conhecimento e desenvolver uma agenda de aprendizagem. A revisão de dados engloba as iniciativas Completude de coleção, correção e classificação, de crowdsourcing em GLAMs. A curadoria digital engloba as iniciativas de contextualização e co-curadoria. Em concordância com os ciclos de DCU ágil, nos quais o caminho de Design de interação mantém-se um ciclo à frente do caminho de desenvolvimento, a curadoria digital foi definida como protótipo.

A lacuna de conhecimento que a estratégia buscou solucionar refere-se a informações sobre arquitetura e urbanismo que ainda não são apresentadas no sistema, mas que pela motivação de usuários poderiam ser acrescentadas. A agenda de aprendizagem foi proposta para que o usuário passe por estágios de completude de coleção, correção e classificação, de modo a adquirir competência para moderar revisões de outros usuários, até que alcance o papel de curador. Nesse papel, as perspecticas do usuário podem ser exploradas a partir de uma subcoleção selecionada por ele no acervo. Contudo, a reflexão de membros-núcleo e coordenação sobre as contribuições dos usuários são fundamentais para avaliar o valor das práticas e se elas estão de acordo com a filosofia central da comunidade. A comunidade aprende refletindo e refina seu domínio enquanto os processos de gamificação possibilitam que ideias novas sejam exploradas como práticas de aprendizado para o usuário e como construção de um corpo de conhecimento para a comunidade. 


\section{Capítulo 9}

\section{Avaliação da pesquisa}

Neste capítulo, os diferentes problemas abordados por esta pesquisa são avaliados. No Capítulo 4, apresentamos a validade de cada método de pesquisa. Neste capítulo, na Seção 9.1, avaliamos a pesquisa como um todo descrevendo como os métodos de pesquisa selecionados relacionaram-se de modo a construir a validade dos resultados. Por fim, na Seção 9.2, os resultados da pesquisa são avaliados a partir da perspectiva da teoria e da prática.

\subsection{Validade dos resultados}

Esta pesquisa foi desenvolvida com os métodos de pesquisa-ação e pesquisa quantitativa experimental e não-experimental, sendo portanto uma pesquisa social empírica envolvendo dados qualitativos e quantitativos. A qualidade de qualquer pesquisa social empírica pode ser avaliada por quatro testes: validade do construto, validade interna, validade externa e confiabilidade [Yin09].

Validade do construto em pesquisa-ação refere-se a medidas operacionais corretas para os conceitos sendo estudados. Algumas táticas disponíveis para aumentar validade de construto são o uso de múltiplas fontes de evidência; o estabelecimento de uma cadeia de evidências ambas importantes durante a coleta de dados -; e ter rascunhos dos relatórios do estudo sendo revisados por informantes-chave.

Nesta pesquisa, a validade do construto foi assegurada por múltiplas fontes de evidência, incluindo documentação, registro em banco de dados, observação-participante, diários de campo, questionário e experimentos (veja Seção 5.1). A validade do construto foi também assegurada por submeter relatórios à FAPESP com a descrição do ciclos de pesquisa finalizados para o período e a publicação de artigos com a descrição dos resultados da pesquisa-ação de 2016 a 2018 para o Seminário RITE, artigos 3, 5 e 7 da Seção 1.5, que é composto de uma audiência de membros e usuários típicos do Arquigrafia que vai além dos participantes das reuniões semanais. Nos seminários, os resultados de pesquisa também puderam ser discutidos em mesas-redondas, que forneceram feedback sobre a validade e utilidade da pesquisa em seu contexto de aplicação.

Um banco de dados foi construído para registro de métricas de engajamento e o banco de dados de produção do sistema forneceu os dados necessários para o cálculo das métricas e para monitoramento de evidências de mudanças de um ciclo para outro, que foram complementados com o monitoramento de métricas do Google Analytics. Adicionalmente, uma pasta no Google Docs mantém todos os documentos com evidências empíricas incluindo os diários de campo escritos pelos alunos, os resultados de testes de usabilidade e de aplicação de questionários.

Validade do construto para experimentos controlados, pesquisa causal comparativa e pesquisa correlacional, refere-se a validade de inferências sobre os construtos, ou variáveis, no estudo. 
Para esse fim, é necessário selecionar as variáveis corretas para os objetivos do estudo, suportadas pela teoria, e, selecionar os grupos, e os procedimentos e estatísticas aplicados a eles, de forma mais equiparada possível, de modo que apenas variáveis em análise possam justificar inferências. Conforme descrito no Capítulo 4, esses tratamentos foram adotados.

Validade interna em pesquisa-ação refere-se ao estabelecimento de uma relação causal, na qual acredita-se que certas condições conduzem a outras. Algumas táticas disponíveis são correspondência de padrões, construção de explicações, abordar explicações rivais e modelos lógicos. Correspondência ou casamento de padrões refere-se ao ato de verificação da presença de um padrão em um conjunto de dados. A construção de explicações visa compreender os resultados à luz de teoria(s), enquanto que explicações rivais podem tornar evidente que um resultado não foi fruto apenas de uma causa. Modelos lógicos são diagramas visuais que descrevem a cadeia de causas e efeitos que levam a um resultado de interesse.

A correspondência de padrões foi feita por analisar os conceitos-chave das áreas envolvidas e classificá-los como pertencentes a um mesmo conjunto, no qual um implica no outro. Isto foi feito ao relacionar o modelo 3C de colaboração, as três dimensões da motivação humana e as três dimensões da prática. Associamos esses conceitos dentro da construção de comunidades online como a necessidade de fornecer meios para o diálogo entre membros, de evoluir membros para gerar aprendizado e de dar enfoque sobre as práticas relevantes para a comunidade.

Nas publicações da Seção 1.5, a construção de explicações foi explorada nas seções de reflexão, interpretando os resultados a partir de teorias, com o suporte de evidências quantitativa e qualitativa, com o objetivo de ilustrar a cadeia de evidências de porquê, como e quais efeitos foram encontrados após as intervenções.

As descobertas foram descritas nos artigos abordando explicações rivais, o que gerou a análise dos resultados por meio de Maximal Repeating Patterns (MRPs) [SE91], Task Unrelated Thought (TUT) [SOH03] e lapsos de atenção [RMA $\left.{ }^{+} 97, \mathrm{SDH}^{+} 04\right]$, ou ainda micro e macro nível de envolvimento [Cal11, $\mathrm{ICM}^{+}$15], como descrito no artigo 9 da Seção 1.5. Por exemplo, buscamos entender porque os usuários de um grupo experimental realizaram prioritariamente um conjunto de ações, enquanto outro grupo executou outro conjunto; ou porque muitas ações em um grupo resultaram em notas maiores na escala de engajamento de usuário e mais ações do mesmo tipo em outro conjunto resultaram em menores notas na escala.

Validade interna em experimentos controlados e pesquisa causal-comparativa, assim como em pesquisa-ação, refere-se ao estabelecimento de uma relação causal. O enfoque neste caso, porém, é sobre a inferência correta sobre a covariação entre uma variável independente e uma dependente refletir relação causal. Como visto no 4, as ameaças à validade interna foram tratadas para experimentos controlados e pesquisa causal-comparativa. Validade interna em pesquisa correlacional refere-se à mesma categoria de ameaças que ocorrem em pesquisa causal-comparativa e o mesmo tratamento foi aplicado, uma vez que trata-se do mesmo conjunto de dados.

Validade externa refere-se à definição do domínio no qual as descobertas de um estudo podem ser generalizadas. Enquanto a pesquisa quantitativa experimental ou não experimental utiliza-se de generalização estatística, a pesquisa social empírica utiliza-se de generalização analítica, na qual "o pesquisador está se esforçando para generalizar um conjunto particular de resultados para alguma teoria mais ampla" [Yin09].

Nesta pesquisa, o arcabouço teórico sobre o qual a proposta de abordagem foi construída busca explicar as relações entre construtos-chave, sem especificar um domínio específico. Em outras palavras, embora a pesquisa-ação tenha sido aplicada no domínio de GLAMs, o arcabouço teórico não contém especificidades deste domínio. Adicionalmente, a proposta de abordagem foi descrita em dois níveis: para comunidades online de colaboração aberta; e para estas no domínio de GLAMs. O objetivo foi separar a abordagem específica de um domínio a partir da abordagem mais ampla sendo estudada. 
Contudo, é importante ressaltar que no contexto de pesquisa-ação, validade externa é avaliada por transferability ou "isto me serve!" [FIL08], em vez de generalização como ocorre, por exemplo, em experimentos. Por esse motivo, a validade externa é obtida por comparação com ações similares e uso da pesquisa e seus produtos em outros contextos. Em outras palavras, a pesquisa serve como fonte para outra pesquisa e para aplicação em contextos similares.

Como visto no 4, as ameaças à validade externa foram tratadas para experimentos controlados e pesquisa causal-comparativa. Validade externa em pesquisa correlacional refere-se às ameaças que ocorrem em pesquisa causal-comparativa e o mesmo tratamento foi aplicado. Adicionalmente, pesquisas em ambientes online oferecem uma vantagem porque ocorrem diretamente no ambiente de interesse, o que lhes confere validade externa alta [MP18].

Por fim, confiabilidade refere-se a repetição da pesquisa. Yin [Yin09] sugere reforçar a confiabilidade da pesquisa por minimizar os erros e vieses em um estudo. Uma pesquisa-ação confiável é aquela em que o princípio de recuperabilidade (recoverability) é possível de ser aplicado. Recuperabilidade refere-se à repetição por outros pesquisadores restrita a contextos similares, em que procedimentos precisam ser bem definidos para possibilitar repetição [FIL08]. Yin observa ainda que a ênfase está em fazer o mesmo procedimento novamente, não em replicação dos resultados. Algumas táticas para garantir confiabilidade são usar um protocolo de pesquisa-ação e desenvolver um banco de dados monitorados na pesquisa-ação. Ambas as táticas foram aplicadas nesta pesquisa.

Para experimentos controlados, pesquisa causal-comparativa e pesquisa correlacional, confiabilidade refere-se a repetibilidade e reprodutibilidade. Repetibilidade diz respeito a pesquisa poder ser repetida e encontrar os mesmos resultados sob as mesmas condições. Reprodutibilidade refere-se a um estudo inteiro poder ser reproduzido em outro contexto. A ênfase está em replicar os resultados em ambos os casos, porém repetibilidade ocorre no mesmo contexto e reprodutibilidade em contexto diferente. Os protocolos desenvolvidos e o banco de dados monitorados tornam possível a replicação tanto no mesmo contexto, quanto em contextos distintos. Além disso, para todos os casos apresentamos a avaliação de significância estatística, com p-value, e os tamanhos de efeito, os quais podem ser checados em procedimentos de replicação.

\subsection{Avaliação dos Resultados}

Os principais resultados desta pesquisa são avaliados a partir do ponto de vista da teoria e da prática nas próximas subseções.

\subsubsection{Implicações para a teoria}

A partir de um ponto de vista teórico, o objetivo deste estudo foi expandir o corpo de conhecimento de engajamento de usuários na área de gamificação de comunidades online de colaboração aberta, especialmente, no que diz respeito às seguintes questões:

- (QPI) Qual o efeito do uso de elementos de jogos no engajamento de usuários em uma comunidade online de colaboração aberta no domínio de GLAMs?

- (QPII) Como integrar a gamificação com o monitoramento e a avaliação de engajamento de usuários durante o desenvolvimento de uma comunidade online de colaboração aberta?

Por meio da pesquisa-ação, buscou-se construir uma proposta de abordagem para equipes de desenvolvimento de software, projetistas e membros-núcleo de uma comunidade online de colaboração aberta, que enfrentam o problema de falta de engajamento de usuários, a partir da gamificação baseada em seu principal referencial teórico: a motivação intrínseca do usuário. 
A pesquisa foi iniciada no contexto do Arquigrafia, buscando compreender o problema de falta de engajamento de usuários. A literatura de engajamento em comunidades online, apontou a gamificação como uma possível solução. Porém, as evidências foram baseadas em estudos pontuais, que não informavam como os elementos de jogos eram inseridos nos sistemas e como o processo de medição e avaliação das métricas era realizado, e em muitos casos, nem as próprias métricas eram informadas. As duas questões de pesquisa acima foram criadas nesse contexto.

Entendendo a motivação intrínseca como uma necessidade do ser humano que é vivenciada em um contexto específico, elaborou-se um arcabouço teórico para relacioná-la ao contexto da pesquisa-ação: comunidades online de colaboração aberta. Nesse contexto, motivação intrínseca relaciona-se com diretrizes e estágios de vida de comunidades de prática e com o modelo de colaboração, os quais por sua vez são aplicados sobre um domínio de práticas compartilhadas.

A Tabela 9.1 apresenta um resumo dos resultados na perspectiva da teoria. 
Tabela 9.1: Proposta de abordagem - Perspectiva da teoria

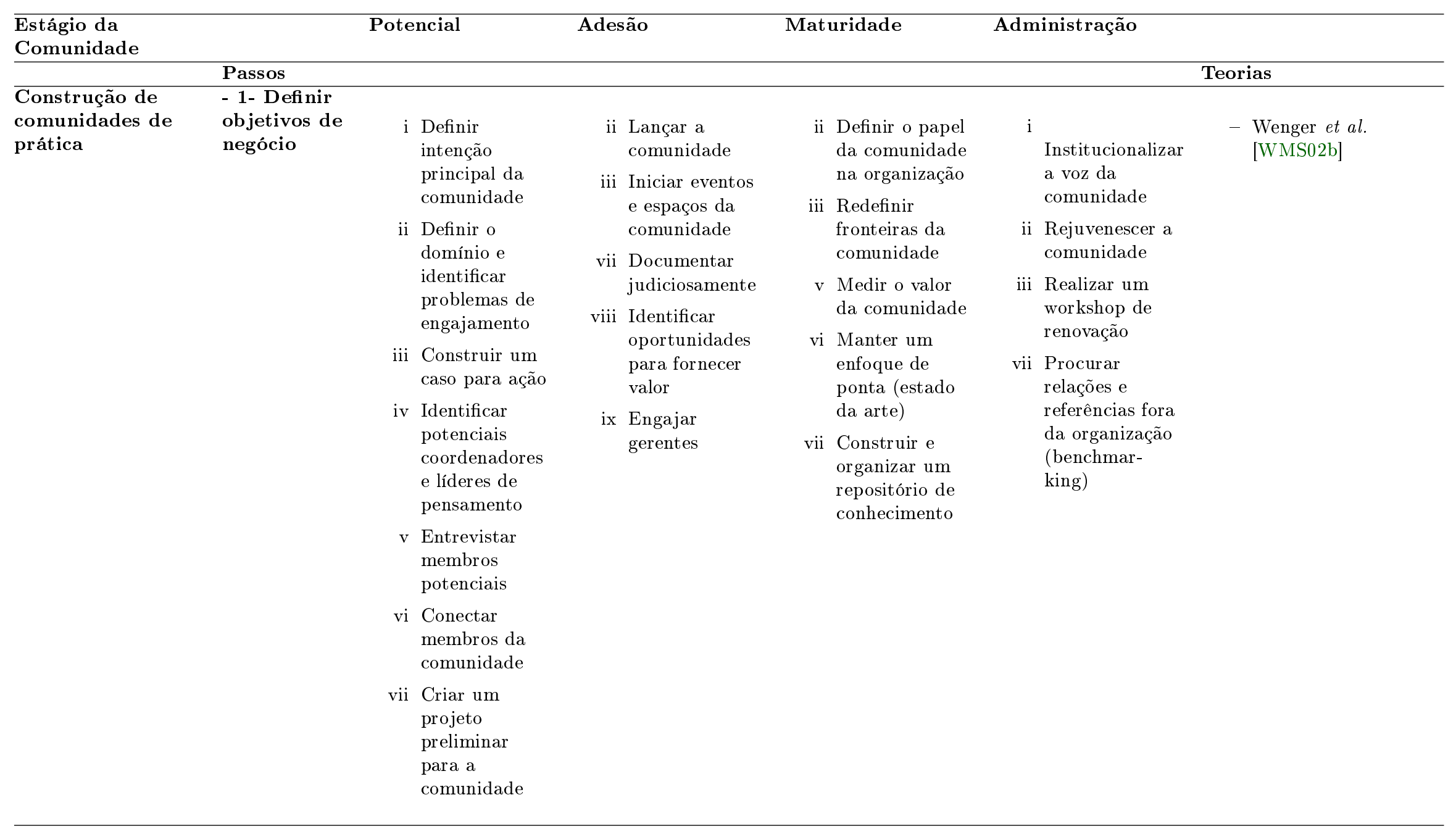


- Bartle [Bar96], Yee

[Yee06], Andrade et al. [AMBI16]

- 4- Delinear comportamentos-alvo

- 4.1- Associar motivação (SDT), colaboração e prática compartilhada

- 5- Conceber ciclos de atividade

- 6- Não esquecer da diversão

- Werbach \& Hunter [WH12]

- Ryan \& Deci [RD00a], Fuks et al. [FRGL05], Wenger et al. [WMS02a], Kim [Kim00]

- Schell [Sch14]

- 7- Definir estética

- 8- Implantar as ferramentas apropriadas

- Schell [Sch14]

- 9- Monitorar engajamento de usuários

- Werbach \& Hunter [WH12]

- Zichermann \& Cunningham [ZC11], Iacovides et al. $\left[\mathrm{ICM}^{+} 15\right]$, Smallwood et al. $\left[\mathrm{SDH}^{+} 04\right]$

\section{Avaliação de}

engajamento de usuário
- 10- Avaliar métricas objetivas de engajamento (frequência, recenticidade, duração, viralidade, classificação, ações, tempo de reação e ndias)

- 11- Avaliar heurísticas de design

- 12- Testar com usuários

- 13- Avaliar métricas subjetivas de engajamento (atenção focada, usabilidade percebida, apelo estético e recompensa)
- Zichermann \& Cunningham [ZC11], Iacovides et al. $\left[\mathrm{ICM}^{+} 15\right]$, Smallwood et al. $\left[\mathrm{SDH}^{+} 04\right]$

- Sharp et al. [SRP07]

- Jarvinen [Jär12], Kohavi et al. $\left[\mathrm{KDF}^{+} 13\right]$

- O'Brien et al. [OCH18]

- Wildemuth et al. [WOM10] 
A pesquisa mostrou a relação entre construtos vindos a partir de teorias distintas e a proposta de abordagem tem as diretrizes e estágios de vida de uma comunidade de prática como espinha dorsal. Para aplicação em um domínio específico, os comportamentos-alvo de uma comunidade são associados a práticas compartilhadas de um domínio, como o de GLAMs. Esses comportamentos-alvo são objetos de gamificação com o objetivo de construir valor/significado para os membros da comunidade.

Por esse motivo, são projetados com ciclos de atividade de modo a evoluir o membro em uma escala de papéis, que referem-se a níveis alcançados de competência em uma prática. Esse processo, em paralelo, possibilita a evolução da prática compartilhada, que para ser apreendida, necessita-se administrar o conhecimento gerado. Busca-se, portanto, o despertar do interesse em participar, evoluindo para o engajamento com as práticas compartilhadas de uma comunidade, à medida que, recompensa-se com aprendizado e evolução pessoal.

A partir desse entendimento, entendemos que a proposta de abordagem pode ser avaliada por meio de conceitos e fatores críticos de sucesso relacionados à prática da participação e o engajamento de comunidade. Fatores críticos de sucesso, critical success factors (CSFs), também chamados fatores-chave de sucesso (key success factors), foram definidos pela primeira vez por John Rockard, professor da Sloan School of Business do MIT, como: "as poucas áreaschave onde as coisas devem dar certo para o negócio florescer. Se os resultados nessas áreas não são adequados, os esforços da organização para o período serão inferiores aos definidos" [LB84]. Desde então, fatores críticos de sucesso têm sido usados em uma ampla variedade de contextos para avaliar a efetividade de propostas, projetos e estratégias nos mais diversos domínios [GE92, BCMSF12, AJF06, BTB ${ }^{+}$14, Sal06, CC08].

Líderes e praticantes da Collaborative Leaders Network [Net18] apresentaram quatro fatores críticos de sucesso para engajamento de comunidade. Alves et al. [ALV10, DBP16] propuseram cinco conceitos como boas referências para a prática da participação. Nas Tabelas $9.2 \mathrm{e}$ 9.3, esses dois arcabouços são usados para examinar quão bem a proposta de abordagem corresponde aos fatores propostos como críticos para engajamento de comunidade e aos conceitos propostos para a prática da participação, respectivamente. Os dois arcabouços apresentados são utilizados para avaliar as implicações teóricas dos resultados centrais desta pesquisa.

Os fatores críticos de sucesso para engajamento de comunidade - 1) Honrar indivíduos, grupos e comunidades pelas realidades que enfrentam; 2) Transparência; 3) Pessoas podem trabalhar em questões difíceis e alcançar resultados importantes; e 4) O processo deve possuir um líder da organização que permaneça totalmente envolvido - foram construídos tendo o respeito, transparência, confiança e liderança, respectivamente, como elos centrais. A organização que é mencionada é o ambiente no qual a comunidade de prática surge, que pode ser uma empresa ou uma universidade, ou ainda uma faculdade da universidade, como é o caso do Arquigrafia. Ao integrar as diferentes teorias e diretrizes vindas de áreas distintas, tendo a comunidade de prática como corpo para associação das demais, entendemos que os quatro fatores críticos estão sendo atendidos pela proposta, como relacionado na Tabela 9.2.

Colaborando com os fatores críticos de sucesso descritos, entendemos que as evidências empíricas desta pesquisa também indicam que um fator crítico de sucesso para engajamento de comunidades é a medição do engajamento, uma vez que é a maneira pela qual torna-se possível avaliar se as atividades realizadas pela comunidade, tanto no nível da prática compartilhada em um domínio, quanto no nível de projeto do sistema online, trouxeram efeitos positivos para o engajamento dos usuários. Para medição do engajamento, consideramos métricas subjetivas e objetivas de engajamento de usuários que precisam ser monitoradas ao longo do desenvolvimento de uma comunidade. 
Tabela 9.2: Avaliando resultados da pesquisa usando Fatores críticos de sucesso (FCS) para engajamento de comunidade [Net18].

\begin{tabular}{lll}
\hline FCS & Definição & Proposta de abordagem desta pesquisa \\
\hline Honrar & É de vital importância, especialmente se outros & A proposta busca atender a motivação intrínseca \\
indiví- & indivíduos são beneficiados. Antes de impor um & [DR12, DKR99, SDT16] de usuários para \\
duos, & projeto, se for dada a opção de avaliação pela & participar de comunidades online e ao mesmo \\
grupos e & comunidade, esta pode avaliar os benefícios e & tempo contruir um corpo de conhecimento a ser \\
comuni- & participar do projeto antes de ser implementado. & compartilhado com a comunidade \\
dades & Essa abordagem está relacionada com o conceito & (ganha-ganha). A compreensão de quais práticas \\
pelas re- & que todos ganham (ganha-ganha). A linguagem, & compartilhar é realizada por meio de discussões \\
alidades & o comportamento e o posicionamento do & com todos os membros, mediadas pelo \\
que en- & patrocinador devem permanecer fiéis a esse senso & coordenador da comunidade e membros-núcleo, \\
frentam & de resultado. & os quais coletam informações relevantes para \\
& & extrair e evoluir conhecimento a ser \\
& & compartilhado.
\end{tabular}

Transpa- As discussões realizadas dentro e fora da reunião As seguintes diretrizes, a partir de construção de rência devem ser abertamente compartilhadas. $\mathrm{O}$ conteúdo das discussões deve ser compartilhado com o grupo o mais rápida e plenamente possível, e os conflitos devem ser reconhecidos abertamente. O fato de o processo ter um objetivo específico deve sempre fazer parte da discussão. Qualquer senso de agendas ocultas e discussões secretas (em vez de separadas) pode prejudicar o trabalho. Encontre histórias, metáforas e analogias para possibilitar que até os assuntos mais complexos fiquem acessíveis. Participantes precisam sair com o sentimento que o processo inteiro foi "colocado no quadro". comunidades de prática [WMS02b], tem o objetivo de tornar práticas, conhecimentos e relacionamentos transparentes: Iniciar eventos e espaços da comunidade; Documentar judiciosamente; Identificar oportunidades para fornecer valor; Definir o papel da comunidade na organização; Construir e organizar um repositório de conhecimento; Encontrar ideias, insights e práticas que valem a pena compartilhar; Identificar lacunas em conhecimento e desenvolver uma agenda de aprendizagem; e Fornecer mentoria a novos membros.

Pessoas Esse processo opera na filosofia de que os seres podem humanos têm um "eu superior" (higher self). Há traba- partes do processo que são especificamente lhar em projetadas para chamar esse "eu superior", questões honrá-lo quando ele está presente e celebrar a difíceis capacidade do grupo de exibir esse eu em um e contexto de grupo. Maior capacidade de alcançar realmente ouvir, perdoar e honrar perspectivas resulta- vastamente diferentes estão entre os dos comportamentos aplicados no processo.

As diretrizes Delinear comportamentos-alvo [WH12], Conceber ciclos de atividade [WH12], Definir História (fantasia) [Sch14] e Definir Mecânica (desafio) [Sch14] visam desenvolver um ciclo de aprendizado em que desafios e habilidades são equilibrados de modo que indivíduos sejam estimulados a participar, gerando conhecimento, que é recompensado com o crescimento de níveis de papel dentro da comunidade. Cada papel indica competência adquirida. Esse processo possibilita que novatos relacionem-se com membros mais experientes. Enquanto membros ganham competência em práticas, vão evoluindo para papéis mais centrais da comunidade (autonomia). As recompensas também evoluem de motivadas extrinsecamente em estágios iniciais da comunidade, ou para entregar recompensa rápida a novatos, para motivadas intrinsecamente em estágios mais avançados da comunidade, ou recompensa com significado real aos membros.

Líder Este comportamento envia uma mensagem para totalmente envolvido. a comunidade de que o processo é importante para o patrocinador/organização e que a comunidade é importante para o patrocinador/organização. O líder é capaz de representar os pontos de vista da organização e assume compromissos de forma contínua.
As diretizes de comunidades de prática [WMS02b] apontam o papel de coordenador da comunidade como central para a "saúde" de uma comunidade. 
Tabela 9.3: Avaliando resultados da pesquisa usando conceitos para a prática da participação [ALV10, $D B P 16]$.

\begin{tabular}{ll}
\hline Conceito & Definição \\
\hline Comuni- & "Organiza as pessoas em relação ao seu grupo de \\
dade & $\begin{array}{l}\text { pertencimento e tem na solidariedade uma forma } \\
\text { de saber. Como capacidade de reconhecer a }\end{array}$ \\
& alteridade e construir uma teia de trocas, de \\
& reciprocidades", esse processo, em construção, "é \\
& experimental e circular, proporcionando o \\
& diálogo profundo e a celebração das diversidades \\
& individuais em torno de projetos comuns" \\
& [DBP16]. \\
\hline Identi- & "Reconhecimento das múltiplias influências e dos \\
dade & múltiplos papéis que desempenhamos, \\
& valorizando cada um em sua particularidade; é \\
& reconhecer o valor da tradição e da cultura locais \\
& e perceber suas conexões com a escala global", \\
& mas "como coexistências, não hierarquias". "A \\
& partir das diferenças, reconhecer o que nos une e \\
& o que nos faz nós mesmos" [ALV10, DBP16].
\end{tabular}

Diálogo "É a relação com o outro". "É pelo diálogo que nos reconhecemos como seres inacabados, em movimento, o que nos faz estar abertos para a mudança, para a convivência, para o esforço coletivo". "É preciso o ouvir compartilhado, um espaço em que todas as opiniões são ouvidas". "É pelo próprio exercício de falar e escutar com presença que o sentido do coletivo se fortalece e novos tipos de inteligências individuais e coletivas podem emergir" [ALV10, DBP16].

Proposta de abordagem desta pesquisa

Entendendo o conceito de comunidade como central, a abordagem foi construída tendo a sustentabilidade de comunidades de práticas como espinha dorsal, na qual a motivação intrínseca de usuários e a colaboração devem ser projetadas sobre práticas compartilhadas buscando a evolução pessoal de membros e construção de conhecimento.

O estágio de maturidade de uma comunidade de prática tem a percepção de um senso de identidade como meio natural de alcançar maior confiança no valor do domínio da comunidade. Os estágios propostos por Wenger [WMS02b] indicam que a identidade é construída ao longo dos ciclos, enquanto aprende-se sobre práticas compartilhadas e o que membros valorizam como significante para desenvolvimento da comunidade.

O Modelo 3C de colaboração [FRGL05] integrado na proposta de abordagem tem a comunicação, cooperação e coordenação como três aspectos centrais da colaboração. Os comportamentos-alvo da comunidade, objetos da gamificação, são projetados tendo o entendimento que cada um dos aspectos precisam ser atendidos para propiciar colaboração eficiente.

Potência "Capacidade de ser potente, de ter energia para a de ação ação, fortalecer o sujeito para que conheça suas capacidades, talentos e potencialidades, para reconhecer sua condição e transformar a realidade" [DBP16].

Os ciclos de atividade [WH12] com história (fantasia) e mecânica (desafio) [Sch14] (gamificação) em busca de crescimento de competências e as recompensas de extrínsecas a intrínsecas [SDT16] visam fortalecer o indivíduo, reconhecendo seu aprendizado. Fornecer monitoria a novos membros, visa estabelecer relacionamentos entre membros mais e menos experientes, possibilitando alcançar autonomia para ambos. Adicionalmente, esse processo é construído sobre estágios de vida da comunidade, sendo que cada estágio possui atividades que mais energizam indivíduos para a ação, conforme Wenger [WMS02b].

Felicidade "Abordagens de bem-viver". "Remete à construção de uma cultura de paz, centrada no autoconhecimento e na paz interior". Sentido de comunhão, pertencimento e diálogo, "que se fundem na criação coletiva" [DBP16].
Felicidade na proposta é vista como o atendimento de necessidades psicológicas básicas do ser humano - relacionamento, competência e autonomia - por meio da colaboração em práticas compartilhadas de um domínio. Ao projetar gamificação, esse processo não pode esquecer da diversão [WH12], em níveis apropriados [Laz08] para cada contexto. A ideia é tornar a tarefa inerentemente agradável, reforçando a motivação intrínseca do indivíduo ao realizá-la, enquanto visa seu crescimento em competências, relacionamentos e autonomia desejados. 
Os conceitos identidade, diálogo, potência de ação e felicidade são construídos dentro de uma comunidade. Na proposta de abordagem, os três primeiros são relacionados a comportamentosalvo que são projetados visando felicidade, entendendo-a como atendimento de motivação intrínseca, colaboração e realização de atividades com diversão, dentro de uma comunidade de práticas compartilhadas.

O processo para responder a QPII - Como integrar a gamificação com o monitoramento e a avaliação de engajamento de usuários durante o desenvolvimento de uma comunidade online de colaboração aberta? - trouxe portanto a definição do arcabouço teórico que integra teorias das áreas envolvidas e o aplica na proposta de abordagem. Adicionalmente, as pesquisas quantitativas realizadas durante os ciclos de pesquisa-ação, servindo também como refinamento da proposta de abordagem, somaram esforços com a pesquisa correlacional e a pesquisa causalcomparativa sobre os três anos de monitoramento tornando possível responder a QPI - Qual o efeito do uso de elementos de jogos no engajamento de usuários em uma comunidade online de colaboração aberta no domínio de GLAMs? - visando o período subsequente ao lançamento da intervenção, ou durante o ciclo da pesquisa-ação, e o período a partir do fato passado, buscando verificar se os efeitos sobre o engajamento foram pontuais ou sustentados ao longo de um período.

Respondemos a QPI, com o entendimento que o uso de elementos de jogos em uma comunidade online de colaboração aberta, no domínio de GLAMs, tem um efeito positivo sobre o engajamento de usuários, desde que o projeto de inserção dos elementos de jogos seja adequado ao nível de habilidade do usuário para o desafio proposto [WH12], esteja associado a motivação extrínseca ou intrínseca do usuário [DR12, DKR99, SDT16], a qual envolve colaboração [FRGL05] em uma prática compartilhada [WMS02b], que esteja de acordo com o estágio de vida da comunidade [WMS02b], bem como, o perfil de usuário [SRP07] e de jogador [Bar96].

Entendemos também que em uma comunidade online de colaboração aberta, pode-se ter usuários novatos, casuais, frequentes e experientes frequentando a comunidade em um mesmo período. Usuários novatos podem continuamente entrar em uma comunidade. Nesse caso, a recepção de novatos pode ser realizada a partir de elementos de jogos associados a motivação extrínseca, contudo, conforme o usuário vai se tornando um membro mais experiente, apenas elementos de jogos associados a motivação intrínseca podem tornar a participação do usuário sustentável. Wenger declara que usuários novatos, além de competência em uma prática compartilhada, buscam relacionamento com membros seniôres, para aprender com eles.

Portanto, se a comunidade considerar apenas a motivação extrínseca de membros, quando esta for alcançada, a comunidade os perde. Perdendo usuários mais experientes, o interesse de novatos também diminui, o que conduz ao fim de uma comunidade. Portanto, motivação intrínseca dos membros sendo atendida, é a chave para uma comunidade sustentável. Por ser esta a base da teoria da gamificação, elementos de jogos projetados com esse fim têm maiores chances de obter engajamento sustentado. Esta pesquisa apresenta uma proposta de abordagem para aplicar esse princípio, entendendo a proposta como uma abordagem cíclica a ser continuamente melhorada.

Nesse contexto, entende-se que a proposta de abordagem difere dos trabalhos relacionados apresentados na seção 3.3, porque foi construída para o contexto de desenvolvimento de um sistema de software de colaboração aberta, visando a criação de uma comunidade online. Além disso, a apresentação dos elementos de jogos aos usuários, na proposta de abordagem desta tese, não é definida de acordo com necessidades psicológicas específicas - autonomia, competência ou relacionamento. O entendimento refletido na proposta é o de que as três necessidades precisam ser atendidas e o usuário irá interagir com maior intensidade com elementos que refletem melhor seu objetivo com a utilização mas, o projeto de gamificação precisa apresentar elementos de interação que tornem possível ao usuário experienciar as três necessidades psicológicas para cada comportamento-alvo de uma comunidade. 
Em adição, uma implicação para a teoria desta pesquisa pode ser a pesquisa-ação aplicada neste estudo. A pesquisa-ação usou uma abordagem para entender como integrar pesquisa com gamificação e monitoramento de engajamento de usuários durante o desenvolvimento de uma comunidade de colaboração aberta, a fim de gerar impacto tanto teórico quanto prático. Portanto, a proposta de abordagem sofreu influências do método em que foi desenvolvida.

\subsubsection{Implicações para a prática}

Como uma característica do método de pesquisa-ação, esta pesquisa fornece implicações para a prática de: 1) gamificação de comunidades online de colaboração aberta; 2) monitoramento e avaliação de engajamento de usuários; e 3) aplicação da proposta de abordagem no domínio de GLAMs.

Com respeito à gamificação de comunidades online de colaboração aberta, a pesquisa apresenta uma proposta de abordagem para equipes de desenvolvimento aplicarem na prática a teoria de gamificação. Aplicar a proposta no Arquigrafia possibilitou avaliar a aplicabilidade da proposta e os problemas reais enfrentados durante o desenvolvimento. As lições aprendidas durante o processo são descritas no ciclo de pesquisa-ação em que foram definidas e classificadas de acordo com a fase do DCU em que podem ser aplicadas.

A proposta de abordagem da gamificação de uma comunidade online de colaboração aberta, dentro do processo cíclico de DCU ágil, considerando o estágio de vida da comunidade e o arcabouço teórico definido nesta pesquisa, é uma implicação para a prática de gamificação, que visa ajudar equipes de desenvolvimento a compreender como implementar a gamificação nesse contexto.

Adicionalmente, a proposta inclui workshops para produção colaborativa da mecânica dos elementos de jogo, o que possibilita que a colaboração não seja pensada apenas no nível da comunidade, mas também no seu desenvolvimento, envolvendo membros-núcleo, coordenador da comunidade e demais membros da comunidade interessados. O objetivo é tornar a colaboração a essência da comunidade, sendo promovida em todos os níveis, inclusive no processo de desenvolvimento de software.

Para monitoramento e avaliação de engajamento de usuários, as seguintes lições aprendidas podem ser destacadas: necessidade de criar um ambiente totalmente automatizado para cálculo das métricas de engajamento; analisar a correlação de cada ação realizada com cada métrica de engajamento; categorizar as ações dos usuários de acordo com os tipos de elementos de interação acessados: elementos colaborativos, elementos de projeto de jogos e elementos funcionais; analisar o engajamento por meio do cruzamento entre as ações recorrentes dos usuários combinadas com o tempo médio de reação do usuário a cada ação pode informar melhor o engajamento do usuário do que apenas a frequência de ações sozinha; analisar as táticas de uso com MRPs como uma forma de melhor compreender os padrões de ação por grupo de usuários com notas baixas, médias e altas a partir da UES; analisar a distribuição de acessos a cada tipo de elemento de interação do usuário de acordo com as notas baixas, médias e altas para cada métrica objetiva de engajamento; e analisar as notas baixas, médias e altas a partir da UES para realizar a pesquisa correlacional entre tipos de elementos de interação acessados ou entre elementos de interação em isolamento.

Essas lições implicam em um modo de avaliar engajamento que utiliza-se de análise de ações ou elementos de interação do usuário em isolamento, ou em conjunto, sendo os conjuntos descritos de acordo com o tipo de elemento de interação acessado. No caso desta pesquisa, descrevemos três tipos: elementos de jogos, elementos colaborativos e elementos funcionais. Cada um deles representa, respectivamente, a gamificação, a colaboração e a função do sistema. Sendo assim, gamificação pode ser avaliada e comparada com os demais elementos de interação tanto em um nível de elemento de jogo isolado quanto no nível do conjunto de elementos de jogo implementados. As Tabelas 9.4, 9.5 e 9.6 apresentam os resultados na perspectiva da prática. 
Tabela 9.4: Proposta de abordagem - Perspectiva da prática.

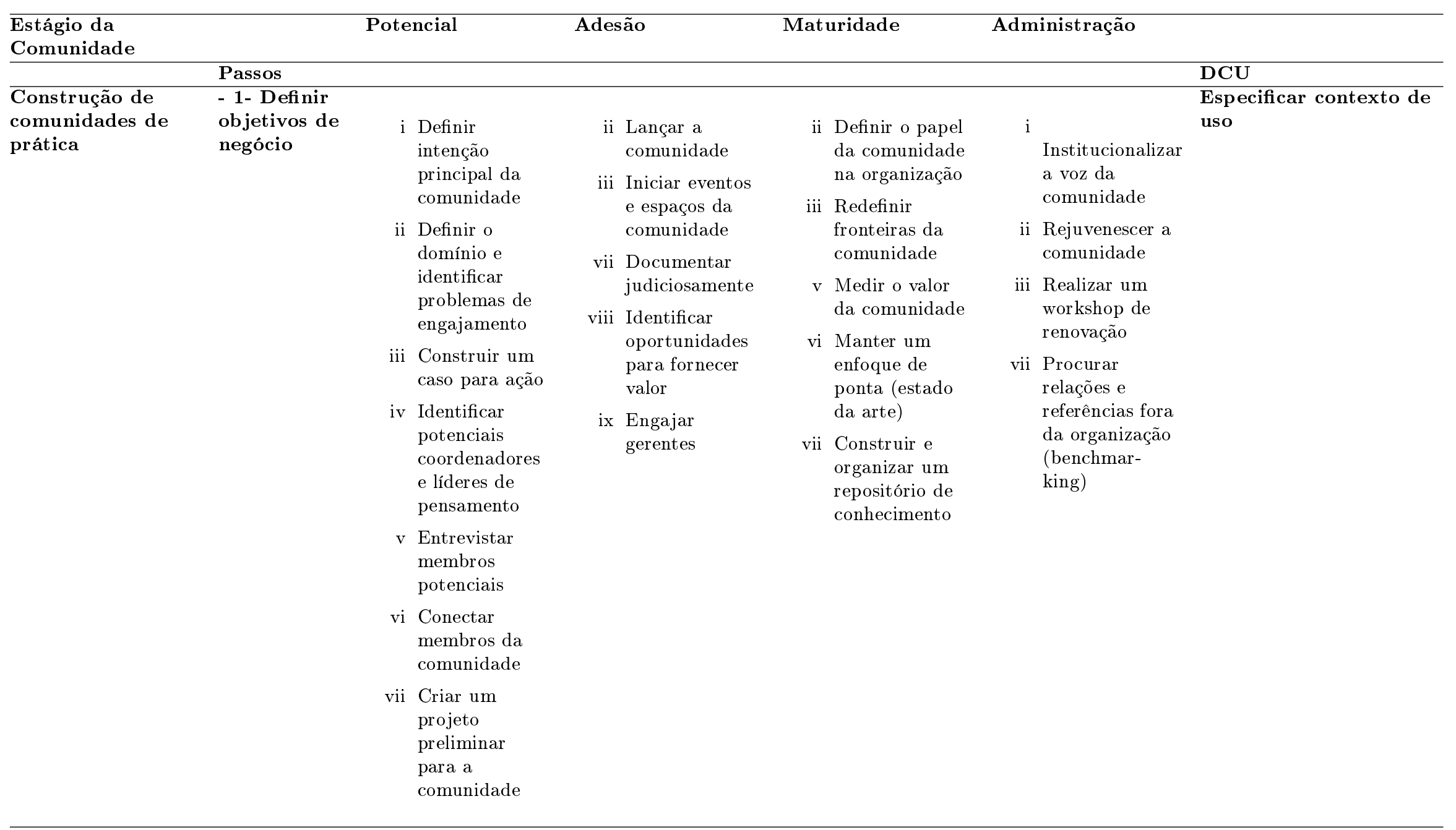


- 4- Delinear comportamentos-alvo

- 4.1- Associar motivação (SDT), colaboração e prática compartilhada

- 5- Conceber ciclos de atividade

- 5.1- Definir história (escada de progressão)

- 5.2- Definir mecânica (ciclos de engajamento)

- 5.2.1- Selecionar elemento de jogo

- 6- Não esquecer da diversão

\section{- 7- Definir estética}

Criar soluções de

- 8- Implantar as ferramentas apropriadas

- 8.1- Selecionar/Desenvolver tecnologia

- 8.1.1- Implementar componentes de sofware

- 9- Monitorar engajamento

- 9.1- Implementar monitoramento automatizado de métricas objetivas de engajamento

Avaliação de engajamento de usuário
- 10- Avaliar métricas objetivas de engajamento

- 10.1- Correlacionar ação realizada com métrica objetiva de engajamento

- 10.2- Categorizar as ações realizadas de acordo com os tipos de elementos de interação

- 10.3- Combinar as ações recorrentes dos usuários com o tempo médio de reação

- 10.4- Analisar táticas de uso com MRPs por nota alcançada em cada métrica objetiva

- 10.5- Analisar a distribuição de acessos a cada tipo de elemento de interação por nível de métrica objetiva

- 11- Avaliar heurísticas de design

- 12- Testar com usuários

- 12.1- Executar experimento controlado (online ou laboratório)

- 12.2- Aplicar questionário ou entrevista

- 13- Avaliar métricas subjetivas de engajamento

- 13.1- Correlacionar ação realizada com métrica subjetiva de engajamento

- 13.2- Analisar táticas de uso com MRPs por nível de métrica subjetiva

- 13.3- Analisar a distribuição de acessos a cada tipo de elemento de interação por nível de métrica subjetiva 
Tabela 9.5: Proposta de abordagem - Detalhamento da diretriz Delinear comportamentos-alvo.

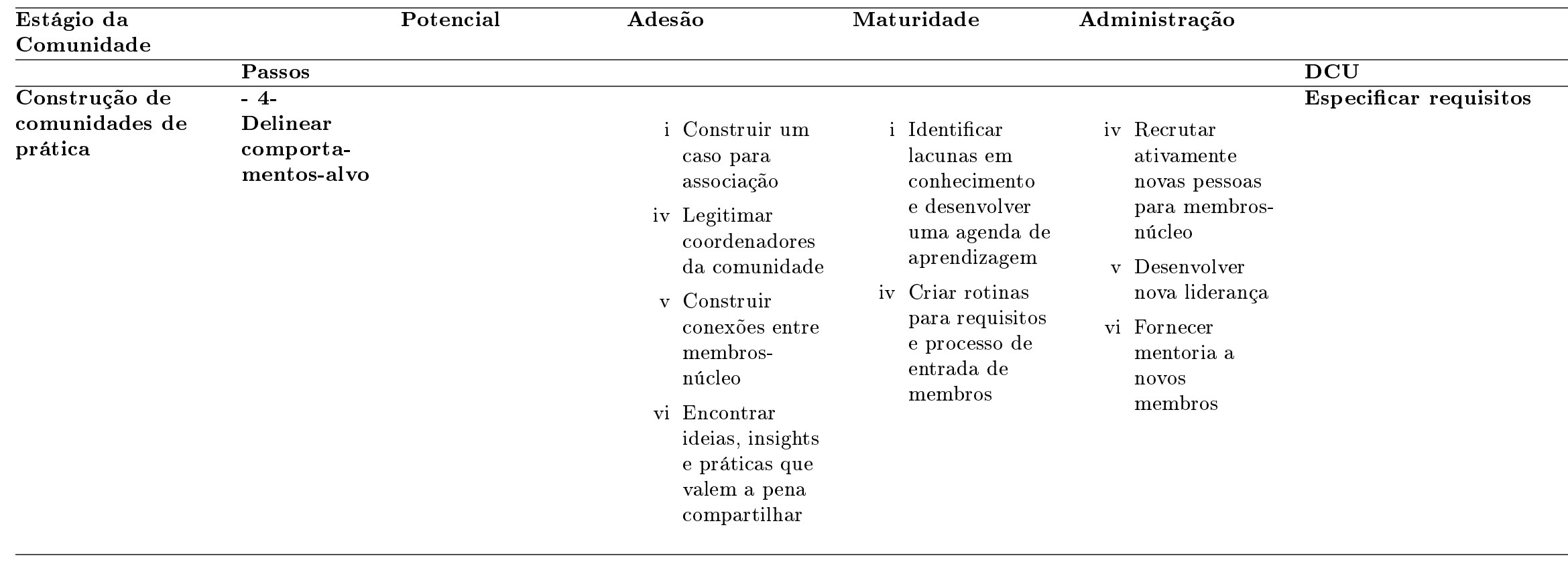




\section{Gamificação}

suportada por

Teoria da

autodeterminação

- 4.1- Associar motivação (SDT), colaboração e prática compartilhada

\begin{tabular}{lll}
\hline Diálogo entre membros & $\begin{array}{l}\text { Conhecimento } \\
\text { (Comunicação) }\end{array}$ & $\begin{array}{l}\text { Práticas da comunidade } \\
\text { (Cooperação) }\end{array}$ \\
Relacionamento & Autonomia & Competência \\
Engajamento mútuo & Empreendimento conjunto & Repertório compartilhado \\
\hline
\end{tabular}

(+) Construir LOCAIS de reunião flexíveis, extensíveis [Kim00]

o Abrir um diálogo entre perspectivas internas e externas [WMS02a]

o Desenvolver espaços da comunidade tanto públicos quanto privados [WMS02a]

(+) Facilitar a execução de SUBGRUPOS de membros [Kim00]

(+) Criar PERFIS de membros significativos e evolutivos [Kim00]

o Projetar para a evolução [WMS02a]

o Definir e articular o seu PROPÓSITO [Kim00]

o Concentrar no valor [WMS02a] = motivação intrínseca [RD00a]

$(+)$ Projetar para uma variedade de PAPÉIS [Kim00]

o Convidar diferentes níveis de participação [WMS02a]

(+) Desenvolver um forte programa de LIDERANÇA [Kim00]

(+) Encorajar CONDUTA apropriada [Kim00]
(+) Promover EVENTOS cíclicos [Kim00];

(+) Integrar os RITUAIS de vida da comunidade [Kim00]

o Combinar familiaridade e entusiasmo [WMS02a]

o Criar um ritmo para a comunidade [WMS02a] 
Tabela 9.6: Proposta de abordagem - Delinear comportamentos-alvo para GLAMs.

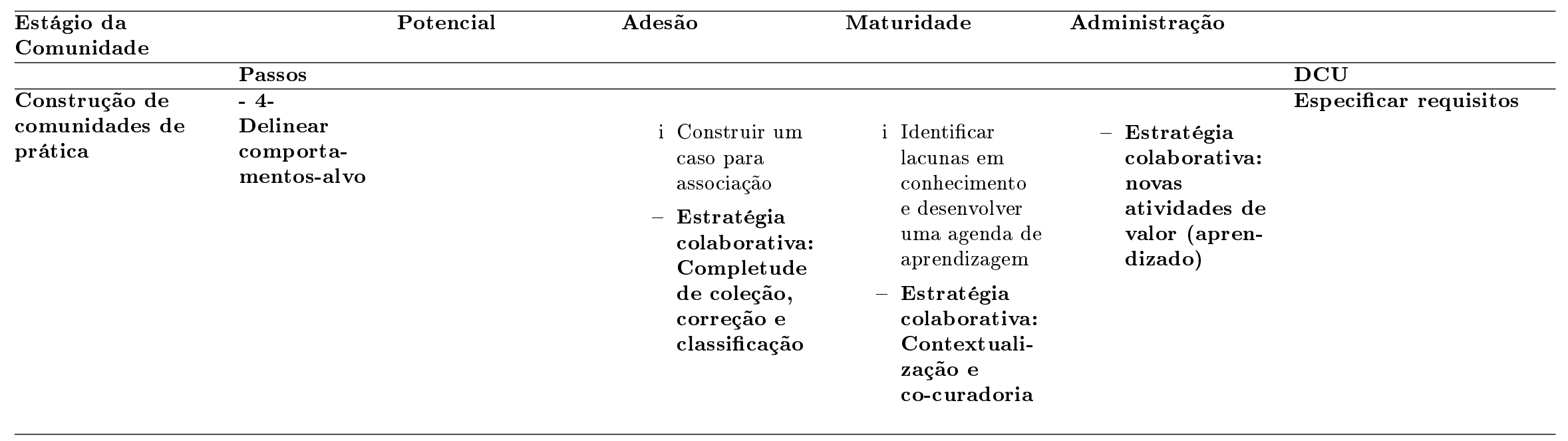


Adicionalmente, a análise estatística aplicada foi descrita no Capítulo 7 e nos artigos que descrevem os experimentos e a pesquisa correlacional durante os ciclos de pesquisa-ação. As análises apresentaram intervalos de confiança e tamanhos de efeito.

A proposta de abordagem buscou responder aos problemas que Seaborn e Fels [SF15] destacaram em seu survey sobre a prática de gamificação: os estudos teóricos não apresentam aplicações na prática que possam demonstrar a teoria proposta em um contexto real; há a necessidade de monitorar a inserção da gamificação durante o processo de desenvolvimento para analisar a evolução e o impacto no comportamento dos usuários, porém não por meio de estudos pontuais, que representam a maior parcela de pesquisas práticas publicadas na área; a maioria dos estudos não apresenta análises estatísticas e não isola o efeito da gamificação, havendo a necessidade de explorar como a gamificação pode ser implementada em domínios específicos.

Por fim, temos a implicação para a prática no contexto de GLAMs. As práticas comumente disponibilizadas para participação de usuários em comunidades de GLAMs foram relacionadas aos comportamentos-alvo de comunidades, sendo esse conjunto o objeto de gamificação. Para rápida recompensa de usuários novatos por suas contribuições, elementos de jogos relacionados a motivação extrínseca podem ser projetados, porém tais elementos precisam evoluir para estarem relacionados a motivação intrínseca que trouxe o usuário para uma comunidade de GLAMs. Para a equipe de desenvolvimento e membros-núcleo, a compreensão de quais práticas são valorosas para a comunidade começa a tornar-se clara a partir do estágio 3 de vida da comunidade.

A principal implicação para a prática é a apresentação de como integrar a gamificação com o monitoramento e a avaliação de engajamento de usuários no contexto de desenvolvimento de uma comunidade online de colaboração aberta, atendendo a teoria da gamificação. 


\section{Capítulo 10}

\section{Síntese e Conclusões}

\subsection{Síntese de resultados}

Construir comunidades de colaboração aberta engajadas, passa pela construção de comunidades de prática sustentáveis e por isso esta é a "espinha dorsal" da proposta de abordagem apresentada nesta tese. Engajamento não nasce da inclusão de elementos de jogos ou de elementos de colaboração em uma comunidade. Engajamento, no contexto de uma comunidade de colaboração aberta, nasce da construção de uma comunidade que olha para as práticas específicas de um domínio e as desenvolve, visando não apenas solucionar os problemas da área, mas também desenvolver os indivíduos que da comunidade participam.

Na construção de comunidades online de colaboração aberta, elementos de interface podem tornar possível a colaboração (elementos de colaboração) ou potencializar o engajamento (elementos de jogos) desde que ambos sejam inseridos em uma comunidade de prática com fundações sólidas para seu desenvolvimento: foco em um domínio e abertura ao novo.

Auto-desenvolvimento é o que mantém membros em uma comunidade, portanto aprendizagem deve ser projetada. Um processo que inicia com dicas compartilhadas para práticas precisa evoluir para um corpo de conhecimento sobre o domínio e este deve ser o "norte" que orienta coordenadores e membros-núcleo na construção de uma comunidade.

As teorias fundacionais de gamificação apresentam a motivação intrínseca do usuário como o meio de engajá-lo de forma sustentável, enquanto a motivação extrínseca atrai a atenção para um domínio. Porém, se a motivação extrínseca não for desenvolvida a ponto de se tornar intrínseca, quando os objetivos externos à tarefa forem alcançados, o indivíduo perderá o interesse. Isso é especialmente verdadeiro em ambientes de contribuição voluntária. A comunidade, portanto, deve sempre responder indicando o valor de contribuir para o desenvolvimento pessoal de cada indivíduo e da própria comunidade.

A tese investigada neste trabalho é a de que para engajar indivíduos em uma comunidade online de colaboração aberta, é preciso motivá-los intrinsecamente, que por sua vez depende de projetar a comunidade para desenvolvimento pessoal de seus participantes e construção de conhecimento. A teoria de gamificação está em conformidade com a motivação intrínseca de usuários, portanto, no campo teórico pode ajudar a promover melhor engajamento. Contudo, não existem abordagens de como projetar a inserção de elementos de jogos baseadas na motivação intrínseca e de modo a avaliar engajamento resultante de forma sistemática. Apresentamos uma proposta de abordagem nesta tese que reúne gamificação, colaboração e avaliação de engajamento sobre uma base sólida: construção de comunidades de prática.

Entendemos que aproveitando o poder da união das diretrizes e passos apresentados por cada uma dessas áreas, torna-se possível projetar a entrada de elementos de jogos com melhor afinidade com o que é proposto pela teoria de gamificação, buscando analisar e promover maior engajamento. 
O estudo longitudinal tornou claro o entendimento de que gamificação pode aumentar engajamento de uma comunidade de colaboração aberta no domínio de uma GLAM sobre arquitetura e urbanismo. Mas, sua sustentabilidade depende de um projeto com conhecimento profundo do domínio da comunidade e do que é valoroso para seus membros.

Nesse contexto, entendendo elementos de jogos como potencializadores de engajamento, eles precisam ser associados a comportamentos-alvo que precisam ser solucionados de acordo com o estágio de vida da comunidade, bem como, de acordo com o seu domínio. Por esse motivo, em estágios iniciais de comunidades, elementos de jogos associados a motivação extrínseca podem funcionar bem para aumentar engajamento, uma vez que no estágio de adesão entregar valor rápido e consequentemente, recompensa rápida a seus participantes, é mais importante do que apresentar conhecimento solidificado. Contudo, o mesmo não é verdade em estágios mais maduros de uma comunidade, quando o real valor do domínio de conhecimento é a prioridade dos membros, mais do que resultados rápidos.

Portanto, o projeto de entrada de elementos de jogos, pode evoluir a partir de elementos associados a motivação extrínseca que caminham para elementos associados a estratégias colaborativas baseadas em motivação intrínseca dos usuários. O próprio ciclo de desenvolvimento da comunidade possibilita aprender o que motiva intrinsecamente seus membros em cada estágio da comunidade.

Definir qual elemento de jogo entrar em cada estágio da comunidade, é limitar a capacidade de criação de projetistas, uma vez que existem inúmeros elementos de jogos. Por exemplo, o livro "Patterns in game design" de Bjork Holopainen [BH04] apresenta mais de 200 padrões de elementos de jogos.

A ideia da proposta de abordagem dessa tese é a de que entendendo melhor como projetar uma comunidade e a motivação intrínseca de seus indivíduos, é possível selecionar elementos de jogos mais adequados ao contexto do que apenas usar os mesmos elementos descritos em boa parte da prática de gamificação: pontos, distintivos e quadro de liderança.

O projeto construído dessa forma possibilita que o usuário aprenda ensinando por meio do compartilhamento de cada novo aprendizado alcançado; é portanto uma troca de perspectivas entre membros de uma comunidade em busca de um mesmo ideal de cultura e conhecimento. Dessa forma, gamificação pode conectar-se com os verdadeiros valores dos indivíduos e não apenas persuadindo-os a realizarem atividades que roubem seu tempo - um bem tão precioso - para algo que de fato não agregue valor à vida deles e aos objetivos da comunidade, como ocorre em algumas práticas de pontificação não fundamentadas na motivação intrínseca.

Vontade é definida como a potência ou faculdade soberana da alma humana, sendo a força propulsora de todas as nossas ações [Den10]. A gamificação da colaboração em comunidades pode ajudar as pessoas a se conectarem com suas verdadeiras potencialidades, porém apenas quando desenvolvida por meio de abordagens apoiadas na motivação intrínseca de indivíduos; uma vez que entrevendo novas perspectivas de alcançar um resultado desejado, podemos nos sentir convidados a alcançá-lo. Portanto, nesta tese duas questões de pesquisa foram formuladas, as quais são definidas abaixo com um sumário de resultados.

\section{- (QPI) Qual o efeito do uso de elementos de jogos no engajamento de usuários em uma comunidade online de colaboração aberta no domínio de GLAMs?}

O uso de elementos de jogos em uma comunidade online de colaboração aberta, no domínio de GLAMs, tem um efeito positivo sobre o engajamento de usuários, desde que o projeto de inserção dos elementos de jogos seja adequado ao nível de habilidade do usuário para o desafio proposto [WH12], esteja associado a motivação extrínseca ou intrínseca do usuário [DR12, DKR99, SDT16], a qual envolve colaboração [FRGL05] em uma prática compartilhada [WMS02b], que esteja de acordo com o estágio de vida da comunidade [WMS02b], bem como, o perfil de usuário [SRP07] e de jogador [Bar96]. 
- (QPII) Como integrar a gamificação com o monitoramento e a avaliação de engajamento de usuários durante o desenvolvimento de uma comunidade online de colaboração aberta?

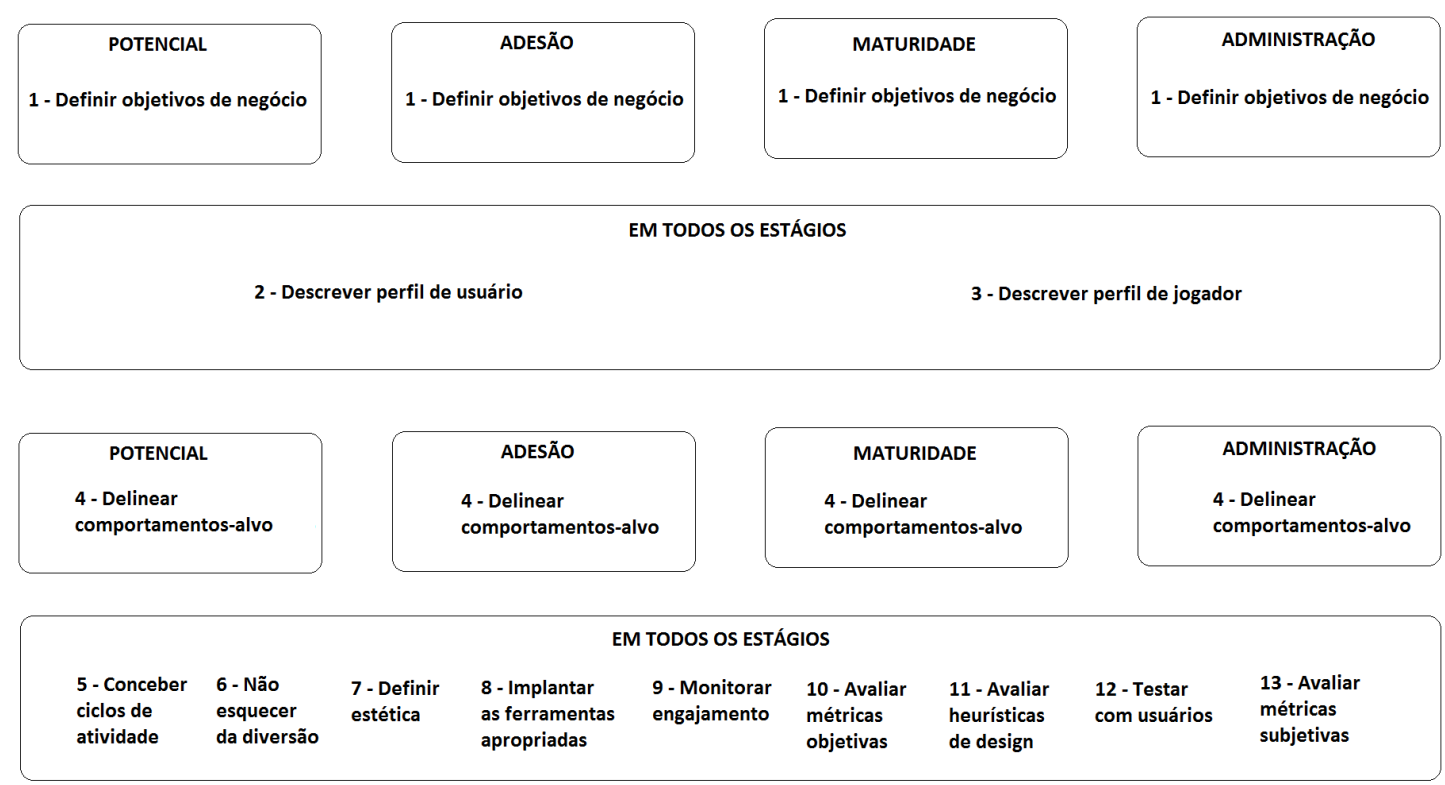

Figura 10.1: Resumo gráfico da proposta de abordagem.

\subsection{Limitações do estudo}

Nesta pesquisa várias limitações do estudo podem ser identificadas. A primeira delas é o fato de que apenas a revisão de dados foi implementada, enquanto que a curadoria digital foi apenas prototipada durante a pesquisa-ação no Arquigrafia. Embora o objetivo fosse o de construir uma proposta de abordagem ao longo dos ciclos, a implementação da estratégia colaborativa completa tornaria possível avaliá-la em seu contexto.

Contudo, de acordo com os ciclos de vida de conteúdo digital, as iniciativas de crowdsourcing completude de coleção, correção e classificação ocorrem antes das iniciativas de contextualização e curadoria, uma vez que as duas últimas são beneficiadas a partir da análises dos resultados das três primeiras. Portanto, a curadoria digital não poderia entrar em produção simultaneamente com a revisão de dados. Adicionalmente, a curadoria digital foi prototipada de acordo com o DCU ágil, no qual o caminho de design está sempre um ciclo à frente do caminho de desenvolvimento, o que tornou possível a validação da equipe para o fluxo de navegação da curadoria.

Adicionalmente, o papel da pesquisadora como uma facilitadora pode ser considerado como um fator de viés nesta pesquisa. Contudo, a pesquisa-ação foi considerada como um método adequado e prático de pesquisa para um ambiente de desenvolvimento de software. Para a pesquisadora, este método forneceu a oportunidade de aprender a partir da experiência e troca de conhecimentos com as equipes de desenvolvimento de software, design, bem como, com clientes e usuários típicos, a quem só temos agradecimentos a fazer.

O contexto em que a pesquisa foi desenvolvida envolveu uma equipe de desenvolvimento e design que foi mudando ao longo dos ciclos, tendo períodos com dois membros até alcançar sete membros. A adaptação e treinamento dos novos participantes desalocava tempo de desenvolvimento. Além disso, a equipe foi formada majoritariamente por alunos que ainda estavam 
aprendendo a programar em ambientes web ou móvel. Contudo, entendemos que esta também é uma força do Arquigrafia, pois possibilitou treinar alunos em desenvolvimento de software, configurando-se em uma formação complementar para todos os alunos envolvidos.

Os componentes de software foram implementados para a proposta da comunidade onde a pesquisa foi aplicada, Arquigrafia, mais do que para ser aplicada dentro do desenvolvimento de software de comunidades online de quaisquer áreas de domínio. Contudo, um esforço de refatoração de código foi feito pela equipe de desenvolvimento de modo a separar componentes específicos do contexto do Arquigrafia dos componentes comuns a quaisquer GLAMs, de modo a facilitar uso futuro.

\subsection{Implicações para estudos futuros}

Para entender os efeitos de uma intervenção em um sistema, é necessário avaliar quais ações os usuários acessaram e como elas se correlacionam com as métricas de engajamento. Os efeitos de um elemento de interação do usuário podem ser comparados com os efeitos de outro. É necessário comparar efeitos obtidos durante o acesso a um determinado elemento e a um conjunto de elementos para avaliar se o elemento sozinho ou a interação de um conjunto de elementos produziu maior engajamento.

Ao classificar os elementos de interação do usuário como elementos de jogos ou colaborativos, pretendemos avaliar, respectivamente, o efeito da gamificação ou colaboração no envolvimento do usuário. Em estudos futuros, a análise das ações do usuário podem ser decompostas, por exemplo, correlacionando características da colaboração - ou elementos de interação do usuário relacionados a comunicação, coordenação e cooperação - e cada dimensão do engajamento do usuário. O mesmo comportamento pode ser executado para elementos de jogos e elementos funcionais, isto é, decompondo-os em características específicas de cada elemento de interação. O benefício dessa decomposição é o isolamento, ainda mais refinado, dos efeitos de uma intervenção no sistema.

A frustração é uma função não só da interação atual, mas também de um estado prévio de frustração [FA09]. Esse comportamento pode implicar que os usuários que experimentaram frustração em um sistema durante o acesso anterior são propensos a uma experiência frustrante em novos acessos. Estudos futuros podem analisar o correlação entre cada ação do usuário e cada dimensão de engajamento, diferenciando ações de novatos e usuários existentes. Para os últimos, pesquisadores podem comparar ações do acesso anterior e as do acesso atual para entender melhor se engajamento ou frustração foi vivenciada pelos usuários. A partir desses resultados, os pesquisadores podem projetar apoio adequado de acordo com o perfil de usuários: desde usuários novatos ou pré-existentes, a grupos determinados pelas próprias análises de ações recorrentes dos usuários.

Adicionalmente, esta pesquisa tornou clara a importância da gestão de conhecimento na construção de comunidades online de colaboração aberta. Por esse motivo, estudos sobre esta área, especialmente no contexto de comunidades online de colaboração aberta no domínio de uma prática compartilhada, como de GLAMS, podem ajudar membros-núcleo e coordenadores de comunidade a organizar o processo de coleta, armazenamento e síntese de significados a partir de conhecimento gerado pela comunidade. Por exemplo, estudos podem focar em como e quais tipos de ferramentas podem suportar síntese de conhecimento a partir da contribuição individual à integração no corpo de conhecimento. Para esse fim, protocolos para gestão de conhecimento precisam ser desenvolvidos de acordo com o contexto de cada comunidade, tendo a dimensão da prática compartilhada bem definida. Por fim, a proposta de abordagem desta pesquisa pode ser aplicada e avaliada em diferentes contextos para construção de comunidades online de colaboração aberta por meio de gamificação. 


\section{Referências Bibliográficas}

[ABM07] David Avison, Richard Baskerville e Michael D Myers. The structure of power in action research projects. Em Information Systems Action Research, páginas 19-41. Springer, 2007. 37

[AH00] Arthur Armstrong e John Hagel. The real value of online communities. Knowledge and communities, 74(3):85-95, 2000. 10

[AJF06] Peyman Akhavan, Mostafa Jafari e Mohammad Fathian. Critical success factors of knowledge management systems: a multi-case analysis. European business review, 18(2):97-113, 2006. 153

[AKLP11] Simon Attfield, Gabriella Kazai, Mounia Lalmas e Benjamin Piwowarski. Towards a science of user engagement (position paper). Em WSDM Workshop on User Modelling for Web Applications, 2011. 14, 16

[ALV10] D.M.G. et al. ALVES. Em busca da sustentabilidade educadora ambientalista. Ambientalmente Sustentable, Coruña, 5(9-10):7-35, January 2010. xv, 153, 155

[AMBI16] Fernando Andrade, Leonardo Marques, Ig Ibert Bittencourt e Seiji Isotani. Qpj-br: Questionário para identificação de perfis de jogadores para o portuguêsbrasileiro. Em Brazilian Symposium on Computers in Education (Simpósio Brasileiro de Informática na Educação-SBIE), volume 27, página 637, 2016. $31,138,152$

[And18] Fernando Roberto Hebeler Andrade. Gamificação personalizada baseada no perfil do jogador. Tese de Doutorado, Universidade de São Paulo, 2018. 31, 32

[Aul82] Arvid Aulin. The cybernetic laws of social progress, 1982. 38

[Bar96] Richard Bartle. Hearts, clubs, diamonds, spades: Players who suit muds. Journal of MUD research, 1(1):19, 1996. xi, 19, 74, 138, 152, 156, 166

[Bar04] Richard A Bartle. Designing virtual worlds. New Riders, 2004. 19, 30

[BC04] Emily Brown e Paul Cairns. A grounded investigation of game immersion. Em CHI'04 extended abstracts on Human factors in computing systems, páginas 1297-1300. ACM, 2004. 14, 16

[BCMSF12] Sussy Bayona, Jose A Calvo-Manzano e Tomás San Feliu. Critical success factors in software process improvement: A systematic review. Em International Conference on Software Process Improvement and Capability Determination, páginas 1-12. Springer, 2012. 153

[Bea70] Monroe C Beardsley. The aesthetic point of view. Metaphilosophy, 1(1):39-58, 1970. 15 
[Ben84] Izak Benbasat. An analysis of research methodologies. The information systems research challenge, páginas 47-85, 1984. 38

[Ber17] Guy Berthiaume. Collaboration between galleries, libraries, archives and museums, 2017. Available on-line at: https://www.canada.ca/en/libraryarchives/news/2017/10/collaboration_betweengallerieslibrariesarchivesandmuseums.html. 3

[BH04] Staffan Bjork e Jussi Holopainen. Patterns in game design (game development series). 2004. 166

[BML09] Moira Burke, Cameron Marlow e Thomas Lento. Feed me: motivating newcomer contribution in social network sites. Em Proceedings of the SIGCHI conference on human factors in computing systems, páginas 945-954. ACM, 2009. 1

[BMR17] Ana Paula O Bertholdo, Claudia de O Melo e Artur S Rozestraten. Improving engagement metrics in an open collaboration community through notification: an online field experiment. Em International Conference on Social Computing and Social Media, páginas 103-116. Springer, 2017. 69

$\left[\mathrm{BMR}^{+} 18\right]$ Ana Paula O Bertholdo, Claudia de O Melo, Artur S Rozestraten, Marco A Gerosa e Heather L O'Brien. User engagement in an open collaboration community after the insertion of a game design element: an online field experiment. Em AMCIS 2018 Proceedings - Virtual Communities and Collaboration (http://aisel.aisnet.org/amcis2018/VirtualCC/Presentations/11/), 2018. 17

[BNCP12] Sanat Kumar Bista, Surya Nepal, Nathalie Colineau e Cecile Paris. Using gamification in an online community. Em Collaborative Computing: Networking, Applications and Worksharing (CollaborateCom), 2012 8th International Conference on, páginas 611-618. IEEE, 2012. 1, 10, 30, 32

[BNPC14] Sanat Kumar Bista, Surya Nepal, Cécile Paris e Nathalie Colineau. Gamification for online communities: A case study for delivering government services. international Journal of Cooperative information Systems, 23(02):1441002, 2014. 30,32

[Bog11] Ian Bogost. Persuasive games: exploitationware. Gamasutra, May, 3, 2011. 1, 2

[Bor17] Simone de Sousa Borges. Gamification design in computer-supported collaborative learning: towards an approach for tailoring influence principles to player roles. Tese de Doutorado, Universidade de São Paulo, 2017. 1

[Bra08] Daren C Brabham. Crowdsourcing as a model for problem solving: An introduction and cases. Convergence, 14(1):75-90, 2008. 11

[Bro10] Emily Brown. The life and tools of a games designer. Em Evaluating User Experience in Games, páginas 73-87. Springer, 2010. 17

$\left[\mathrm{BTB}^{+} 14\right]$ Magdalena Boork, Maria Thomtén, Magnus Brolin, Matthijs Uyterlinde, Koen Straver, Carolien Kraan, Kerstin Kleine-Hegermann, Erik Laes, P Valkering e Simone Maggiore. Key success factors and barriers to end-user engagement in smart grid projects. Em BEHAVE2014-Behaviour and Energy Efficiency Conference, 2014. 153 
[Bur05] Winslow Burleson. Developing creativity, motivation, and self-actualization with learning systems. International Journal of Human-Computer Studies, 63(4):436-451, 2005. 39, 71

[Bus14] Patricia L Busk. Causal-comparative study. Wiley StatsRef: Statistics Reference Online, páginas 1-2, 2014. 43

[BVD15] Jailson Brito, Vaninha Vieira e Adolfo Duran. Towards a framework for gamification design on crowdsourcing systems: The game approach. Em Information Technology-New Generations (ITNG), 2015 12th International Conference on, páginas 445-450. IEEE, 2015. 1, 2

[BWH96] Richard L Baskerville e A Trevor Wood-Harper. A critical perspective on action research as a method for information systems research. Journal of information Technology, 11(3):235-246, 1996. 37

[Cal11] Gordon Calleja. In-game: From immersion to incorporation. MIT Press, 2011. 17,148

[CC92] Mihaly Csikszentmihalyi e Isabella Selega Csikszentmihalyi. Optimal experience: Psychological studies of flow in consciousness. Cambridge university press, 1992. 14, 17, 18

[CC08] Tsun Chow e Dac-Buu Cao. A survey study of critical success factors in agile software projects. Journal of systems and software, 81(6):961-971, 2008. 153

[CGCC15] Eduardo H Calvillo-Gámez, Paul Cairns e Anna L Cox. Assessing the core elements of the gaming experience. Em Game user experience evaluation, páginas 37-62. Springer, 2015. 20

[Cha97] Peter McFaul Chapman. Models of engagement: Intrinsically motivated interaction with multimedia learning software. Tese de Doutorado, University of Waterloo, 1997. 14

[Cha98] Carol Morgan Charles. Introduction to educational research. ERIC, 1998. 43

[Che07] Jenova Chen. Flow in games (and everything else). Communications of the $A C M, 50(4): 31-34,2007.18$

[Cle14] Juliana Augusto Clementi. Diretrizes motivacionais para comunidades de prática baseadas na gamificaaão. Tese de Doutorado, Universidade Federal de Santa Catarina - (Master in Engineering), 2014. 30, 32

[CM01] Martin V Covington e Kimberly J Müeller. Intrinsic versus extrinsic motivation: An approach/avoidance reformulation. Educational Psychology Review, 13(2):157-176, 2001. 11

$\left[\mathrm{CNI}^{+}\right.$03] John M. Carroll, Dennis C. Neale, Philip L. Isenhour, Mary Beth Rosson e D.Scott McCrickard. Notification and awareness: synchronizing task-oriented collaborative activity. International Journal of Human-Computer Studies, 58(5):605 - 632, 2003. Notification User Interfaces. 39, 71

[Coh88] Jacob Cohen. Statistical power analysis for the behavioral sciences 2nd edn, 1988. 110

[Cou03] Alec Couros. Communities of practice: A literature review. Available on: http://www. tcd. ie/CAPSL/academic_practice/pdfdocs/Couro s_2003. pdf \{10. 5. 2008\}, 2003. 11 
[Cre02] John W Creswell. Educational research: Planning, conducting, and evaluating quantitative. Prentice Hall Upper Saddle River, NJ, 2002. 4, 39, 41, 42, 43, 44

[Cre13] John W Creswell. Research design: Qualitative, quantitative, and mixed methods approaches. Sage publications, 2013. 33

[DBP16] Juscelino Dourado, Fernanda Belizário e Alciana Paulino. Escolas sustentáveis. Oficina de Textos, 2016. xv, 153, 155

[DDKN11] Sebastian Deterding, Dan Dixon, Rilla Khaled e Lennart Nacke. From game design elements to gamefulness: defining gamification. Em Proceedings of the 15th international academic MindTrek conference: Envisioning future media environments, páginas 9-15. ACM, 2011. xi, xiii, 1, 20, 21, 25, 90

[Den10] León Denis. O problema do ser, do destino e da dor. FEB Editora, 2010. 166

[Den17] Norman K Denzin. The research act: A theoretical introduction to sociological methods. Routledge, 2017. 36

[Det12] Sebastian Deterding. Gamification: designing for motivation. interactions, 19(4):14-17, 2012. 2

[Det14] Sebastian Deterding. Eudaimonic design, or: Six invitations to rethink gamification. Rethinking Gamification. Edited by Mathias Fuchs, Sonia Fizek, Paolo Ruffino, Niklas Schrape., 2014. 1, 2

[Dia08] Paulo Dias. Da e-moderação à mediação colaborativa nas comunidades de aprendizagem. Educação, Formação É Tecnologias, páginas 4-10, 2008. 77

[Dic93] B. Dick. You want to do an action research thesis?, 1993. Available online at: http://www.scu.edu.au/schools/gcm/ar/art/arthesis.html. Acessed on: November 2011. $4,6,33$

[DKR99] Edward L Deci, Richard Koestner e Richard M Ryan. A meta-analytic review of experiments examining the effects of extrinsic rewards on intrinsic motivation. Psychological bulletin, 125(6):627, 1999. 2, 5, 12, 71, 74, 133, 138, 154, 156, 166

[DMK04] Robert Davison, Maris G Martinsons e Ned Kock. Principles of canonical action research. Information systems journal, 14(1):65-86, 2004. 4, 35, 36

[DOG11] Lucas Santos De Oliveira e Marco Aurélio Gerosa. Collaborative features in content sharing web 2.0 social networks: A domain engineering based on the 3c collaboration model. Em International Conference on Collaboration and Technology, páginas 142-157. Springer, 2011. 108

[dPHeANI14] Instituto do Patrimônio Histórico e Artístico Nacional (IPHAN). Patrimônio cultural, 2014. Available on-line at: http://portal.iphan.gov.br/pagina/detalhes/218 (Accessed on: August, 2018.). 11

[DR75] Edward L Deci e Richard M Ryan. Intrinsic motivation. Wiley Online Library, 1975. 13

[DR85] Edward L Deci e RM Ryan. Intrinsic motivation and self-determination in human behavior. New York and London: Plenum, 1985. 12 
[DR12] Edward L Deci e Richard M Ryan. Motivation, personality, and development within embedded social contexts: An overview of self-determination theory. The Oxford handbook of human motivation, páginas 85-107, 2012. 2, 5, 11, 12, 71, $74,133,138,154,156,166$

[dRSndjd85] Diário da República Série $\mathrm{nA}^{\circ} \quad 153 \quad 6 \quad$ de julho de 1985. Lei portuguesa do patrimônio, $1985 . \quad$ Available on-line at: https://dre.pt/application/dir/pdf1sdip/1985/07/15300/18651874.PDF (Accessed on: August, 2018.). 11

[DS16] Ali Darejeh e Siti Salwah Salim. Gamification solutions to enhance software user engagementâa systematic review. International Journal of HumanComputer Interaction, 32(8):613-642, 2016. 27

[EK17] Ashlee Edwards e Diane Kelly. Engaged or frustrated?: Disambiguating emotional state in search. Em Proceedings of the 40th International ACM SIGIR Conference on Research and Development in Information Retrieval, páginas 125-134. ACM, 2017. 98, 128

[Ens14] Emma Enström. On difficult topics in theoretical computer science education. Tese de Doutorado, KTH Royal Institute of Technology, 2014. 4

[FA09] Henry Feild e James Allan. Modeling searcher frustration. Proceedings from HCIR, 2009. 98, 128, 168

[FIL08] Denise Del Re FILIPPO. Suporte à coordenação em sistemas colaborativos: uma pesquisa-ação com aprendizes e mediadores atuando em fóruns de discussão de um curso a distância. 281f. Tese de Doutorado, Tese (Doutorado em Informática)-Pontifícia Universidade Católica do Rio de Janeiro, Rio de Janeiro, 2008. 4, 6, 33, 34, 35, 36, 149

[FL13] Andrea Forte e Cliff Lampe. Defining, Understanding, and Supporting Open Collaboration: Lessons From the Literature. AMERICAN BEHAVIORAL SCIENTIST, 57(5, SI):535-547, MAY 2013. 1, 8

[FRG $\left.{ }^{+} 08\right]$ Hugo Fuks, Alberto Raposo, Marco A Gerosa et al. The 3c collaboration model. Em Encyclopedia of E-collaboration, páginas 637-644. IGI Global, 2008. 90

[FRG $\left.{ }^{+} 11\right]$ Hugo Fuks, AB Raposo, MA Gerosa, M Pimentel, D Filippo e CJP de Lucena. Teorias e modelos de colaboração. Sistemas colaborativos, páginas 16-33, 2011. 7

[FRGL05] Hugo Fuks, Alberto B Raposo, Marco A Gerosa e Carlos JP Lucena. Applying the $3 \mathrm{c}$ model to groupware development. International Journal of Cooperative Information Systems, 14(02n03):299-328, 2005. xi, 5, 7, 8, 71, 133, 152, 155, 156,166

[FWH11] Jack R Fraenkel, Norman E Wallen e Helen H Hyun. How to design and evaluate research in education. New York: McGraw-Hill Humanities/Social Sciences/Languages, 2011. 43

[GE92] Klaus G Grunert e Charlotte Ellegaard. The concept of key success factors: theory and method. MAPP, 1992. 153

[GFL03] Marco Aurélio Gerosa, Hugo Fuks e Carlos Lucena. Analysis and design of awareness elements in collaborative digital environments: A case study in the aulanet learning environment. Journal of Interactive Learning Research, 14(3):315, 2003. $7,72,90$ 
[GMA06] Lorraine R Gay, Geoffrey E Mills e Peter Airasian. Educational research: Competencies for analysis and applications, 2006. 43, 101

[GO14] Cynthia Grant e Azadeh Osanloo. Understanding, selecting, and integrating a theoretical framework in dissertation research: Creating the blueprint for your âhouseâ. Administrative Issues Journal, 4(2):4, 2014. 133

[GTS13] Stephen M Garcia, Avishalom Tor e Tyrone M Schiff. The psychology of competition: A social comparison perspective. Perspectives on Psychological Science, 8(6):634-650, 2013. 28

[Ham17] Juho Hamari. Do badges increase user activity? a field experiment on the effects of gamification. Computers in human behavior, 71:469-478, 2017. 97

[Har17] Stevan Harnad. To cognize is to categorize: Cognition is categorization. Em Handbook of Categorization in Cognitive Science (Second Edition), páginas 2154. Elsevier, 2017. 89

[Has03] Marc Hassenzahl. The thing and i: understanding the relationship between user and product. Em Funology, páginas 31-42. Springer, 2003. 18

[Hip05] E. v. Hippel. Democratizing Innovation. The MIT Press, Cambridge, Massachusetts, 2005. 10

[HK04] Margaret Hedstrom e John Leslie King. On the lam: Library, archive, and museum collections in the creation and maintenance of knowledge communities. Mapping innovation: Six depth studies, 2004. 4

[HKS14] Juho Hamari, Jonna Koivisto e Harri Sarsa. Does gamification work?-a literature review of empirical studies on gamification. Em 2014 $4^{\text {rth }}$ Hawaii International Conference on System Sciences, páginas 3025-3034. IEEE, 2014. 26

[HLZ04] Robin Hunicke, Marc LeBlanc e Robert Zubek. Mda: A formal approach to game design and game research. Em Proceedings of the AAAI Workshop on Challenges in Game AI, volume 4, página 1722, 2004. 20

[Huv08] Isto Huvila. Participatory archive: towards decentralised curation, radical user orientation, and broader contextualisation of records management. Archival Science, 8(1):15-36, 2008. 1

[HWJ03] Dennis E Hinkle, William Wiersma e Stephen G Jurs. Applied statistics for the behavioral sciences, volume 663. Houghton Mifflin College Division, 2003. 102

$\left[\mathrm{ICM}^{+} 15\right]$ Ioanna Iacovides, Anna L Cox, Patrick McAndrew, James Aczel e Eileen Scanlon. Game-play breakdowns and breakthroughs: exploring the relationship between action, understanding, and involvement. Human-computer interaction, 30(3-4):202-231, 2015. 17, 97, 148, 152

[IMN04] Jakob H Iversen, Lars Mathiassen e Peter Axel Nielsen. Managing risk in software process improvement: an action research approach. Mis Quarterly, páginas 395-433, 2004. 37

[IPdK08] Wijnand IJsselsteijn, Karolien Poels e Yvonne AW de Kort. The game experience questionnaire: Development of a self-report measure to assess player experiences of digital games. TU Eindhoven, Eindhoven, The Netherlands, 2008. 18 
[Jär12] Pertti Järvinen. On boundaries between field experiment, action research and design research. University of Tampere, School of Information Sciences, Reports in Information Sciences, 14, 2012. 38, 152

[JE02] Susan A Jackson e Robert C Eklund. Assessing flow in physical activity: The flow state scale-2 and dispositional flow scale-2. Journal of Sport and Exercise Psychology, 24(2):133-150, 2002. 31

[Kap12] Karl M Kapp. The gamification of learning and instruction: game-based methods and strategies for training and education. John Wiley \& Sons, 2012. 1,3

$\left[\mathrm{KDF}^{+}{ }^{12}\right]$ Ron Kohavi, Alex Deng, Brian Frasca, Roger Longbotham, Toby Walker e Ya Xu. Trustworthy online controlled experiments: Five puzzling outcomes explained. Em Proceedings of the 18th ACM SIGKDD international conference on Knowledge discovery and data mining, páginas 786-794. ACM, 2012. 38

$\left[\mathrm{KDF}^{+} 13\right]$ Ron Kohavi, Alex Deng, Brian Frasca, Toby Walker, Ya Xu e Nils Pohlmann. Online controlled experiments at large scale. Em Proceedings of the 19th ACM SIGKDD international conference on Knowledge discovery and data mining, páginas 1168-1176. ACM, 2013. 38, 152

[Kim00] Amy Jo Kim. Community building on the web: Secret strategies for successful online communities. Addison-Wesley Longman Publishing Co., Inc., 2000. 76, $77,80,85,86,142,152,161$

[KK18] Jussi Kasurinen e Antti Knutas. Publication trends in gamification: a systematic mapping study. Computer Science Review, 27:33-44, 2018. 29

[KMS97] N. F. Kock, R. J. McQueen e J. L. Scott. Can action research be made more rigorous in a positivist sense? the contribution of an iterative approach. Journal of Systems and Information Technology, 1(1):1-32, 1997. 4, 6, 33

[Koc04] Ned Kock. The three threats of action research: a discussion of methodological antidotes in the context of an information systems study. Decision support systems, 37(2):265-286, 2004. 35

[KR11] Robert E Kraut e Paul Resnick. Encouraging contribution to online communities. Building successful online communities: Evidence-based social design, páginas $21-76,2011.1,10$

[KW04] G Keppel e TD Wickens. Effect size, power, and sample size. Design and Analysis. A Researcherâs Handbook, ed, 4:159-801, 2004. 110

[Laz08] Nicole Lazzaro. The four fun keys. Game Usability: Advancing the Player Experience, páginas 315-344, 2008. 74, 75, 138, 155

[LB84] Joel K Leidecker e Albert V Bruno. Identifying and using critical success factors. Long range planning, 17(1):23-32, 1984. 153

[LGE08] Aleck Lin, Shirley Gregor e Michael Ewing. Developing a scale to measure the enjoyment of web experiences. Journal of Interactive Marketing, 22(4):40-57, 2008. 16

[Lit05] Jordan Litman. Curiosity and the pleasures of learning: Wanting and liking new information. Cognition \& emotion, 19(6):793-814, 2005. 17 
[LKB $\left.{ }^{+} 17\right]$ Jemma Looyestyn, Jocelyn Kernot, Kobie Boshoff, Jillian Ryan, Sarah Edney e Carol Maher. Does gamification increase engagement with online programs? a systematic review. PloS one, 12(3):e0173403, 2017. 2, 27, 28, 40

[LL90] Edwin A Locke e Gary P Latham. A theory of goal setting $\& 3$ task performance. Prentice-Hall, Inc, 1990. 12

[LL02] Edwin A Locke e Gary P Latham. Building a practically useful theory of goal setting and task motivation: A 35-year odyssey. American psychologist, $57(9): 705,2002.12$

[LLYTD12] Janette Lehmann, Mounia Lalmas, Elad Yom-Tov e Georges Dupret. Models of user engagement. Em International Conference on User Modeling, Adaptation, and Personalization, páginas 164-175. Springer, 2012. 14, 17

[LMK01] Yi-Guang Lin, Wilbert J McKeachie e Yung Che Kim. College student intrinsic and/or extrinsic motivation and learning. Learning and individual differences, 13(3):251-258, 2001. 11

[LSN07] R David Lankes, Joanne Silverstein e Scott Nicholson. Participatory networks: the library as conversation. Information technology and libraries, 26(4):17, 2007. 1

[LW91] Jean Lave e Etienne Wenger. Situated learning: Legitimate peripheral participation. Cambridge university press, 1991. 9

[Mal80] Thomas W Malone. What makes things fun to learn? heuristics for designing instructional computer games. Em Proceedings of the 3rd ACM SIGSMALL symposium and the first SIGPC symposium on Small systems, páginas 162-169. ACM, 1980. 17

[Mar13] Diego Ribeiro Marins. Um processo de gamificação baseado na teoria da autodeterminação. Tese de Doutorado, Dissertação de Mestrado. Universidade Federal do Rio de Janeiro. Rio de Janeiro: UFRJ, 2013. 29, 32

[Mas43] Abraham Harold Maslow. A theory of human motivation. Psychological review, 50(4):370, 1943. 12

[Mel13] Claudia de Oliveira Melo. Productivity of agile teams: an empirical evaluation of factors and monitoring processes. Tese de Doutorado, Universidade de São Paulo, 2013. 4, 33, 36

$\left[\mathrm{MFF}^{+} 70\right]$ Abraham Harold Maslow, Robert Frager, James Fadiman, Cynthia McReynolds e Ruth Cox. Motivation and personality, volume 2. Harper \& Row New York, 1970. 12

[MM01] J. Mckay e P. Marshall. The dual imperatives of action research. Information Technology $\& 3$ People, v.14, n.1, páginas 46-59, 2001. 33

[MNMM99] Ronald C Martella, J Ronald Nelson e Nancy E Marchand-Martella. Research methods: Learning to become a critical research consumer. Allyn \& Bacon, 1999. 43

$\left[\mathrm{MOC}^{+} 11\right]$ Kevin McNally, Michael P OâMahony, Maurice Coyle, Peter Briggs e Barry Smyth. A case study of collaboration and reputation in social web search. $A C M$ Transactions on Intelligent Systems and Technology (TIST), 3(1):4, 2011. 106 
[MP02] David R Millen e John F Patterson. Stimulating social engagement in a community network. Em Proceedings of the 2002 ACM conference on Computer supported cooperative work, páginas 306-313. ACM, 2002. 39, 71

[MP18] Daniel Muise e Jennifer Pan. Online field experiments. Asian Journal of Communication, páginas 1-18, 2018. 149

[MR05] Tom Manly e Ian H Robertson. The sustained attention to response test (sart). Em Neurobiology of attention, páginas 337-338. Elsevier, 2005. 97

[MRGAM15] Alberto Mora, Daniel Riera, Carina Gonzalez e Joan Arnedo-Moreno. A literature review of gamification design frameworks. Em 2015 7th International Conference on Games and Virtual Worlds for Serious Applications (VS-Games), páginas 1-8. IEEE, 2015. 21, 25

[MRGH99] Tom Manly, Ian H Robertson, Maria Galloway e Kari Hawkins. The absent mind:: further investigations of sustained attention to response. Neuropsychologia, 37(6):661-670, 1999. 90

[Muk12] Mavuto M Mukaka. A guide to appropriate use of correlation coefficient in medical research. Malawi Medical Journal, 24(3):69-71, 2012. xiii, 44, 102

[MWHA17] B Morschheuser, K Werder, J Hamari e J Abe. How to gamify? a method for designing gamification. Em Proceedings of the 50th Annual Hawaii International Conference on System Sciences (HICSS), Hawaii, USA, January 4-7, 2017. 30,32

[MZGAM15] Alberto Mora, Panagiotis Zaharias, Carina González e Joan Arnedo-Moreno. Fraggle: a framework for agile gamification of learning experiences. Em International Conference on Games and Learning Alliance, páginas 530-539. Springer, 2015. 30,32

[NC01] Jeanne Nakamura e Mihaly Csikszentmihalyi. The Concept of Flow. Oxford University Press, Oxford, United Kingdom, 2001. 18

[NC14] Jeanne Nakamura e Mihaly Csikszentmihalyi. The concept of flow. Em Flow and the foundations of positive psychology, páginas 239-263. Springer, 2014. 2

[Net18] Collaborative Leaders Network. Critical success factors for community engagement, 2018. Available on-line with Attribution 3.0 Unported (CC BY 3.0) at: https://collaborativeleadersnetwork.org/strategy-tools/criticalsuccess-factors-for-community-engagement/ (Accessed on: October, 2018.). xv, 153,154

[Nic84] John G Nicholls. Achievement motivation: Conceptions of ability, subjective experience, task choice, and performance. Psychological review, 91(3):328, 1984. 13

[Nic12] Scott Nicholson. A user-centered theoretical framework for meaningful gamification. Games+ Learning + Society, 8(1):223-230, 2012. 29, 32

[NR07] W Lawrence Neuman e Karen Robson. Basics of social research: Qualitative and quantitative approaches. Power, 48:48, 2007. 33

[NTRV13] Fiona Fui-Hoon Nah, Venkata Rajasekhar Telaprolu, Shashank Rallapalli e Pavani Rallapalli Venkata. Gamification of education using computer games. Em International Conference on Human Interface and the Management of Information, páginas 99-107. Springer, 2013. 29, 32 
[OA11] Johan Oomen e Lora Aroyo. Crowdsourcing in the cultural heritage domain: opportunities and challenges. Em Proceedings of the 5th International Conference on Communities and Technologies, páginas 138-149. ACM, 2011. xii, xiv, 1, 144, 145

[O'B16] Heather O'Brien. Theoretical perspectives on user engagement. Em Why Engagement Matters, páginas 1-26. Springer, 2016. 1, 88

[OCH18] Heather OâBrien, Paul Cairns e Mark Hall. A practical approach to measuring user engagement with the refined user engagement scale (ues) and new ues short form. International Journal of Human-Computer Studies, 2018. 88, 89, 152

[OL13] Heather L O'Brien e Mahria Lebow. Mixed-methods approach to measuring user experience in online news interactions. Journal of the Association for Information Science and Technology, 64(8):1543-1556, 2013. 16, 98, 110, 128

[OP04] Chitu Okoli e Suzanne D Pawlowski. The delphi method as a research tool: an example, design considerations and applications. Information 83 management, 42(1):15-29, 2004. 30

[OT08] Heather L O'Brien e Elaine G Toms. What is user engagement? a conceptual framework for defining user engagement with technology. Journal of the American Society for Information Science and Technology, 59(6):938-955, 2008. xi, $1,14,15,43,75,88,97$

[OT10] Heather L O'Brien e Elaine G Toms. The development and evaluation of a survey to measure user engagement. Journal of the American Society for Information Science and Technology, 61(1):50-69, 2010. 16, 74, 75, 87, 88

[Pof16] Marcio Poffo. Utilização da gamificação para motivar a aprendizagem: um estudo de caso em engenharia de software. Tese de Doutorado, Dissertação de Mestrado. Universidade do Vale do Itajai, 2016. 30, 32

[Pre00] Jenny Preece. Online communities: Designing usability and supporting socialbilty. John Wiley \& Sons, Inc., 2000. 10

[RD00a] Richard M Ryan e Edward L Deci. Intrinsic and extrinsic motivations: Classic definitions and new directions. Contemporary educational psychology, 25(1):5467, 2000. xi, 11, 12, 13, 14, 16, 30, 71, 74, 76, 86, 93, 138, 142, 152, 161

[RD00b] Richard M Ryan e Edward L Deci. Self-determination theory and the facilitation of intrinsic motivation, social development, and well-being. American psychologist, 55(1):68, 2000. 12

[RGK90] Jane Radatz, Anne Geraci e Freny Katki. Ieee standard glossary of software engineering terminology. IEEE Std, 610121990(121990):3, 1990. 90

[Rid16] Mia Ridge. Making digital history: The impact of digitality on public participation and scholarly practices in historical research. Tese de Doutorado, Open University, 2016. 144

$\left[\mathrm{RMA}^{+}\right.$97] Ian H Robertson, Tom Manly, Jackie Andrade, Bart T Baddeley e Jenny Yiend. Oops!': performance correlates of everyday attentional failures in traumatic brain injured and normal subjects. Neuropsychologia, 35(6):747-758, 1997. 90, $97,114,128,148$

[Rob10] Margaret Robertson. Can’t play, won’t play. Hide E3 Seek, 6:2010, 2010. 1, 3 
[RP04] Margaret Riel e Linda Polin. Learning communities: Common ground and critical differences in designing technical support. Designing for virtual communities in the service of learning, páginas 16-52, 2004. 9

[Rya95] Richard M Ryan. Psychological needs and the facilitation of integrative processes. Journal of personality, 63(3):397-427, 1995. 13

[Sal06] Outi Salo. Enabling software process improvement in agile software development teams and organisations. VTT publications, 618, 2006. 153

[SARV12] Jorge Simões, Ademar Aguiar, Rebeca Redondo e Ana Vilas. Aplicação de elementos de jogos numa plataforma de aprendizagem social. Em II Congresso Internacional TIC e Educação. Anais do II Congresso Internacional TIC e Educação, Portugal, 2012. 31, 32

[Sch14] Jesse Schell. The Art of Game Design: A book of lenses. CRC Press, 2014. 18, $26,74,75,138,152,154,155$

$\left[\mathrm{SDH}^{+}\right.$04] Jonathan Smallwood, John B Davies, Derek Heim, Frances Finnigan, Megan Sudberry, Rory O'Connor e Marc Obonsawin. Subjective experience and the attentional lapse: Task engagement and disengagement during sustained attention. Consciousness and cognition, 13(4):657-690, 2004. 90, 97, 114, 128, 148, 152

[SDT16] SDT. Self determination theory., 2016. Available on-line at: http://selfdeterminationtheory.org/theory Acessed on: 29 August 2016. $2,5,12,25,71,74,133,138,154,155,156,166$

[SE78] Gerald I Susman e Roger D Evered. An assessment of the scientific merits of action research. Administrative science quarterly, páginas 582-603, 1978. 4, 34

[SE91] Antonio C Siochi e Roger W Ehrich. Computer analysis of user interfaces based on repetition in transcripts of user sessions. ACM Transactions on Information Systems (TOIS), 9(4):309-335, 1991. 90, 148

[Sea99] Carolyn B. Seaman. Qualitative methods in empirical studies of software engineering. IEEE Transactions on software engineering, 25(4):557-572, 1999. 33

[SF15] Katie Seaborn e Deborah I Fels. Gamification in theory and action: A survey. International Journal of Human-Computer Studies, 74:14-31, 2015. 1, 2, 17, $20,21,25,26,27,58,163$

[SHMM17] Michael Sailer, Jan Ulrich Hense, Sarah Katharina Mayr e Heinz Mandl. How gamification motivates: An experimental study of the effects of specific game design elements on psychological need satisfaction. Computers in Human Behavior, 69:371-380, 2017. 29

[Sim15] J Simões. Using Gamification to Improve Participation in Social Learning. Tese de Doutorado, University of Vigo, 2015. 31, 32

[Sis77] Henry L Sisk. Management and organization. South-Western Publishing Company Cincinnati, OH, 1977. 38

[SOH03] Jonathan Smallwood, Marc Obonsawin e Derek Heim. Task unrelated thought: The role of distributed processing. Consciousness and cognition, 12(2):169-189, 2003. 97, 148 
[SRP07] H. Sharp, Y. Rogers e J. Preece. Interaction Design: Beyond Human-Computer Interaction - 2nd edition. John Wiley \& Sons Ltd, 2007. 18, 74, 138, 152, 156, 166

[SRV13] Jorge Simões, Rebeca DíAz Redondo e Ana FernáNdez Vilas. A social gamification framework for a k-6 learning platform. Computers in Human Behavior, 29(2):345-353, 2013. 31, 32

[SRVA14] Jorge Simões, Rebeca Redondo, Ana Vilas e Ademar Aguiar. Using gamification to improve participation in social learning environments. Learning and Diversity in the Cities of the Future, página 169, 2014. 31, 32

[SSZV09] JL González Sánchez, Francisco Montero Simarro, N Padilla Zea e FL Gutiérrez Vela. Playability as extension of quality in use in video games. Em 2nd International Workshop on the Interplay between Usability Evaluation and Software Development (I-USED), 2009. 18

[Ste64] William Stephenson. The play theory of mass communication. Transaction Publishers, 1964. 15

[SW05] Penelope Sweetser e Peta Wyeth. Gameflow: a model for evaluating player enjoyment in games. Computers in Entertainment (CIE), 3(3):3-3, 2005. 17

[Sy07] Desirée Sy. Adapting usability investigations for agile user-centered design. Journal of Usability Studies, 2(3):112-132, May 2007. xii, 143

[Tom02a] Harry Tomlinson. E-moderating: The key to teaching and learning online. 2002. 77

[Tom02b] Elaine G Toms. Information interaction: Providing a framework for information architecture. Journal of the American Society for Information Science and Technology, 53(10):855-862, 2002. 15

[UEPA14] UPA User Experience Professionals Association. What is user-centered design?, January 2014. xi, 72

[VdS14] Luiz Carlos Vieira e Flávio Soares Corrêa da Silva. Understanding fun. Videojogos 2014, Portugal, 2014. 17, 18

[VZ03] Claudio Vignali e Mike Zundel. The marketing management process and heuristic devices: an action research investigation. Marketing Intelligence $\& 3$ Planning, 21(4):205-219, 2003. xi, 4, 34

[Wen98] Etienne Wenger. Communities of practice: Learning, meaning, and identity. Cambridge university press, 1998. 11

[WH12] Kevin Werbach e Dan Hunter. For the win: How game thinking can revolutionize your business. Wharton Digital Press, 2012. xi, 21, 22, 26, 30, 74, 75, 137, $138,145,152,154,155,156,166$

[Wik18] the free encyclopedia Wikipedia. Patrimônio cultural, 2018. Available on-line at: https://pt.wikipedia.org/wiki/Patrim2018.). 11

[WMS02a] Etienne Wenger, Richard McDermott e William M Snyder. Seven principles for cultivating communities of practice. Cultivating Communities of Practice: a guide to managing knowledge, 4, 2002. 76, 77, 78, 86, 142, 152, 161 
[WMS02b] Etienne Wenger, Richard Arnold McDermott e William Snyder. Cultivating communities of practice: A guide to managing knowledge. Harvard Business Press, 2002. xiv, 5, 9, 10, 30, 133, 134, 135, 137, 151, 154, 155, 156, 166

[WOM10] Barbara M Wildemuth, Jung Sun Oh e Gary Marchionini. Tactics used when searching for digital video. Em Proceedings of the third symposium on Information interaction in context, páginas 255-264. ACM, 2010. 152

[WRB14] Oscar Wongso, Yusep Rosmansyah e Yoanes Bandung. Gamification framework model, based on social engagement in e-learning 2.0. Em Technology, Informatics, Management, Engineering, and Environment (TIME-E), 2014 2nd International Conference on, páginas 10-14. IEEE, 2014. 30, 32

[WT13] Etienne Wenger-Trayner. The practice of theory: Confessions of a social learning theorist. Reframing Educational Research: Resisting the'what works' agenda. Abingdon and New York: Routledge, 2013. 38, 133

[WTdL11] Etienne Wenger, Beverly Trayner e Maarten de Laat. Promoting and assessing value creation in communities and networks: A conceptual framework. The Netherlands: Ruud de Moor Centrum, 2011. 5, 9, 10, 133

[Yee06] Nick Yee. Motivations for play in online games. CyberPsychology 63 behavior, 9(6):772-775, 2006. 19, 31, 138, 152

[Yin09] Robert K. Yin. Case Study Research: Design and Methods (Applied Social Research Methods). Applied Social Research Methods Series. SAGE Publications, 4th edição, 2009. 34, 147, 148, 149

[Yin13] Robert K Yin. Case study research: Design and methods. Sage publications, 2013. 4

[YJML11] Mao Ye, Krzysztof Janowicz, Christoph Mülligann e Wang-Chien Lee. What you are is when you are: the temporal dimension of feature types in locationbased social networks. Em Proceedings of the 19th ACM SIGSPATIAL International Conference on Advances in Geographic Information Systems, páginas 102-111. ACM, 2011. 89

[Zan16] Ozgur Zan. A brief introduction to motivation theory, 2016. Available on-line at: http://www.ozgurzan.com/management/management-theories/theoriesabout-motivation/ Acessed on: 29 August 2016. 12

[ZC11] G. Zichermann e C. Cunningham. Introduction - Gamification by Design: Implementing Game Mechanics in Web and Mobile Apps. Sebastopol, California: OŔeilly Media. p. xiv. ISBN 1449315399, 1st edition, 2011. 1, 17, 20, 26, 51, $52,66,68,74,75,87,97,152$ 


\section{Índice Remissivo}

Engajamento, 14

Gamificação, 20

Motivação, 11 